Inert Electrodes Program

Fiscal Year 1990

Annual Report

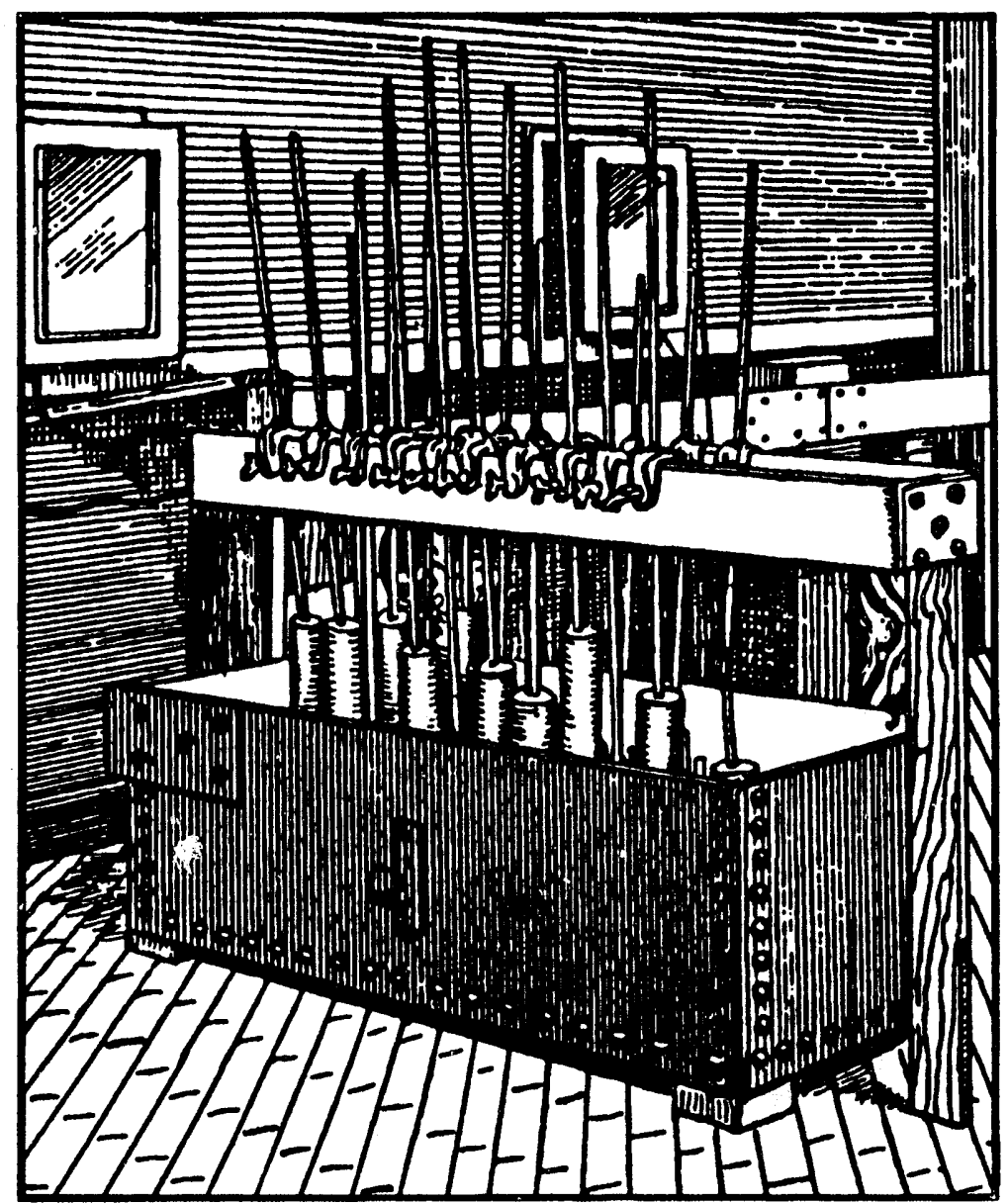

August 1991

Work supported by the U.S. Department of Energy under Contract DE-AC06-76RLO 1830

Pacific Northwest Laboratory

Operated for the U.S. Department of Energy

by Battelle Memorial Institute 


\title{
DISCLAIMER
}

This report was prepared as an account of work sponsored by an agency of the United States Government. Neither the United States Government nor any agency thereof, nor Battelle Memorial Institute, nor any of their employees, makes any warranty, expressed or implied, or assumes any legal liability or responsibility for the accuracy, completeness, or usefulness of any information, apparatus, product, or process disclosed, or represents that its use would not infringe privately owned rights. Reference herein to any specific cummercial product, process, or service by trade name, trademark, manufacturer, or otherwise does not necessarily constitute or imply its endorsement, recommendation, or favoring by the United States Government or any agency thereof, or Battelle Memorial institute. The views and opinions of authors expressed hercin do not necessarily state or reflect those of the United States Government or any agency thereof.

\author{
PACIFIC NORTHWEST LABORATORY \\ operated by \\ BATTELLE MEMORIAL INSTITUTE \\ for the \\ UNITED STATES DEPARTMENT OF ENERGY \\ under Contract DE-AC06-76RLO 1830
}

Printed in the United States of America

Available to DOE and DOE contractors from the

Office of Scientific and Technical Information, P.O. Box 62, Oak Ridge, TN 37831; prices available from (615) 576-8401. FTS 626-8401.

Available to the public from the National Technical Information Service, U.S. Department of Commerce, 5285 Port Royal Rd., Springfield, VA 22161.

\section{On the cover:}

Aluminum reduction pots at the Pittsburgh Reduction Company's (Alcoa's) plant in 1889. Adapted from a photograph, courtesy of Alcoa. 
PNL- -7777

DE92 000846

Inert Electrodes Program

FISCAL YEAR 1990 ANNUAL REPORT

Principal Authors:

C. F. Windisch Jr.

D. M. Strachan

Contributing Authors:

N. C. Davis

L. G. Morgan

J. W. Shade

N. D. Stice

R. E. Westerman

August 1991

Prepared for the U.S. Department of Energy under Contract DE-AC06-76RLO 1830

Pacific Northwest Laboratory

Richland, Washington 99352 
The Inert Electrodes Program, conducted by Pacific Northwest Laboratory (PNL), involves improving the Hall-Heroult Cells used by the aluminum industry for the electrochemical production of aluminum. The PNL research centers on developing more energy-efficient, longer-lasting anodes, cathodes, and ancillary equipment.

During FY 1989 and FY 1990, preparations for the pilot cell test continued. Numerous unanticipated problems were encountered that delayed the test schedule. The delays resulted primarily from three factors: 1) modifications for anode design based on the results obtained from the prototype test (documented here); 2) difficulties in procuring a manufacturer for the cermet inert anodes to be used in the pilot cell; and 3) problems in the actual scale-up activities, both in the production of the ferrite powder and in the fabrication of the anodes themselves. Issues related to scaling up the fabrication of the anodes are still being addressed in FY 1991.

Important accomplishrients in FY 1989 and FY 1990 include the completion of laboratory cell tests in which the effects of current density, precorrosion, and silica content on anode performance were confirmed; the performance of tests that resulted in the identification of the reaction layer on cermet anodes; the initiation of electrochemical tests to determine the source of the anode impedance; the completion of studies to identify and summarize optimal fabrication conditions for the cermet inert anodes, including advanced compositions; the testing of anodes with advanced composition; the refinement of the electrical connection for the anode; and modeling the dynamics of the anode array to be used in the pilot cell. 


\section{ACKNOWLEDGMENTS}

The authors wish to acknowledge the technical assistance of H. E. Kissinger, K. H. Pool, N. T. Saenz, S. 0. Slate, D. E. Smith, E. H. Shade, R. W. Stephens, Pacific Northwest Laboratory (PNL), for their contributions to the performance of the experimental and analytical work; the assistance and cooperation of the staff at the Reynolds Metals Company facility, Sheffield, Alabama, in ferforming the prototype anode test; the valuable contributions of W. E. Haupin, M. W. Adkins, and F. R. Huettig, program consultants; the assistance of $D$. K. Hilliard in performing the editorial review of the report; the programmatic assistance provided by $M . J$. McMonigle, Office of Industrial Processes, U.S. Department of Energy (DOE), Washington, D.C., and the Richland Operations Office, DOE; and the programmatic support provided by the Office of Industrial Processes, DOE. 


\section{CONTENTS}

SUMMARY

ACKNOWLEDGMENTS

1.0 INTRODUCTION . . . . . . . . . . . . . . . . . . 1

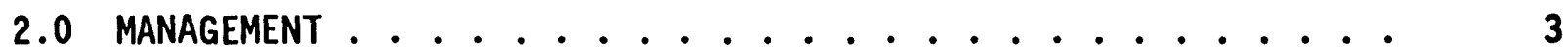

3.0 INERT ELECTRODE STUDIES . . . . . . . . . . . . . 7

3.1 CONFIRMATION TESTING . . . . . . . . . . . . . . 8

3.2 ELECTROCHEMICAL STUDIES ............... 10

3.3 MATERIALS CHARACTERIZATION . . . . . . . . . . 15

3.4 ADVANCED COMPOSITIONS . . . . . . . . . . . . . 20

4.0 ANODE SCALE-UP/PILOT CELL ACTIVITIES . . . . . . . . . 23

4.1 PILOT CELL PLANNING/SCHEDULE . . . . . . . . . . . . 23

4.2 PROTOTYPE ANODE TEST . . . . . . . . . . . . . 25

4.3 CERAMIC POWDER PRODUCTION . . . . . . . . . . . 26

4.4 ELECTRICAL CONNECTION . . . . . . . . . . . . . 29

4.5 WATER MODEL . . . . . . . . . . . . . . 30

5.0 PLANNED FY 1991 STUDIES . . . . . . . . . . . . . . 33

6.0 CONCLUSIONS . . . . . . . . . . . . . . . . 35

7.0 REFERENCES . . . . . . . . . . . . . . . . . . . 37

APPENDIX A - DETERMINATION OF THE HIGH CURRENT DENSITY LIMIT FOR CERMET ANODES .................

APPENDIX B - EFFECTS OF PREOXIDATION AND ELECTROLYTE CONCENTRATION $\mathrm{SIO}_{2}$ ON ANODE PERFORMANCE ............. B. 1

APPENDIX C - EFFECTS OF PRECORROSION AND SILICA ON CERMET INERT ANODE PERFORMANCE ................. ANALYSIS STUDIES OF A CERMET INERT ANODE MATERIAL . • 
APPENDIX E - INERT ANODE FABRICATION DEVELOPMENT: A SPREADSHEET DOCUMENTATION OF INFORMATION CONTAINED IN LABORATORY

RECORD BOOKS ..................... E.1

APPENDIX F - TESTING OF ADVANCED ANODE COMPOSITIONS . . . . . . F.1

APPENDIX G - WATER MODEL OF A LARGE-SCALE INERT ANODE TEST $\ldots . . G .1$ 


\section{FIGURES}

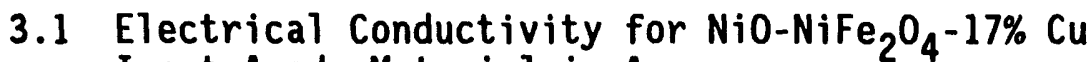

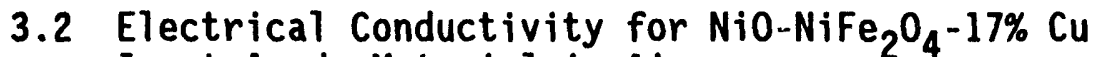
Inert Anode Material in Air. . . . . . . . . . . . . 


\subsection{INTRODUCTION}

The Inert Electrodes Program is being conducted at the Pacific Northwest Laboratory (PNL) (a) for the U.S. Department of Energy (DOE), Office of Industrial Processes (OIP). The purpose of the program is to develop longlasting, energy-efficient anodes and ancillary equipment for Hall-Heroult cells used to produce aluminum metal. Emphasis has been placed on the development of anodes made from a ceramic/metal composite consisting of $\mathrm{NiO}$ and $\mathrm{Ni}-\mathrm{Fe}$ ferrite and a $\mathrm{Cu} / \mathrm{Ni}$ metal phase. Based on early laboratory results, these anodes are expected to have lifetimes of 5 to 7 years, as opposed to the current technology, which requires replacenient of carbon anodes approximately every 20 days. The program is in a transition stage, in which experience gained with laboratory-scale anodes is being scaled up in preparation for a large-scale pilot cell test that is now scheduled to take place in FY 1991.

This annual report covers the progress made at PNL over two years: FY 1989 and FY 1990. Progress during this period was in two general areas. The first area falls under the title Inert Electrode Studies and deals with laboratory-scale tests performed at PNL to develop a better understanding of the behavior of the cermet inert anodes. This area, covered in Section 3.0, includes 1) a series of $20 \mathrm{~A}$ cell tests designed to answer certain questions about inert anode operating conditions and corrosion, 2) electrochemical studies to characterize reactions and properties of the inert anode interface, 3) optimization and summarization of the fabrication parameters for the cermet inert anodes, and 4) the development and testing of some advanced anode compositions. The second area is titled Anode Scale-Up/Pilot-Cell Activities and concerns the various activities more closely related to scaling up the inert anode technology. This area, covered in Section 4.0, includes 1) a discussion of the schedule for the pilot cell test, 2) the results of the prototype anode test which was intended to lay the groundwork for the pilot cell test, 3) progress made in obtaining and working with a vendor for producing the ferrite powder and fabricating the anodes to be used in the

(a) Operated for the U.S. Department of Energy by Battelle Memorial Institute under Contract DE-ACO6-76RLO 1830. 
pilot cell test, 4) the development of an improved electrical connection for the anodes, and 5) the results of water modeling to predict the efficiency of dissolution of alumina in the pilot cell.

For many of the activities discussed in this report, formal PNL progress reports or final reports have been written. These reports are referenced in the text and complete citations are included in Section 7.0. For other activities, reports with a limited distribution were issued. These reports are noted in the text and a copy of each is appended to this document. For both types of activities, a summary of the principal conclusions is given in the text and the reader is referred to the appropriate report for more details. For the activities not discussed in any previous report, a more complete discussion is given in this document. 


\subsection{MANAGEMENT}

Laboratory work at PNL continued to demonstrate that inert anode technology is viable and helped determine some of the important operating characteristics of the anodes. Efforts to scale up the technology also continued. The prototype anode test was performed, which helped lay the groundwork for the pilot cell test. Some problems were encountered in preparing for the pilot cell test, so the schedule for performing the test had to be modified. Nevertheless, significant progress toward completing the pilot cell test was made. In particular, many unanticipated issues regarding scale up of ferrite powder production and the fabrication of the anodes have arisen; and these have been, or are currently being, resolved. Considerable experience has been gained from these scale-up activities.

Two papers were presented at the 119th meeting of The Minerals, Metals and Materials Society (TMS), Anaheim, California, February 18-22, 1990: Results of 100 Hour Electrolys is Test of a Cermet Anode: Operational Results and Industry Perspective by R. D. Peterson, N. E. Richards, A. T. Tabereaux, 0. H. Koski, L. G. Morgan, and D. M. Strachan; and Results of 100 Hour Electrolysis Test of a Cermet Anode: Materials Aspects by D. M. Strachan, O. H. Koski, L. G. Morgan, R. E. Westerman, R. D. Peterson, N. E. Richards, and A. T. Tabereaux. These papers were also published in Light Metals 1990, pp. 385-394 and 395-402, TMS, Warrendale, Pennsylvania. In addition, the poster titled An Optical Microscopic Study of the Relationship between Morphology and Performance of Cermet Anodes for the Aluminum Industry by C. F. Windisch Jr., N. T. Saenz, N. D. Stice, and D. H. Parks, was exhibited at the 92nd Annual Meeting of the American Ceramic Society, Dallas, Texas, Apri1 22-26, 1990.

The following five technical reports were published during FY 1989 and FY 1990: Fiscal Year 1987 Annual Report for the Inert Electrodes Program by D. M. Strachan, O. H. Koski, S. C. Marschman, C. H. Schilling, C. F. Windisch Jr., B. B. Brenden, N. C. Davis, and P. E. Hart, PNL-6746, Picific Northwest Laboratory, Richland, Washington, December 1988; Laboratory Testing of Nonconsumable Anode Materials, S. C. Marschman, PNL-6805, Pacific Northwest 
Laboratory, Richland, Washington, March 1989; Fiscal Year 1988 Annual Report for the Inert Electrodes Program, D. M. Strachan, S. C. Marschman, N. C. Davis, J. R. Friley, and C. H. Schilling, PNL-7106, Pacific Northwest Laboratory, Richland, Washington, October 1989; Results from an Electrolys is Iest of a Prototype Inert Anode by D. M. Strachan, C. F. Windisch Jr., O. H. Koski, L. G. Morgan, R. D. Peterson, N. E. Richards, and A. T. Tabereaux, PNL-7345, Pacific Northwest Laboratory, Richland, Washington, May 1990; and Characterization of the Reaction Layer or Film on PNL Inert Anodes: Progress Report for April-December 1989, C. F. Windisch Jr. and N. D. Stice, PNL-7326, Pacific Northwest Laboratory, Richland, Washington, May 1990.

The following two technical reports were published in FY 1991 on the results of studies conducted at PNL, partly during FY 1990: Final Report on the Characterization of the Film on Cermet Inert Anodes, C. F. Windisch Jr. and N. D. Stice, PNL-7589, Pacific Northwest Laboratory, Richland, Washington, January 1991; and Report on the Source of the Electrochemical Impedance on Cermet Inert Anodes, C. F. Windisch Jr. and N. D. Stice, PNL-7629, Pacific Northwest Laboratory, Richland, Washington, February 1991.

The paper titled An Electrochemical Impedance Study on Cermet Inert Anodes in Alumina-Saturated Molten Cryolite by C. F. Windisch Jr. was accepted for publication in the Journal of the Electrochemical Society; scheduled publication date is July 1991.

A workshop for potential inert anode producers was held in Denver, Colorado, November 29, 1988. Formal presentations were made by DOE-HQ, industrial representatives, and PNL staff. A general consensus of the attendees from industry was that if the inert anodes are shown to be viable, then various companies would have an interest in their manufacture. Four meetings were held with Reynolds Metals Company staff to discuss the prototype anode test and the pilot cell test. Three of the meetings were at PNL and one was at the Reynolds Metals Company facility in Sheffield, Alabama, just prior to performing the prototype anode test at the Reynolds facility in March 1989. Six program review meetings were held by PNL and DOE-HQ staff: three were in Washington, D.C., and three were at PNL. With respect to scale-up activities, two visits were made by PNL staff to Cercom, Inc., Vista, California and the 
Ceramic Magnetics Company facility, Fairfield, New Jersey. Ceramic Magnetics is the current vendor for the cermet anodes to be used in the pilot cell test, and Cercom manufactured the anode that was used in the prototype anode test.

Three consultants were retained by the program. Mr. F. R. Huettig was retained for his expertise in the ferrite industry. Mr. Huettig assisted in the scale-up and production of the inert anodes. Dr. W. E. Haupin was retained because of his extensive knowledge of aluminum smelting operations and research, both in the laboratory and industrial setting. Dr. Haupin provided valuable advice on experiment design, data interpretation, and scaleup issues. Mr. M. W. Adkins was retained to assist the program by making economic assessments of the inert anode technology.

The program staff hosted several visitors involved with aluminum smelting and/or inert anode technology. These included the Reynolds Metals Company staff, N. E. Richards, R. D. Peterson, A. T. Tabereaux, and T. Alcorn; J. Thonstad, University of Norway, Trondheim, Norway; and E. J. Frazer, CSIRO, Port Melbourne, Australia. 


\subsection{INERT ELECTRODE STUDIES}

The tasks described in this section cover investigations into the various properties of the cermet inert anodes being developed at PNL. These activities were performed at PNL during FY 1989 and FY 1990 and were largely independent of the anode scale-up/pilot cell activities discussed in the next section. There are four tasks in this section, each dealing with a certain type of testing of the cermet inert anodes: 1) confirmation testing, 2) electrochemical studies, 3) materials characterization of the anode, and 4) the development and evaluation of advanced anode compositions.

The confirmation tests were performed to better define the operating conditions for the cermet inert anodes. The focus of these experiments, performed in $20 \mathrm{~A}$ electrolysis cells, was on the effects of current density and bath composition. The electrochemical studies were performed to determine if a film forms on the cermet inert anodes during electrolysis and to characterize it. The presence of a film was proposed as a result of previous PNL studies (Strachan et a1. 1988) and was believed to protect the anode from corrosion during electrolysis. The materials characterization studies discussed in this section focused on determining the optimum fabrication and sintering conditions for the production of inert anodes. Microstructure and various physical properties of the anodes, including electrical conductivity, were determined and interpreted to optimize the important processing parameters. Finally, evaluation of the advanced anode compositions was performed using $20 \mathrm{~A}$ cells. These anode compositions were developed at PNL (Strachan et al. 1989) and proposed to have equivalent or better performance than the composition developed by Alcoa Laboratories. In particular, the advanced anode compositions exhibited much higher conductivities. Previous corrosion testing on these anodes, however, was inconclusive. This work was meant to help clarify the behavior of the advanced anode compositions under electrolysis conditions. 


\subsection{CONFIRMATION TESTING}

This section discusses the results of two types of confirmation tests that were conducted in FY 1989 and FY 1990 to determine the effects of certain operating conditions on the performance of cermet inert anodes. Specifically, the effects of current density and the presence of silica and a preoxidized condition were evaluated in $20 \mathrm{~A}$ laboratory cells.

\subsubsection{High Current Density Limit}

This section explains the confirmation tests that were conducted to determine the maximum current density at which the cermet inert anodes could be operated without significant corrosion or instability.

\subsubsection{Background}

Researchers at PNL determined (Strachan et al. 1988), Juring the testing and development of cermet inert anodes, that a current density of $0.5 \mathrm{~A} / \mathrm{cm}^{2}$ caused little or no corrosion of the anodes under the laboratory conditions used. This low current density represented a departure from the normal anode current density of approximately $1 \mathrm{~A} / \mathrm{cm}^{2}$ in a typical carbon-based industrial electrolysis cell. If a lower current density such as $0.5 \mathrm{~A} / \mathrm{cm}^{2}$ is used in an operating cell with cermet inert anodes, serious consideration must be paid to the design of the anode and the electrolysis cell. To date, no systematic study has been performed to determine the effect of current density i a the performance of a cermet anode other than in short-term tests (Strachan et al. 1988; 1989) with small anodes $\left(1 \mathrm{~cm}^{2}\right.$ exposed surface area). The purpose of the current study was to determine the highest current density at which a cermet anode could be operated under stable conditions. The stability of the anode current density and voltage was used to determine the upper current density limit because aluminum metal purity analysis takes at least $4 \mathrm{~h}$ to perform.

\subsubsection{Results}

The results of these tests were previously reported in a document with limited distribution. A copy of this document is provided in Appendix $A$. The important conclusions from this work are given below. 


\subsubsection{Conclusions}

An experiment was conducted in which a current density of $1.2 \mathrm{~A} / \mathrm{cm}^{2}$ was sustained on a cermet inert anode for $4 \mathrm{~h}$ without apparent voltage or current anomalies. Earlier the anode had been run at current densities ranging from $0.5 \mathrm{~A} / \mathrm{cm}^{2}$ to $0.9 \mathrm{~A} / \mathrm{cm}^{2}$ over a period of about $13 \mathrm{~h}$. At a current density of $1.5 \mathrm{~A} / \mathrm{cm}^{2}$, the anode-to-reference electrode voltage became very unstable--an event that has been previously interpreted as an indicator of enhanced corrosion (Strachan et a1. 1989). Therefore, it appears that the upper 1 imit for stable operation of the cermet inert anode is about $1.2 \mathrm{~A} / \mathrm{cm}^{2}$ based on the results from this test. However, it should be noted that corrosion rates may still be found to vary as a function of current density because of the short duration of this test.

\subsubsection{Effect of Preoxidation and Electrolyte Silica Concentration on Anode Performance}

This section covers the confirmation tests that were performed to determine the effect of silica in the electrolyte on the corrosion properties of the cermet inert anodes, and whether a preoxidized condition on the anode has any deleterious effects on anode performance.

\subsubsection{Background}

Two operational factors were different in the prototype anode test conducted at the Reynolds Metals Company facility in Sheffield, Alabama, (and discussed in Section 4.2) from tests previously conducted in the laboratory. These factors were 1) the prototype anode was heated in air in a separate furnace and transferred to the electrolytic cell, and 2) some silica-based insulating material was believed to have entered the cell and dissolved in the cryolite during the test. The purpose of this work was to investigate the effects these differences might have had in the increased corrosion of the prototype anode relative to smaller anodes used in laboratory cells.

\subsubsection{Results}

The results of these tests were previously reported in a document with limited distribution. A copy of this document is provided in Appendix B. The important conclusions from tiilis work are given below. 


\subsubsection{Conclusions}

Two anodes were tested and the results of these tests indicated that preheating the anode in air does not result in enhanced corrosion. However, the oxidized layer at the anode surface appeared to be thicker and have a slightly different character after heating in air than that observed when the anode was preheated in the cell above the electrolyte. The aluminum metal purity results did not indicate any enhanced anode corrosion from this difference. The corrosion rate of the anodes, based on the metal purity values, appeared to be independent of the anode current density and preheat conditions. Addition of $\mathrm{SiO}_{2}$ to the electrolyte appeared to lower the rate of increase in the impurities in the aluminum metal. This may be due to the formation of silicate minerals or enhanced volatilization. The amount of $\mathrm{Si}$ in the Al metal was independent of $\mathrm{SiO}_{2}$ addition and time.

The test results suggested that neither preheating the anode in air nor the presence of silica in the electrolyte were probable causes for the corrosion of the prototype anode.

\subsection{ELECTROCHEMICAL STUDIES}

The purpose of these studies was to characterize the electrochemical interface between the cermet inert anodes and the molten cryolitic electrolyte. Two principal issues regarding this interface were the focus of research in FY 1989 and FY 1990: 1) whether a film formed on the cermet inert anodes during electrolysis and, if it did, the characterization of this film, and 2) the source of the electrochemical impedance on the cermet inert anodes. Ancillary tests were also performed to support the activities discussed in Section 3.1.2 (i.e., by using the electrochemical approaches developed in this work to determine the effects of silica and precorrosion on the performance of the cermet inert anodes).

\subsubsection{Characterization of Film on Cermet Inert Anodes}

This section covers the research attempts in FY 1989 and FY 1990 to determine whether a film forms on cermet inert anodes during electrolysis in molten cryolite. Both electrochemical and postmortem microscopic techniques were used in these studies. 


\subsubsection{Background}

Studies conducted at PNL in FY 1988 and early in FY 1989 indicated that cermet inert anodes evaluated at PNL exhibited a characteristic impedance during the electrolytic production of aluminum in bench-scale Hall-Heroult cells. This impedance was found to have the following characteristics (Strachan et a1. 1988):

- It was largely resistive in nature.

- It varieg as a function of current density, giving a minimum at about $0.5 \mathrm{~A} / \mathrm{cm}^{2}$.

- It appeared to depend on alumina concentration in the electrolyte. In general, the impedance seemed to increase with increasing alumina concentration.

- It exhibited a time dependence. Different anodes gave different impedances at different times after polarization.

- Discontinuous changes in the impedance occurred at high current densities (>1 A/ $\mathrm{cm}^{2}$ ) causing "spikes" in the current or voltage data.

Based on these characteristics, researchers (Strachan et al. 1988) originally proposed that a resistive film formed on inert anodes during electrolysis. They argued that the formation of this film was necessary to protect the inert anode from the corrosion reactions that would otherwise occur in the molten electrolyte. Researchers also proposed that an anode current density of $0.5 \mathrm{~A} / \mathrm{cm}^{2}$ formed a film with optimum passivating-like characteristics. At lower current densities, incomplete film formation was proposed to result in the corrosion of the metallic phase of the cermet. At higher current densities, it was proposed that the film became too thick and its resistance became too high to sustain the current density. Consequently, the film ruptured, resulting in sudden and severe corrosion of the electrode's metal phase. These rupturing events in the film were indicated by sudden drops in impedance and appeared as "spikes" in the voltage data for a cell under galvanostatic (constant current) control.

Researchers also proposed that the quality of the film depended on the alumina concentration in the electrolyte. Higher alumina concentrations seemed to favor a more resistive, presumably thicker, film. Consequently, it 
was considered more likely that the film would rupture at high alumina concentration (close to saturation) when current densities were above $0.5 \mathrm{~A} / \mathrm{cm}^{2}$. Problems with reproducing the experimental results were encountered, however, when attempts were made to relate anode impedance explicitly to alumina concentration. It was thel concluded that the film impedance was dynamic, changing with time and with small fluctuations in cell conditions.

Attempts to identify the composition of the film in FY 1988 were largely unsuccessful (Strachan et a). 1988). Postmortem X-ray diffraction of frozen electrolyte near the surface region showed the presence of alumina, but it was uncertain whether the alumina was part of a film or simply precipitate that formed on the anode during cool-down. Because of the uncertainties in identifying the film, it was decided that additional work was needed to establish, with more evidence, whether a film truly exists or some other explanation for the characteristic impedance is more likely.

The work conducted in this section was intended to determine whether sufficient evidence could be collected to verify the presence of a protective film. If such a film could be found, the purpose of the research was to characterize it, both in terms of composition and its important properties.

\subsubsection{Results}

During FY 1989 and FY 1990, experiments were performed to identify the properties and composition of the film using a variety of techniques. The results from these studies are discussed in two PNL reports. In the report titled Characterization of the Reaction Layer or Film on PNL Inert Anodes: Progress Report for April-December 1989 (Windisch and Stice 1990), the results of electrochemical impedance and potential-step studies are discussed; in the report titled Final Report on the Characterization of the Film on Inert Anodes (Windisch and Stice 1991a), the results of microscopy studies are given. The important conclusions from this work are summarized below.

\subsubsection{Conclusions}

The results of this work suggested an alumina film does not form to protect the cermet inert anodes from dissolution. Rather, significant morphological and compositional changes occur at or near the anode surface. 
These changes and the chemical reactions that cause them involve the cermet material itself and appear to be responsible for some of the properties that were previously assigned to an alumina film. The changes include an increase in surface roughness with current density and the formation of a reaction layer predominantly on the spinel phase. The roughness appears to be caused by different reactivities of the phases in the cermet material and may contribute to the previously determined variations in electrochemical impedance.

\subsubsection{Source of Electrochemical Impedance}

This section discusses the results of studies that were performed primarily during FY 1990 to determine the source of the impedance on cermet inert anodes.

\subsubsection{Background}

The electrochemical impedances measured on the cermet inert anodes were previously attributed by PNL scientists to an alumina film (Strachan et al. 1988). In light of the conclusions in Section 3.2.1, another explanation for the source of the impedance was required. The objective of this work was to obtain more electrochemical impedance data under a variety of conditions and on different anodes to see if any relationships could be developed between experimental parameters that might clarify the source of the anode impedance.

\subsubsection{Results}

Most of the experimental work in these studies was conducted in FY 1990 , although the analysis of the data and report writing were performed largely in FY 1991. In the PNL technical report titled Report on the Source of the Electrochemical Impedance on Cermet Inert Anodes (Windisch and Stice 1991b), the results of these studies are discussed in detail.

\subsubsection{Conclusions}

Although most of the analysis of the impedance data was performed in FY 1991, the following conclusions are given to make this report more complete.

The electrochemical impedances of cermet inert anodes in aluminasaturated molten cryolite as a function of frequency, current density, and 
time indicated that a significant component of the impedance is due to the gas bubbles produced at the anode during electrolysis. The data also showed a connection between surface structure and impedance which appears to be related to the effects of surface structure on bubble flow. Given the results of this work, it is doubtful that a resistive film contributes significantly to the electrochemical impedances on inert anodes. Properties previously assigned to such a film are more likely due to the bubbles and those factors that affect the properties and dynamics of the bubbles at the anode surface.

\subsubsection{Effects of Precorrosion and Silica}

This section discusses the results of applying the electrochemical approaches developed in Section 3.2.1 (primarily potential-step tests) and postmortem microscopic analysis to determining the effects of silica and a precorroded condition on cermet inert anode performance. This work was intended to supplement the studies reported in Section 3.1.2.

\subsubsection{Background}

Previous studies at PNL suggested that a badly corroded inert anode could not recover its desired operating stability even if cell operating conditions were changed to be less aggressive. Other studies (Strachan et al. 1990) suggested that silica may assist the corrosion of inert anodes during their operation. The current studies used electrochemical methods and po. tmortem microscopic analysis of inert anodes in bench-scale aluminum reduction cells to determine if these two effects could be substantiated and, if so, to help provide chemical bases for their effects.

\subsubsection{Results}

The results of these tests were previously reported in a document with limited distribution. A copy of this document is provided in Appendix $C$. The important conclusions from this work are given below.

\subsubsection{Conclusions}

The results of this study were consistent with similar studies performed at PNL using $20 \mathrm{~A}$ cells and discussed in Section 3.1.2. In general, potential-step response data could not distinguish any effect of either silica 
or precorrosion. This result indicated that the electrochemical approach used to characterize the reactions at the electrode interface (discussed in Section 3.2.1) may not be appropriate for all electrode/electrolyte conditions. However, the precorroded anodes did exhibit a higher impedance and in some cases, significantly higher levels of noise in the current signals; this result is consistent with the previous study (Windisch and Stice 1991b). In addition, the presence of silica in the electrolyte did not appear to have any adverse effect on the anodes, which supports the conclusions in Section 3.1.2.

\subsection{MATERIALS CHARACTERIZATION}

This section covers the results of a research effort in FY 1989 to use thermal analysis techniques to develop a better understanding of the effects of sintering conditions on anode materials reactions, and to use this information to optimize the various sintering parameters. Electrical conductivity measurements were also performed to help characterize the anodes prepared under different sintering conditions.

\subsubsection{Background}

Most of the anodes that have been produced for the Inert Electrodes Program have been made at PNL using modifications of the procedures developed by Alcoa Laboratories. However, much of the background work leading to these procedures was neither contained in the various Alcoa reports nor complete. In this section, results are discussed from studies that were performed to help fill in some of the gaps by determining the best temperatures and atmospheric conditions for processing the ferrite-based anode materials. The two principal experimental methods used in the attempt to better understand the sintering reactions were differential thermal analysis (DTA), and thermal gravimetric analysis (TGA).

Specifically, the focus of the thermal analysis studies was to determine

- the rate of binder release from the sample as a function of temperature and oxygen in the environment.

- the rate of oxidation of metal phase by the oxygen in the environment,

- evidence of inter-constituent reactions. 
Electrical conductivity studies were also performed on samples of cermet inert anodes to help better understand the properties of these materials and to serve as a baseline for the post-test analysis of anodes from the scaledup testing conducted at the Reynolds Metals Company facility.

\subsubsection{Results}

The results of the DTA/TGA tests were previously reported in a document with limited distribution. A copy of this document is provided in Appendix $D$. The important conclusions from this work are given below.

Two cermet inert anode specimens were submitted for four-point electrical conductivity measurements. One of the specimens was fresh, while the other had been heated to $1000^{\circ} \mathrm{C}$ in air. The latter specimen had an oxide coating similar to the one that might exist on an anode just prior to being used in a Hall-Heroult cell. The conductivities were measured in $\mathrm{Ar}$ and in air between room temperature and $1300^{\circ} \mathrm{C}$ at about $50^{\circ} \mathrm{C}$ intervals. The first run was made in $\mathrm{Ar}$, and the specimens were not removed from the furnace when the atmosphere was changed to air.

The results of electrical conductivity measurements are summarized in Figures 3.1 and 3.2. In general, the measured conductivities were about $70 \mathrm{ohm}^{-1} \mathrm{~cm}^{-1}$. The data taken in Ar (Figure 3.1) indicated that the specimen with the oxidized surface had a slightly higher conductivity. The slope of the straight line portions of the curves suggest activation energies of 0.01 aJ $\left(a=\right.$ atta or $\left.10^{-10}\right)$ for the low-temperature data and 0.03 aJ for the high-temperature portion of the curve.

When the conductivities were measured in air, the oxidized and unoxidized specimens yielded conductivity values similar to those measured for each specimen in Ar between room temperature and about $1200^{\circ} \mathrm{C}$. That is, the previously unoxidized specimen had a lower conductivity than the oxidized specimen and was about equal to the conductivity measured in Ar. Above this temperature, the conductivities of both specimens decreased rapidiy either because the materials were degrading or because the probe contact degraded. The difference in the conductivity between the oxidized and unoxidized specimens (Figure 3.2) was nearly the same as the difference observed when the measurements were made in Ar (Figure 3.1). When cooled in air from $1300^{\circ} \mathrm{C}$, 


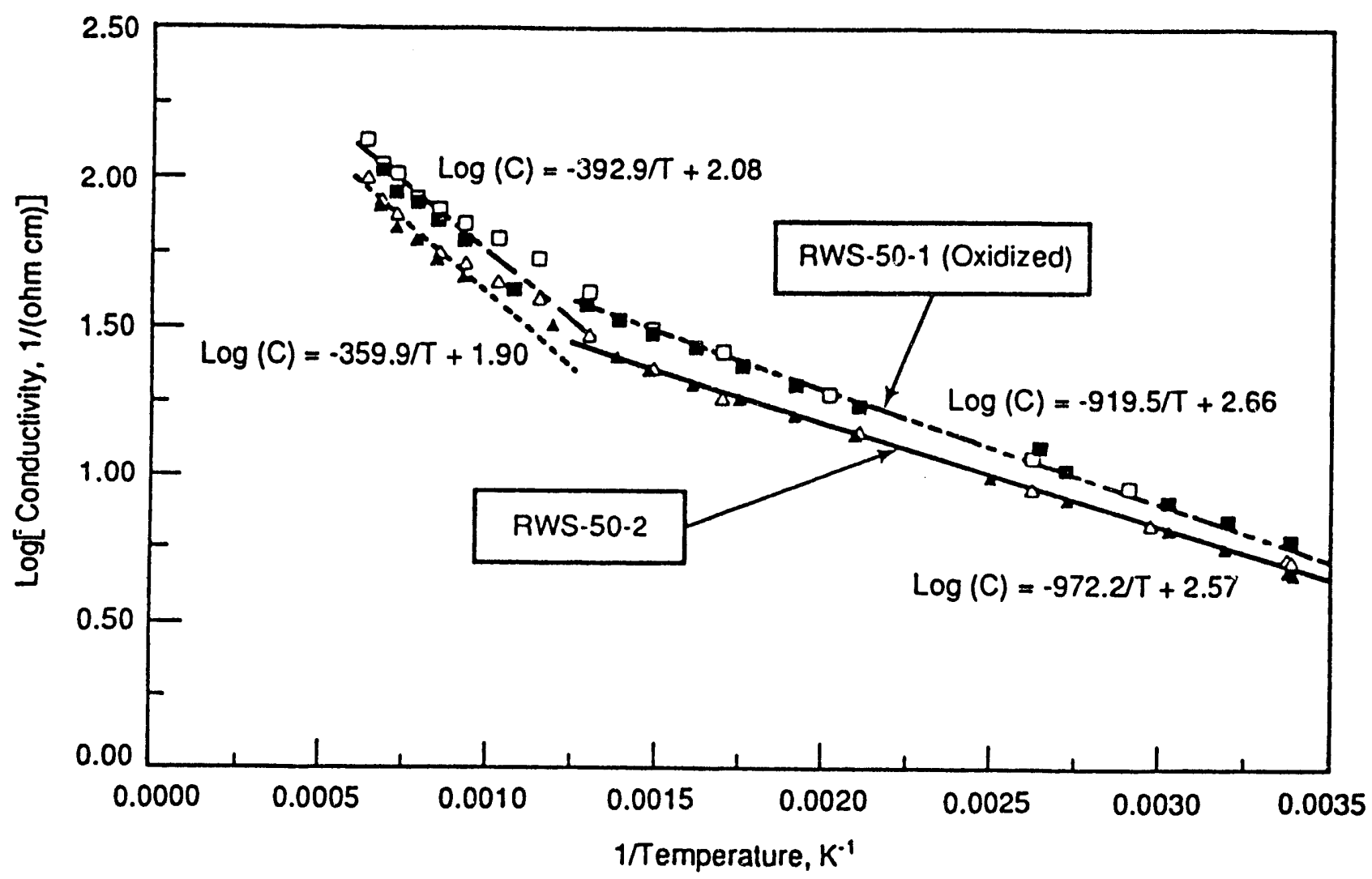

FIGURE 3.1. Electrical Conductivity for $\mathrm{NiO}-\mathrm{NiFe}_{2} \mathrm{O}_{4}-17 \% \mathrm{Cu}$ Inert Anode Material in Ar. Open symbols are data obtained with increasing temperature; filled symbols are for decreasing temperature.

the specimens exhibited extremely high resistivities (low conductivities), which were approximately $60 \mathrm{ohm} \mathrm{m}$. It should be noted that the highest temperatures at which the conductivities were measured are about $50^{\circ} \mathrm{C}$ higher than the typical temperature of a Hall-Heroult cell.

When the specimens were finally removed after the air test, they had bent under the light load of the electrical contacts. This result supports previous mechanical strength measurements, in which it was observed that the $\mathrm{NiO}-\mathrm{NiFe}_{2} \mathrm{O}_{4}-17 \% \mathrm{Cu}$ material becomes plastic at about $1000^{\circ} \mathrm{C}$ (Strachan et al. 1989). The result of the electrical measurements at the start of the experiment in air suggest that if the specimen was bent at the end of the test in $\mathrm{Ar}$, there was little effect on the conductivity measurement. 


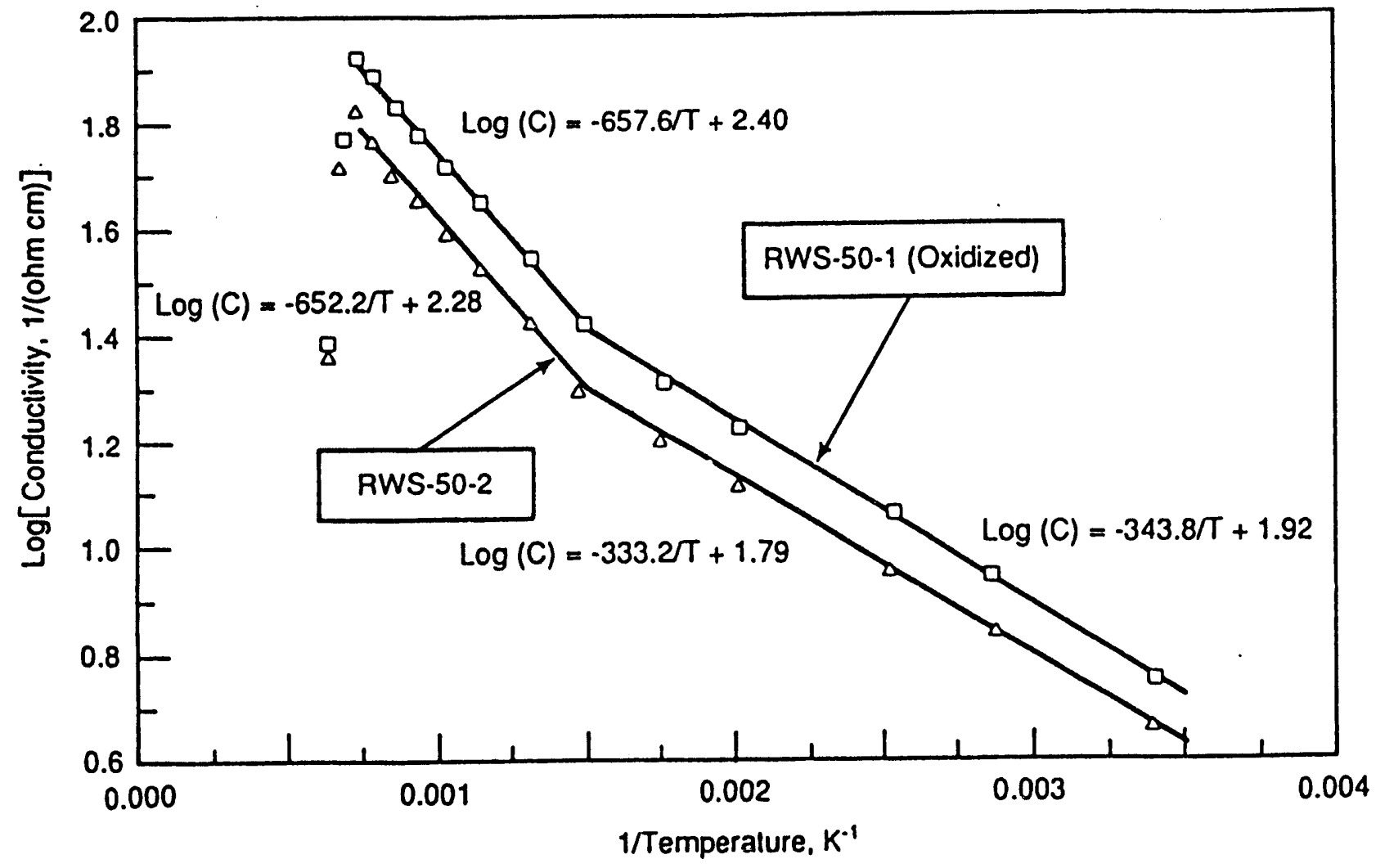

FIGURE 3.2. Electrical Conductivity for $\mathrm{NiO}-\mathrm{NiFe}_{2} \mathrm{O}_{4}-17 \% \mathrm{Cu}$ Inert Anode Material in Air. Data taken for increasing temperature only.

\subsubsection{Conclusions}

An assessment of the DTA/TGA results was made in light of past anode fabrication practices, both full-scale and laboratory-scale, and on perceived information needs based on these data. Following are the conclusions from these results:

- the DTA/TGA data were in qualitative agreement with historical and thermodynamic expectations

- the insights obtained by DTA/TGA methods into the complex reactions taking place in a cermet body are qualitative, and multiple interpretations in the absence of supporting information are possible

- further DTA/TGA experiments are not recommended until some of the sintering reactions are better understood 
- additional experiments that could be performed to shed more light on sintering mechanisms were suggested as indicated in Appendix D

Results from the conductivity studies provided some additional information regarding the fundamental properties of the cermet inert anodes. The activation energies for the low-temperature portion of the conductivity curves were consistent with the primary conductor being a degenerate semiconductor. The low-activation energies suggest that the addition of $\mathrm{Cu}$ metal to the $\mathrm{NiO}-\mathrm{NiFe}_{2} \mathrm{O}_{4}$ powder increases the electrical conductivity by a mechanism other than metallic conduction. The break in the conductivity curves occurs at about the same temperature as the reported magnetic transition, about $580^{\circ} \mathrm{C}$.

\subsection{ADVANCED COMPOSITIONS}

During FY 1989 and FY 1990, development of cermet inert anodes continued. This work included both the refinement of the fabrication procedures for the Alcoa $5324^{(a)}$-type anodes and the synthesis of new cermet anode compositions. This section concerns two specific activities related to cermet anode development: 1) documenting PNL cermet anode materials development efforts over the past 6 years, and 2) testing advanced anode compositions.

\subsubsection{Anode Support and Documentation}

Several hundred anodes of different sizes have been produced at PNL over the past 6 years using various production methods. Some of these anodes have been included in the tests reported elsewhere and some have been produced using different methods and compositions in an effort to understand the processing parameters. To a large extent, the information obtained from this effort was not published, but was documented in laboratory record books. This information needed to be collected into a single document so information could be readily available for future reference. Consequently, the information was consolidated and summarized in a computer-based spreadsheet. The spreadsheet

(a) 5324 was the designation for the $\mathrm{NiO}-\mathrm{NiFe}_{2} \mathrm{O}_{4}-17 \% \mathrm{Cu}$ anode material that was developed by Alcoa Laboratories (Weyand, et a1. 1986). This composition has been used as the reference comosition for the studies at PNL. 
(representing about 200 separate sintering test runs conducted at PNL), along with appropriate supporting information, was previously reported in a document with limited distribution. A copy of this document is provided in Appendix E.

\subsubsection{Testing Advanced Anode Compositions}

This sections discusses the tests of two advanced anode compositions that were designed to minimize anode wear. One of the compositions was "composite" in that it varied across the anode. The compositional variation was used to make the anodes more durable in both the vapor and liquid interface regions. Other work at PNL has shown that an anode having only the 5324-type composition exhibits different amounts of wear in these two regions (Strachan et al. 1990).

\subsubsection{Background}

Many anodes with compositions different from that developed by Alcoa Laboratories have been fabricated and evaluated at PNL in support of the Inert Electrodes and Sensor Development Programs. (a) During the early part of the programs, anodes with a fine microstructure were sought. When these techniques were reasonably well-developed, anodes with an increased metal content were also fabricated. However, only microstructural examination of the anodes with increased metal content were performed. The highest metal content that could be incorporated into an anode was about 25 wt\% wi hout bleeding the metal phase. Anodes with increased conductivity were aiso developed by adding about 1 wt\% $A 1$ in the metal phase of the cermet when the

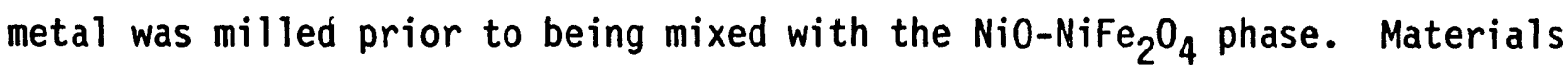
with electrical conductivities almost four times that of carbon were developed, but not tested in an electrolysis test. The purpose of this work was to test anodes of advanced composition in an attempt to understand the behavior of the materials during an electrolysis test.

(a) The Sensors Development Program, sponsored by DOE-OIP, is conducted at PNL to support the Inert Electrodes Program by developing sensors to monitor and control operating conditions in aluminum reduction cells. The FY 1989 annual report for this program has been published (Windisch et al. 1990). 
Two anodes with advanced compositions were tested: 1) one with a composition including $25 \mathrm{wt} \% \mathrm{Cu} / \mathrm{Ni} / \mathrm{Al}$ alloy, and 2) one with a composition that varied from high metal alloy at the base to no metallic phase at the top. The latter composite anode had $25 \mathrm{wt} \% \mathrm{Cu} / \mathrm{Ni} / \mathrm{Al}$ alloy in the bottom third, $17 \mathrm{wt} \% \mathrm{Cu}$ in the middle third, and no metallic phase in the top third.

\subsubsection{Results}

The results of the testing on advanced anode compositions were previously reported in a document with limited distribution. A copy of this document is provided in Appendix F. The important conclusions from this work are given below.

\subsubsection{Conclusions}

During this test, three anodes were studied: one at a current density of $0.5 \mathrm{~A} / \mathrm{cm}^{2}$ for approximately $66 \mathrm{~h}$, one at a current density of $0.5 \mathrm{~A} / \mathrm{cm}^{2}$ for $66 \mathrm{~h}$ and an additional $24 \mathrm{~h}$ at $1.3 \mathrm{~A} / \mathrm{cm}^{2}$, and a third anode at $0.5 \mathrm{~A} / \mathrm{cm}^{2}$ for approximately $24 \mathrm{~h}$. The first two anodes were operated together in the cell until one anode was removed from the cell after $66 \mathrm{~h}$. Results from this test were somewhat inconclusive in that the rate at which impurities dissolved in the molten Al appeared to be independent of the anode current density and anode surface area. The extrapolated back emf was observed to decrease during the first $20 \mathrm{~h}$, but that did not appear to be caused by the anode but by changes elsewhere in the cell,

The anode that was operated for $66 \mathrm{~h}$ at a current density of $0.5 \mathrm{~A} / \mathrm{cm}^{2}$ appeared to have only a small amount of corrosion; the anode that operated an additional $24 \mathrm{~h}$ at a current density of $1.3 \mathrm{~A} / \mathrm{cm}^{2}$ appeared to have suffered more corrosion. The composite anode that operated for about $24 \mathrm{~h}$ at a current density of $0.5 \mathrm{~A} / \mathrm{cm}^{2}$ showed little indication of corrosion. However, the upper portion of the anode that was made of only oxide material did show signs of degradation. In the composite anode, the different materials bonded together well and no cracks between regions of different materials were noted in post-test analysis. 


\subsection{ANODE SCALE-UP/PILOT CELL ACTIVITIES}

\subsection{PILOT CELL PLANNING/SCHEDULE}

The performance of the pilot cell test of the cermet inert anodes was originally scheduled for FY 1989. However, numerous problems were encountered: in the operation of the prototype test; in the procurement of a manufacturer for the cermet inert anode to be used in the pilot cell; and in the actual scale-up activities, both in the production of the ferrite powder and in the fabrication of the anodes themselves. Issues related to scalingup the fabrication of the anodes are still being addressed in FY 1991.

An outline of the various activities related to the pilot cell test schedule during FY 1989 and FY 1990 is given below:

Date Activity

9/88 A meeting was held at PNL with N. E. Richards and A. T. Tabereaux from Reynolds Metals Company. The decision was made to run a "prototype anode" test prior to the pilot cell test in order to get experience and preliminary data. The pilot cell test schedule was made contingent on the performance of the prototype anode test.

11/88 The subcontract with Reynolds was modified to include the prototype anode test and Cercom, Inc. (Vista, California) was awarded the subcontract to fabricate the prototype anode.

12/88 The first prototype anode fabricated by Cercom was rejected by PNL after preliminary analysis, and Cercom was requested to fabricate another.

2/89 The second prototype anode from Cercom was accepted and the prototype anode test was scheduled for $3 / 89$.

3/89 The prototype anode test was performed at the Reynolds Metals Company facility in Sheffield, Alabama. The pilot cell test was scheduled for $7 / 89$ contingent on the success of the prototype anode test.

5/89 A meeting was held at PNL with A. T. Tabereaux and R. D. Peterson from Reynolds to discuss preliminary results from the prototype anode test. Mixed results from this test led to the recommendation that the pilot cell test be deferred until the analysis of prototype anode data was complete.

6/89 A formal recommendation was made to postpone the pilot cell test until issues related to materials behavior and the scaled-up fabrication were resolved. 
7/89 A program review meeting was held in Washington, D.C. Results from the prototype anode test were discussed.

8/89 It was learned that the previous supplier for ferrite powder (Stackpole Carbon Corp., Pittsburgh, Pennsylvania) used for the prototype anode (and expected to be the source of additional ferrite powder needed for the pilot cell anodes) no longer routinely made the ferrite powders needed for the inert anodes. The search for another supplier of the powder was initiated.

9/89 M. J. McMonigle visited PNL and a new schedule was developed contingent on the identification of a producer of the ferrite powder and a company to fabricate the anodes. The new date for the pilot cell test was set for $1 / 90$. In light of the mixed results with the prototype anode test, it was decided to let the subcontract with Cercom expire and review alternatives related to anode design and fabrication. A. T. Tabereaux and $T$. Alcorn from Reynolds also visited PNL to discuss the new schedule. A preliminary design was provided by $T$. Alcorn for the anode cluster to be used in the pilot cell test.

10/89 The Ceramic Magnetics Company was identified by PNL consultant F. R. Huettig as a candidate for producing ferrite powder for the cermet inert anodes and for fabricating these anodes as well. D. M. Strachan visited Ceramic Magnetics to discuss the company's capabilities and interests and to observe their facilities. Ceramic Magnetics was the successful bidder for the ferrite powder.

11/89 An order for 455-kg of press-ready ferrite powder was placed with Ceramic Magnetics. The order also included small $(25 \mathrm{~kg})$ batches of the ferrite powder that would be analyzed by PNL. Results of the analysis on the small batches would be used to recommend contitions for production of the $455-\mathrm{kg}$ needed for anode fabrication. A purchase order for fabrication of the pilot cell test anodes was submitted for internal PNL review. Results from the prototype anode test still left open the question of what type of anode sidewall configuration to use. This issue was not resolved until the program review meeting in Washington, D.C. in $1 / 90$.

1/90 A program review meeting was held in Washington, D.C. The final design for the pilot cell anodes was developed. The new design had minimal sidewalls. A new schedule for the pilot cell test was discussed but was considered contingent on acquisition of the ferrite powder and success in anode fabrication. The purchase order for anode fabrication was revised for anodes without significant sidewalls. It was anticipated that the fabrication of the anodes would be performed by Ceramic Magnetics, the same company that was producing the ferrite powder. Solicitation for fabrication of the anodes was initiated via normal PNL procurement procedures. PNL staff also visited the Ceramic Magnetics facility to discuss fabrication issues. 
2/90 The first 25-kg batch of press-ready ferrite powder was received from Ceramic Magnetics. The powder was rejected due to an excess amount of unreacted iron oxide.

3-5/90 Additional batches of ferrite powder were received from Ceramic Magnetics. Some problems with temperature control in the furnace apparently caused inadequate sintering. Eight batches were received over the subsequent months until a satisfactory product was accepted in 9/90.

5-7/90 A revised purchase order for fabricating the pilot cell anodes was completed. PNL proceeded to solicit competitive bids for the fabrication work.

9/90 Three companies responded to the solicitation for fabrication work. The bid from Ceramic Magnetics was accepted after evaluation of the bids that were received.

10/90 A new schedule was established for the pilot cell test. Based on the preliminary work with the small batches of ferrite powder, a procedure was developed for fabricating the $455-\mathrm{kg}$ batch to be used for the pilot cell anodes. Ceramic Magnetics agreed to begin processing this powder upon receipt of a formal purchase order. Once the powder was made, two test anodes were to be made by Ceramic Magnetics for evaluation by PNL before fabrication of the 26 anodes to be used in the pilot cell test. If the test anodes were acceptable, the balance of the anodes would be fabricated by $3 / 1 / 91$. Assuming the anode fabrication work was successful, the pilot cell test was to be initiated during $3 / 91$.

\subsection{PROTOTYPE ANODE TEST}

This portion of the report discusses the prototype test that was performed at the Reynolds Metals Company facility in Sheffield, Alabama. This test was performed to gain experience in an industrial setting with cermet inert anodes before testing them in the pilot cell.

\subsubsection{Background}

As a result of a meeting between PNL staff and Reynolds staff at PNL in September 1988 it was decided to perform an electrolysis test on a large cermet inert anode at the Reynolds Metals Company facility in Sheffield, Alabama, prior to performing the pilot cell test. The proposed "prototype anode" test would allow PNL and Reynolds staff to work together, to determine and resolve issues concerning the operation of the inert anodes, and to evaluate the performance of a commercially-produced anode. It was considered 
important to resolve these issues before conducting the more definitive, large-scale, pilot cell test.

\subsubsection{Results}

The results of the prototype anode test are discussed in the PNL technical report titled Results from Electrolysis Test of a Prototype Inert Anode (Strachan et a1. 1990) and in two presentations at the 119th Annual TMS Meeting in Anaheim, California, February 18-22 (Strachan et al. 1990; Peterson et a1. 1990).

\subsubsection{Conclusions}

The principal conclusions from the prototype anode test were that, despite meeting the $100-h$ test criterion, the anode was not yet ready for industrial application due to serious materials-related problems. Severe corrosion of the anode was observed upon post-test analysis and based on metal purity analyses. Certain possible causes for the materials problems were identified and addressed in the separate laboratory tests discussed in Section 3.1.2. In light of the results reported in Section 3.1.2, it was concluded that the most likely reason for the severe degradation of the prototype anode was the design of the test cell. It is anticipated that some of these design limitations will not be present in the pilot cell tesi; however, certain issues related to control of operation (e.g., preht iting and transferring the inert anodes and maintaining a certain alumina concentration), may prove problematic for the pilot cell test as well. Future discussions concerning operation of the pilot cell test will be conducted as needed in FY 1991.

\subsection{CERAMIC POWDER PRODUCTION}

This section of the report summarizes the progress made by Ceramic Magnetics in the fabrication of the ferrite powder that will be used in the fabrication of the anodes for the pilot cell test.

\subsubsection{Background}

Between February 1990 and September 1990, eight 25-kg batches of ferrite powder were prepared at Ceramic Magnetics Company for evaluation at PNL. 
Evaluation of these batches was performed to determine the best set of conditions for making the larger $455-\mathrm{kg}$ batch for the pilot cell anodes. The 8-month period was much longer than was anticipated for developing a suitable powder production scheme. Nevertheless, important information was learned concerning the scale-up of powder production.

\subsubsection{Results and Discussion}

The 25-kg batches of Ceramic Magnetics ferrite powder were labeled XBAT$2^{(a)}$ through XBAT-9 in order of the sequence in which they were produced. The first five samples, XBAT-2 through XBAT-6, were calcined at increasingly higher temperatures (between $800^{\circ}$ and $950^{\circ} \mathrm{C}$ ). (b) Samples XBAT-2 and XBAT-3 were reddish-brown, indicating incomplete reaction of the $\mathrm{NiO}$ and $\mathrm{Fe}_{2} \mathrm{O}_{3} \cdot \mathrm{X}$ ray diffraction of the XBAT-2 through XBAT-6 showed varying amounts of $\mathrm{Fe}_{2} \mathrm{O}_{3}$, consistent with their color. Sample XBAT-6, which was calcined at $950^{\circ} \mathrm{C}$, exhibited almost complete reaction between $\mathrm{Fe}_{2} \mathrm{O}_{3}$ and $\mathrm{NiO}$, with an estimated 5 to $10 \%$ unreacted $\mathrm{Fe}_{2} \mathrm{O}_{3}$. Two additional batches, XBAT-7 and XBAT-8, were prepared with the latter calcined at $980^{\circ} \mathrm{C}$. Sample XBAT- 8 showed no detectable $\mathrm{Fe}_{2} \mathrm{O}_{3}$ as indicated by $x$-ray diffraction. Sintered anodes were made from all of the Ceramic Magnetics powders, and their densities measured, their microstructures examined; and some were tested electrochemically in benchscale cells. All of the microstructures appeared adequate and those tested electrochemically (including the $\mathrm{Fe}_{2} \mathrm{O}_{3}$-1adened XBAT-2) performed indistinguishably from the standard PNL anodes in small, short-term tests. The densities, however, varied, probably reflecting the compositional differences.

Sample XBAT- 8 was considered representative of material produced using the optimum conditions. No evidence for significant amounts of $\mathrm{Fe}_{2} \mathrm{O}_{3}$ was found in XBAT-8 using XRD, and small anodes made from it had microstructures

(a) Sample XBAT-1 was a trial sample that was produced for internal use at Ceramic Magnetics and was never sent to PNL.

(b) The observed dependence on temperature appears to have arisen from a disparity between the temperature of the powder and that of the temperature controller. Additional tests showed the temperature of the powder was about $25^{\circ} \mathrm{C}$ lower than that indicated by the furnace temperature gauge. 
similar to anodes made previously at PNL from 5324 powder (i.e., with low porosity and a uniform distribution of phases). Also, the densities of the small anodes were very similar to standard PNL anodes. For example, an alloxide anode made from XBAT-8 at a consolidation pressure of 20 kpsi had a density of $5.72 \mathrm{~g} / \mathrm{cm}^{3}$, compared to $5.70 \mathrm{~g} / \mathrm{cm}^{3}$ for a standard all-oxide anode made from 5324 powder. Similarly, when the ferrite powder was blended with 17 wt\% $\mathrm{Cu}$, the XBAT-8 powder produced an anode with a density of $5.99 \mathrm{~g} / \mathrm{cm}^{3}$ compared to $6.11 \mathrm{~g} / \mathrm{cm}^{3}$ for an anode made from the standard 5324 powder.

A large $15-\mathrm{kg}$ billet was also made by Ceramic Magnetics from XBAT-8, but without spray drying the ferrite powder and without organic binder. One of the reasons for this approach was that the Ceramic Magnetics staff do not like to have binder-containing materials in their sintering furnaces. They would prefer to use a material that is binder-free. The ferrite powder used for the billet was wet-blended with the Cu powder, dried, pressed at $13 \mathrm{kpsi}$, and sintered. This billet had a significant amount (about $30 \%$ ) of $\mathrm{Cu}$ that had bled from the cermet and accumulated at the base of the billet. In the past, most $\mathrm{Cu}$ bleeding was limited to sma?l droplets on the outer surfaces of the articles that were produced. The reasons for the heavy $\mathrm{Cu}$ bleeding are not known exactly, but it is assumed that the metal phase was more nearly pure $\mathrm{Cu}$. In the spray dried materials used in the past (i.e., the 5324 powder from Stackpole), it had always been observed that pure $\mathrm{Cu}$ was mixed with the ferrite powder but the resulting metal phase in the cermet was a $\mathrm{Cu} / \mathrm{Ni}$ alloy. It has been speculated that the alloy results from reduction of $\mathrm{NiO}$ by the binder. This speculation is supported by the general Cu-color of the binderless cermet from Ceramic Magnetics once it had been cut and polished. Since the material obtained from Ceramic Magnetics did not contain binder, it appears that the $\mathrm{Cu}$ bled from the billet because the melting point of the metal phase was lower in the material without binder than with binder.

$X$-ray diffraction applied to a portion of the billet showed an absence of splitting of the peak assigned to the $\mathrm{Cu}-\mathrm{Ni}$ alloy, suggesting that the metal phase was closer to pure $\mathrm{Cu}$. Microscopic analysis also showed that the distribution of the metal phase was not uniform. There was a heavy Cu concentration near the bottom and increased porosity toward the interior of the billet. Portions of the material were also removed for density 
measurements. These samples were found to have low density. Normal densities for the cermet material are about $6.1 \mathrm{~g} / \mathrm{cm}^{3}$, whereas the material from Ceramic magnetics had a density of about $5.7 \mathrm{~g} / \mathrm{cm}^{3}$. These results strongly indicated that spray drying and a binder were required to achieve an anode more similar to those previously fabricated and tested at PNL.

In November 1990, Ceramic Magnetics began to produce a $455-\mathrm{kg}$ batch of powder for the pilot cell anodes using conditions similar to those for XBAT8. It was anticipated that the first full-scale anode made from the spray dried powder would be delivered in December 1990. The anode was to be subsequently analyzed by PNL.

There was some concern that the anodes would not have the high densities that have been routine in the laboratory anodes. The main reason for concern was the isostatic pressure used at Ceramic Magnetics. This pressure was 13,000 psi rather than the more than 20,000 psi used at PNL to produce highly dense anodes. The need for high isostatic pressures was a topic discussed with Ceramic Magnetics, although the effects of lower density on the performance of the anodes are unknown.

\subsection{ELECTRICAL CONNECTION}

This portion of the report covers work to improve the electrical connection in the cermet inert anodes. The objective of this work was to obtain a connection with good electrical continuity and improved mechanical integrity.

\subsubsection{Background}

During FY 1989 and FY 1990, various cup-shaped anodes made at PNL were found to have cracks or bulges in them indicating a lack of size reduction in the high alloy $\mathrm{Cu} / \mathrm{Ni}$ core used to provide the mechanical and electrical connection within the anode. These problems were addressed, with application to the scaled-up pilot cell anodes in mind, by improving the design of the core and the fabrication process as described below. 


\subsubsection{Results and Discussion}

The diameter of the $\mathrm{Cu} / \mathrm{Ni}$ core within the anode was first reduced to improve the ratio of core-to-total anode diameter. The bottom diameter of the core was made slightly greater than the top diameter to "lock" the core into position even if cracking occurs. This modification was introduced by minor changes to the anode assembly procedure.

The core material design was also altered to include a greater percentage of the standard $17 \% \mathrm{Cu}$ cermet. The composition currently being used, and planned for the pilot cell anodes, has $50 \%$ cermet powder (containing $17 \% \mathrm{Cu}$ ) blended with $50 \%$ metal powder $(64 \% \mathrm{Cu}+35 \% \mathrm{Ni}+1 \% \mathrm{Al})$.

Previously, the standard cermet blend-back used 25\% cermet powder. However, the more recent $50 \%$ blend-back of the cermet powder had a core that was readily drilled and tapped without difficulty. The increased cerict powder blended into the core should improve the thermal expansion match between the core and the anode body.

The use of vibrational milling of the $\mathrm{Cu}-\mathrm{Ni}$ alloy with a trace of aluminum is a significant improvement in the process of preparing the core material. This alloy is then blended with the highly active cermet powder to obtain a core material with good sinterability. The shrinkage of the core is estimated to be within $1 \%$ of that of the anode body.

Microstructural evaluation of the interface between the core material and the cermet body of PNL anodes using the improved design showed a wellintegrated structure with the interface appearing as an increasing alloy gradient. In-cell service of the anode with this type of core was expected to be good. Anodes with this type of electrical connection were used in the $20 \mathrm{~A}$ cell tests performed at PNL that were discussed in Section 3.1 .

\subsection{WATER MODEL}

This section covers the results of tests during FY 1989 to determine whether the pilot cell test design will allow sufficient stirring of the bath to dissolve added alumina efficiently. 


\subsubsection{Background}

In the pilot cell test, six cermet inert anodes will be tested under nearly industrial conditions. There is concern, however, that the rising oxygen gas bubbles produced at the anodes, in the pilot-cell design, will cause insufficient stirring of the electrolyte to dissolve and distribute alumina uniformly to each anode. Adequate distribution of dissolved alumina is necessary to prevent excessive corrosion of the anodes because results from previous research (Section 3.1) suggested minimal corrosion under aluminasaturated conditions. To address this potential problem, a water model was constructed of the anode cluster and the half of the pilot cell in which the inert anodes will be tested. Using this model, flow patterns in the cell could be observed.

\subsubsection{Results}

The results of these tests were previously reported in a document with limited distribution. A copy of this document is provided in Appendix $G$. The important conclusions from this work are given below.

\subsubsection{Discussion}

Results from this water model indicated that there should be sufficient stirring from the bubble action coupled with the thermal and concentration gradients in an actual cell to provide adequate distribution of the dissolved alumina to each anode in the cluster. 


\subsection{PLANNED FY 1991 STUDIES}

The following work is planned, in progress, or has already been completed in FY 1991:

- Inert Electrode Studies

- Studies on film formation have been completed and reported (Windisch and Stice 1991a). See Section 3.2.1.

- Studies on the anode impedance have been completed and reported (Windisch and Stice 1991b). See Section 3.2.2.

- A study on the effect of anode microstructure will be completed and reported.

- Anode Scale-Up/Pilot Cell Activities

- Efforts to fabricate the anodes for the pilot cell test will continue.

- The pilot cell test will be performed if the anodes can be fabricated successfully.

- The results of the test will be analyzed and reported after the pilot cell test is performed. 


\subsection{CONCLUSIONS}

The conclusions for each of the activities performed in FY 1989 and FY 1990 are given at the end of the appropriate section in this report. The most critical, on-going activity of the program is the pilot cell test. For this activity, the important conclusions are summarized below:

- Delays in performing the pilot cell test were due to numerous unanticipated problems: in the operation of the prototype test and the materials behavior issues raised by the results of this test; in the procurement of a manufacturer for the cermet inert anodes to be used in the pilot cell; and in the actual scale-up activities, both in the production of the ferrite powder and in the fabrication of the anodes themselves.

- The prototype anode test was valuable because it provided the opportunity for PNL and Reynolds staff to work together and learn something about the operation of cermet inert anodes in an industrial setting. The performance of the prototype anode left many questions regarding materials properties and cell operation, however. Some of these issues have not been fully resolved.

- Although unresolved issues remain from the post-test evaluations of the prototype anode, discussions with DOE-HQ staff in July 1989 and January 1990 have resulted in their decision to proceed with the pilot cell test to be conducted at the Reynolds Metals Company. The original schedule for conducting the pilot cell test at Reynolds was tentatively established assuming that the required additional cermet powder could be acquired and the anodes fabricated by the end of December 1989. This schedule could not be met because of the time required to obtain a purchase agreement for the required powder, the additional tests needed to fabricate the powder correctly, and the unanticipated on-going work needed to fabricate the anodes themselves. The pilot cell test is currently scheduled to be conducted in FY 1991.

Other important accomplishments in FY 1989 and FY 1990 included the completion of laboratory cell tests that confirmed the effects of current density, precorrosion, and silica content on anode performance; the performance of tests that identified the reaction layer on cermet anodes; the initiation of electrochemical tests to determine the source of the anode impedance; the completion of studies to identify and summarize optimal fabrication conditions for the inert anodes, including advanced compositions; the testing of anodes with advanced composition; the refinement of the electrical connection for the inert anode; and modeling the dynamics of the pilot cell. 


\subsection{REFERENCES}

Strachan, D. M., O. H. Koski, S. C. Marschman, C. H. Schilling, and C. F. Windisch Jr. 1988. Fiscal Year 1987 Annual Repor't for the Inert Electrodes Program. PNL-6746, Pacific Northwest Laboratory, Richland, Washington.

Strachan, D. M., S. C. Marschman, N. C. Davis, J. R. Friley, and C. H. Schilling. 1989. Fiscal Year 1988 Annual Report for the Inert Electrodes Program. PNL-7106, Pacific Northwest Laboratory, Richland, Washington.

Strachan, D. M., C. F. Windisch Jr., O. H. Koski, L. G. Morgan, R. D. Pederson, N. E. Richards, and A. T. Tabereaux. 1990. Results from Electrolysis Test of a Prototype Inert Anode. PNL-7345, Pacific Northwest Laboratory, Richland, Washington.

Weyand, J. D., D. H. DeYoung, S. P. Ray, G. P. Tarcy, and F. W. Baker. 1986. Inert Anodes for Aluminum Smelting: Final Technical Report for the Period 1980 September 29 - 1985 September 30. DOE-CONS-40158-20, Alcoa Laboratories, Alcoa Center, Pennsylvania.

Windisch, C. F., Jr., O. H. Koski, N. D. Stice, C. L. Nikias, and L. G. Morgan. 1990. Fiscal Year 1989 Annual Report for the Sensors Development Program. PNL-7309, Pacific Northwest Laboratory, Richland, Washington.

Windisch, C. F., Jr., and N. D. Stice. 1990. Characterization of the Reaction Layer or Film on PNL Inert Anodes: Progress Report for April December 1989. PNL-7326, Pacific Northwest Laboratory, Richland, Washington.

Windisch, C. F., Jr., and N. D. Stice. 1991a. Final Report on the Characterization of the Film on Inert Anodes. PNL-7589, Pacific Northwest Laboratory, Richland, Washington.

Windisch, C. F., Jr., and N. D. Stice. 1991b. Report on the Source of the Electrochemical Impedance on Cermet Inert Anodes. PNL-7629, Pacific Northwest Laboratory, Richland, Washington. 
APPENDIX A

DETERMINATION OF THE HIGH CURRENT DENSITY LIMIT FOR CERMET ANODES 


\section{Inert Electrodes Program \\ DETERMINATION OF THE HIGH CURRENT DENSITY LIMIT FOR CERMET ANODES}

D. M. Strachan

March 1990

Prepared for

The U.S. Department of Energy

under Contract DE-AC06-76RLO 1830

Pacific Northwest Laboratory

Richland, Washington 99352 


\section{CONTENTS}

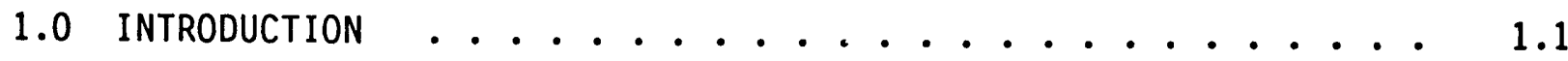

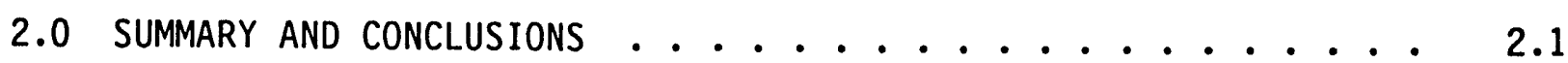

3.0 EXPERIMENTAL METHODS AND MATERIALS ................. 3.1

3.1 Electrical MeASUREMENTS $\ldots \ldots \ldots . \ldots . \ldots . \ldots . \ldots$

3.2 CHEMICAL ANALYSES . . . . . . . . . . 3.2

3.2 .1 Metal Analyses ............ 3.2

3.2.2 Bath Ratio Analyses ............ 3.2

3.2.3 Dissolved $\mathrm{Al}_{2} \mathrm{O}_{3}$ Analyses .......... 3.2

3.3 SOLID STATE ANALYSES ...................... 3.3

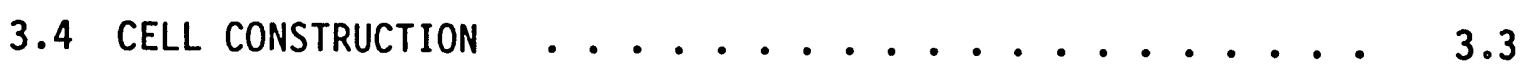

4.0 RESULTS ................................ 4.1

4.1 ELECTRICAL MEASUREMENTS ................... 4.1

4.2 METAL PURITY RESULTS . . . . . . . . . . . . 4.5 


\section{$\underline{\text { FIGURES }}$}

3.1 A Schematic of The Electrolysis Cell Used For Test \# 71 . . . 3.4

4.1 Voltage History For Test \# 71 . . . . . . . . . . . 4.2

4.2 Current History For Test \#71 . . . . . . . . . . . . . 4.3

4.3 Amperage Data From The Anode In Test \# 71 . . . . . . . . . 4.4

4.4 A Portion of The Voltage Trace Between The Reference

4.5 A Photomicrograph of The Bottom Portion of The Anode Used in Test \# 71 .................. . . 4.8

4.6 A Photomicrograph of The Bottom Corner of The Anode

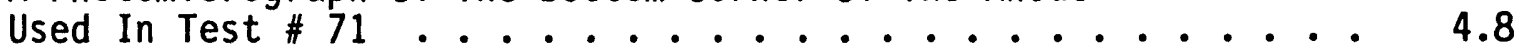

\section{TABLES}

4.1 Metal Purities For Selected Elements In The Al Metal From Test \#71 ................ 4.7 


\subsection{INTRODUCTION}

During the testing and development of cermet anodes at PNL for use in the electrolytic production of Al from cryolite-based electrolytes, Marschman (1989) determined that a current density of $0.5 \mathrm{~A} / \mathrm{cm}^{2}$ yielded conditions under which little or no corrosion of the anode was observed. This low current density represents a marked departure from the normal anode current density of approximately $1 \mathrm{~A} / \mathrm{cm}^{2}$ in a typical commercial electrolysis cell. If a lower current density such as $0.5 \mathrm{~A} / \mathrm{cm}^{2}$ must be used in a operating cell with cermet anodes, serious consideration must be paid to the design of the anode and the electrolysis cell. To date, no systematic study has been performed to determine the effect of current density on the performance of a cermet anode other than the work by Koski (Windisch et al. 1990) using short-term tests with small anodes ( $1 \mathrm{~cm}^{2}$ anodes exposed surface area).

The purpose of the study reported here was to determine the highest current density at which a cermet anode could be operated under stable conditons. The astability of the anode current and voltage were used to determine the upper current density limit because aluminum metal purity analyses takes 4 or more hours to perform. 


\subsection{SUMMARY AND CONCLUSIONS}

An experiment was conducted in which a current density of $1.2 \mathrm{~A} / \mathrm{cm}^{2}$ was sustained without apparent voltage or current analomies on a cermet anode for a period of $4 \mathrm{~h}$. Prior to that time period the anode had been run at current densities ranging from $0.5 \mathrm{~A} / \mathrm{cm}^{2}$ to $0.9 \mathrm{~A} / \mathrm{cm}^{2}$ over a period of about $13 \mathrm{~h}$. At a current density of $1.5 \mathrm{~A} / \mathrm{cm}^{2}$, the anode-to-reference electrode voltage became very unstable - an event that has been previously interpreted as an indicator of enhanced anode corrosion. Therefore, it appears that the upper limit for stable operation of the cermet anode is about $1.2 \mathrm{~A} / \mathrm{cm}^{2}$ based on the results from this test. However, it should be noted that corrosion rates may still be found to vary as a function of current density because of the short duration of this test.

During this test a second anode was to be used to verify the high current density limit. This second anode fractured while being cleaned of electrolyte buildup after it had been successfully installed in the cell. This limited the number of metal purity values that were obtained for the total test. 


\subsection{EXPERIMENTAL METHODS AND MATERIALS}

In this test, the electrolysis was started at an anode current density of $0.5 \mathrm{~A} / \mathrm{cm}^{2}$ to establish a baseline of operation. After a $12 \mathrm{~h}$ period, the current density was gradually increased in $0.1 \mathrm{~A} / \mathrm{cm}^{2}$ increments up to $0.9 \mathrm{~A} / \mathrm{cm}^{2}$ over a $4 \mathrm{~h}$ time period. The anode was operated at each current density step for about $1 \mathrm{~h}$. After about $4 \mathrm{~h}$ at $0.9 \mathrm{~A} / \mathrm{cm}^{2}$, the current density was increased more rapidly to $1.5 \mathrm{~A} / \mathrm{cm}^{2}$ and then decreased to a nominal current density $1.3 \mathrm{~A} / \mathrm{cm}^{2}$ (see Section 4.0 for additional discussion of the highest operating current density).

A second anode was to be used in the cell to verify the high current density value obtained using the first anode. Unfortunately, the second anode fractured during a cleaning operation to remove electrolyte buildup on its surface and about one third of the anode fell into the molten aluminum pool. Metal samples were not collected after this event, because the portion of the anode in the aluminum pool could not be retrieved and hence contaminated the molten aluminum.

The surface area of the anodes to be immersed in the electrolyte was calculated assuming a right circular cylinder; this surface area was used to calculate the current needed for the test. The side wall of the anode was assumed to be $90 \%$ efficient in carrying the current.

\subsection{ELECTRICAL MEASUREMENTS}

A Fluke Helios I (Redmond, Washington) data logger was used to collect voltage, temperature, and current data at a normal rate of once every 5 minutes. The power supply was used in the constant current mode and the voltage varied as required to maintain constant current. Current scans were obtained by manually lowering the current and noting the current and voltage at steady state.

One channel of a two pen strip chart recorder was connected to the power supply voltage output and the other channel across a $0.1 \mathrm{ohm}$ standard resistor in series with the electrolysis cell. It has been observed in previous tests at PNL that when an anode begins to corrode, the voltage, under constant current cell operation, becomes erratic and begins to fluctuate. This 
observed phenomenon was used in this test to determine the high current density limit for the cermet anode.

A standard electrode (Burgman, Leistra, and Sides 1986) was also used to monitor the voltage drop between itself and the anode and cathode. The continuously monitored signals were recorded using a strip chart recorder.

\subsection{CHEMICAL ANALYSES}

Samples of the electrolyte were taken throughout the test. The samples consisted of small quantities $(10 \mathrm{~g}$ to $15 \mathrm{~g})$ of electrolyte and liquid aluminum metal.

\subsubsection{Metal Analyses}

Metal samples were weighed after removing the glass tubing. Approximately $1 \mathrm{~g}$ of each metal sample was weighed accurately and dissolved in concentrated hydrochloric acid. If needed, a small volume of concentrated nitric acid was added to the hydrochloric acid in order to completely dissolve the metal. The dissolved metal solution was then diluted to a volume of $100 \mathrm{~mL}$ and the impurities quantitatively determined by Inductively Coupled Plasma (ICP) Spectroscopy. Elements with known interferences with the $\mathrm{Al}$ spectrum were not reported.

\subsubsection{Bath Ratio Analyses}

Electrolyte or bath ratio analyses were made using a $\mathrm{pH}$ method. A sample of finely crushed electrolyte $(=1 \mathrm{~g})$ was added to $25.0 \mathrm{~mL}$ of 1.001 * $0.010 \mathrm{~N} \mathrm{KOH}$ solution containing $\mathrm{Al}(\mathrm{OH})_{3}$ and sodium tartrate. Approximately 50 $\mathrm{mL}$ of hot deionized water was added to the beaker and the resulting solution was boiled for 6 minutes. After cooling to room temperature in a cooling bath, $25.0 \mathrm{~mL}$ of $1.005 \pm 0.010 \mathrm{~N} \mathrm{HCl}$ was added to the mixture. After 10 minutes, the $\mathrm{pH}$ was measured and recorded when the value was constant. A calibration curve was constructed by performing this analysis on a set of standard electrolyte samples.

\subsubsection{Dissolved $\mathrm{Al}_{2} \underline{0}_{3}$ Analyses}

The dissolved $\mathrm{Al}_{2} \mathrm{O}_{3}$ content of the electrolyte was routinely determined by accurately weighing an approximately $1 \mathrm{~g}$ sample of finely crushed electrolyte to the nearest $0.1 \mathrm{mg}$. About $50 \mathrm{~mL}$ of 30 mass $\% \mathrm{AlCl}_{3}$ solution was added to the sample in a beaker, and brought to a boil for 10 minutes. While 
the mixture was still very hot, it was rapidly transferred to a medium speed ashless filter containing a small amount of filter aid (finely divided ashless filter paper used to speed and enhance filtration). The material was quantitatively transferred from the beaker by washing repeatedly with boiling water. Finally, the filter was washed repeatedly with boiling water until the filtered solution tested neutral to litmus paper and gave no precipitate when added to a small portion of $0.1 \mathrm{M} \mathrm{AgCl}$. Using metal forceps, the filter paper containing the residual $\mathrm{Al}_{2} \mathrm{O}_{3}$ was transferred to a $\mathrm{Pt}$ crucible, which had been heated to constant mass in a $1000^{\circ} \mathrm{C}$ furnace. A loose-fitting cover was placed on the crucible and the crucible placed in the cooler part of the $1000^{\circ} \mathrm{C}$ furnace for 10 minutes. After the preliminary ashing was complete, the crucible was moved to the hottest portion of the furnace for an additional 15 minutes. This treatment provided sufficient time and temperature for the sample to come to constant mass.

After the high temperature treatment, the crucible was quickly transferred to a desiccator and allowed to cool for 15 minutes, and was then weighed. The mass of the residual solid was the $\mathrm{Al}_{2} \mathrm{O}_{3}$ content of the electrolyte. This method was also checked using standard electrolyte samples.

\subsection{SOLID STATE ANALYSES}

The anodes and associated cermet pellets were examined microscopically using an optical microscope and a scanning electron microscope (SEM). The samples were cut in half, polished, and examined under the optical microscope. Before examining the samples in the SEM, the cermet samples were given an electrically conductive coating of carbon by vapor deposition. For the most part, the SEM was operated in the quantitative mode using pure $\mathrm{Cu}$ as an intensity standard.

\subsection{CELL CONSTRUCTION}

The cell was constructed as shown in Figure 3.1 . An $18 \mathrm{~cm} \mathrm{ID,} 19 \mathrm{~cm} 0 D$ pure alumina tube, closed at the bottom end, was used as the cell liner. The alumina tube was $46 \mathrm{~cm}$ in height. The connection between the $A 1$ and $T i B_{2}$ cathode and the outer graphite crucible was made with a graphite stud through a hole drilled in the alumina tube. The $\mathrm{TiB}_{2}$ cathode plate and the graphite stud were cemented in place with graphite cement. The walls of the graphite crucible were about $2.5 \mathrm{~cm}$ thick. A $3 \mathrm{~mm}$ thick Inconel ${ }^{\circledR}$ shell provided the 


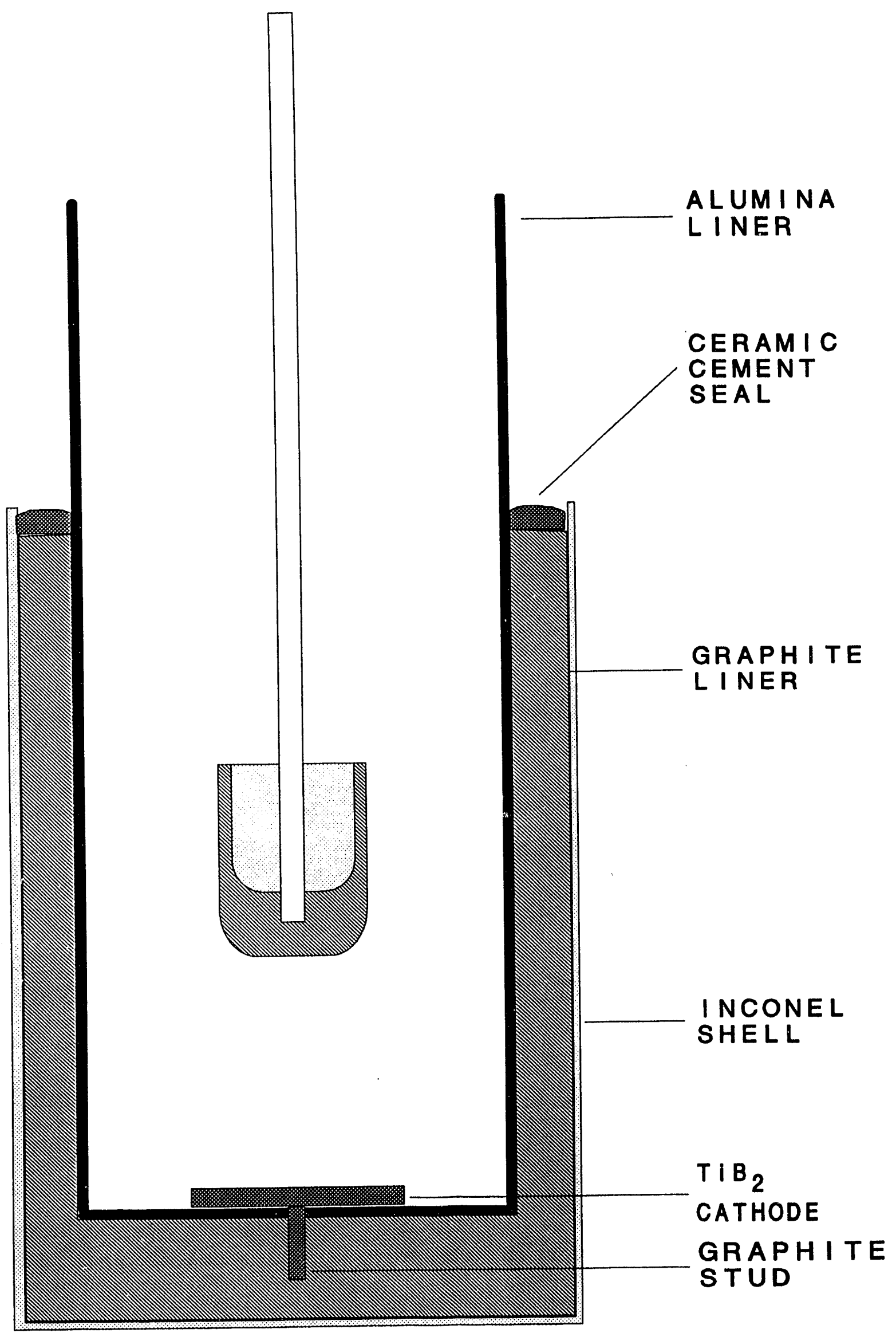

FIGURE 3.1. A Schematic of The Electrolysis Ceit Used For Ceii $\# 71$ 
external container. Approximately $1.5 \mathrm{~kg}$ of $\mathrm{Al}$ in the form of $7.5 \mathrm{~cm}$ diameter $4 \mathrm{~cm}$ thick disks was placed in the bottom of the cell. Approximately $6 \mathrm{~kg}$ of premixed powdered electrolyte was then placed on top of the Al metal. The exact quantities of each were determined by weight. The anode used in this test was suspended above the powdered electrolyte during the heatup of the cell. A $6 \mathrm{~mm} \mathrm{Ni}$ rod was used as the electrical connection/mechanical support for the anode. This rod was shrouded with an alumina tube sealed at the anode with a refractory cement. The cup of the anode was filled with refractory alumina powder. 


\subsection{RESULTS}

Results from this test are discussed in the following sections.

\subsection{ELECTRICAL MEASUREMENTS}

The voltage and current history for this cell are shown in Figures 4.1 and 4.2, respectively. The voltage and current behavior for the anode is somewhat less constant than in earlier tests because the anode current density was changed using a combination of current increases and varying the anode's immersion depth. The sudden decrease to zero at $22 \mathrm{~h}$ in both figures came when the anode was dropped into the cell while attempting to adjust the anode height. About three hours later, the power supply failed and was replaced with a unit having a greater range.

After the replacement power supply was installed, the voltage was increased to about $7.5 \mathrm{~V}$. This voltage was sufficient to obtain an anode current density of $0.5 \mathrm{~A} / \mathrm{cm}^{2}$. The power to the power supply was then turned off. The power was then turned on to the emersed anode while the power supply was set in the voltage control mode and the current allowed to go to any value demanded by the voltage applied. This procedure was done in an effort to insure that a continuous protective film or reaction layer was produced on the surface of the anode. The results from this experiment are shown in Figure 4.3. Two equations were used to fit the data by the least squares method. These equations are shown in Figure 4.3. Both equations contain a diffusive term, $t \frac{1}{2}$, which suggests that the resistance of the system increases, i.e., current decreases, with the square root of time. In one equation, the second term suggests the formation of a resistive film that increases linearly with time, giving rise to an increasing resistance or decreasing current. An exponential term is included in the second equation and is suggested by the shape of the curvature of the data. For the time period over which the data were collected, the equation incorporating the exponential term appears to fit the data better. The significance of this form of the equation is not yet known. More data are needed to confirm the form of the equation; such information may be obtained in other studies within the project.

Initial measurements of the anode current density suggested an upper operating limit of $1.3 \mathrm{~A} / \mathrm{cm}^{2}$ for stable operation. However, an actual anode 


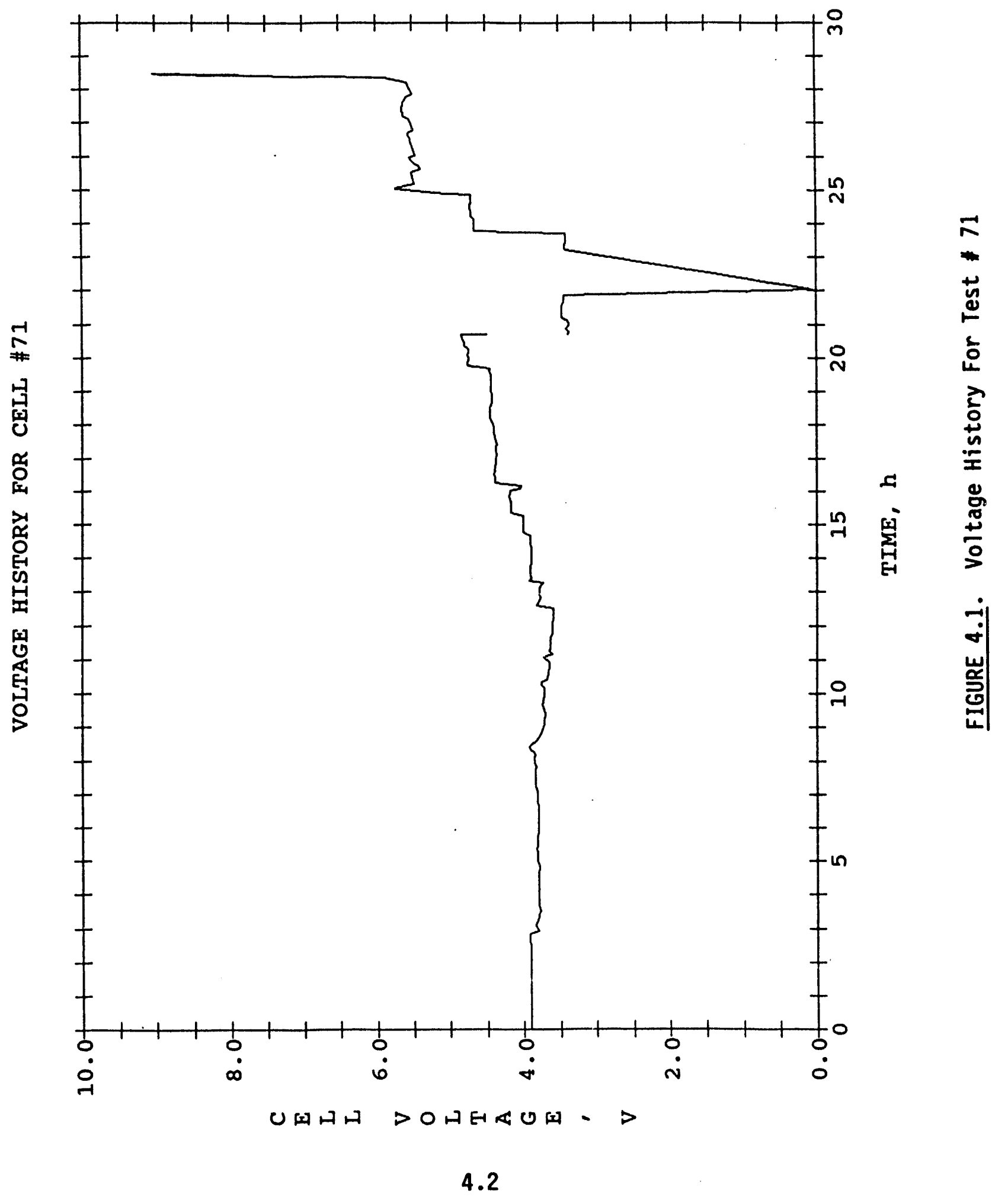




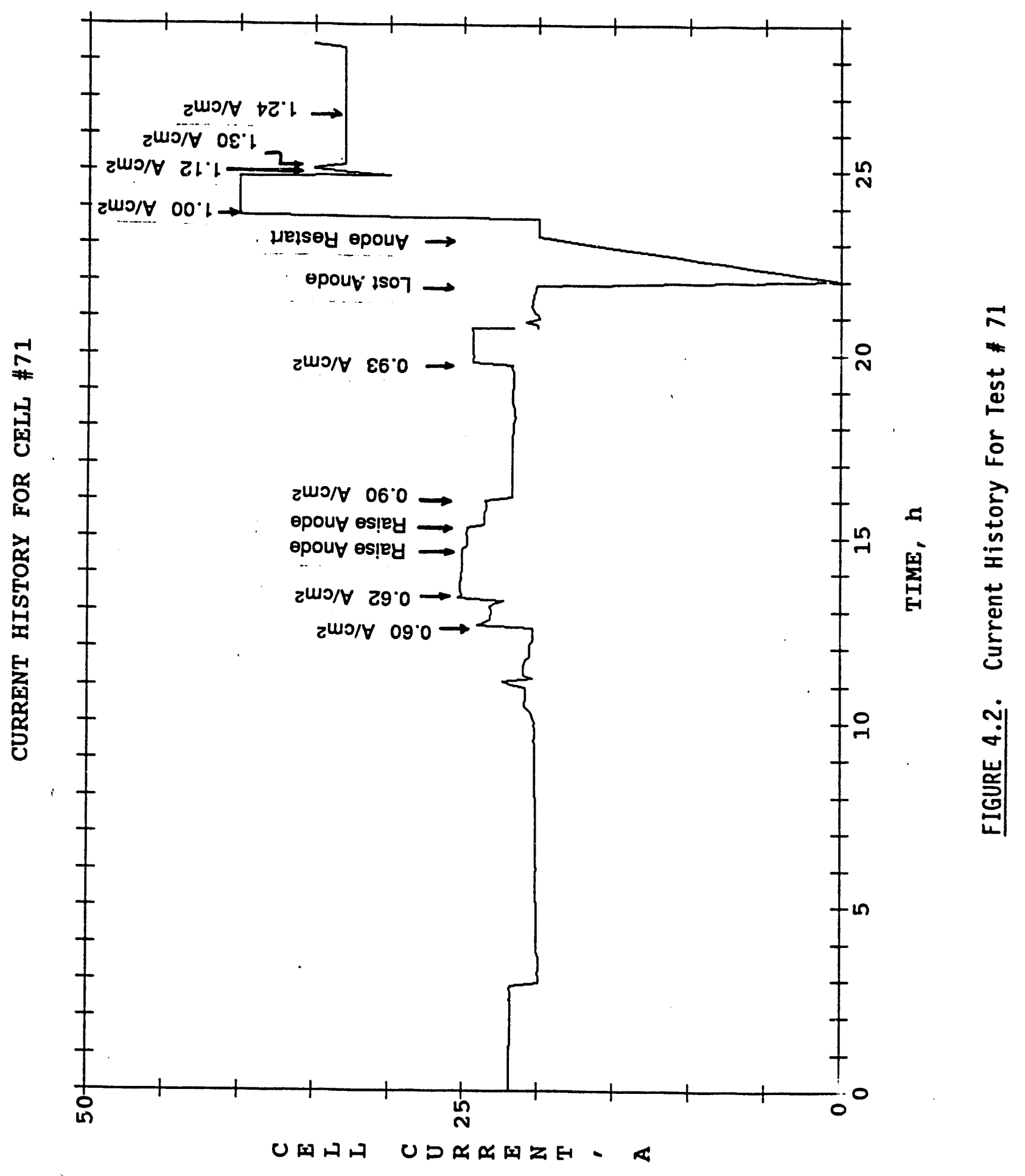

4.3 


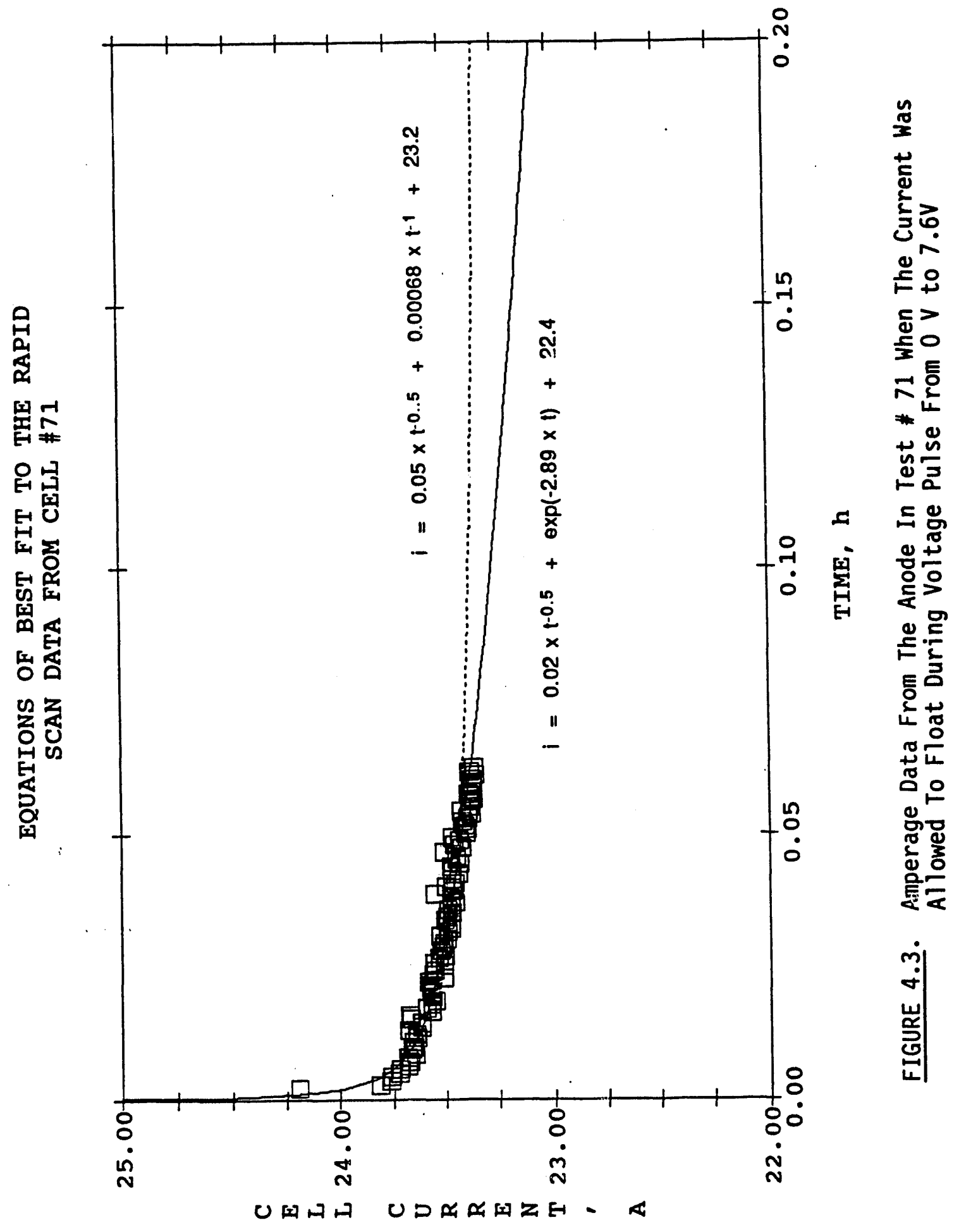

4.4 
current density limit of about $1.2 \mathrm{~A} / \mathrm{cm}^{2}$ is more likely based on an average of the anode immersion depths used to calculate the average current density.

The current density was increased to approximately $1.5 \mathrm{~A} / \mathrm{cm}^{2}$ toward the end of the test to determine if this higher current density could be sustained. The reference electrode response was monitored as the current was increased. A t:race from the strip chart recorder is shown in Figure 4.4. At the bottom of the figure one can see the small amount of noise associated with the operation at a anode current density of $1.2 \mathrm{~A} / \mathrm{cm}^{2}$. When the anode current density was increased to $1.5 \mathrm{~A} / \mathrm{cm}^{2}$, the voltage noise level increased dramatically thereby indicating unstable operation based on past PNL test experiences.

\subsection{METAL PURITY RESULTS}

Only four metal samples were collected during the experiment. The results of the metal analyses are shown in Table 4.1. Although there are insufficient data to draw any significant conclusions, it is interesting to note the marked decrease in the impurities at $22 \mathrm{~h}$. No additional metal samples were collected after this time because approximately one third of the second anode fell into the molten $\mathrm{Al}$ and could not be retrieved thereby precluding the usefulness of additional metal samples.

\subsection{SOLID-STATE ANALYSES}

Photomicrographs of the bottom portion and bottom corner of the anode used in Test \# 71 are shown in Figures 4.5 and 4.6 , respectively. Visual inspection of the sectioned anode indicated a greater depth of affected anode surface on the bottom corner of the anode relative to flat portion of the bottom. Similar behavior has been observed in other anodes tested and is assumed to be a function of regions of high curent flux. Additional analyses are pending. 


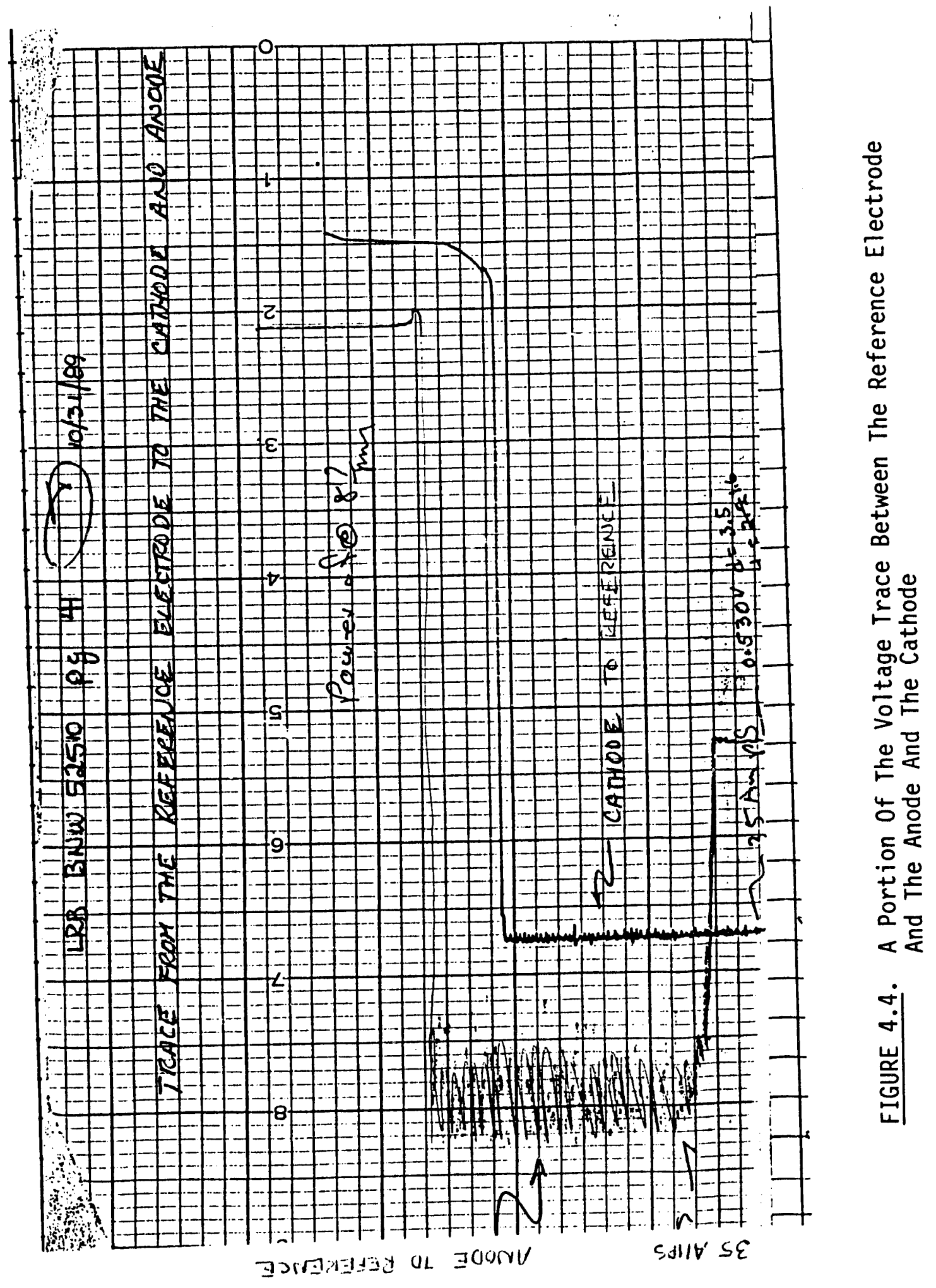




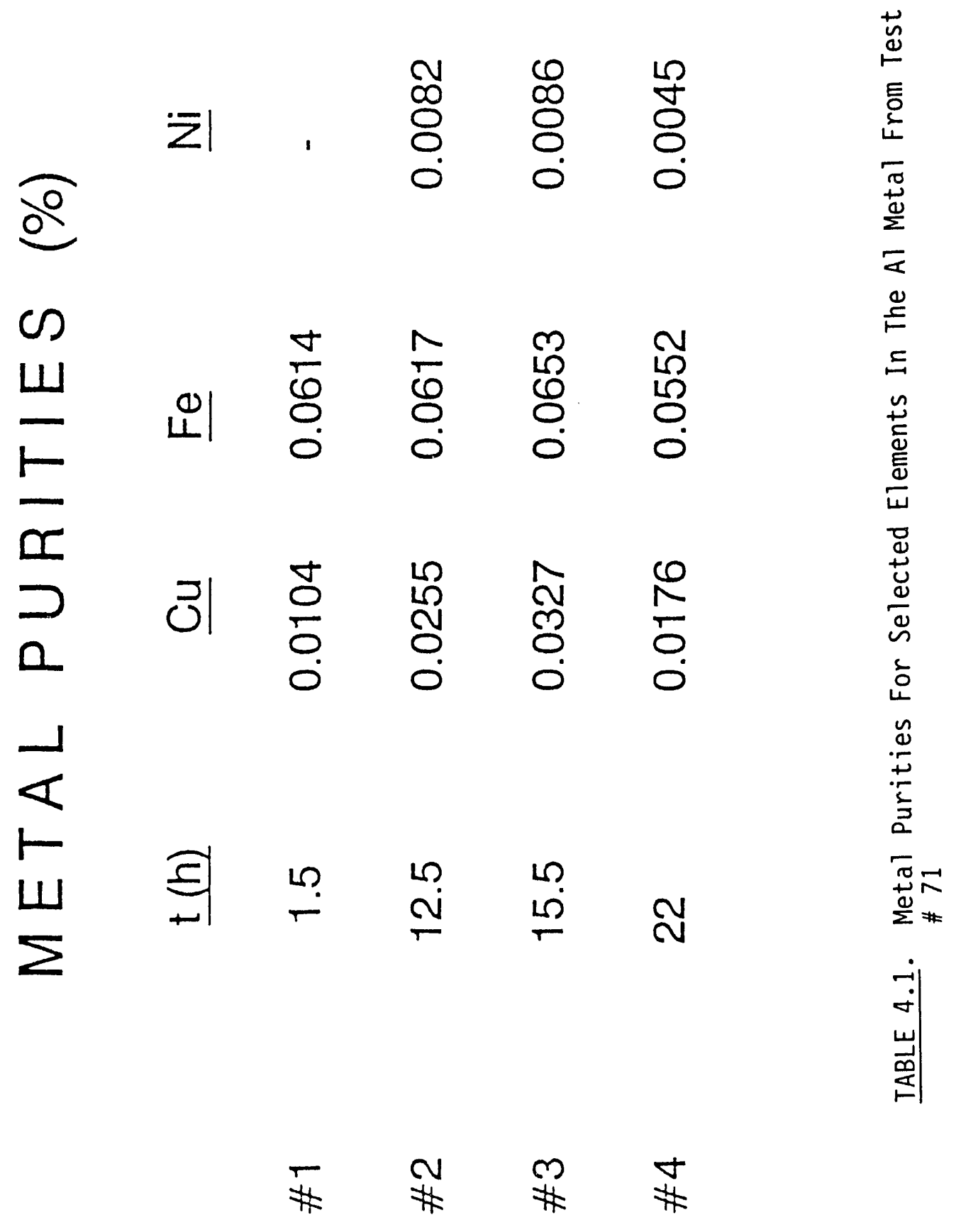




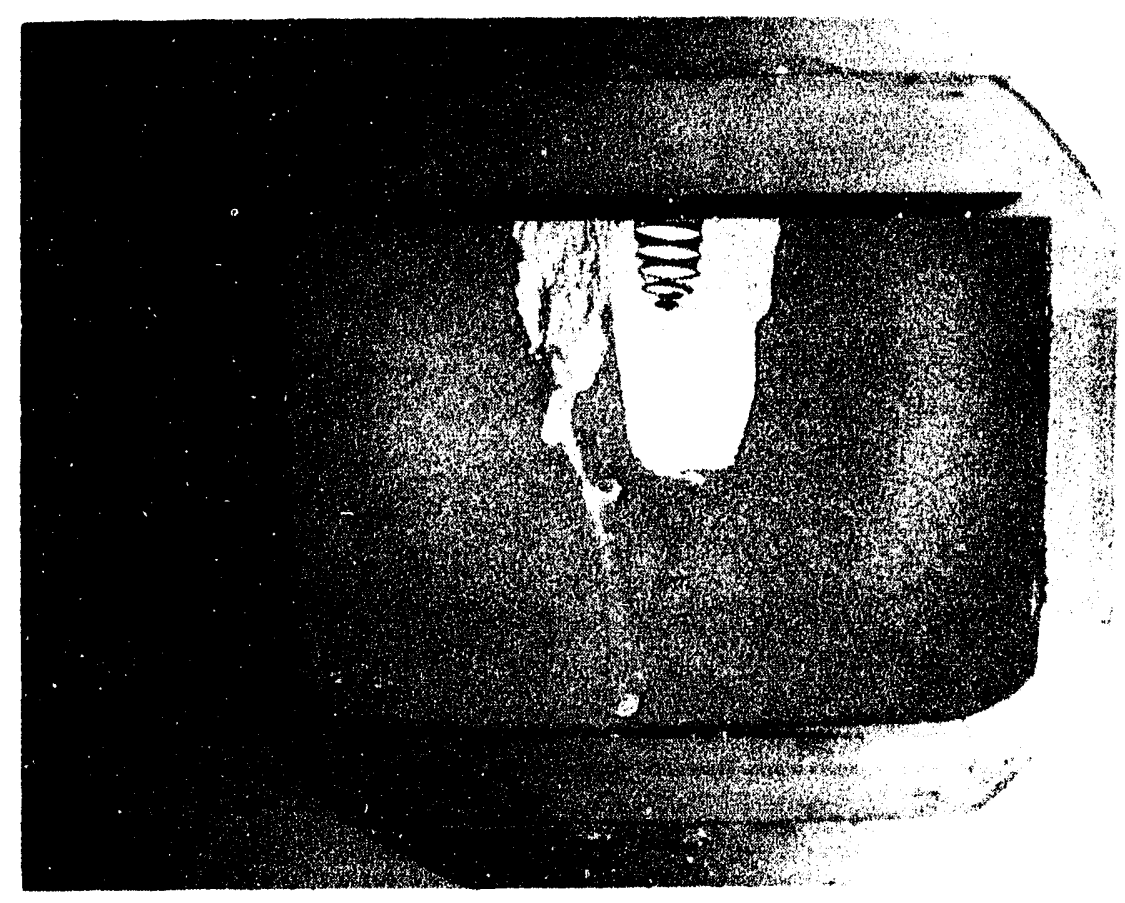

FIGURE 4.5. A Photomicrograph of The Bottom Portion of the Anode Used In Test \#71 (Photograph \#89M261A)

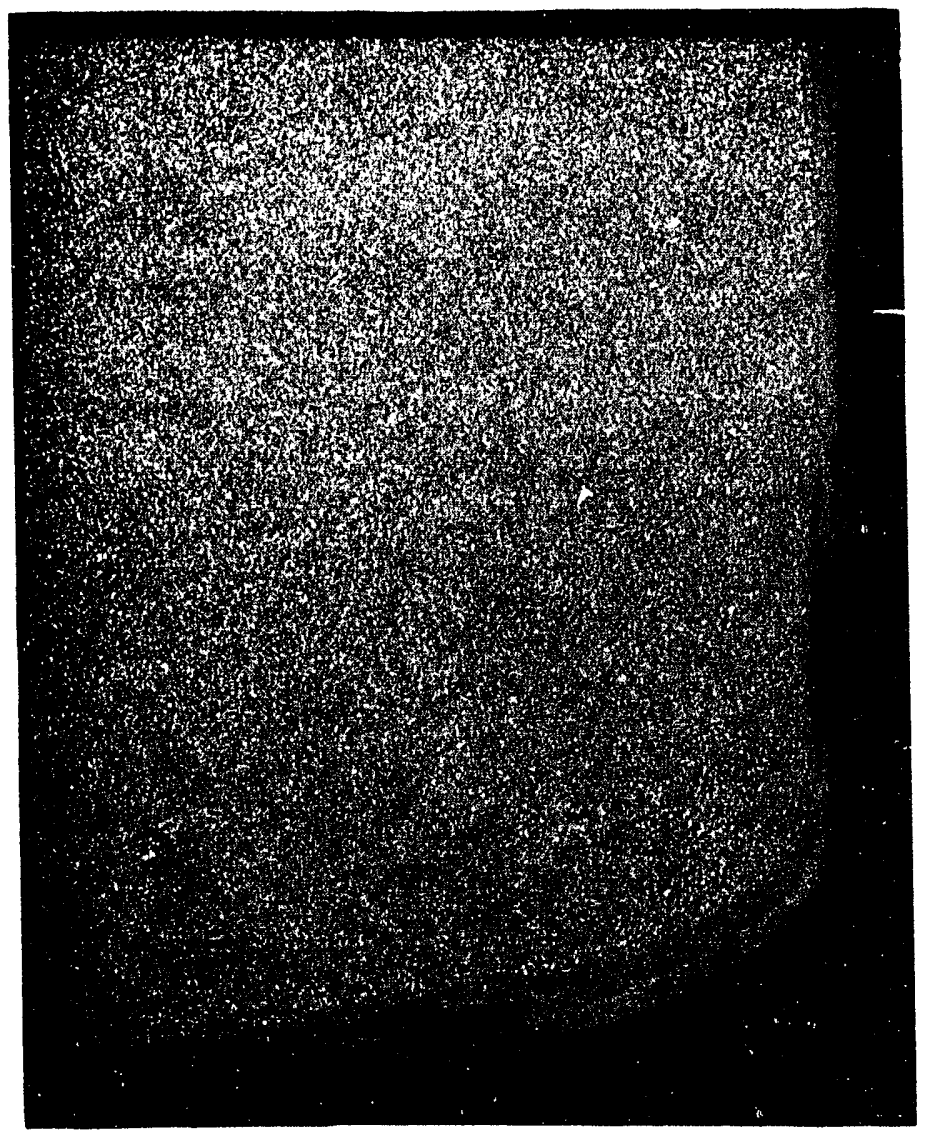

Flille 4.6. A photomicromaln of the Bottom Corner of the Anode Used

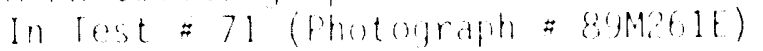


APPENDIX B

EFFECTS OF PREOXIDATION AND ELECTROLYTE SID 2 CONCENTRATION ON ANODE PERFORMANCE 
Inert Electrodes Program

THE EFFECT OF PREOXIDATION AND ELECTROLYTE

$\mathrm{SIO}_{2}$ CONCENTRATION ON ANODE PERFORMANCE

D. M. Strachan

March 1990

Prepared for

The U.S. Department of Energy

under Contract DE-AC06-76RLO 1830

Pacific Northwest Laboratory

Richland, Washington 99352 


\section{CONTENTS}

1.0 INTRODUCTION . . . . . . . . . . . . . . . . . . 1.1

2.0 SUMMARY AND CONCLUSIONS . . . . . . . . . . . . . . . 2.1

3.0 EXPERIMENTAL METHODS AND MATERIALS . . . . . . . . . . . 3.1

3.1 ANODE AND CELL CONSTRUCTION . . . . . . . . . . . 3.1

3.2 CHEMICAL ANALYSIS .................... 3.1

3.2.1 Metal Analyses ............... 3.1

3.2.2 Bath Ratio Analyses ............ . 3.2

3.2.3 Dissolved $\mathrm{Al}_{2} \mathrm{O}_{3}$ Analyses ............ 3.2

3.3 SOLID STATE ANALYSES . . . . . . . . . . . . 3.3

3.4 CELL CONSTRUCTION . . . . . . . . . . . . . 3.3

4.0 RESULTS . . . . . . . . . . . . . . . . . . 4.1

4.1 Electrical MEASUREMENTS . . . . . . . . . . . . 4.1

4.2 METAL PURITY . . . . . . . . . . . . . . 4.1

4.3 SOLID-STATE ANALYSES . . . . . . . . . . . . 4.7

4.3.1 Anode \# 180 .................. 4.7

4.3.2 Anode \# 181 ................... 4.11 


\section{FIGURES}

3.1 A Schematic of The Electrolysis Cell Used For Test \# 70 . . . 3.4

4.1 Voltage History For Test \#70 . . . . . . . . . . . 4.2

4.2 Current History For Test \#70 . . . . . . . . . . . . 4.3

4.3 Typical Current Scan From Test \#70 . . . . . . . . . . 4.4

4.4 A Summary of The Current Scans Taken During Test \#70 . . • . 4.5

4.5 Metal Impurities From Test \#70 . . . . . . . . . . . 4.6

4.6 Silicon Concentrations In The Al From Test \#70 . . . . . 4.8

4.7 A Photomicrograph of The Companion Pellet For Anode \# 180

4.8 A Photomicrograph of A Globule of Material On The Pellet Shown In Figure 4.6 ................ 4.9

4.9 A Photomicrograph of A Typical Area On The Bottom of The Pellet Shown In Figure 4.6 .............. 4.10

4.10 A Photomicrograph of An Area In Which Two Metallic Grains Show Evidence of $\mathrm{Ni}$ Exsolution ............ 4.13

4.11 A Photomicrograph Of The Bottom Portion Of Anode \# 180 . . . 4.13

4.12 A Photomicrograph of The Bottom Portion of Anode \#181 . . . 4.14 


\subsection{INTRODUCTION}

The prototype anode test conducted at the Reynolds Metals Company (Reynolds) facility in Sheffield, Alabama, had two different operational factors than tests previously conducted in the laboratory. These factors are 1) the prototype anode was heated in air in a separate furnace and transferred to the electrolytic cell, and 2) some silica-based material is believed to have entered the cell during the test. The purpose of the test described in this report is to investigate the effect these differences might have had in the increased corrosion of the prototype anode relative to smaller anodes used in laboratory tests.

In laboratory cell tests, the anodes are preheated during the time the cell and its contents are being brought to operating temperature. The anode to be tested is positioned anywhere from the top to $3 \mathrm{~cm}$ above the powdered electrolyte at the start of the cell's heatup. At the Reynolds' facility, the cell was started with a graphite anode. The cermet anode was heated in a separate furnace in air and a hot transfer to the cell was used after the graphite anode had been removed. Thus, laboratory anodes were heated in cryolite vapors while the prototype cermet anode was heated in air. Heating the anode in air was not expected to enhance corrosion because the anode is in contact with $\mathrm{O}_{2}$ during electrolysis. However, the enhanced corrosion observed on the prototype cermet anode after the test at the Reynolds' facility indicated this assumption should be verified.

Also during the test at Reynolds, a ceramic wool blanket was used as part of the furnace insulation. Occasionally small portions of this insulation material fell into the cell during times when samples were taken, the temperature was checked, or observations made. Weyand et al (1986) reported that the presence of $\mathrm{SiO}_{2}$ in the electrolyte may enhance the corrosion of the cermet anode. One of the objectives of the test reported here was to determine if the presence of $\mathrm{SiO}_{2}$ in the electrolyte causes enhanced corrosion of the cermet anode.

In an effort to understand the condition of each anode before electrolysis, a small pellet, produced during the same sintering run as the anode, was suspended next to the anode by a Pt wire. These pellets were removed from the celi/furnace just prior to the start of electrolysis using 
the test anode. These pellets were later sectioned to determine the surface condition of the anode prior to its use in the electrolysis cell. 


\subsection{SUMMARY AND CONCLUSIONS}

Two anodes were tested and the results of these tests indicate that preheating the anode in air does not result in enhanced corrosion. However, the oxidized layer of the anode surface after heating in air appears to be thicker and have a slightly different character than that observed when the anode is preheated in the cell above the electrolyte. The aluminum metal purity results do not indicate any enhanced corrosion from this difference. The corrosion rate of the anodes, based on the metal purity values, appears to be independent of the anode current density and preheating conditions. Addition of $\mathrm{SiO}_{2}$ to the electrolyte appears to cause the rate of increase in impurities in the aluminum metal to decrease. This may be caused by the formation of silicate minerals or by enhanced volatilization. The amount of $\mathrm{Si}$ in the $\mathrm{Al}$ metal was independent of $\mathrm{SiO}_{2}$ addition and time.

These test results suggest that neither preheating the anode in air nor the presence of silica in the electrolyte were probable causes of the prototype anode's corrosion behavior. 


\subsection{EXPERIMENTAL METHODS AND MATERIALS}

\subsection{ANODE AND CELL CONSTRUCTION}

Two anodes were used in this test. Both were constructed as previously described (Strachen et al. 1989) from 83\% 5324 spray-dried oxide powder (Stackpole Corporation, St. Mary, Pennsylvania) and 17\% Cu metal (Alamo Supply Co., Inc. Houston, Texas). These two powders were blended, poured into a mold, pressed, and sintered. A metallic core consisting of an alloy of $65 \% \mathrm{Cu}$ and $35 \% \mathrm{Ni}$ was used to form a core for the electrical connection/mechanical support. A $6 \mathrm{~mm} \mathrm{Ni}$ rod was used to make the electrical and support connection to the anode. The $\mathrm{Ni}$ rod and threaded electrical connection was protected by $\mathrm{placing}$ an $\mathrm{Al}_{2} \mathrm{O}_{3}$ tube over the $\mathrm{Ni}$ rod and filling the inside of the cup portion of the anode with calcined $\mathrm{Al}_{2} \mathrm{O}_{3}$ powder. The $\mathrm{Al}_{2} \mathrm{O}_{3}$ powder was used to protect the support/electrical connection from corrosion in the fluoridecontaining vapors.

The surface area of the anodes to be immersed in the electrolyte was calculated assuming a right circular cylinder; this surface area was used to caiculate the current needed for the test. The side wall of the anode was assumed to be $90 \%$ efficient in carrying the current.

A Fluke Helios I (Redmond, Washington) data logger was used to collect voltage, temperature, and current data at a normal rate of once every 5 minutes. The power supply was used in the constant current mode and the voltage varied as required to maintain constant current. Current scans were obtained by manually lowering the current and noting the current and voltage at steady state.

\subsection{CHEMICAL ANALYSIS}

Small (5g to $15 \mathrm{~g}$ ) samples of the electrolyte and metal were taken throughout the test. The electrolyte samples were not analyzed. Samples were collected using a sampling gun (Leco, Warrendale, Pennsylvania; similar to a spring-loaded syringe) with a $6 \mathrm{~mm}$ fused quartz tube into which the molten sample was drawn.

\subsubsection{Metal Analyses}

Metal samples were weighed after removing the glass tubing. Approximately $1 \mathrm{~g}$ of each metal sample was weighed accurately and dissolved in 
concentrated hydrochloric acid. If needed, a small volume of concentrated nitric acid was added to the hydrochloric acid in order to completely dissolve the metal. The dissolved metal solution was then diluted to a volume of $100 \mathrm{~mL}$ and the impurities quantitatively determined by Inductively Coupled Plasma (ICP) Spectroscopy. Elements with known interferences with the Al spectrum were not reported.

\subsubsection{Bath Ratio Analyses}

Electrolyte or bath ratio analyses were made using a $\mathrm{pH}$ method. A sample of finely crushed electrolyte $(=1 \mathrm{~g})$ was added to $25.0 \mathrm{~mL}$ of $1.001 \pm 0.010 \mathrm{~N}$ $\mathrm{KOH}$ solution containing $\mathrm{Al}(\mathrm{OH})_{3}$ and sodium tartrate. Approximately $50 \mathrm{~mL}$ of hot deionized water was added to the beaker and the resulting solution was boiled for 6 minutes. After cooling to room temperature in a cooling bath, $25.0 \mathrm{~mL}$ of $1.005 \neq 0.010 \mathrm{~N} \mathrm{HCl}$ was added to the mixture. After 10 minutes, the $\mathrm{pH}$ was measured and recorded when the value was constant. A calibration curve was constructed by performing this analysis on a set of standard electrolyte samples.

\subsubsection{Dissolved $\mathrm{Al}_{2} \mathrm{O}_{3}$ Analyses}

The dissolved $\mathrm{Al}_{2} \mathrm{O}_{3}$ content of the electrolyte was routinely determined by accurately weighing an approximately $1 \mathrm{~g}$ sample of finely crushed electrolyte to the nearest $0.1 \mathrm{mg}$. About $50 \mathrm{~mL}$ of 30 mass\% $\mathrm{AlCl}_{3}$ solution was i fded to the sample in a beaker, and brought to a boil for 10 minutes. While the mixture was still very hot, it was rapidly transferred to a medium speed ashless filter containing a small amount of filter aid (finely divided ashless filter paper used to speed and enhance filtration). The material was quantitatively transferred from the beaker by washing repeatedly with boiling water. Finally, the filter was washed repeatedly with boiling water until the filtered solution tested neutral to litmus paper and gave no precipitate when added to a small portion of $0.1 \mathrm{M} \mathrm{AgCl}$. Using metal forceps, the filter paper containing the residual $\mathrm{Al}_{2} \mathrm{O}_{3}$ was transferred to a $\mathrm{Pt}$ crucible, which had been heated to constant mass in a $1000^{\circ} \mathrm{C}$ furnace. A loose-fitting cover was placed on the crucible and the crucible placed in the cooler part of the $1000^{\circ} \mathrm{C}$ furnace for 10 minutes. After the preliminary ashing was complete, the crucible was moved to the hottest portion of the furnace for an additional 15 minutes. This treatment provided sufficient time and temperature for the sample to come to constant mass. 
After the high temperature treatment, the crucible was quickly transferred to a desiccator and allowed to cool for 15 minutes, and was then , eighed. The mass of the residual solid was the $\mathrm{Al}_{2} \mathrm{O}_{3}$ content of the electrolyte. This method was also checked using standard electrolyte samples.

\subsection{SOLID STATE ANALYSES}

The anodes and associated cermet pellets were examined microscopically using an optical microscope and a scanning electron microscope (SEM). The samples were cut in half, polished, and examined under the optical microscope. Before examining the samples in the SEM, the cermet samples were given an electrically conductive coating of carbon by vapor deposition. For the most part, the SEM was operated in the quantitative mode using pure $\mathrm{Cu}$ as an intensity standard.

\subsection{CELL CONSTRUCTION}

The cell was constructed as shown in Figure 3.1 . A $18 \mathrm{~cm} \mathrm{ID,} 19 \mathrm{~cm}$ OD pure alumina tube, open at the bottom end, was used as the cell liner. The alumina tube was $46 \mathrm{~cm}$ in height. The walls of the graphite crucible were about $2.5 \mathrm{~cm}$ thick. A $3 \mathrm{~mm}$ thick Inconel shell provided the external container. Approximately $1.5 \mathrm{~kg}$ of $99.99 \% \mathrm{Al}$ in the form of $7.5 \mathrm{~cm}$ disks about $4 \mathrm{~cm}$ thick was placed in the bottom of the cell. Approximately $6 \mathrm{~kg}$ of premixed electrolyte was then placed on top of the Al metal. The exact quantities of each were determined by weight. The anode was positioned just above the powdered electrolyte during heating of the cell and its contents. The anode connection/support was made from $6 \mathrm{~mm} \mathrm{Ni}$ rod and shrouded with an alumina tube that was sealed at the anode with a refractory cement. The cup of the anode was filled with refractory alumina powder. 


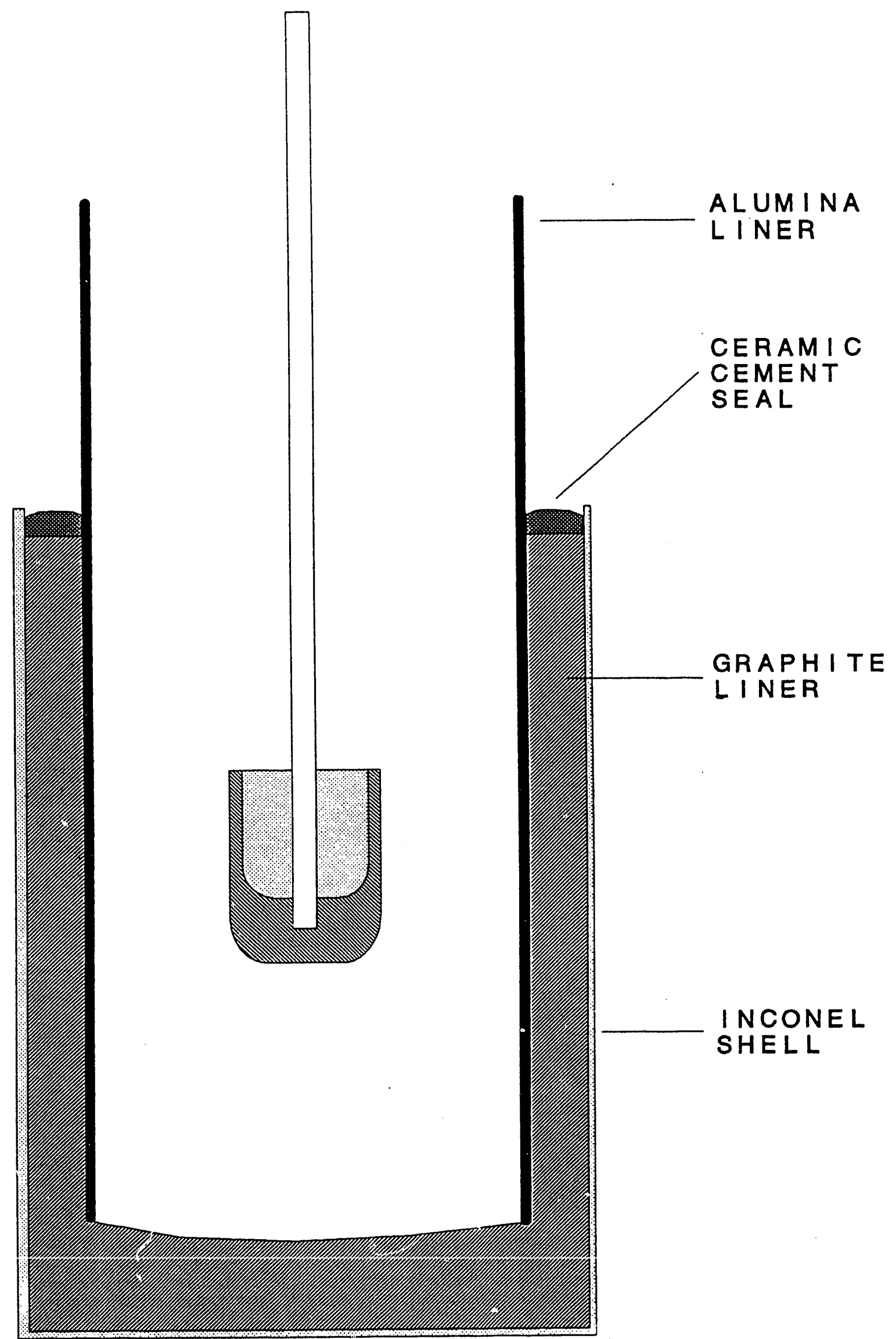

FIGURE 3.1. A Schematic of the Electrolys is Cell Used for Test \#70

$$
3.4
$$




\subsection{RESULTS}

\subsection{ELECTRICAL MEASUREMENTS}

A summary of the voltage and current history of the cell is shown in Figures 4.1 and 4.2 , respectively. Zero on the time axis corresponds to the start of the data logger. The test began when the voltage shown in Figure 4.1 increased from zero volts. Two voltage curves are shown in Figure 4.1; one for the power supply and one for the cell. The voltage at the cell was taken at the top of the $12 \mathrm{~mm}$ stainless steel rods that were threaded into the graphite shell. The difference in voltage comes from the voltage drop in the welding cable between the power supply and the cell (about 0.2 ohms) and the $0.1 \mathrm{ohm}$ standard resistor. Current scans are shown as sharp decreases in the voltage except for the third voltage decrease at about $44 \mathrm{~h}$. The third decrease was due to corrective action when the anode voltage signals appeared to indicate enhanced corrosion.

Two anodes were used in this test. Anode \#180 was run from about $24 \mathrm{~h}$ to $50 \mathrm{~h}$ at which time the electrical connection/support failed and the anode had to be retrieved from the bottom of the cell (a total of $26 \mathrm{~h}$ of electrolysis). Anode \#181 started at about $70 \mathrm{~h}$.

Nine current scans were obtained during this experiment. Each scan consisted of $10-15$ voltage and amperage readings. A sample current scan is shown in Figure 4.3. The results for the intercept (back emf) from the least squares fit to the current scan data are summarized in Figure 4.4. Here the time scale represents the time from the start of electrolysis. Within the ability to measure these values, the back enf of the cell was invariant at $2.22 \pm 0.03 \mathrm{~V}$. This is the same value found in the test of the prototype anode. The theoretical decomposition voltage for an anode evolving $\mathrm{O}_{2}$ gas is $2.1 \mathrm{~V}$, thus the value found in both these tests and the prototype anode test suggests a very low overvoltage for the cermet anode.

\subsection{METAL PURITY}

The results from the analyses of the Al metal samples are summarized in Figure 4.5. The data from anode \#180 (the first anode) are scattered, but with a general upward slope. The data from anode \#181 are much less scattered. The data for anode \# 181 suggest a linear corrosion rate until $\mathrm{SiO}_{2}$ was added. 


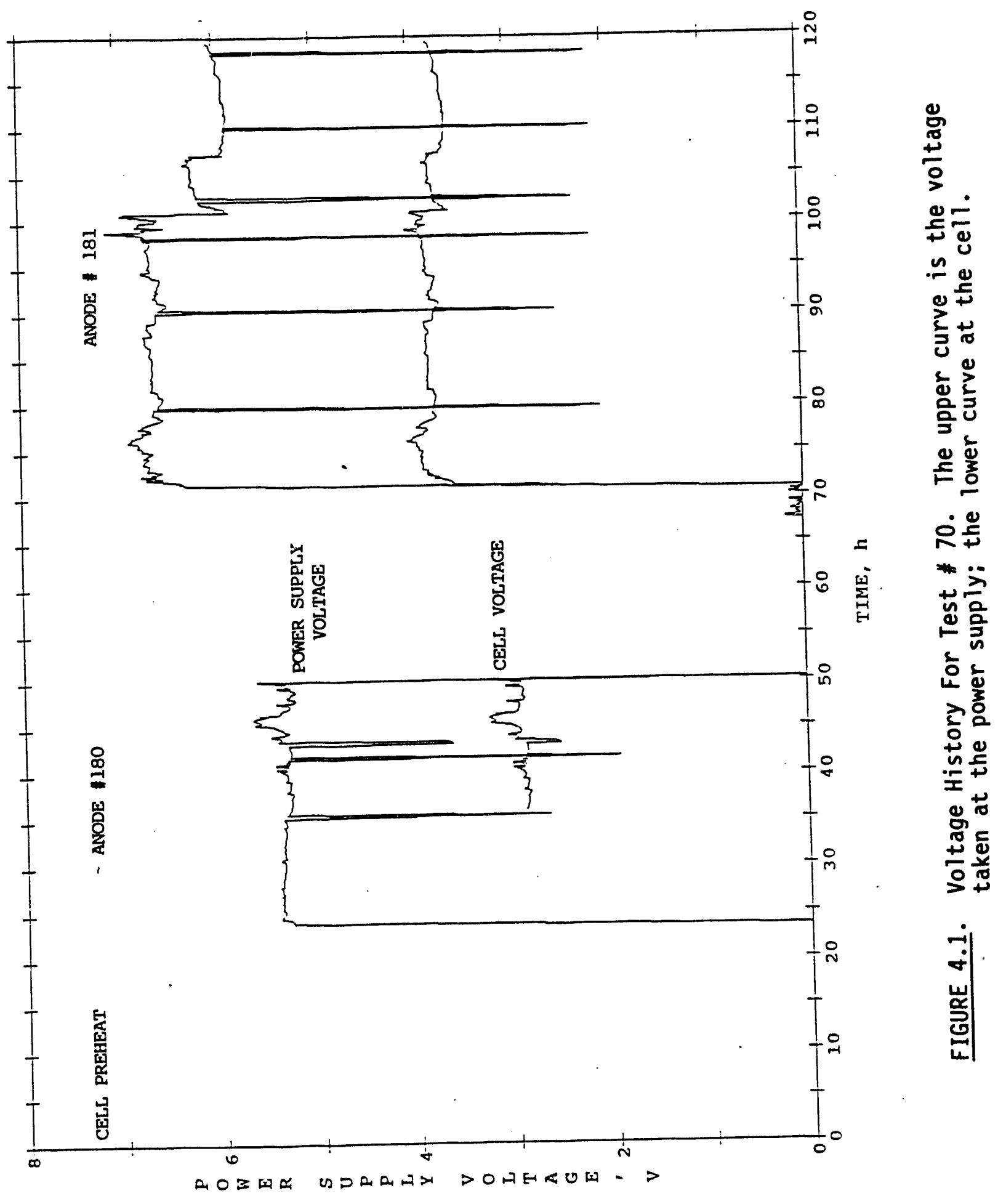

4.2 


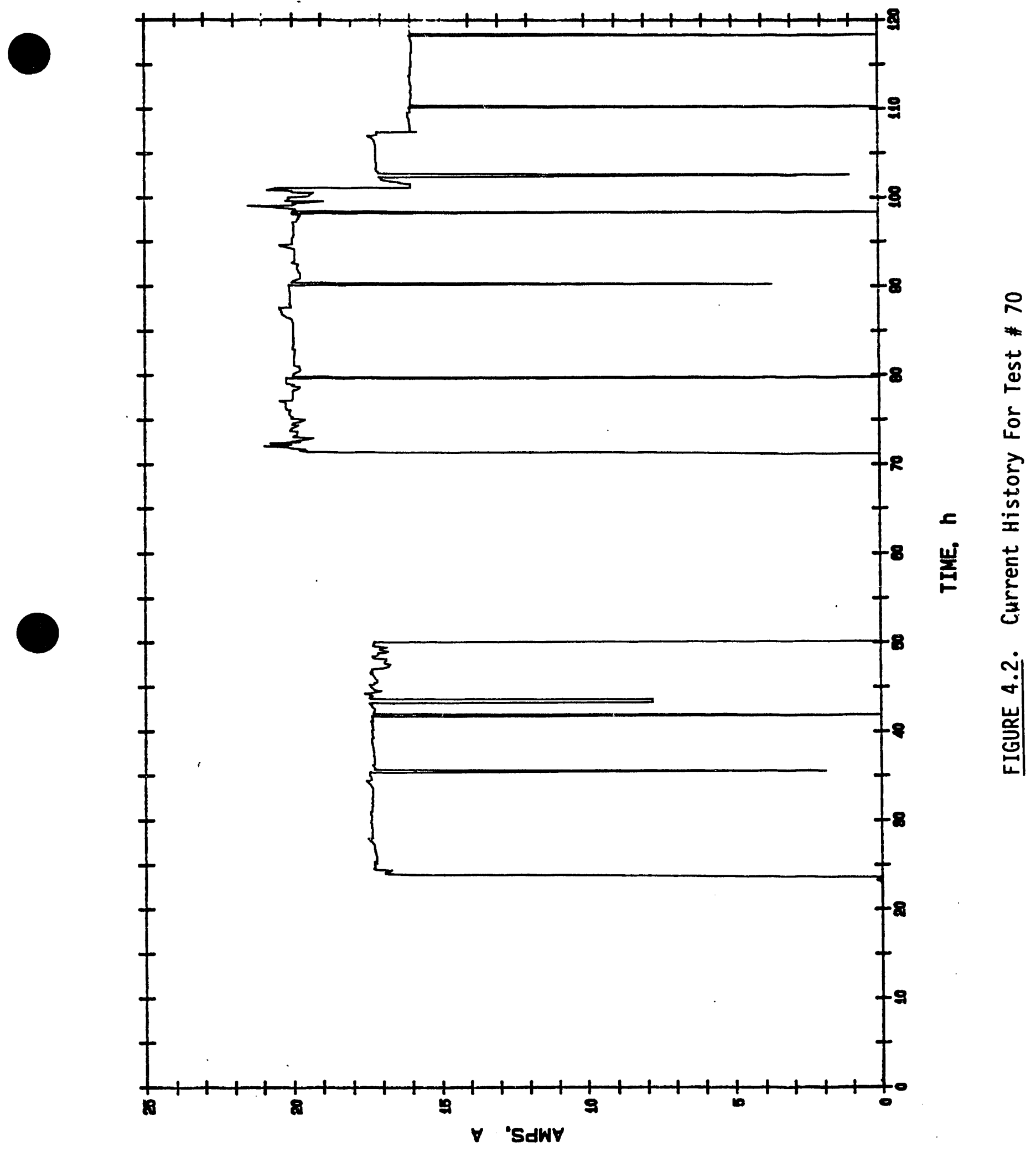

4.3 


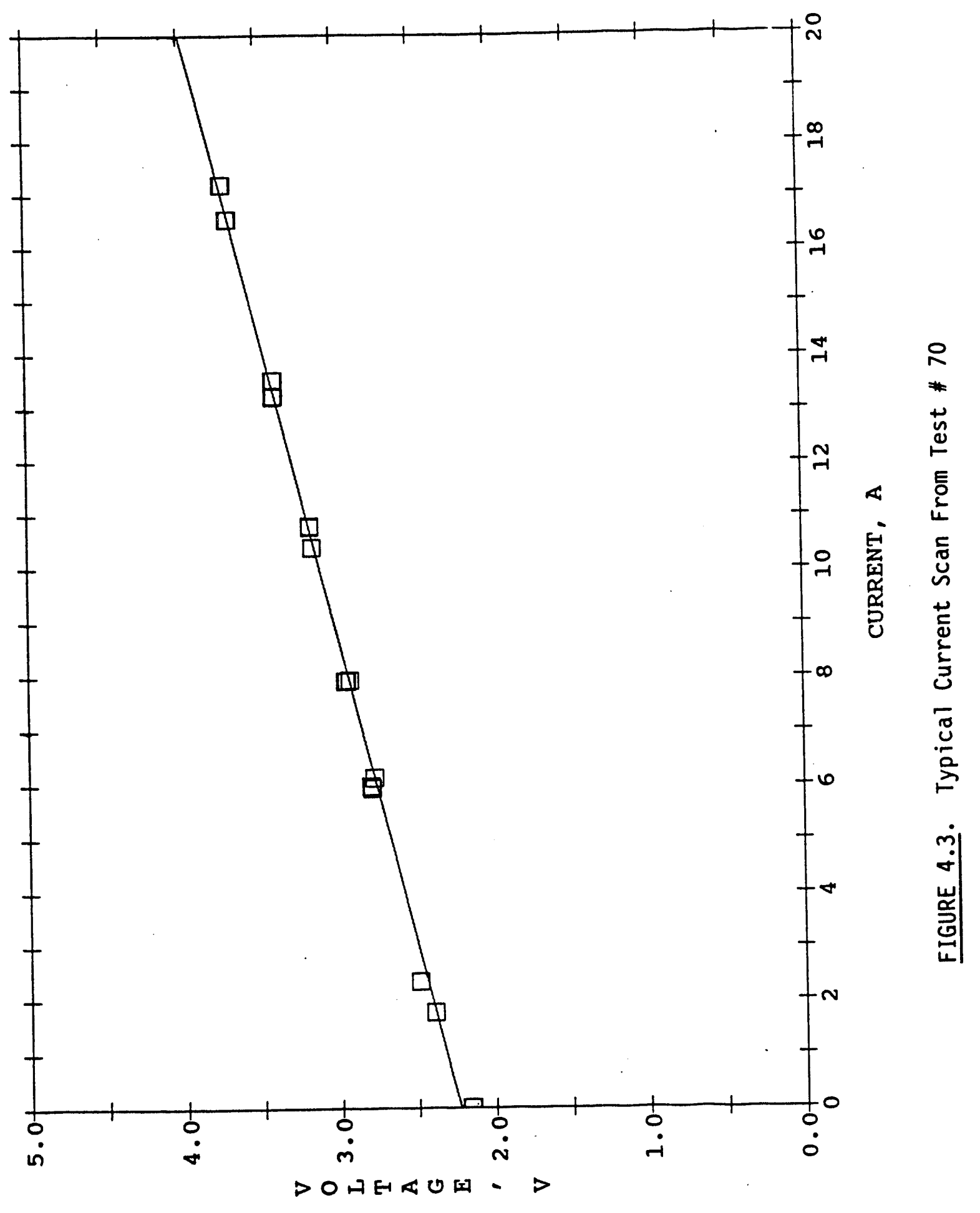

4.4 


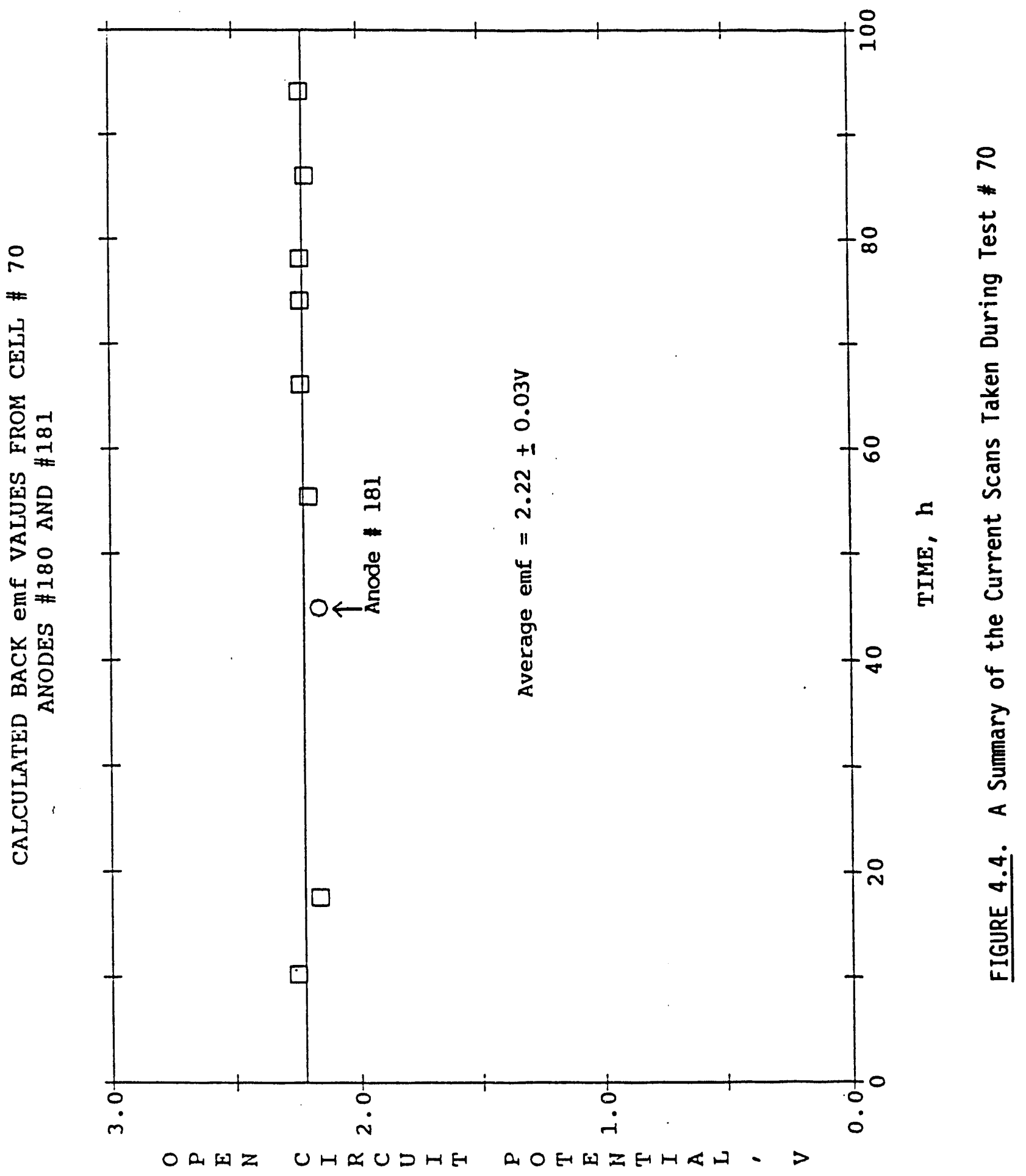

4.5 


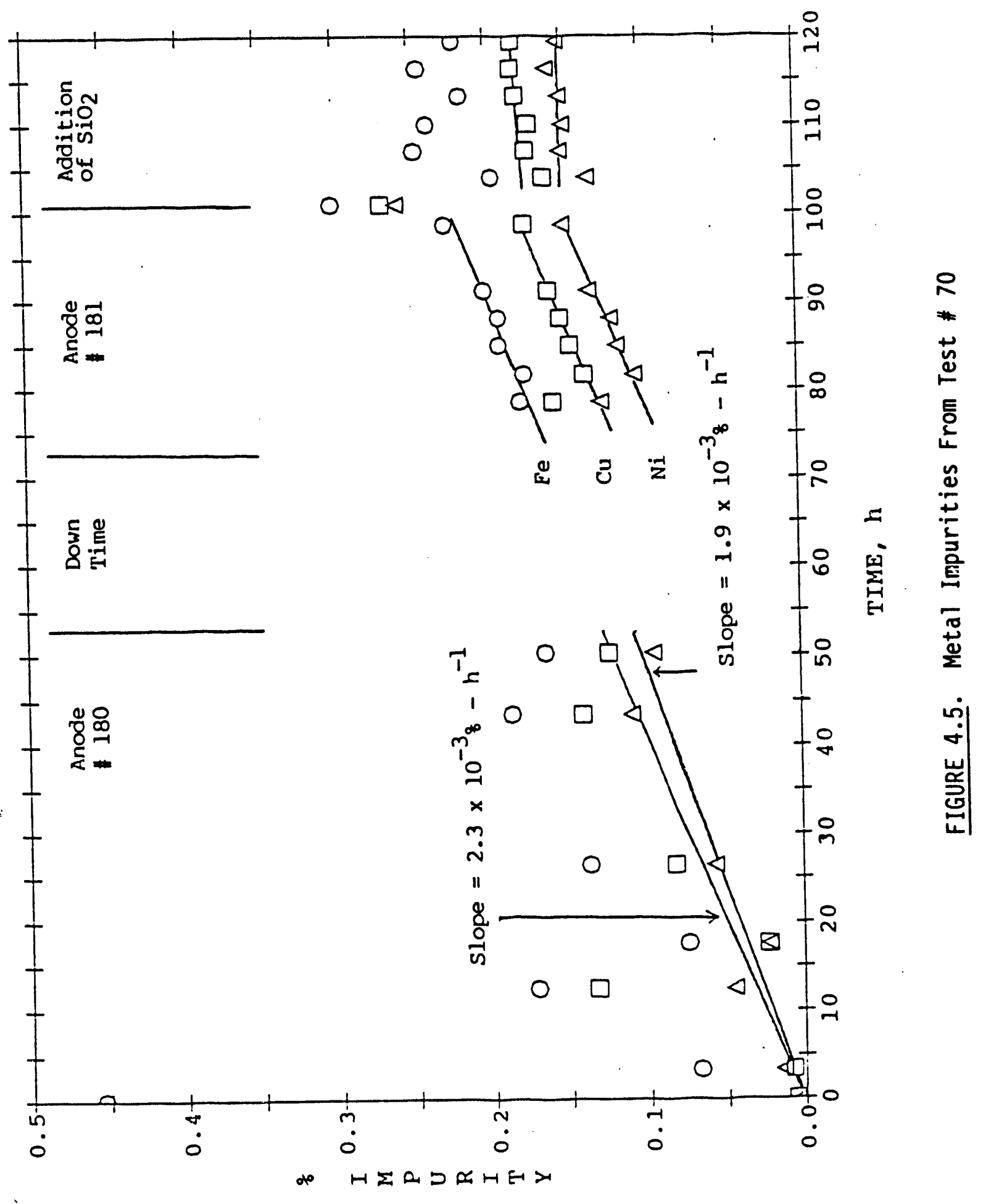

4.6 
The fact that the quantity of all three impurity elements level off at that time suggests the formation of silicate minerals. The slopes of the $\mathrm{Cu}$ and $\mathrm{Ni}$ curves are about $2.3 \cdot 10^{-3} \% / \mathrm{h}$ and $1.9 \cdot 10^{-3} \% / \mathrm{h}$, respectively. Results from the analyses of the $\mathrm{Al}$ metal also indicate that, although the quantity of $\mathrm{SiO}_{2}$ added was approximately three times that normally found in commercial electrolytes, the $\mathrm{Si}$ content of the Al metal was essentially invariant with time (Figure 4.6).

\subsection{SOLID-STATE ANALYSES}

Results of solid-state analyses of the pellets and anodes are summarized here. Many more analyses were performed but for clarity not all of those results are reported here.

\subsubsection{Anode \#180}

The companion cermet pellet for anode \#180 was sectioned, mounted, and polished. Polishing of these cermet materials is difficult because the hardness covers a broad range from the soft $\mathrm{Cu}$ to the relatively hard ferrite. Pieces of glass are sometimes positioned in the mount next to the material being polished in order to minimize rounding of the sample edges. Figure 4.7 shows the sectioned and polished companion pellet to anode \#180. Apparent corrosion had already occurred on the surface of this material due to some globules of material that had formed on the surface during heating. These areas of corrosion are seen in Figure 4.7 as dark gray areas devoid of metallic $\mathrm{Cu}$ (white specks). A globule and associated area of attack are seen under higher magnification in Figure 4.8. In these reflected light photomicrographs, the material in the globule cannot be identified, but subsequent SEM analyses indicated that the material was Al-CU-Ni alloy/oxide. The affected area is generally devoid of metallic $\mathrm{Cu}$, although $\mathrm{Cu}$ is still present in reduced quantities and in a different phase. In this example, the affected area is about $320 \mu \mathrm{m}$ in thickness. The porosity of this area also appears to have increased but increased porosity is difficult to determine because in such a friable material, some or even all, of the porosity might be an artifact of the polishing.

The oxidized/affected area on the pellet after heating is much thinner in areas where globules did not exist. A photomicrograph of a typical area of the bottom of the pellet is shown in Figure 4.9. The thickness of the 

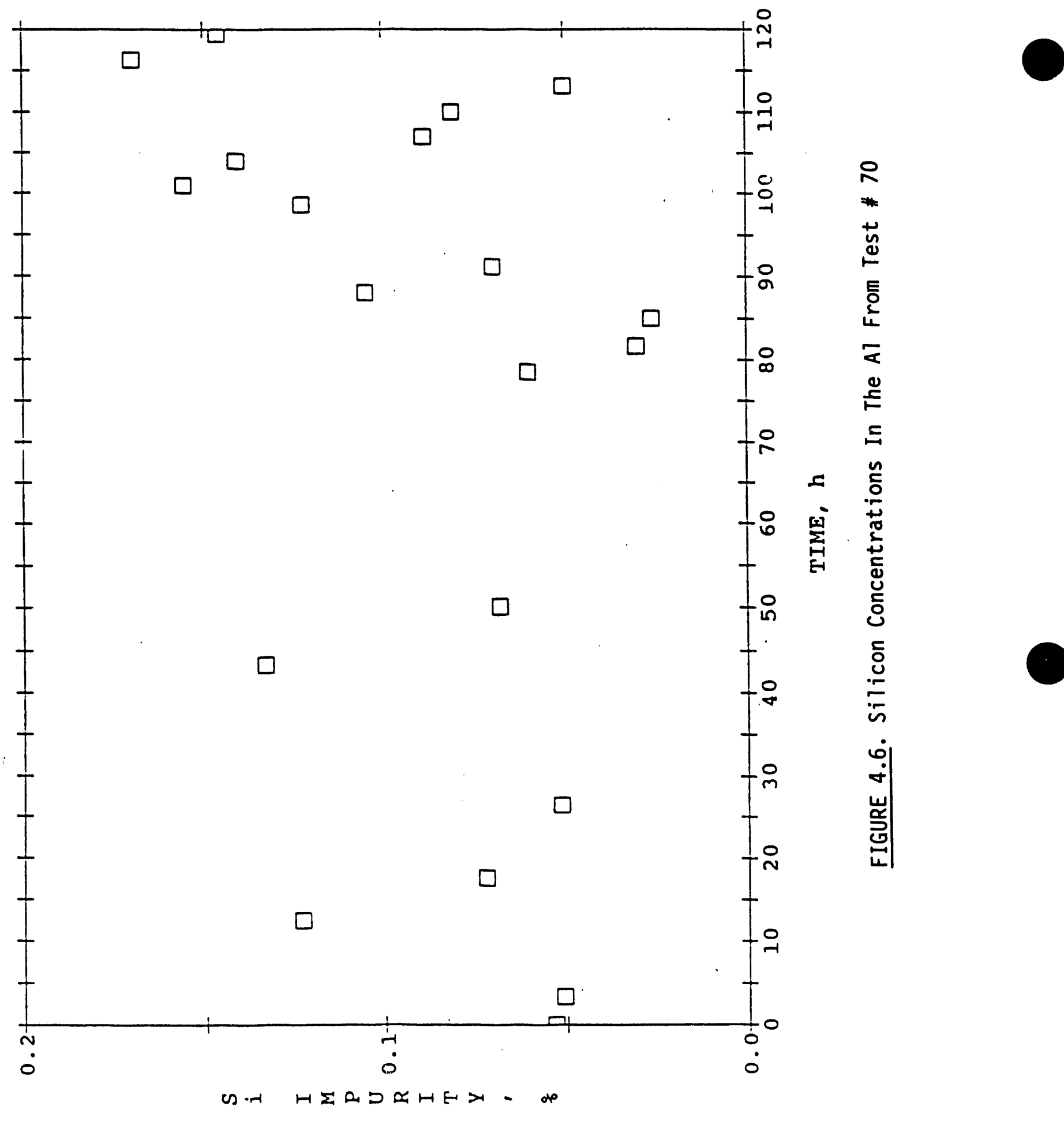


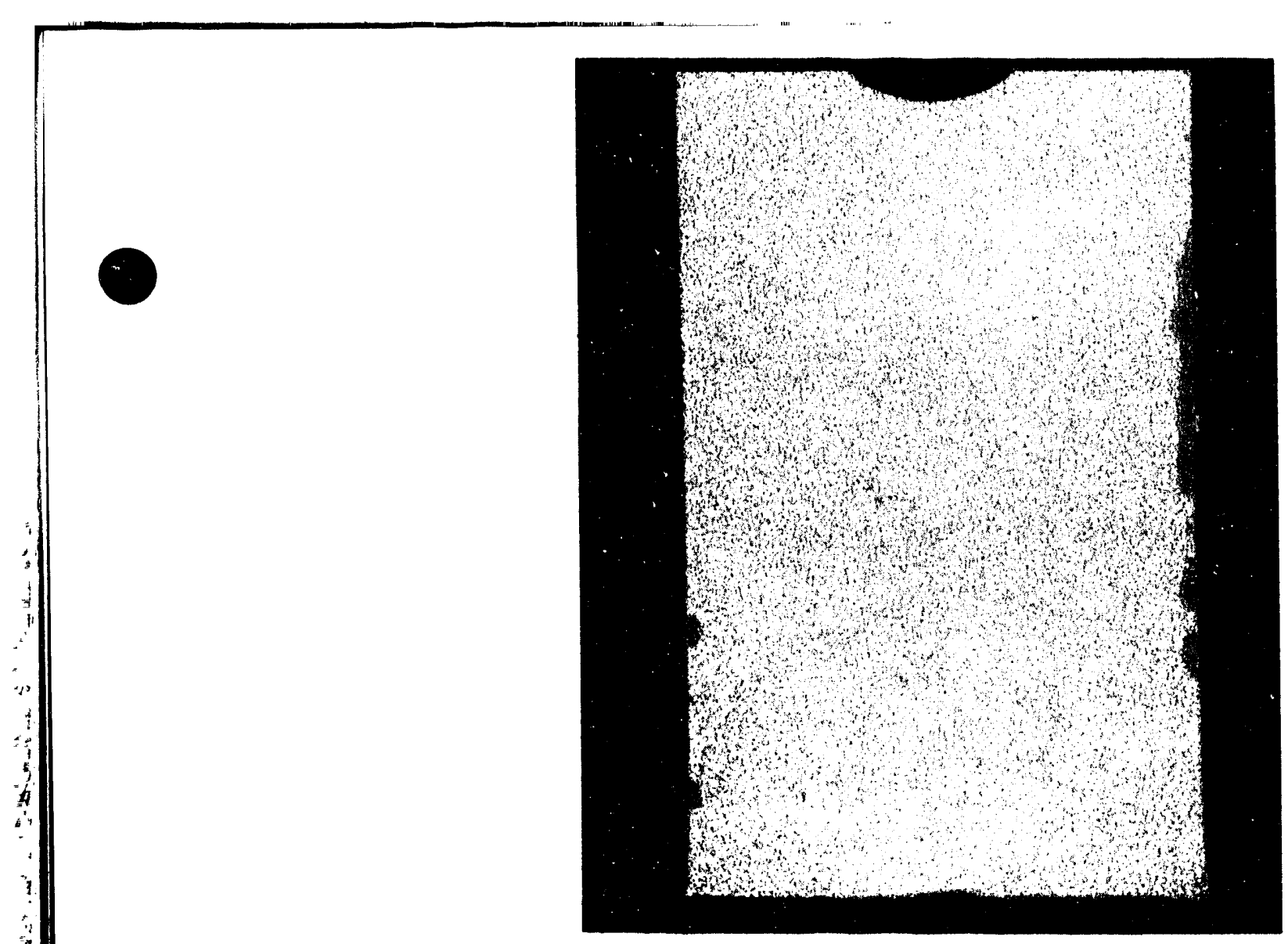

FIGURE 4.7. A Photomicrograph Of The Companion Pellet For Anods \#180.n Cell \#70 (Photo \#89M194A)

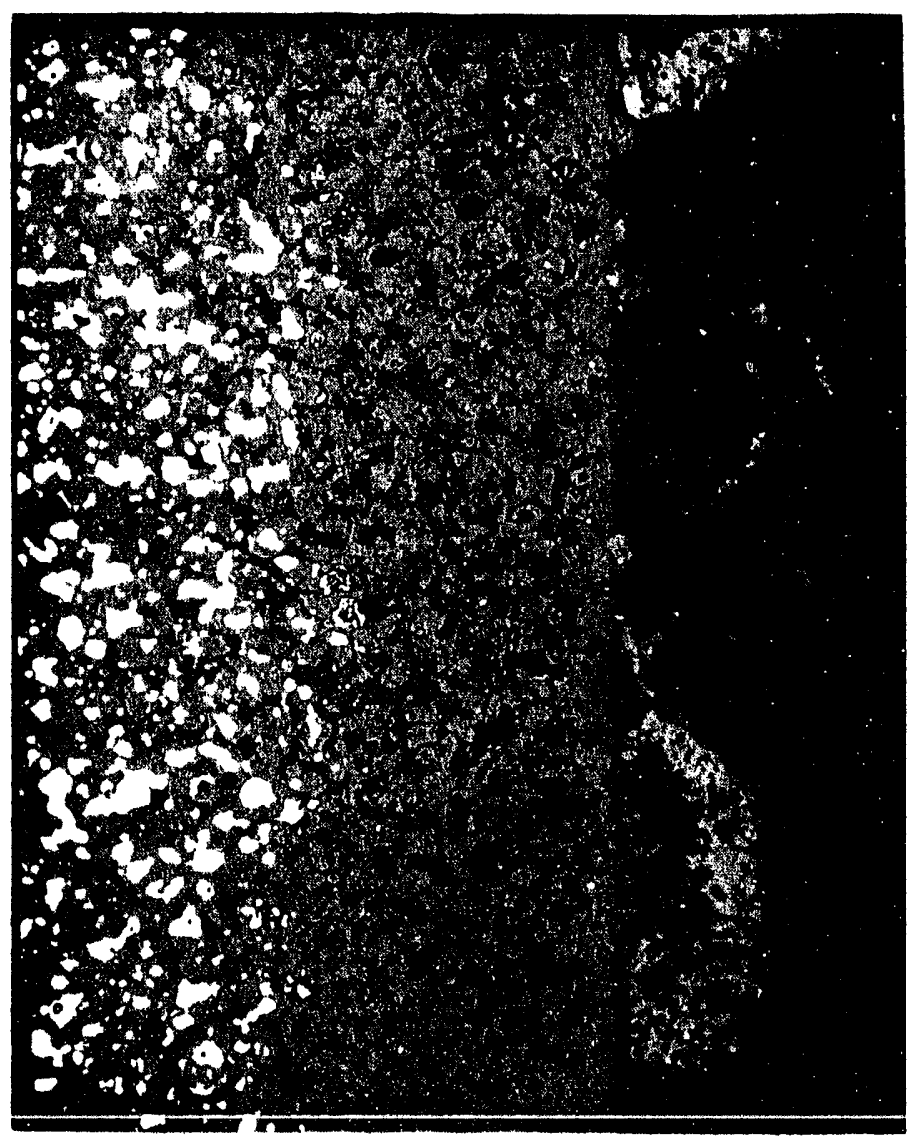

FIGURE 4.8. A Photomicrograph Of A Globule Of Material On the Pellet Shown in Figure 4.6 Photo \# 89M194D)

$$
4.9
$$




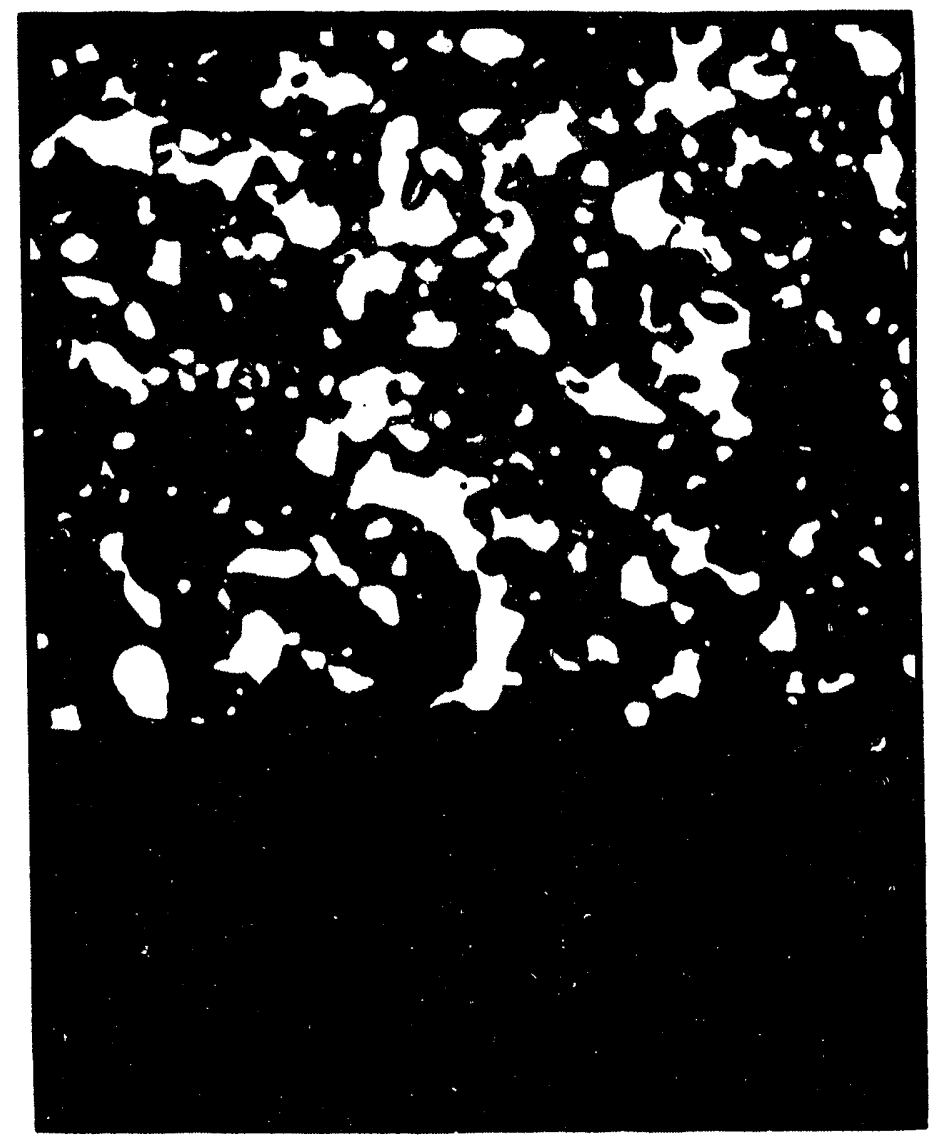

FIGURE 4.9. A Photomicrograph of A Typical Area On The Bottom of The Pellet Shown in Figure 4.6 (Photograph \# 89M194C) 
affected surface in the bottom area is about $70 \mu \mathrm{m}$ and appears to have much less porosity/pull-out than noted in areas where globules existed. The thickness of the affected surface on the sides of the pellet was about $30 \mu \mathrm{m}$.

Examination of the prototype anode after its test indicated that the $\mathrm{Ni}$ in the $\mathrm{Cu} / \mathrm{Ni}$ alloy part of the cermet was preferentially oxidized. Some of this reaction is evidenced in the appearance of the metallic grains in the pellet shown in Figure 4.10. Here the NiO phase appears to be exsolving from the $\mathrm{Cu} / \mathrm{Ni}$ alloy. It should be noted that an alternative explanation for the appearance of these two grains is a polishing artifact. Although the metallic grains generally appear rounded, it is possible that the appearance of these two grains resulted from polishing through the grain to the underlying ceramic phase. At a different part of the pellet a long grain of $\mathrm{Cu}$ was found where one side was next to the affected area and the other side was about $95 \mu \mathrm{m}$ interior to the cermet. Preferential oxidation of $\mathrm{Ni}$ in the $\mathrm{Cu} / \mathrm{Ni}$ alloy is supported by the fact that elemental analyses at both ends of this grain showed conclusively that the end next to the oxidized zone was depleted in $\mathrm{Ni}$ relative to the end in the cermet.

The bottom portion of anode \#180 is shown in Figure 4.11. Evidence of the attack of the cermet during the heating of the cell can be seen along the bottom and sides of the anode. After about $26 \mathrm{~h}$ at a current density of $0.18 \mathrm{~A} / \mathrm{cm}^{2}$, only minimal corrosion was observed. The $\mathrm{Cu}$-depleted zone was about $0.4 \mathrm{~mm}$ thick on the bottom and $0.24 \mathrm{~mm}$ thick on the sides. About $0.1 \mathrm{~mm}$ and $0.06 \mathrm{~mm}$, respectively, of this corrosion was already present from the preheating.

\subsubsection{Anode \#181}

Uneven oxidation of the Anode \# 181 and its associated pellet was not observed after heating in air prior to use in the electrolysis cell. The pellet had an oxidized zone approximately $0.15 \mathrm{~mm}$ in thickness after preheating. The appearance of the oxidized zone did not differ much from the zone on the pellet heated over cryolite, except at the very edge. Here, there appeared to be some recrystallization. Examination in the SEM revealed that the $\mathrm{Cu} / \mathrm{Ni}$ alloy had been purified to pure $\mathrm{Cu}$, which was subsequently oxidized, presumably to CuO under these temperature conditions. 
The bottom portion of anode \#181 is shown in Figure 4.12. Note that the oxidized zone is thickest at the corners. The corrosion at the center of the bottom area of the anode appears to be minimal. No new information was gained from SEM examination. 


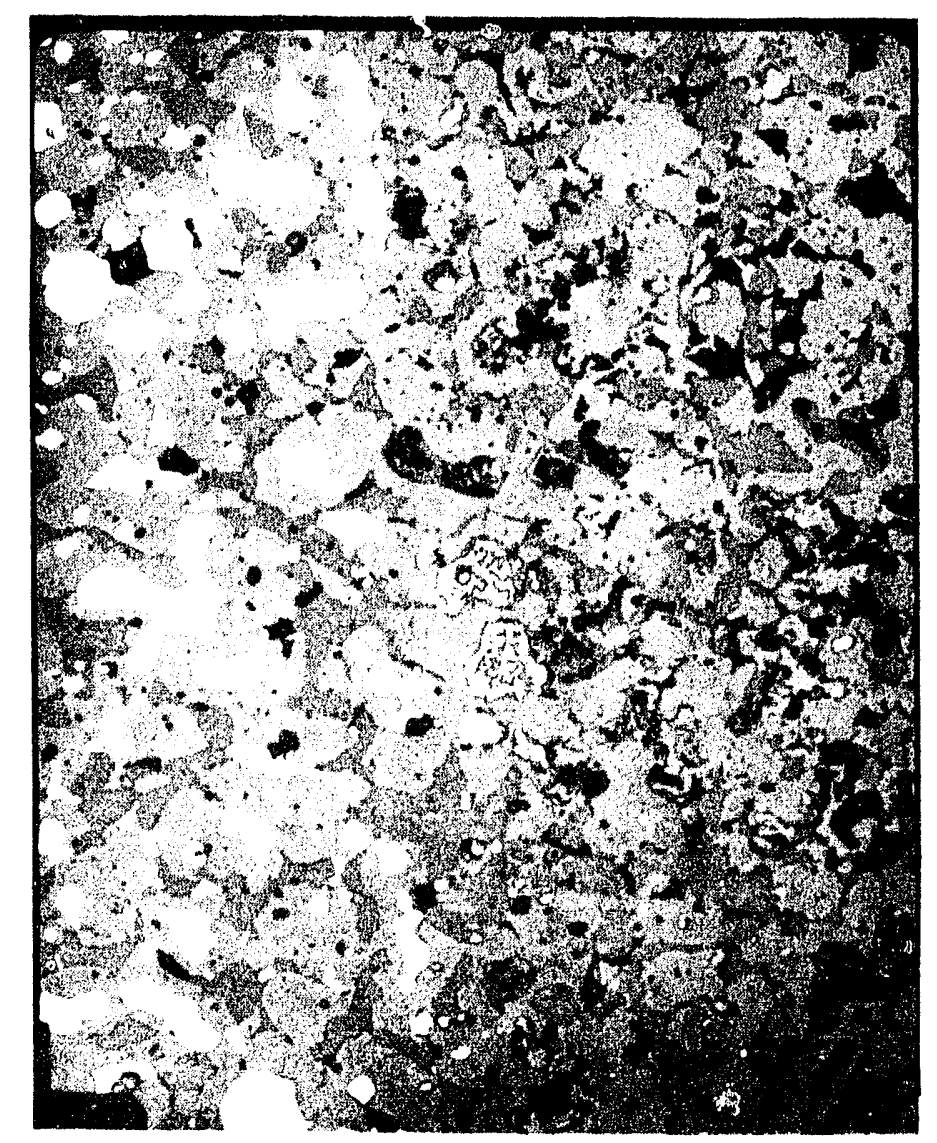

FIGURE 4.10. A Photomicrograph of An Area In Which Two Metallic Grains Show Evidence of $\mathrm{Ni}$ Exsolution (Photograph \#89M194E)

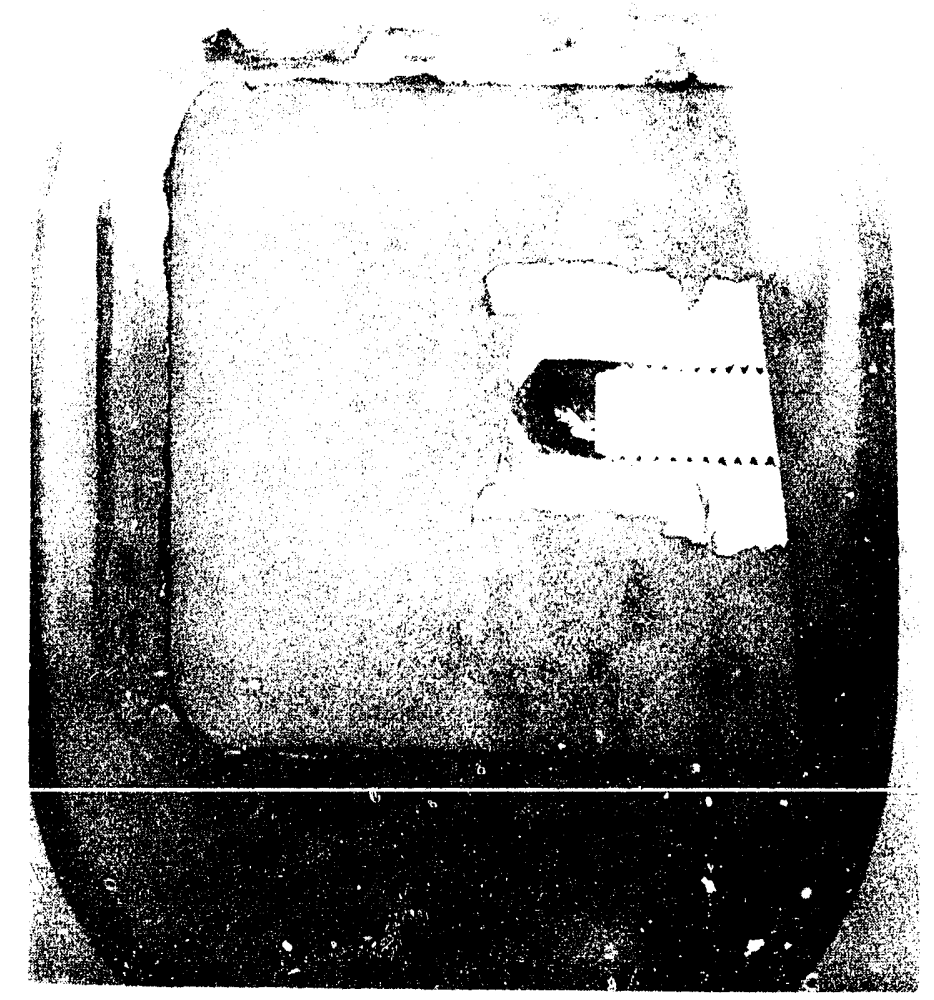

FIGURE 4.11. A Photomicrograph of The Bottom Portion of Anode \#180 (Photograph \# 89M223A) 


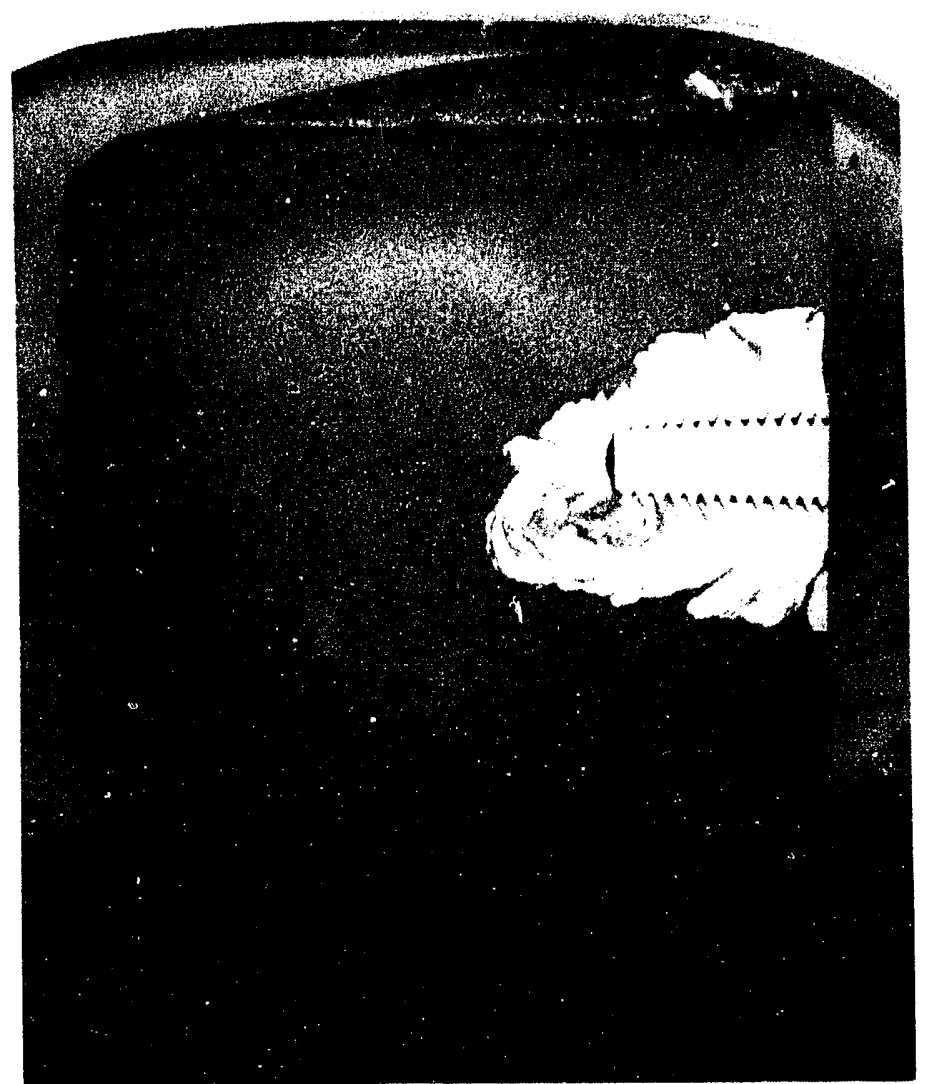

FIGURE 4.12. A Photomicrograph of The Bottom Portion of Anode \# $18 \mathrm{i}$ (Photograph \# 89M225A) 


$$
-
$$


Inert Electrodes Program

EFFECTS OF PRECORROSION AND SILICA ON CERMET INERT ANODE PERFORMANCE

C. F. Windisch, Jr.

N. D. Stice

May 1990

Prepared for

the U.S. Department of Energy

under Contract DE-AC06-76RLO 1830

Pacific Northwest Laboratory

Richland, Washington 99352

Operated for the U.S. Department of Energy

by Battelle Memorial Institute 


\section{EFFECTS OF PRECORROSION AND SILICA ON}

CERMET INERT ANODE PERFORMANCE

Previous studies at Pacific Northwest Laboratory (PNL) suggested that a badly corroded inert anode could not recover its desired operating stability even if cell operating conditions were changed to be less aggressive. (a) Other studies at PNL (Strachan, et al. 1990) and at Alcoa Laboratories (Weyand et al. 1986) suggested that silica assisted the corrosion of inert anodes during their operation. The current studies used electrochemical methods and post-mortem microscopic analysis of inert anodes in bench-scale aluminum reduction cells to determine whether these two effects could be substantiated and, if so, to help provide chemical bases for their effects.

\section{EXPERIMENTAL PROCEDURE}

Electrochemical tests were performed exactly as in previous work at PNL (Windisch and Stice 1990). The effects of precorrosion were studied using inert anodes that were corroded in an alumina-free bath for $1 \mathrm{~h}$ at a current density of about $1 \mathrm{~A} / \mathrm{cm}^{2}$. Optical microscopy of these precorroded anodes showed a porous surface region about $200 \mu \mathrm{m}$ thick that was depleted in copper metal. The precorroded anodes were subsequently polarized at $2.3 \mathrm{~V}$ and $2.5 \mathrm{~V}$ vs. the $\mathrm{Al}_{1} / \mathrm{Al}_{2} \mathrm{O}_{3}$ reference electrode in baths containing $100 \%$ and $50 \%$ alumina (percent of saturation), with a bath ratio (B.R.) of 1.15 , at $983^{\circ} \mathrm{C}$ for exactly $1 \mathrm{~h}$. The current response during the first $20 \mathrm{~s}$ subsequent to polarization was used for potential-step analysis. Electrochemical impedances were measured at $1 \mathrm{kHz}$ during the $1-\mathrm{h}$ interval. After the test, the anodes were analyzed by optical microscopy.

The effects of silica on the potential-step data, electrochemical impedance, and morphology of fresh anodes were studied in the same way. The electrolyte in all of the silica studies was formulated to contain $1 \%$ silica by weight. Scanning electron microscopy/energy dispersive spectroscopy (SEM/EDS) was also used as part of post-mortem analysis to determine the presence of silica within the inert anode material.

(a) M.J. Danielson, O.H. Koski, and N.D. Stice. 1988. Fiscal Year 1988 Annual Report for the Sensors Development Program. Pacific Northwest Laboratory, Richland, Washington. 
Electrochemical and microscopic data on both the precorroded anodes and from tests with silica were analyzed by comparison with the results of studies on fresh anodes discussed previously (Windisch and Stice 1990).

\section{RESULTS AND DISCUSSION}

\section{Precorroded Anodes}

"A" and "B" parameters were calculated from the potential-step responses in a manner similar to previous studies (Windisch and Stice 1990). These data are plotted versus current density in Figure 1 along with data obtained using fresh anodes under exactly the same experimental conditions. The "A" and "B" data for the precorroded anodes show the same general trends as those obtained using fresh anodes. The magnitude of the " $A$ " parameter appears to decrease with increasing current density; the magnitude of the parameter "B" appears to increase with increasing current density. However, the absolute values of parameter " $A$ " are larger for the precorroded anodes than for the fresh anodes. The absolute values of parameter "B" are, in general, smaller for the precorroded anodes than for the fresh anodes.

The variation of parameters " $A$ " and " $B$ " with current density suggest that the processes occurring for fresh anodes are also occurring for precorroded anodes. The larger values of parameters "A" and "B" for the precorroded anodes suggest some other effects are also important for these anodes but that the effects do not perturb the relative importance the "A" and "B" terms have in the electrokinetic relationships (Windisch and Stice 1990). Precorrosion, however, does not indicate any dependence on alumina content contrary to that observed using fresh anodes.

The impedances of the precorroded anodes measured at $1 \mathrm{kHz}$ are shown in Figure 2 along with impedances obtained using fresh anodes. These data indicate significantly higher impedances (about 0.05 to 0.1 ohms $\mathrm{cm}^{2}$ ) for precorroded anodes. The higher impedances may result from the change in surface structure that occurred in the precorrosion step.

Additional noise in the current signals was observed in two cases for the precorroded anodes: at $2.5 \vee$ at $100 \%$ alumina and at $2.3 \quad v$ at $50 \%$ alumina. The noise was between 0.01 to $0.05 \mathrm{~A} / \mathrm{cm}^{2}$ in peak-to-peak magnitude. No clear correlation could be made between the noise and cell operating conditions or 


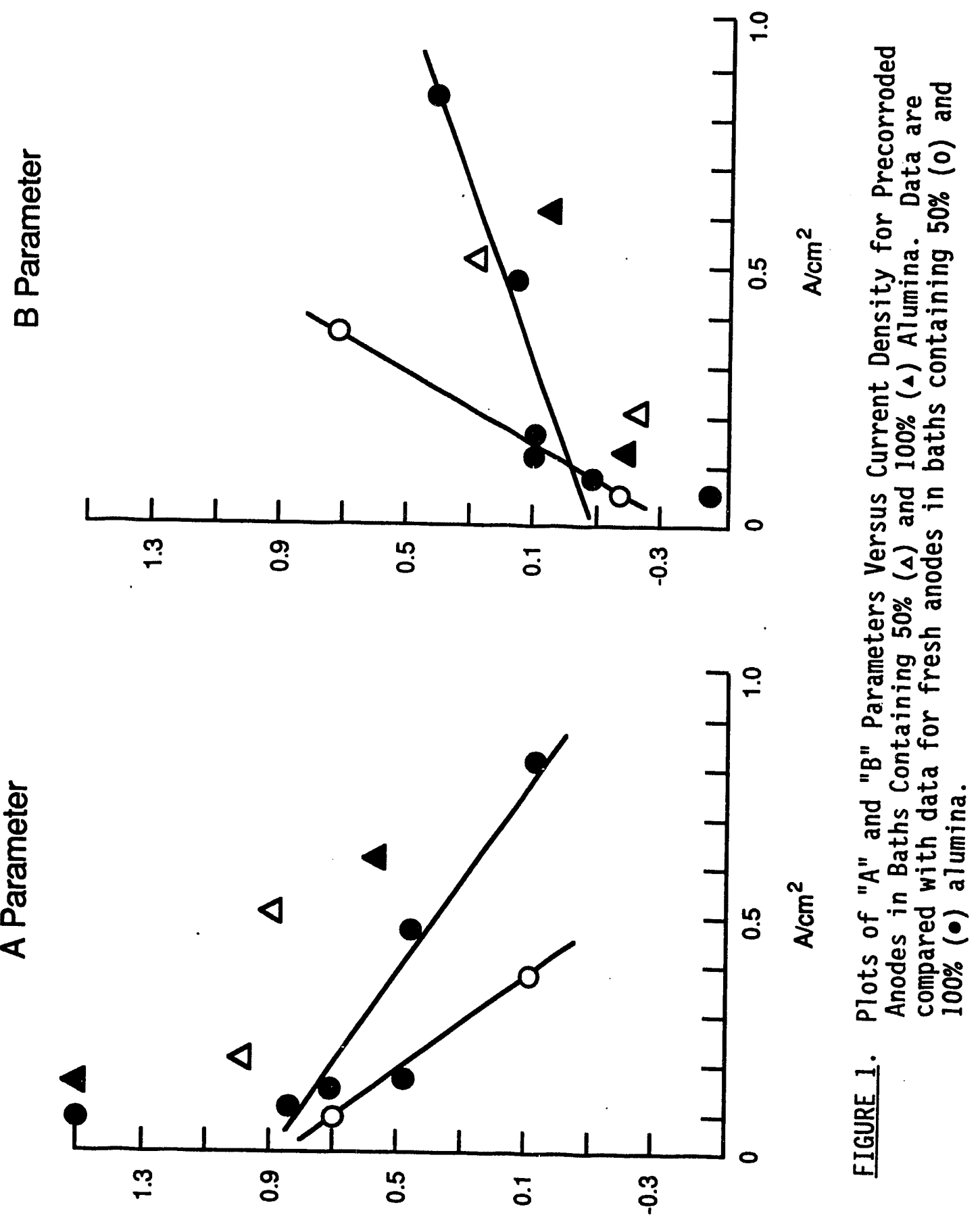




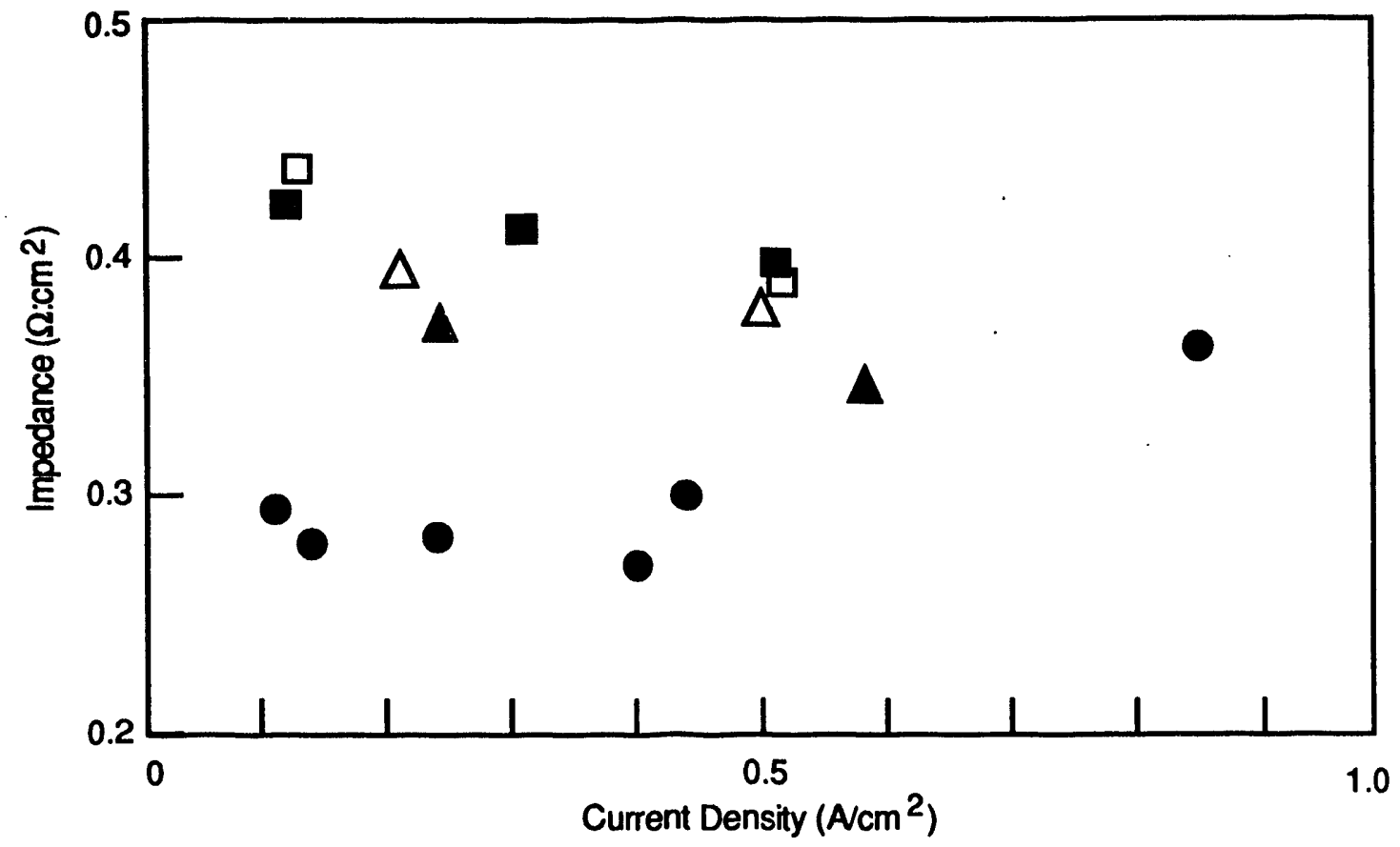

FIGURE 2. Electrochemical Impedances at $1 \mathrm{kHz}$ for. Precorroded Anodes in Baths at $50 \%(\Delta)$ and $100 \%(\Delta)$ Alumina; Fresh Anodes in Baths at $100 \%$ Alumina ( $\bullet$; ; and Fresh Anodes in Baths Containing 1 wt\% Silica at $50 \%$ (D) and $100 \%$ (D) Alumina. 
other results from these tests, although more noise may have been generated from anodes characterized by the most severe copper depletion.

Microscopic examination of the precorroded anodes after their use in alumina-containing baths revealed no significant changes in microstructure that could be related to any test conditions, i.e., either alumina content or current density. Some differences were observed (e.g., in the extent of copper depletion) but they were probably induced during the precorrosion steps and not during the subsequent polarization in the alumina-containing baths.

In summary, the precorrosion step appeared to have no obvious adverse effects on subsequent anode operation in alumina-containing baths in shortterm bench-scale tests, other than imparting an additional impedance to the anode and, possibly, some noise to the current signals. Since mass balances were not performed, any additional corrosion and/or dissolution during polarization in the alumina-containing baths could not be quantified in these tests.

Effects of Silica

As shown in Figure 3, the "A" and "B" parameters for fresh anodes polarized in baths containing 1 wt silica were significantly different from values obtained in baths containing no silica. No clear trends with current density were observed, although the values of the parameter " $A$ " appear to be generally larger than those obtained in baths without silica. Microscopic examination of the anodes revealed virtually no effects of silica on the anodes; the microstructure was virtually identical with and without silica. In addition, no significant amounts of silicon could be found within the anodes using SEM/EDS. Thus, the effects of silica in the bath on the "A" and " $B$ " parameters may be the result of changes in bath properties (e.g., increase in resistivity) that resulted from adding silica.

Electrochemical impedance data shown in Figure 2 indicate a larger impedance for the anodes when silica was present. This is consistent with an increase in bath resistivity upon silica addition.

In summary, silica appears to have no adverse effect on anode operation (separate from the expected changes in the physical properties of the bath) in 


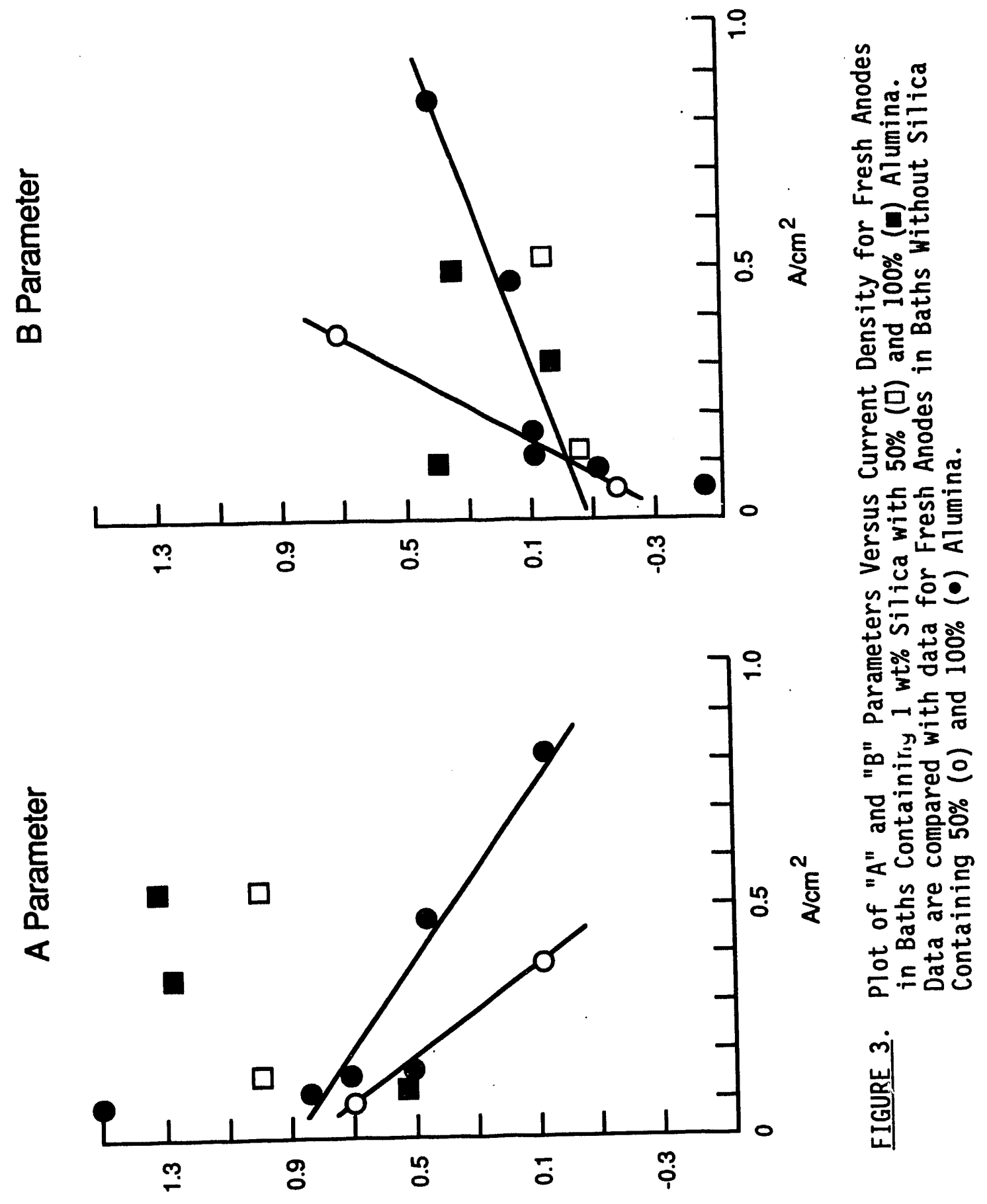


short-term laboratory tests. These results are consistent with those from larger-scale, longer tests previously conducted at PNL(a)

\section{CONCLUSIONS}

The results of the studies reported here support the following conclusions :

- The potential-step studies indicated some differences in variation and/or magnitude of the "A" and "B" parameters between these tests and those performed previously. These differences could not be definitively correlated with any experimental conditions nor with the resuits of posttest microscopic analyses. Consequently, the "A" and "B" parameters, although useful in providing mechanistic information under some conditions (Windisch and Stice 1990), may not give a reliable indication of corrosion in all situations. For this reason, planned future studies on the effects of anode microstructure will use optical microscopy as the primary analysis technique to estimate anode wear and determine wear mechanisms. In iddition, studies will be conducted over a longer, 4 to $6 \mathrm{~h}$, time interval.

- Precorroded anodes, characterized by a copper-depleted surface layer, gave no obvious indication of adverse performance in short-term, labscale evaluation, other than exhibiting a higher impedance and, in some cases, imparting some noise to the current signal.

- The presence of silica in the bath did not appear to have any adverse effect on the anodes as indicated by optical microscopy, in short-term, lab-scale tests. This result is consistent with those of PNL tests using
larger reduction cells. (a)

(a) D.M. Strachan. The Effects of Preoxidation and Eiectroiyte Siô, Concentration on Anode Performance. Pacific Northwest Laboratory, Richland, Washington, March 1990. 


\section{REFERENCES}

J.D. Weyand, et al. 1986. Inert Anodes for Aluminum Smelting: Final Report for the Period 9/29/80 - 9/30/85. Alcoa Laboratories, Alcoa Center, Pennsylvania.

C.F. Windisch Jr. and N.D. Stice. 1990. Characterization of the Reaction

Layer or Film on PNL Inert Anodes: Progress Report for April-December 1989. PNL-7326, Pacific Northwest Laboratory, Richland, Washington.

D.M. Strachan, et al. 1990. Results From Electrolysis Test of a Prototype Inert Anode. PNL-7345, Pacific Northwest Laboratory, Richland, Washington. 
APPENDIX D

DIFFERENTIAL THERMAL ANALYSIS AND THERMAL GRAVIMETRIC ANALYSIS STUDIES OF A CERMET INERT ANODE MATERIAL 
DIFFERENTIAL THERMAL ANALYSIS AND THERMAL GRAVIMETRIC ANALYSIS STUDIES OF A CERMET INERT ANODE MATERIAL
J. W. Shade
R. E. Westerman

June 1989

Prepared for

the U.S. Department of Energy

under Contract DE-AC06-76RLO 1830

Pacific iNorthwest Laboratory

Richland, Washington 99352 
The reactions taking place between the constituents of a $\mathrm{NiO}-\mathrm{NiFe}_{2} \mathrm{O}_{4}-$ $17 \% \mathrm{Cu}$ inert anode material during sintering and the oxygen in the sintering environment are believed to be critical in dictating the ultimate behavior of the inert anode under actual electrolysis conditions. Unfortunately, "ie reactions, including binder volatilization, NiO reduction, metal phase oxidation, metal phase melting and resolidification, and solid-phase particle interactions, are complex and not well understood. Accordingly, differential thermal analysis (DTA), thermal gravimetric analysis (TGA), and $x$-ray diffraction analysis studies were undertaken in an attempt to define the temperature and the extent of some of the reactions taking place. Emphasis was placed on determining (a) the rate of binder release from the specimen, as a function of temperature and oxygen concentration in the environment;

(b) the rate of reaction of the metal phase by the oxygen in the environment; and $(c)$ evidence of inter-constituent reactions.

The reactions evidenced in the DTA and TGA were complex, and capable of being interpreted in several different ways. It is believed that evidence was found for significant superheating and supercooling of the metal phase of the cermet. Analyses are presented for some of the significant DTA and TGA features, though it is recognized that a more detailed study would be required for development of a real understanding of the processes involved. 


\section{CONTENTS}

SUMMARY . . . . . . . . . . . . . . . . . . . .

ACKNOWLEDGMENTS ......................... . . . ix

1.0 INTRODUCTION . . . . . . . . . . . . . . . . . 1.1

2.0 EXPERIMENTAL APPROACH ................... 2.1

2.1 MATERIAIS . . . . . . . . . . . . . . . . 2.1

2.2 EXPERIMENTAL APPARATUS . . . . . . . . . . . . . 2.1

3.0 RESULTS . . . . . . . . . . . . . . . . . . 3.1

4.0 DISCUSSION ............................ 4.1

5.0 CONCLUSIONS ANO RECOMMENDATIONS . . . . . . . . . . . 5.1

6.0 REFERENCES ....................... . . 6.1 


\section{FIGURES}

3.1 DTA and TGA Test Results, Cermet Specimen Tested in a "Pure" Argon Atmosphere . . . . . . . . . . . . . . 3.2

3.2 DTA and TGA Test Rsults, Cermet Specimen Tested in an Argon/8000 ppm Oxygen Atmosphere . . . . . . . . . . 3.3

3.3 DTA and TGA Test Results, Cermet Specimen Tested in an Argon/50 prm 0xygen Atmosphere ............. 3.4

3.4 DTA and TGA Test Results, Cermet Specimen Tested in an Argon/200 ppm 0xygen Atmosphere ............. . 3.5

3.5 DTA and TGA Test Results, Cermet Specimen Tested in an Argon/520 ppm 0xygen Atmosphere .............. 3.6

3.6 X-Ray Diffraction Results on Cermet Specimen After Tests in "Pure" Argon and Argon/8000 ppm 0xygen . . . . . . 3.9 


\section{ACKNOWLEDGMENTS}

The authors are pleased to acknowledge the assistance of R. W. Stephens in the performance of the experimental work, and the technical and programmatic oversight provided by L. G. Morgan. 


\subsection{INTRODUCTION}

The production of cermet anodes from ceramic and metal powders typically involves the following steps:

1. The ceramic and metal powders are prepared and blended in the desired proportions, and placed in a mold containing provision for anode support and electrical connection (i.e., a metal powder "core").

2. The molded powder is hydrostatically pressed [ $25 \mathrm{ksi}(172 \mathrm{MPa})]$ at ambient temperature to form a green compact. This compact can be handled and machined.

3. The green compact is sintered at a high temperature in an atmosphere consisting of an inert gas containing some oxygen (100 to $200 \mathrm{ppm})$. The sintering process densifies and strengthens the cermet body.

A typical green compact sintering schedule for producing laboratory-test anodes involves the following steps:

1. Heat fiom $20^{\circ}$ to $650^{\circ} \mathrm{C}$ in $8 \mathrm{~h}$.

2. Heat from $650^{\circ}$ to $1070^{\circ} \mathrm{C}$ in $6 \mathrm{~h}$.

3. Hold $2 \mathrm{~h}$ at $1070^{\circ} \mathrm{C}$.

4. Heat from $1070^{\circ}$ to $1300^{\circ} \mathrm{C}$ in $4 \mathrm{~h}$.

5. Hold $8 \mathrm{~h}$ at $1300^{\circ} \mathrm{C}$.

6. Furnace cool to room temperature.

Step 1 is intended to remove the bulk of the binder from the cermet body.

Steps 2 and 3 have been found to help prevent the copper metal phase from bleeding out of the cermet body. This could be due to (a) reaction of the copper with oxygen in the atmosphere at the cermet surface: (b) alloying of the copper with nickel derived from the NiO-binder reaction, and subsequent reaction of the nickel at the cermet surface; (c) a change in the viscosity of the metal phase, due to alloying reactions; or (d) other causes.

Steps 4 and 5 allow diffusional bonding to occur between the solid particles of the cerme:, strengthening and densifying the body. 
Step 6 allows the cermet body to cool to room temperature without cracking.

Variations in the sintering process, notably the temperature, heating rats, and oxygen fugacity of the atmosphere, can have a profound effect on the cermet body product. Unfortunately, the sintering reactions have not been well understood, so the sintering variables cannot easily be adjusted to accommodate (a) changes in cermet body composition or size when a specific product is desired; (b) different surface composition requirements; or (c) required changes in the extent of reaction between the binder and the anode constituents.

The objective of the work described in this milestone report was to gain insights into the complex reactions occurring during sintering between the inert anode constituents (binder, metal phase, ferrite phase, oxide phase) and between the anode constituents and the sintering environment (argon + oxygen), with the intent of using the information to optimize the sintering temperature and sintering environment of large-scale anodes. The two principal experimental methods used in the attempt to better understand the sintering reactions were Differential Thermal Analysis (DTA) and Thermal Gravinetric Analysis (TGA). The reaction products formed on the powder samples were characterized post-test by $x$-ray diffraction (XRD).

Specifically, the reactions focused on in the present studies were the following:

1. The rate of binder release from the sample (TGA), as a function of temperature and environment oxygen;

2. The rate of oxidation of metal phase by the environment oxygen (TGA and DTA) and;

3. Evidence of inter-constituent reactions (DTA). 


\subsection{EXPERIMENTAL APPROACH}

\subsection{MATERIALS}

The cermet powder used in the present investigations was a blend of $\mathrm{NiO}-\mathrm{NiFe}_{2} \mathrm{O}_{4}$ powder (a) and 17 wt\% copper designated No. 5324. It is typical of that used by PNL for fabrication of inert anodes for laboratory testing.

The $\mathrm{NiO}-\mathrm{NiFe}_{2} \mathrm{O}_{4}$ powder was provided by Stackpole Corporation, St. Mary, Pennsylvania, in the form of spherical particles of $-50 \mu \mathrm{m}$ diameter. It was manufactured by the calcining, milling, and spray-drying of $\mathrm{NiO} / \mathrm{Fe}_{2} \mathrm{O}_{3}$ starting material. Binder is incorporated in the powder particles, prior to the spray-dry operation. The exact amount and type of binder added is not known, as it is proprietary information. Typically, a weight loss (ascribed to binder volatilization) of $5.5 \%$ is found when anodes made from this powder are sintered.

The copper addition to this cermet powder was made at PNL, by mechanically blending particulate copper (angular particles, 1 to $5 \mu \mathrm{m}$ in major dimension) with the $\mathrm{Fe} / \mathrm{Ni}$ oxide powder. The copper powder $(99.5 \%$ pure copper) was obtained from Alamo Supply Company, Inc., Houston, Texas.

The DTA standard was particulate reagent-grade NiO.

\subsection{EXPERIMENTAL APPARATUS}

The DTA and TGA studies were performed using a Netzch Mode1 STA 409 simultaneous DTA/TGA System distributed by Netzch, Incorporated, Extron, Pennsylvania. This equipment is capable of simultaneous DTA/TGA measurements to temperatures of $1600^{\circ} \mathrm{C}$ in a variety of gas atmospheres.

(a) This designation is used for simplicity to describe the $\mathrm{Ni} / \mathrm{Fe}$ oxide material used in the manufacture of inert anodes. A more accurate designation would be $\mathrm{Ni}_{x} \mathrm{Fe}_{1-x} \mathrm{O}-\mathrm{Ni}_{y} \mathrm{Fe}_{3}-\mathrm{O}_{4}$. 
The DTA portion of the system consists of two Pt - Pt10\%Rh thermocouples joined together so that the thermocouple junctions fit into two small alumina sample crucibles. One of these crucibles contains the sample powder and the other contains a reference material of known thermal properties. During a test the differences in temperature between the sample and reference material are continually monitored. These differences are due to differences in heat capacities of the two materials plus any chemical reactions or phases changes that occur during heating and cooiing. Heat capacity differences typically result in continuous DTA curves while chemical reactions and phase changes result in peaks superimposed on the continuous curve. Melting of a phase, for example, might produce an endothermic peak, while oxidation would be expected to produce an exothermic peak. The size of these peaks is a function of the amount of sample present, the heating rate, and the sensitivity of the instrument. For detailed measurements, it is necessary to make a number of trial runs to determine the sensitivity capabilities of the instrument.

TGA measurements are obtained by continually monitoring the mass changes of the sample and reference powders. The sample and reference crucibles are placed on a thin alumina rod that aiso serves as a thermocouple insulator. The rod is connected to a differential variable transformer so that small mass changes can be measured simultaneously with DTA measurements. Tiese mass changes are recorded on a strip chart. Typically, volatilization and dehydration result in weight losses, while oxidation results in weight gains. Weight change determinations of a few tenths of a milligram are possible.

The actual sample temperature is monitored during a run by means of a thermocouple adjacent to the crucibles. The furnace temperature is controlled by a separate thermocounle near the furnace elements. It is necessary to calibrate the sample temperature for the instrument. For the DTA/TGA system, the sample temperature was calibrated by using the melting and freezing points of $\mathrm{NaCl}$ and gold.

In the present studies $\mathrm{NiO}$ was used in all cases as the DTA reference material. Some preliminary work showed the superiority of $\mathrm{NiO}$ over $\mathrm{Al}_{2} \mathrm{O}_{3}$, as NiO more closely matches the heat capacity of the cermet material. The 
masses of the sample and reference materials lay in the range 0.1 to $0.2 \mathrm{~g}$. Both materials were particulate in nature, and were poured into the 6-mm-diameter (I.D.) alumina crucibles without compaction.

The gas flow through the system was typically maintained at 60 to $140 \mathrm{l} / \mathrm{h}$. The homogenization of the inlet gas was ensured by blending argon and air streams (derived from standard compressed-gas cylinders), then passing the blended stream through a tube containing Teflon ${ }^{\circledR}$ beads.

The oxygen content of the gas inixture was monitored with a solid electrolyte sensor (yttria-stabilized zirconium oxide) using air as the reference gas. The sample crucibles are bathed in the inlet gas in a smallvolume chamber, so the oxygen content at the sample is expected to be reasonably constant over the course of a test. However, the composition of the atmospheres reported herein must be regarded as approximate only, because the oxygen monitor was calibrated for the present scoping studies using oxygen-argon gas mixtures containing only up to $10 \mathrm{ppm}$ oxygen.

The post-test $x$-ray diffraction analysis of the cermet samples was conducted using a computer-controlled Philips APD 3620 System, using copper $\mathrm{K} \alpha$ radiation and a graphite crystal diffracted beam monochromator.

( Teflon is a registered trademark of E. I. du Pont de Nemours Co., Inc., Wilmington, Delaware. 


\subsection{RESULTS}

A total of five runs were made in the course of the present scoping study. Each run utilized a different oxygen concentration in the argon carrier gas:

$\begin{array}{cl}\text { Run No. } & \text { Oxygen Concentration, ppm } \\ 1 & 0 \text { to } 10 \text { ("pure" argon) } \\ 2 & 8000 \\ 3 & 50 \\ 4 & 200 \\ 5 & 520\end{array}$

A heating rate of $300^{\circ} \mathrm{C} / \mathrm{h}$ and a maximum temperature of $1300^{\circ} \mathrm{C}$ was used in all tests.

The DTA/TGA data from Runs 1 through 5 are shown in Figures 3.1 through 3.5, respectively. The TGA curve is the heavier line and weight loss is indicated by a shift to the right. Full scale on the figures is equivalent to a weight change of $50 \mathrm{mg}$, so each small division is equal to $2 \mathrm{mg}$. The thinner line is the DTA curve. Endothermic processes (relative to the standard) shift the DTA curve to the left. The sharply peaked curve emanating from the right-hand ordinate is the temperature trace.

Some features may be noted in the figures that appear to be independent of the oxygen content of the atmosphere. The first of these is the temperature at which.the weight loss occurs due to volatilization/pyrolysis of the organic binder added in the preparation of the spray-dried $\mathrm{NiO}-\mathrm{Ni}$ $\mathrm{Fe}_{2} \mathrm{O}_{4}$ powder. The binder material is believed to be a mixture of polyvinyl alcohol (PVA) and polyethylene glycol (PEG). The figures indicate a definite sample weight loss beginning at about $300^{\circ} \mathrm{C}$ and ending in the range 500 to $580^{\circ} \mathrm{C}$, with a slight break in the weight loss slope at about $400^{\circ} \mathrm{C}$. Two small exothermic peaks occur in the DTA curve that bracket the temperature where this break in the slope of the weight loss curve appears. 


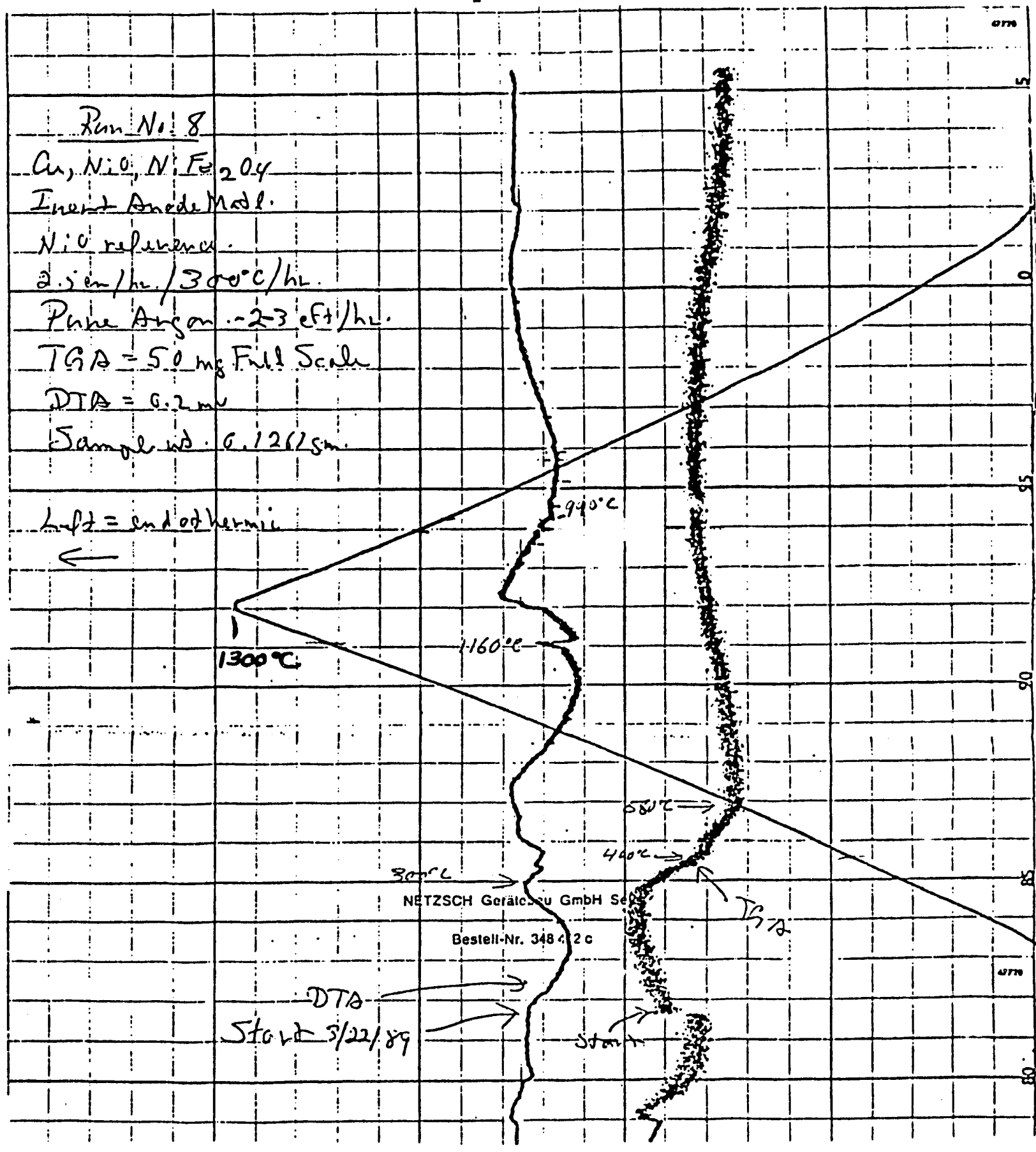

FIGURE 3.1. DTA and TGA Test Results, Cermet Specimen Tested in a "Pure" Argon Atmospinere 


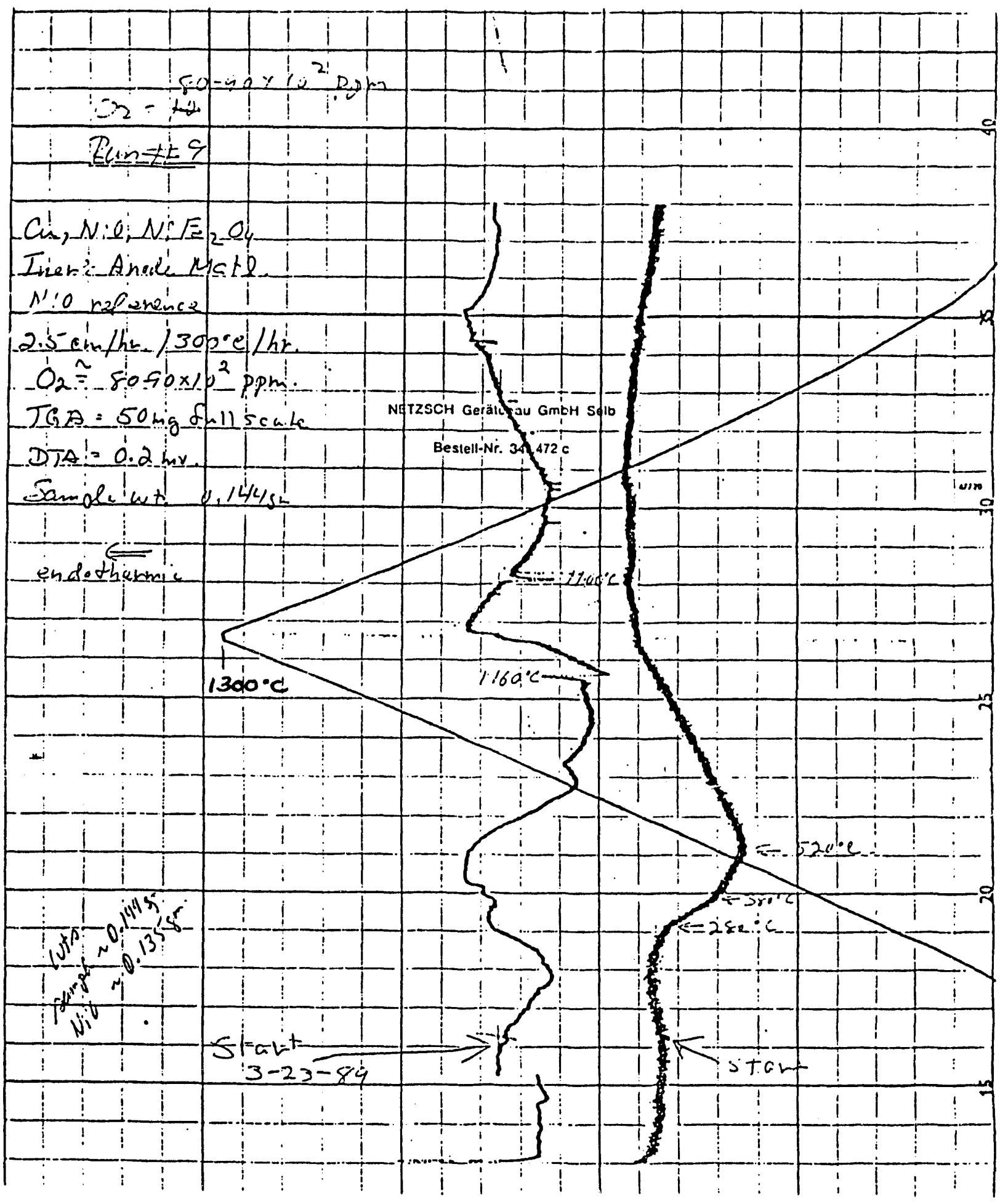

FIGURE 3.2. DTA and TGA Test Results, Cermet Specimen Tested in an Argon/8000 ppm 0xygen Atmosphere 


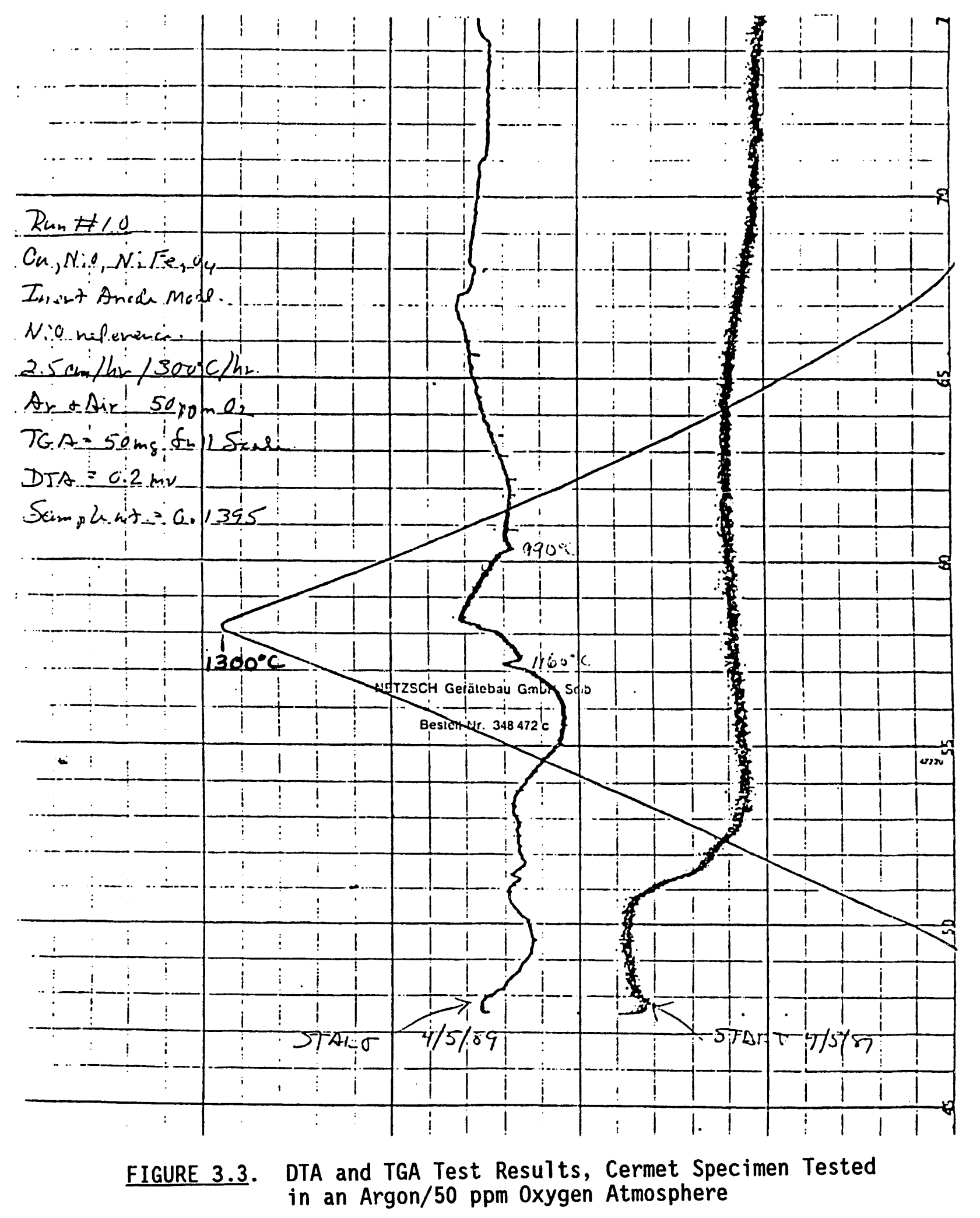




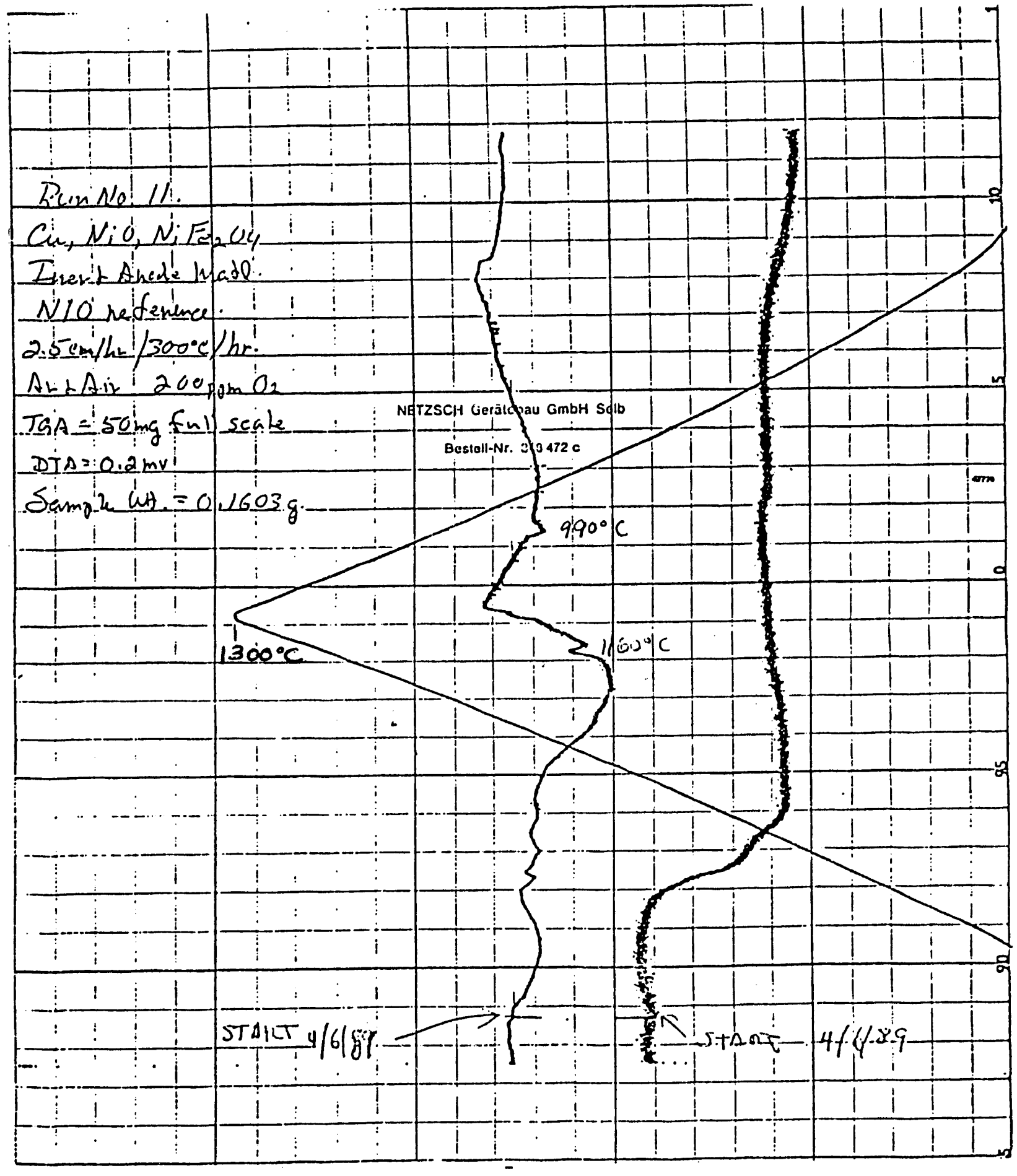

FIGURE 3.4. DTA and TGA Test Results, Cermet Specimen Tested in an Argon/200 ppm 0xygen Atmosphere 


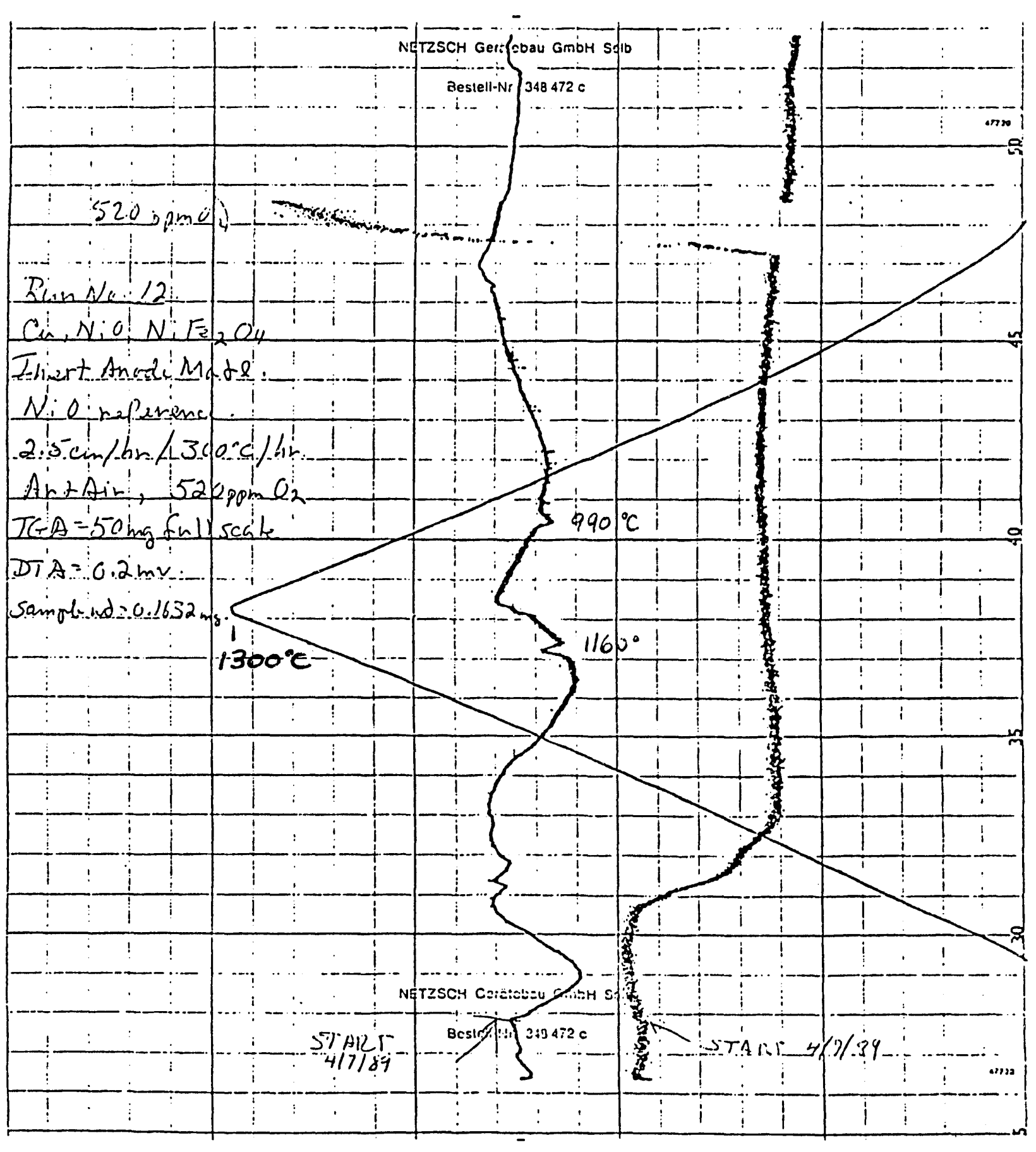

FIGURE 3.5. DTA and TGA Test Results, Cermet Specimen Tested in an Argon/520 ppm 0xygen Atmosphere 
The apparent two-stage binder loss is consistent with a two-component binder mixture. Some pyrolysis of the binder materials (reaction with either oxygen in the gaseous environment or oxygen derived from a solid oxide phase) may be giving rise to the two exothermic peaks noted. On the other hand, it is possible that the break in the weight loss curve might be caused by addition of two curves: a weight loss curve, from binder evolution, and a weight gain curve, from copper oxidation. The present data do not permit a differentiation to be made, though lack of evidence of a general exothermic reaction in the DTA curve beginning at $\sim 400^{\circ} \mathrm{C}$ that could correspond with and support the copper oxidation postulation tends to discount the curve-addition explanation for the break in the curve.

The weight loss for the sample tested in "pure" argon, Figure 3.1, based on the part of the TGA curve indicating the loss of the organic binder, is about $4 \%$. The weight loss for the sample tested in the atmosphere containing $8000 \mathrm{ppm}$ oxygen, based on the same part of the curve in Figure 3.2 , is about $3 \%$. It is not known whether there was less binder to begin with in this sample, or whether the weight gain associated with the oxidation of copper made the binder loss simply appear to be less. Other runs (Runs 3 through 5) yielded sample weight losses ascribable primarily to the loss of the organic binder in the range 4 to $4.5 \%$. The overall sample weight loss, determined by pre-test and post-test sample weighings, also lay in this range. The effect of oxygen in the environment on the rate of binder loss does not appear to be significant.

Another feature that consistently occurred in the DTA traces, regardless of the oxygen content of the sintering atmosphere, was an endothermic peak at $\sim 1160^{\circ} \mathrm{C}$ during the heating cycle in all tests. Apparently associated with this endothermic peak is an exothermic peak, at either $990^{\circ} \mathrm{C}$ (test in "pure" argon and tests with 50,200 , and $520 \mathrm{ppm}$ oxygen) or $1100^{\circ} \mathrm{C}$ (test with $8000 \mathrm{ppm}$ oxygen). The four low-oxygen-test results will be discussed first.

In order to interpret the DTA curves with any degree of confidence, it is necessary to estimate the reactive-phase makeup of the specimen as a 
function of time. (a) Assistance in this regard is afforded by the TGA curve, which allows us to estimate the amount of oxygen picked up by the sample; and equilibrium phase relationships in the $\mathrm{Cu}-0$ system; (b) and post-test XRD analysis of the cermet sample.

If we approximate the atmospheres in the four low-oxygen runs with one containing $100 \mathrm{ppm} \mathrm{O}_{2}$, we can conclude from thermodynamic data that from room temperature to $-700^{\circ} \mathrm{C} \mathrm{CuO}$ can form; between $\sim 700^{\circ} \mathrm{C}$ and $\sim 1220^{\circ} \mathrm{C} \mathrm{Cu}{ }_{2} \mathrm{O}$ is the stable phase; and from $1220^{\circ} \mathrm{C}$ to $1300^{\circ} \mathrm{C}$ liquid copper containing oxygen is the expected phase.

The TGA traces suggest that 1 to $2 \mathrm{mg}$ of oxygen had been picked up by the specimens in the course of the tests. This is enough oxygen to convert 15 to $30 \%$ of the copper present to Cu0, or 30 to $60 \%$ of the copper present to $\mathrm{Cu}_{2} \mathrm{O}$, depending on the kinetics of oxide formation and the rate of approach of the system to equilibrium. While it is impossible to tell from TGA data which oxides are present, the post-test $x$-ray diffraction analysis of the sample exposed in the "pure argon" run showed presence of $\mathrm{Cu}, \mathrm{Cu}_{2} \mathrm{O}, \mathrm{NiO}$, and $\mathrm{NiFe}_{2} \mathrm{O}_{4}$. The $x$-ray diffraction data are summarized in Figure 3.6 . No CuO was found, apparently because the now-consolidated sample could not readily form significant amounts of the equilibrium oxide, i.e., Cu0, on cooling through the temperature range in which this phase is stable. The data obtained from the TGA and XRD analyses would, in any event, suggest that a significant amount of metallic copper phase is still present at the time the $1160^{\circ} \mathrm{C}$ peak occurs.

(a) The reactive phase is considered to be primarily copper, once the binder phase has volatilized, so emphasis has been placed here on copper and its reactions with oxygen in the test environment. It is recognized that some nickel is also contained in the copper phase, apparently due to reaction of the binder with $\mathrm{NiO}$. This nickel is present to the extent of $\sim 20 \%$ of the metal phase, typically, and would be expected to react preferentially with gaseous oxygen. Thus, the estimates presented here of the amounts of copper remaining in the specimens after reaction with gaseous oxygen would be expected to be low.

(b) An excellent summary of the thermodynamics of the $\mathrm{Cu}-0$ system is provided by Neumann, Zhong, and Chang (1984). 
11

"Pure" Argon

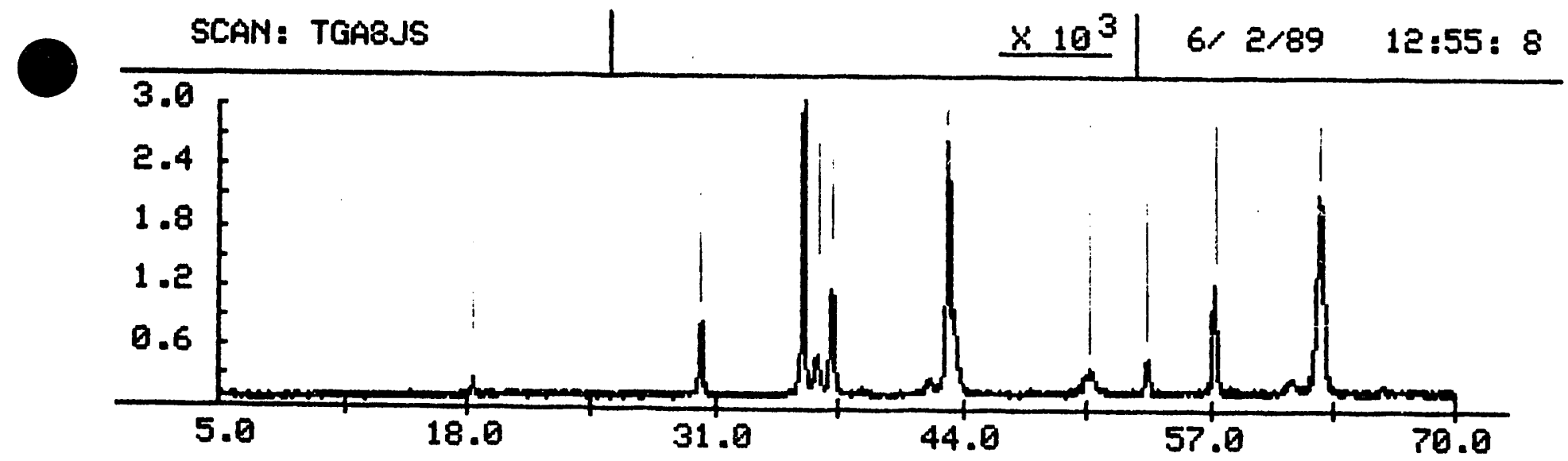

\section{Argon/8000 ppm Oxygen}

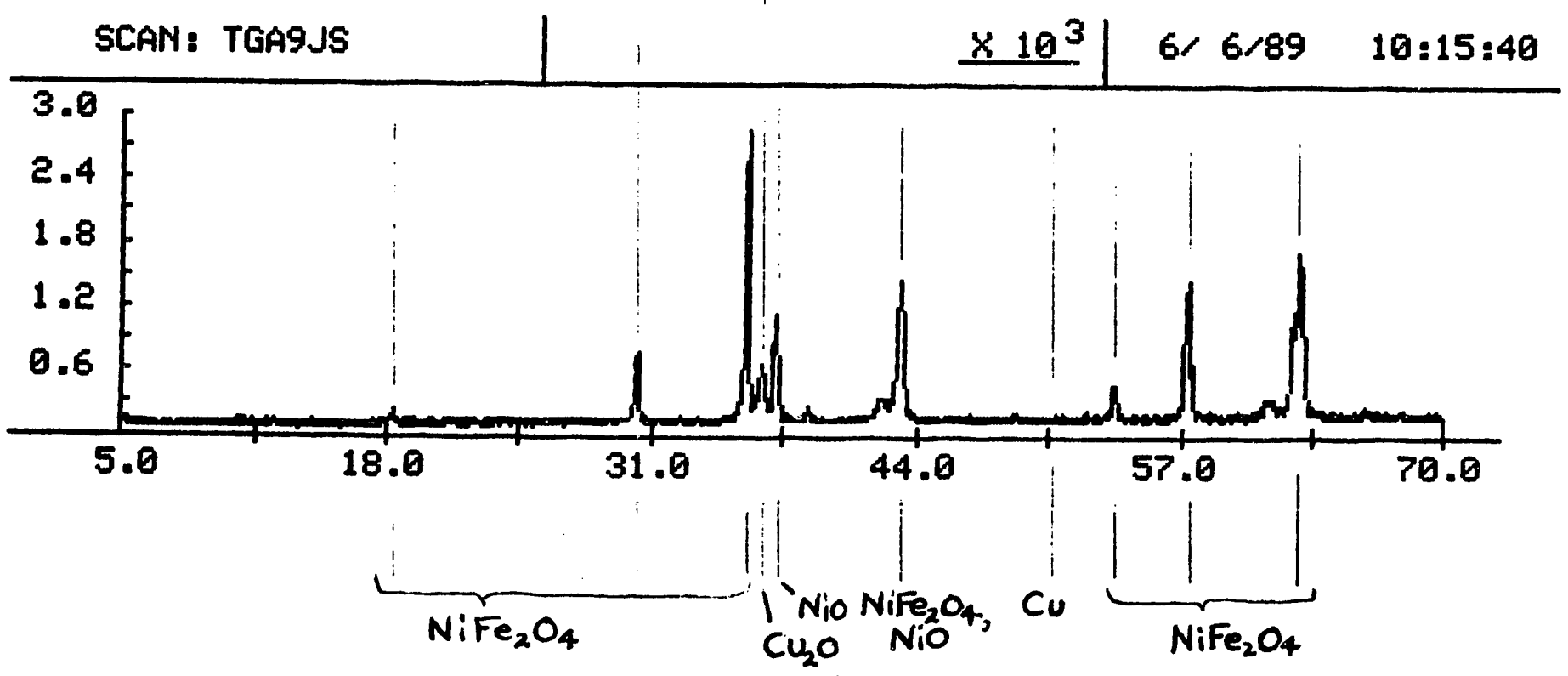

FIGURE 3.6. X-Ray Diffraction Results on Cermet Specimen After Tests in "Pure" Argon and Argon/8000 ppm Oxygen 
The endothermic peak would appear to be at too high a temperature to be associated with the melting point of copper $\left(1085^{\circ} \mathrm{C}\right)$, and the exothermic peak too low. In spite of this disagreement, it is currently believed that this pair of peaks is associated with the melting and re-solidification of copper, for the following reasons:

1. The mean of the temperatures of the two peaks is, in the case of the four low-oxygen tests, very close to the melting point of copper.

2. There is no other evidence for the melting and re-solidification of copper on the DTA curves.

3. There are no other reactions in the $\mathrm{Cu}-\mathrm{O}$ or $\mathrm{NiO}-\mathrm{Fe}_{2} \mathrm{O}_{4}$ system that are currently known to be associated with the two temperatures noted.

4. The extent of the reaction between copper and oxygen is far from complete, ensuring presence of copper metal.

If the melting point of copper were responsible for the peaks, then the melting point overshoot would represent a superheating of the copper particles, and the freezing point undershoot an undercooling of the (now molten) copper particles. The overshoot or undershoot would represent a $\Delta T$ of $80^{\circ}$ to $100^{\circ} \mathrm{C}$. This is consistent with the theory of heterogeneous nucleation of phase changes, which states that the tendency for a liquid droplet to solidify (or by extension, for a droplet to melt) is proportional to the droplet surface area, as the number of nucleation sites is proportional to the surface area of a droplet. Hence, very small particles of a material of high purity (e.g., the copper particles in the cermet powder) would be expected to show a great deal of superheating and supercooling tendency. Turnbull and Cech (1950) showed that small bcc or fcc metal droplets were capable of exhibiting a supercooling of $18 \%$ of their absolute melting points, or a $240^{\circ} \mathrm{C}$ supercooling in the case of copper. This degree of supercooling is much greater than that invoked in the present discussion.

An additional observation supporting the formation of liquid phase copper at $1160^{\circ} \mathrm{C}$ is the continuing apparent endothermic nature of the DTA trace after the peak, until the maximum temperature of $1300^{\circ} \mathrm{C}$ is attained. Such relative endothermic behavior is consistent with a higher heat capacity 
of the sample and a lower thermal conductivity relative to the standard, both of which would be associated with the copper phase being in the molten state between the two peaks noted.

An interpretation of the test using an atmosphere of $8000 \mathrm{ppm}$ oxygen can be made in a similar fashion. The thermodynamic interpretation, which of course presumes equilibrium situations, is as follows: cu0 is the thermodynamically stable oxide phase in the $8000 \mathrm{ppm}$ oxygen environment at temperatures between room temperature and $\sim 900^{\circ} \mathrm{C}$. In the temperature range of $-900^{\circ} \mathrm{C}$ to $\sim 1200^{\circ} \mathrm{C} \mathrm{Cu}{ }_{2}$ is the stable phase. Above $\sim 1200^{\circ} \mathrm{C}$ in the environment specified $\mathrm{Cu}_{2} \mathrm{O}$ is molten. Some CuO could form as the sample was heated from room temperature to $900^{\circ} \mathrm{C}$; how much is of course not known exactly, as non-equilibrium $\mathrm{Cu}_{2} \mathrm{O}$ would be expected to form at the interface between the CuO and the metal during this period. [In the high-temperature oxidation of massive copper, in the range of conditions where CuO is thermodynamically stable, more $\mathrm{Cu}_{2} \mathrm{O}$ forms, in general, than Cu0, because the diffusivity of oxygen through $\mathrm{Cu}_{2} \mathrm{O}$ is much more rapid than through CuO (Uhlig, 1948)].

The TGA curve of Figure 3.2 shows that by the time the $1160^{\circ} \mathrm{C}$ peak occurs, $\sim 4 \mathrm{mg}$ of oxygen has been picked up. If only $\mathrm{Cu}_{2} \mathrm{O}$ formed, this represents $130 \%$ of the oxygen required to convert all of the copper to oxide. If, on the other hand, some Cu0 formed on heating to $900^{\circ} \mathrm{C}$, which could not dissociate rapidly into $\mathrm{Cu}_{2} \mathrm{O}$, and if binder-reduced-nickel oxidation consumed a significant fraction of the oxygen, then some copper phase may have been available to give the "superheated $1160^{\circ} \mathrm{C}$ response." Post-test $\mathrm{x}$-ray diffraction analysis (Figure 3.6) revealed no Cu0 and no copper phase, only $\mathrm{Cu}_{2} \mathrm{O}$, NiO, and $\mathrm{NiFe}_{2} \mathrm{O}_{4}$, so the foregoing explanation cannot be defended by post-test analysis of the sample. However, the fact that significant oxidation (an additional $2 \mathrm{mg}$, by TGA analysis) occurred after the $1160^{\circ} \mathrm{C}$ peak implies that some copper remained at the time of the $1160^{\circ} \mathrm{C}$ peak.

On cooling, the exothermic peak occurs at $1100^{\circ} \mathrm{C}$. This temperature is $\sim 110^{\circ} \mathrm{C}$ higher than the exothermic peaks seen in the low-oxygen tests, and 
likely reflects the supercooled solidification of " $L_{2}$ ", a high-oxygen-content liquid copper in equilibrium with $\mathrm{Cu}_{2} \mathrm{O}$ and oxygen at $8000 \mathrm{ppm}$ (Neumann, Zhong, and Chang, 1984).

Considerable effort has been placed here on attempting to interpret the endothermic/exothermic DTA peaks in the vicinity of $1100^{\circ} \mathrm{C}$. This is because they are believed to be associated with the reaction of copper with oxygen, and because it is believed that the reaction of copper with oxygen at high temperatures, in the sintering process as well as in the electrolytic cell, is important in dictating the effective life of a $\mathrm{NiO}-\mathrm{NiFe}_{2} \mathrm{O}_{4}-17 \% \mathrm{Cu}$ anode material. Many uncertainties are associated with the analysis presented here, but it is believed that the major factors have been addressed to the extent justified on the basis of the limited tests conducted. 


\subsection{DISCUSSION}

The scoping studies conducted in the course of this investigation provided some qualitative information on the gross nature of the reactions occurring during the sintering operation: binder evolution; metal phase melting, solidification, and oxidation; and the nature of the reaction products formed. In general, the DTA/TGA obseivations were in qualitative agreement with thermodynamic expectations and past work experience in fabricating cermet anodes.

The apparent superheat/supercool of the metallic $\mathrm{Cu} / \mathrm{Ni}$ phase was unanticipated. It is not known whether the degree of superheat/supercool would vary with powder blending or powder compaction practice (possible variation in nucleation sites for phase transformation), or whether the processing and final properties of the anode would be significantly sensitive to the phenomenon. The DTA/TGA data obtained in the scoping studies provided only a limited insight into the complex behavior of the cermet material during sintering. Because of the complexity of the potential interactions between cermet constituents, binder, and environmental oxygen, multiple interpretations of the data afforded by the DTA and TGA analysis are possible. In order to fully understand these data, and associate them with a substantially improved understanding of the sintering process, a significant amount of additional DTA, TGA, and analytical support work would be required.

For example, to determine whether there are reactions occurring between the copper phase and the $\mathrm{NiO}$ or $\mathrm{NiFe}_{2} \mathrm{O}_{4}$ phases an investigation would have to be made utilizing these constituents only in the sample, without binder, and the atmosphere should be inert. To determine how much of the weight loss ascribed to binder volatilization was binder and how much was oxygen from binder reaction with the oxide constituents would require supporting inertatmosphere studies and post-test analysis for metal phase, preferably as a function of binder initially present. To determine with accuracy the amount of binder leaving t'ie specimen as a function of oxygen fugacity in the environment would require additional studies of copper (only) in an environment of varying oxygen fugacity, so that the weight loss ascribed 
primarily to binder volatilization/pyrolysis could be corrected for the weight gain of the specimen caused by oxygen reaction with the copper phase. "Standard" runs using samples of NiO and ferrite (individually) should be made in addition to copper, to be certain that their weight change behavior in a varying-oxygen environment is not significant, and that the exo-/endothermicity of their behavior is thoroughly understood. And, of course, the effect of heating rate and sample density on the kinetics of the reactions involved represent important uninvestigated variables.

Because such supporting studies were deemed to be both essential as well as beyond the scope of the present effort, it was decided that the DTA/TGA studies would be terminated at the scoping-study level, without completing the test matrix outlined in the FWP WBS Element 0401, Optimize Anode Firing Conditions.

It is believed that an improved understanding of the reactions taking place in the sintering process is essential for developing satisfactory scaled-up anodes, and that DTA/TGA will play an important role in developing such an improved understanding. The tests described herein have provided a good insight into the types of supporting tests tilat will be required to make such future investigations useful, but specific revelatory information will have to await the conduct of the future studies. 


\subsection{CONCLUSIONS ANC RECOMMENDATIONS}

An assessment of the results of the present study has been made in light of past anode fabrication practice, both full-scale and laboratory-scale, and on perceived information n_eds based on these data. The following conclusions can be drawn from this oversight:

- The DTA/TGA data obtained in the present study was in qualitative agreement with historical and thermodynamic expectations.

- The insights obtained by DTA/TGA methods into the complex reactions taking place in a cermet body are qualitative, and capable of multiple interpretations in the absence of supporting information.

- Further DTA/TGA experiments are not recommended until some of the sintering reactions are better defined.

In order to obtain some of the fundamental information required for the fabrication of high-quality inert anodes, the following recommendations for future investigations are presented:

- An investigation should be undertaken to determine the extent and rate of the reaction of the binder with the constituents of the cermet anode during sintering. Sintering experiments should be conducted using cermet specimens containing varying amounts of binder (e.g., 0 to $5 \%$ by weight), and the composition of the metal phase and the degree of porosity should be determined after sintering. These experiments should be performed with and without copper phase in the specimens. Specimens without copper phase present could be fabricated by using 5324 spray-dried powder without a copper addition.

During these experiments, the composition of the exit gas from the sintering furnace should be determined as a function of time and temperature. (Ideally, all large-scale anode sintering should be accompanied by monitoring the $02 / \mathrm{H}_{2} \mathrm{O} / \mathrm{H}_{2} / \mathrm{CO} / \mathrm{CO}_{2}$ partial pressures in the inlet and exit furnace gases. A suitable alternative would be to have an excellent understanding of the cermet/furnace/furnace heating element/binder system, so that the processes going on during sintering would be completely predictable.)

Experiments should be designed to determine the reason for the beneficial results derived from the $1070^{\circ} \mathrm{C}$ "hold" in the sintering operation. It should be determined whether it is required because of (a) reducing-agent dissipation, permitting copper oxidation and/or preventing nickel reduction, or because of (b) the formation of gas pressurization of the anode due to binder decomposition/evaporation, or because of $(c)$ some other phenomenon. 
- The basic evaporation/decomposition kinetics of the binder alone should be determined as a function of time and temperature. These studies would assist in determining whether binder vapors, or binder furnacewall deposits, are responsible for the high oxygen requirements in the sintering atmosphere; and they would assist in ascertaining which binder(s) is (are) most suitable for the purpose of making cermet anodes.

- Experiments should be conducted to determine whether binder reinoval without reaction with the anode's constituent oxides can be accomplished, or if reduction of cermet constituents, such as NiO, occurs at the lowest practicable binder removal temperature. Also, the effect of anode size on binder elimination must eventually be determined.

- The tendency for liquid copper containing oxygen to wet the surface of a ferrite should be determined as a function of oxygen concentration. Contact-angle determinations of sessile drops of $\mathrm{Cu}-0$ alloy on a flat ferrite surface could yield these data. This information would assist in predicting the behavior of the copper phase both within and on the outer surface of the anode, and assist in interpreting the microstructures in anode materials.

- The intrinsic resistance of the metal phase of cermet anodes to oxidation during sintering and to corrosion/dissolution resistance in the electrolyte of an electrolytic cell, as well as to corrosion in the vapor phase of the cell, is not currently known, and should be determined. Test specimens should be fabricated with $\mathrm{Cu}-\mathrm{Ni}$ alloys ranging in composition from pure copper to $\mathrm{Cu}-20 \mathrm{wt} \% \mathrm{Ni}$, and exposed to electrolytic cell environments for time periods of 100 hours or more. Analysis of these specimens will permit a determination of the importance of nickel contamination of the copper phase to be made. If the tests were performed over various time periods, it would be possible to determine the kinetics of the formation of the various reaction phases formed. 


\subsection{REFERENCES}

1. Neumann, J. P., T. Zhong, and Y. A. Chang. 1984. Bull. Alloy Phase Diagrams, Vol 5., No. 2. Summarized in Binary Alloy Phase Diagrams, Massalski, T. B., Ed., 1986. ASM, Metals Park, OH, pp. 993-944.

2. Turnbu11, D. and E. Cech. 1950. J.App1. Phys. 21, 804.

3. Uhlig, H. 1948. The Corrosion Handbook, John Wiley and Sons, New York, p. 622 . 
APPENDIX E

INERT ANODE FABRICATION DEVELOPMENT: A SPREADSHEET DOCUMENTATION OF INFORMATION CONTAINED IN LABORATORY RECORD BOOKS 


\title{
INERT ELECTRODES PROGRAM
}

INERT ANODE FABRICATION DEVELOPMENT:

A SPREADSHEET DOCUMENTATION OF INFORMATION CONTAINED IN LABORATORY RECORD BOOKS

\author{
N.C. Davis
}

May 1990

Prepared for the U.S. Department of Energy under Contract DE-ACO6-76RLO 1830

Pacific Northwest Laboratory

Richland, Washington 99352

Operated for the U.S. Department of Energy by Battelle Memorial Institute 


\section{INTRODUCTION}

This brief report documents the Pacific Northwest Laboratory's (PNL's) experience in inert anode fabrication. A large quantity of information exists in several PNL Laboratory Records Books (LRB's) regarding anode fabrication parameters, process developments and anode compositions. This information has been consolidated and summarized in a computer based spreadsheet. The spreadsheet summary represents about 200 separate sintering test runs conducted at PNL; the first 13 of these are omitted from the spreadsheet because the information is incomplete for these initial trial runs.

\section{FABRICATION DEVELOPMENT}

The primary goal of PNL's anode fabrication and development effort was to produce a standard cermet anode for testing in laboratory Hall Cells used for the electrolytic production of aluminum. A standard cermet composition, $83 \% \mathrm{NiO}-\mathrm{NiFe}_{2} \mathrm{O}_{4} / 17 \% \mathrm{Cu}$, was the composition used in most of the test runs. As a secondary goal, the composition of the cermet was varied in attempts to improve the microstructure, the sintered density and possibly the electrical conductivity of the anode.

Fabrication development of the standard composition cermet anode progressed from a low density, porous cermet anode having a high copper loss during sintering, to an anode having a relatively high density and uniform copper dispersion (see Figure 1). Figure 1 illustrates a typical microstructure of a standard composition cermet anode obtained using optimum processing parameters. Improvements to the cermet microstructure and other properties have also progressed. The standard $17 \%$ copper cermet has an electrical conductivity of $\sim 100 \mathrm{ohm}^{-1} \mathrm{~cm}^{-1}$. This conductivity was doubled to $\sim 200 \mathrm{ohm}^{-1} \mathrm{~cm}^{-1}$ by adding about $0.5 \mathrm{wt} \%$ aluminum to the cooper when processing the cermet material. The electrical conductivity of the cermet was increased to nearly $700 \mathrm{ohm}^{-1} \mathrm{~cm}^{-1}$ by using a Cu/Ni metal mixture containing a small amount of aluminum. A typical microstructure of an anode containing the $\mathrm{CU} / \mathrm{Ni} / \mathrm{Al}$ metal phase is shown in Figure 2; the material shown has a relatively low density of $6.0 \mathrm{~g} / \mathrm{cm}^{3}$. The microstructure and density of the anodes fabricated using the added aiioy and vibratory miiling (vm) is much improved 

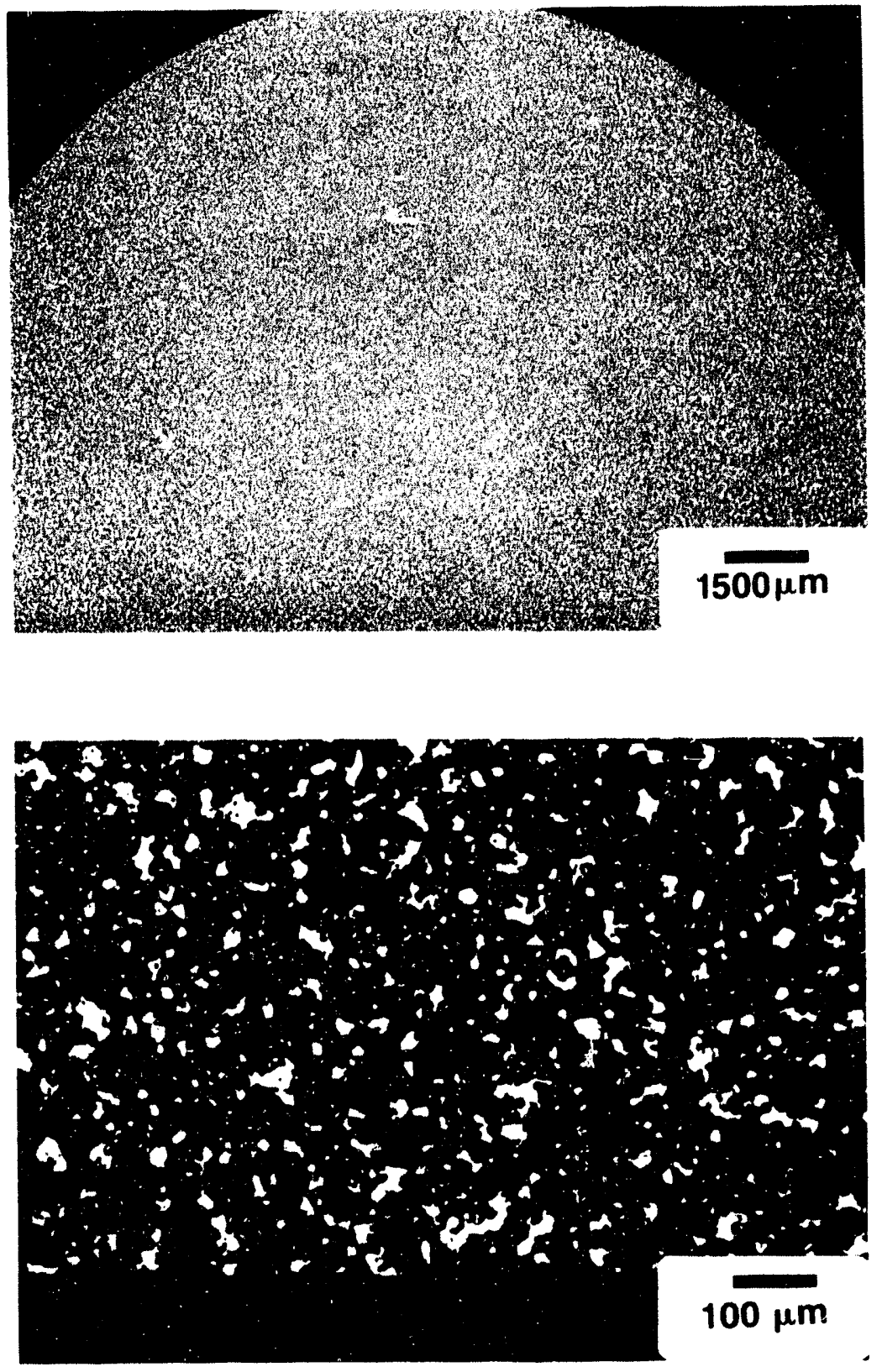

FIGURE 1. Typical microstructure of a $\mathrm{NiO}-\mathrm{NiFe}_{2} \mathrm{O}_{4} / 17 \mathrm{wt} \% \mathrm{Cu}$ composition cermet anode obtained using optimum processing parameters. Material shown from Run 170 (See Table 2). 

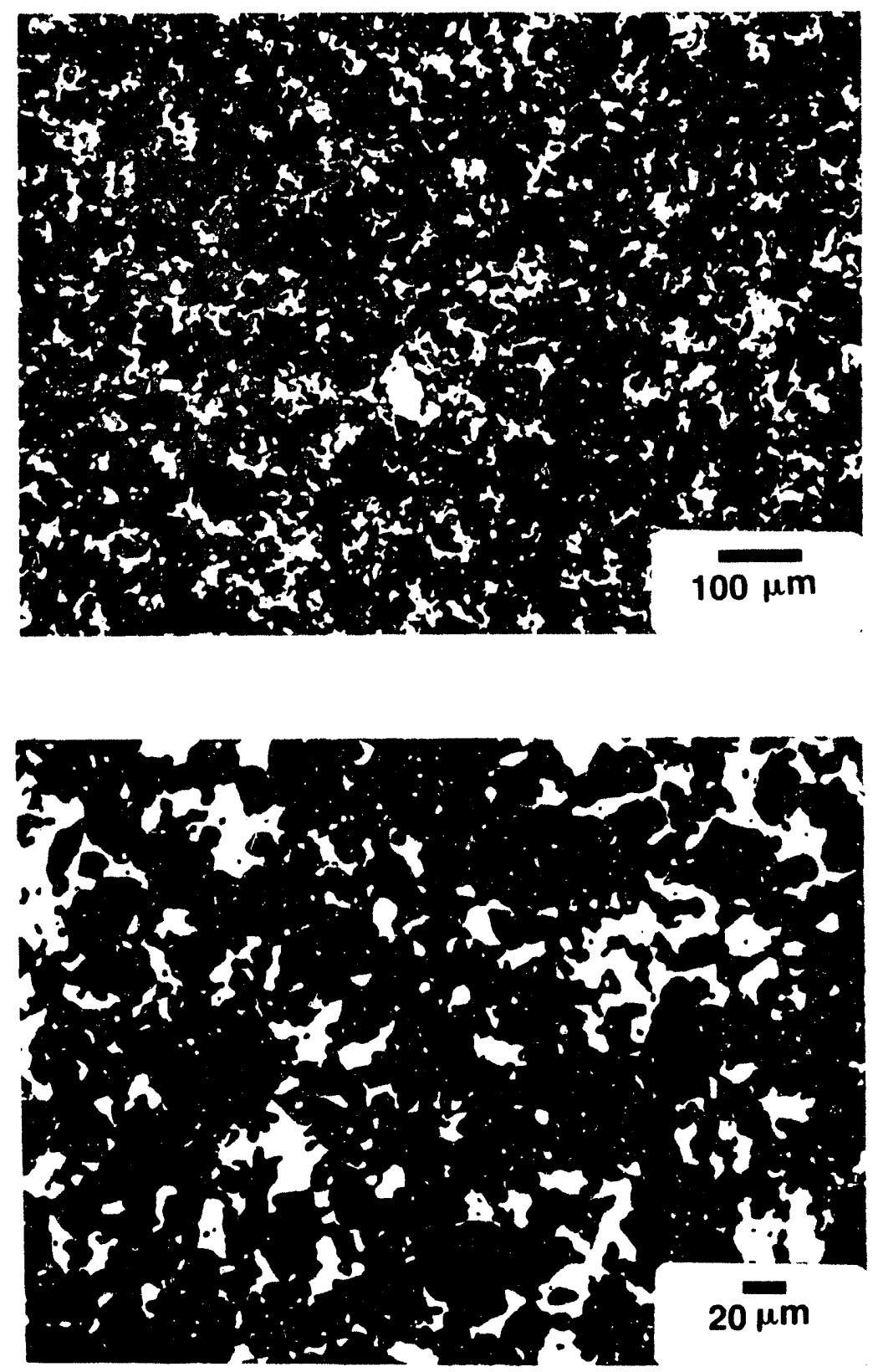

FIGURE 2. Typical microstructure of "high alloy" (21 wt $\mathrm{Cu}, 3 \mathrm{wt} \% \mathrm{Ni}$, $0.5 \mathrm{wt} \% \mathrm{Al}$ ) composition cermet anode. Material shown from Run 189-2 (see Table 2). 
(see Figure 3). These two samples from Runs 173 and 172 are very similar in density and microstructure but differ significantly in electrical conductivity; the sample containing the trace of aluminum has a much higher electrical conductivity. The benefit of this enhanced conductivity has not been fully addressed in cell testing, nor has the durability of this anode composition been thoroughly examined in laboratory-scale tests.

The following explanations and descriptions are presented to assist the reader in the review and understanding of this summary report and accompanying spreadsheet.

\section{SPREADSHEET LABELS AND PROCESS DESCRIPTION}

Run Numbers

Run numbers are consecutive and identify a group of anodes sintered in the same test run.

$\underline{\text { ID }}$

Identification number for the individual anode within a run, but must be taken together with the designation of the anode type to define an individual anode. Each individual anode is not documented in the spreadsheet. Often, a typical anode is used to represent several in a series having the same composition and identical fabrication parameters.

Type

There are three basic anode shapes, unless otherwise noted under comments.

Type $x$, Figures 4 and 5.

All test runs included the type $X$ anode. It was cold pressed with existing tooling using the semi-automatic mode of a double-acting hydraulic press. Several samples are usually pressed in a particular fabrication process using a specific powder composition.

Type $Y$, Figure 6 and Modified Type $Y$ Figures 7 and 8

These figures illustrate a typical Type $Y$ anode. Most of the Hall Cell electrolytic tests conducted at PNL used this type of anode. The shape was 

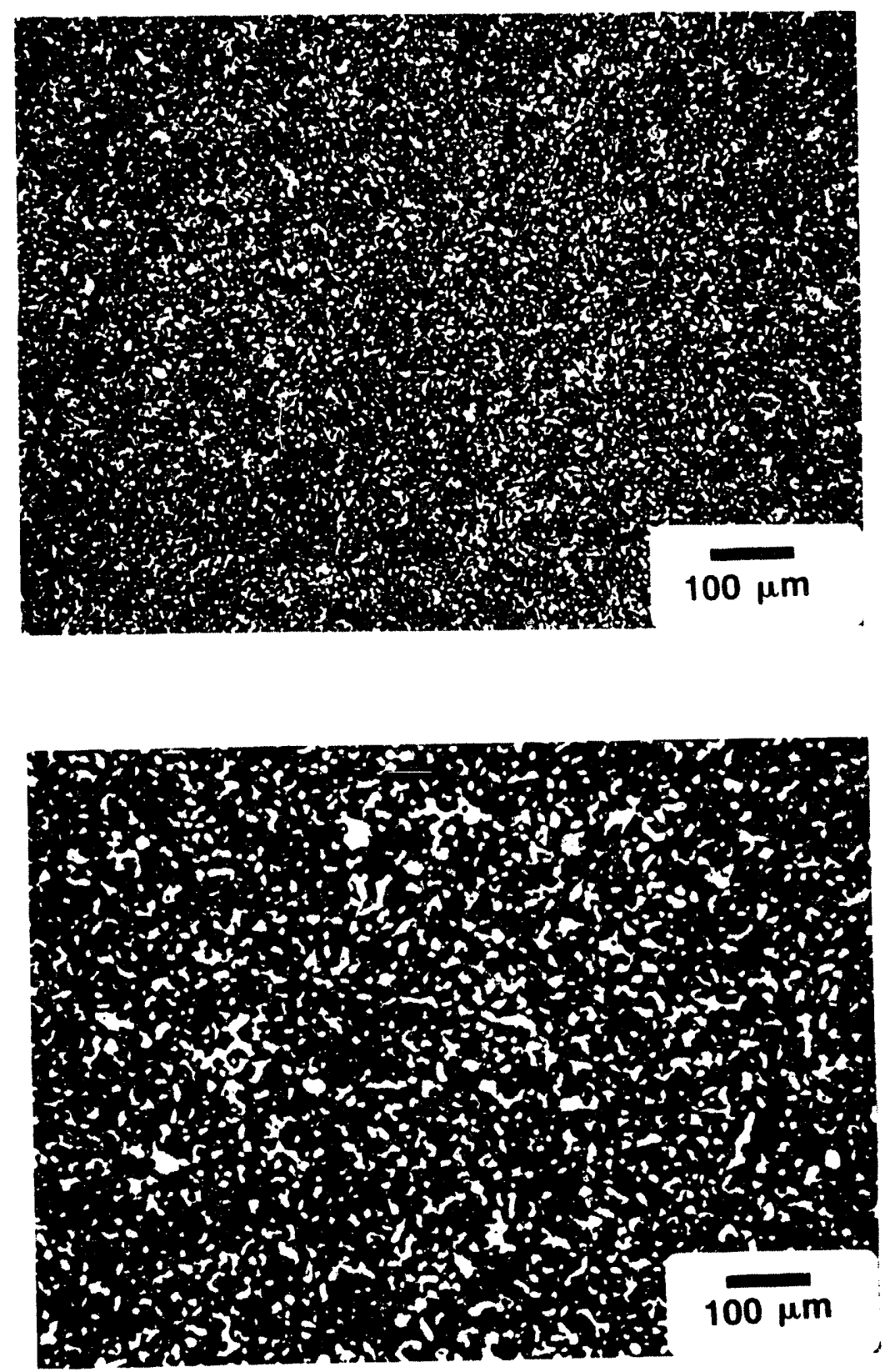

FIGURE 3. Typical microstructure of "high alloy" composition cermet anodes with and without addition of aluminum. Material shown in upper photomicrograph from Run 173 (21 wt\% $\mathrm{Cu}, 3.5 \mathrm{wt} \% \mathrm{Ni}, 0.44 \mathrm{wt} \% \mathrm{Al}$ ) has greatly increased electrical conductivity compared to material shown in lower photomicrograph from Run 172 (21.25 wt $\%$ Cu, 3.75 wt\% $\mathrm{Ni}$ ). (See Table 2 for additional information on Runs 173 and 172.) 


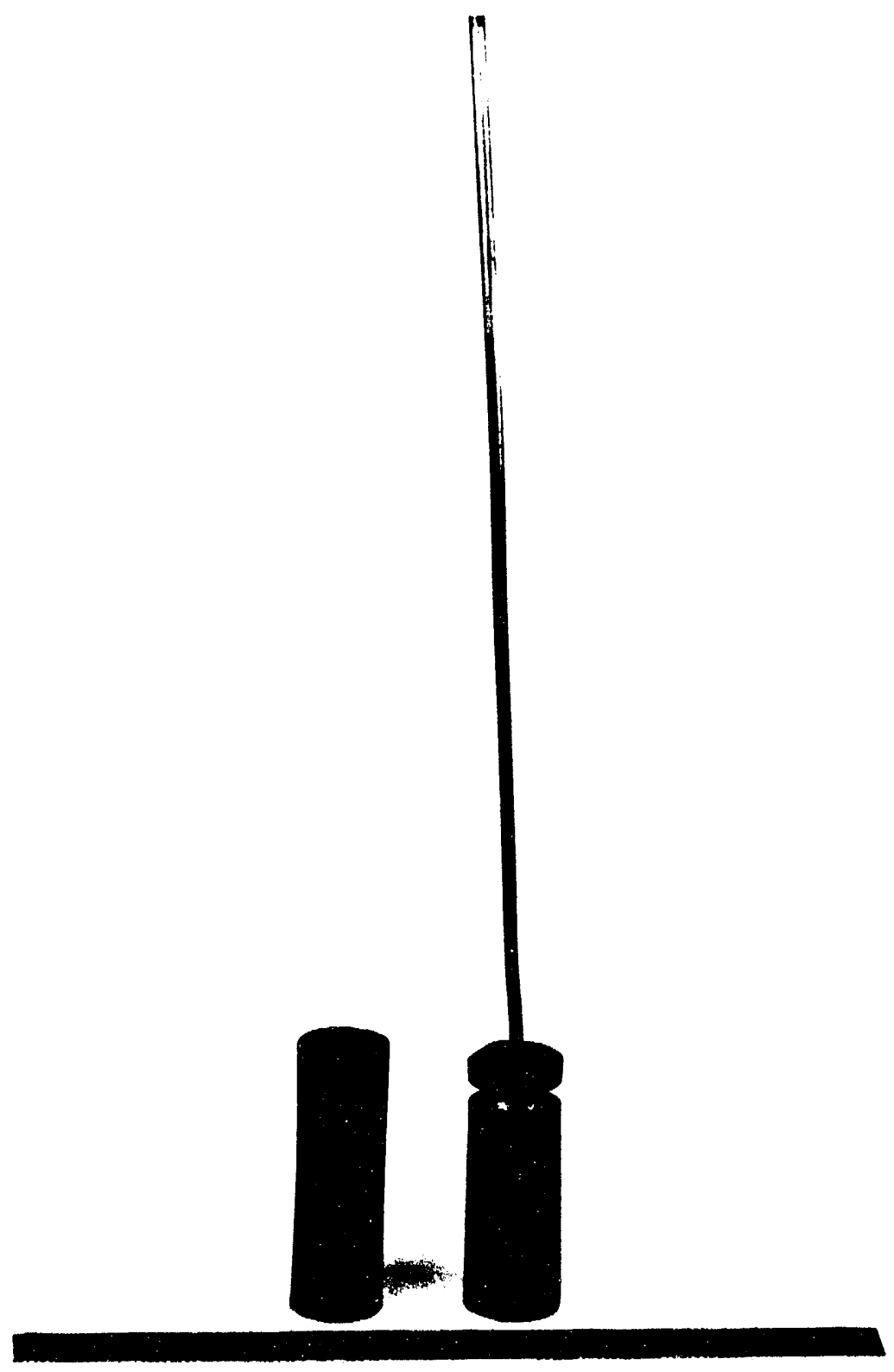

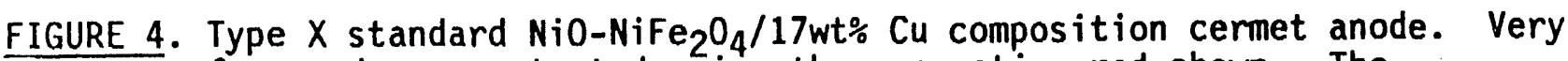
few anodes were tested using the connection rod shown. The cylindrical samples (left anode) were about $0.4 \mathrm{in}$. dias $\times 1$ in. long and were used to evaluate fabrication parameters.

6 


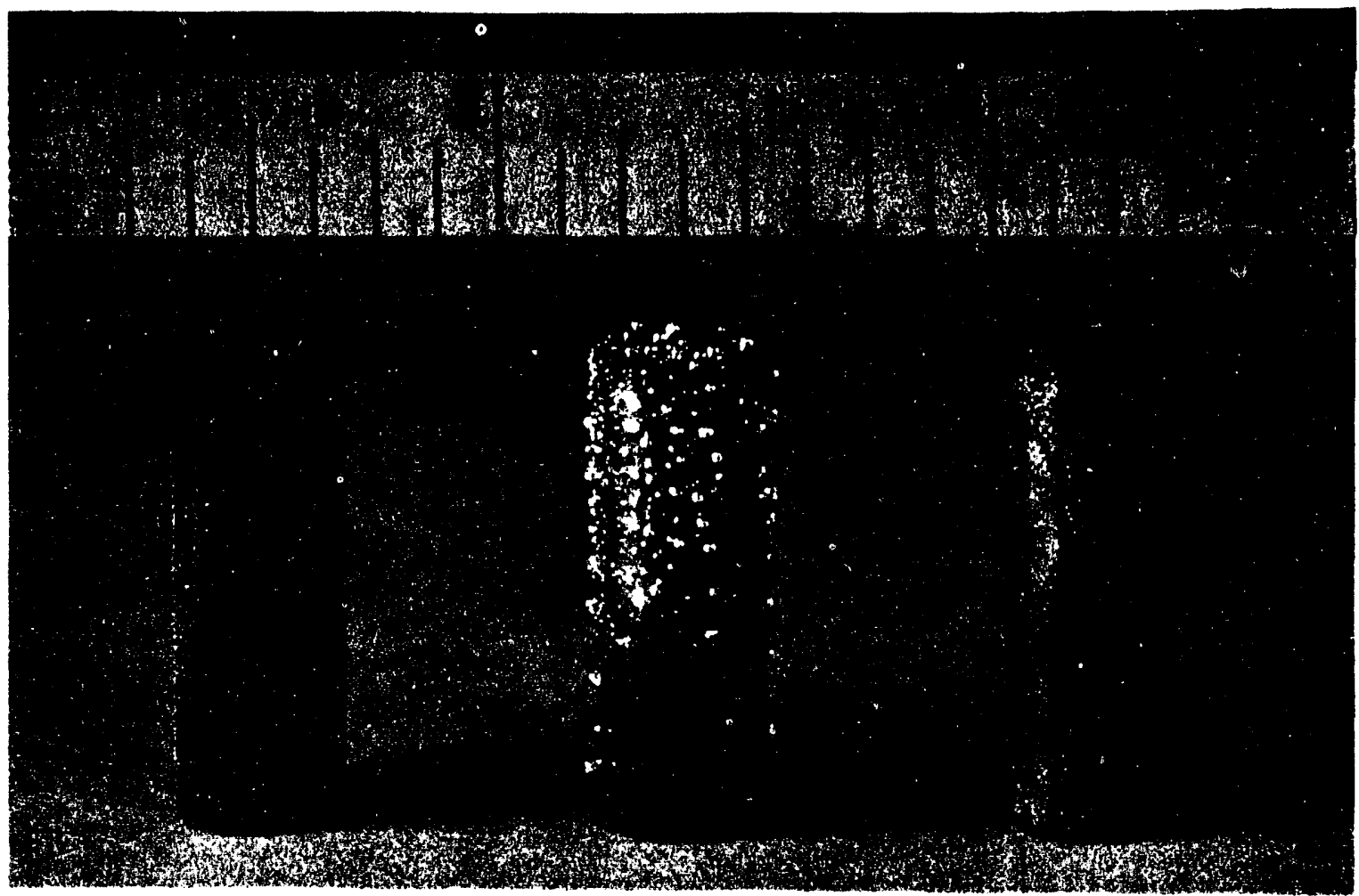

FIGURE 5. Type $X$ anodes having variable metal content. Left anode: standard $\mathrm{NiO}-\mathrm{NiFe}_{2} \mathrm{O}_{4} / 17$ wt\% $\mathrm{Cu}$. Middle Anode: NiO-NiFe $\mathrm{O}_{4} / 2.5 \mathrm{wt} \% \mathrm{Cu}$ showing excessive $\mathrm{Cu}$ bleeding from the material. Right Anode: Ni0-

$\mathrm{NiFe}_{2} \mathrm{O}_{4} / 25 \mathrm{wt} \% \mathrm{Cu} / \mathrm{Ni}$ alloy $(85 \% \mathrm{Cu}, 15 \% \mathrm{Ni})$ showing no metal phase bleeding. Samples shown are typical of those used for density evaluations. 


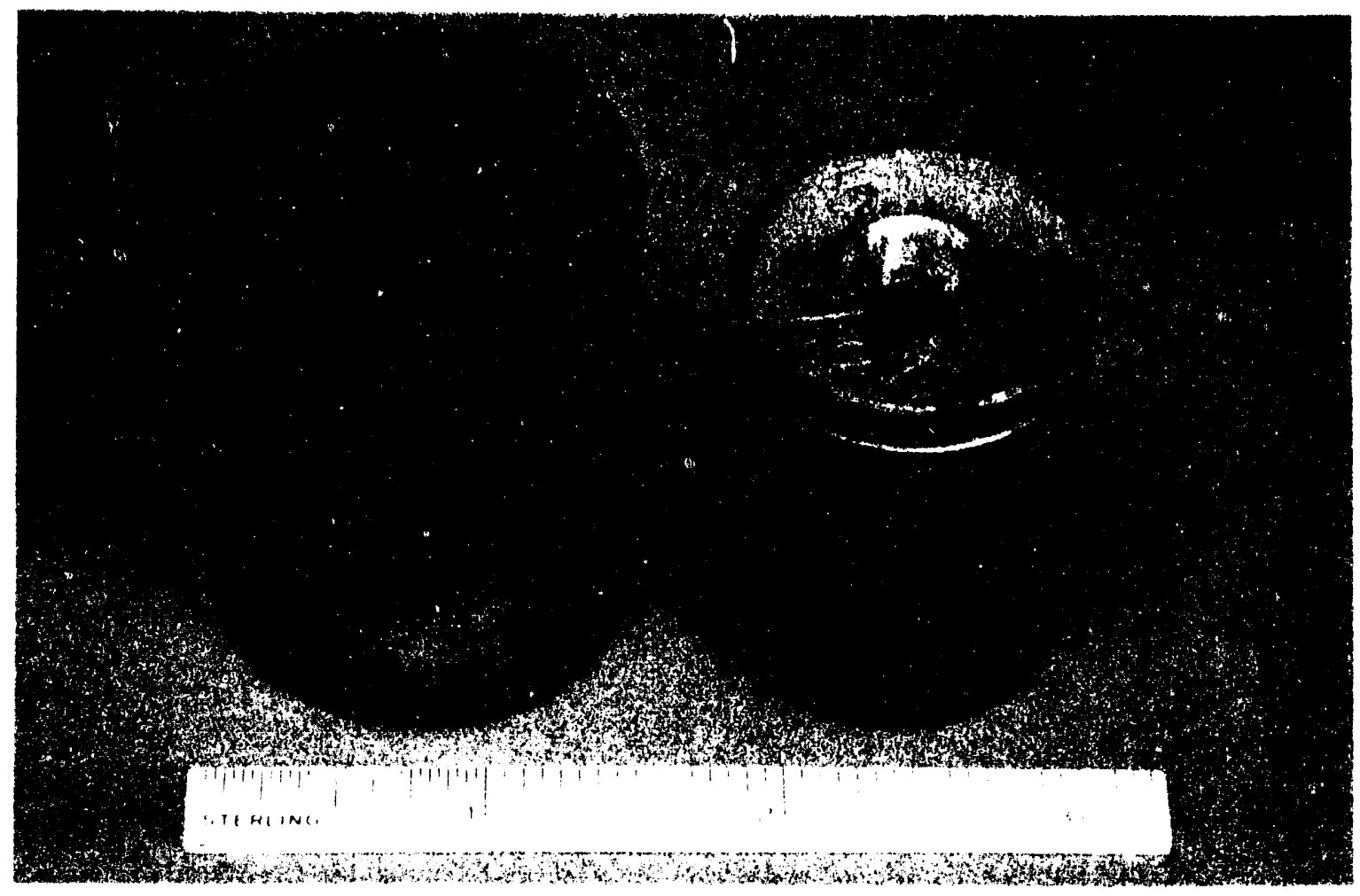

FIGURE 6. Type $\mathrm{Y}$ standard $\mathrm{NiO}-\mathrm{NiFe}_{2} \mathrm{O}_{4} / 17 \mathrm{wt} \% \mathrm{Cu}$ composition cermet anode. Left: green body. Right: Sintered body. Typical shrinkage on sintering is $16 \%$. Sizes made were about 1.25 in. dia $\times 1.5$ to 2.5 in. long. Type $Y$ anodes of this type were used in numerous cell tests as indicated in Table 2. Electrical connections were made by furnace brazing a $\mathrm{Ni}$ rod into the hole. 


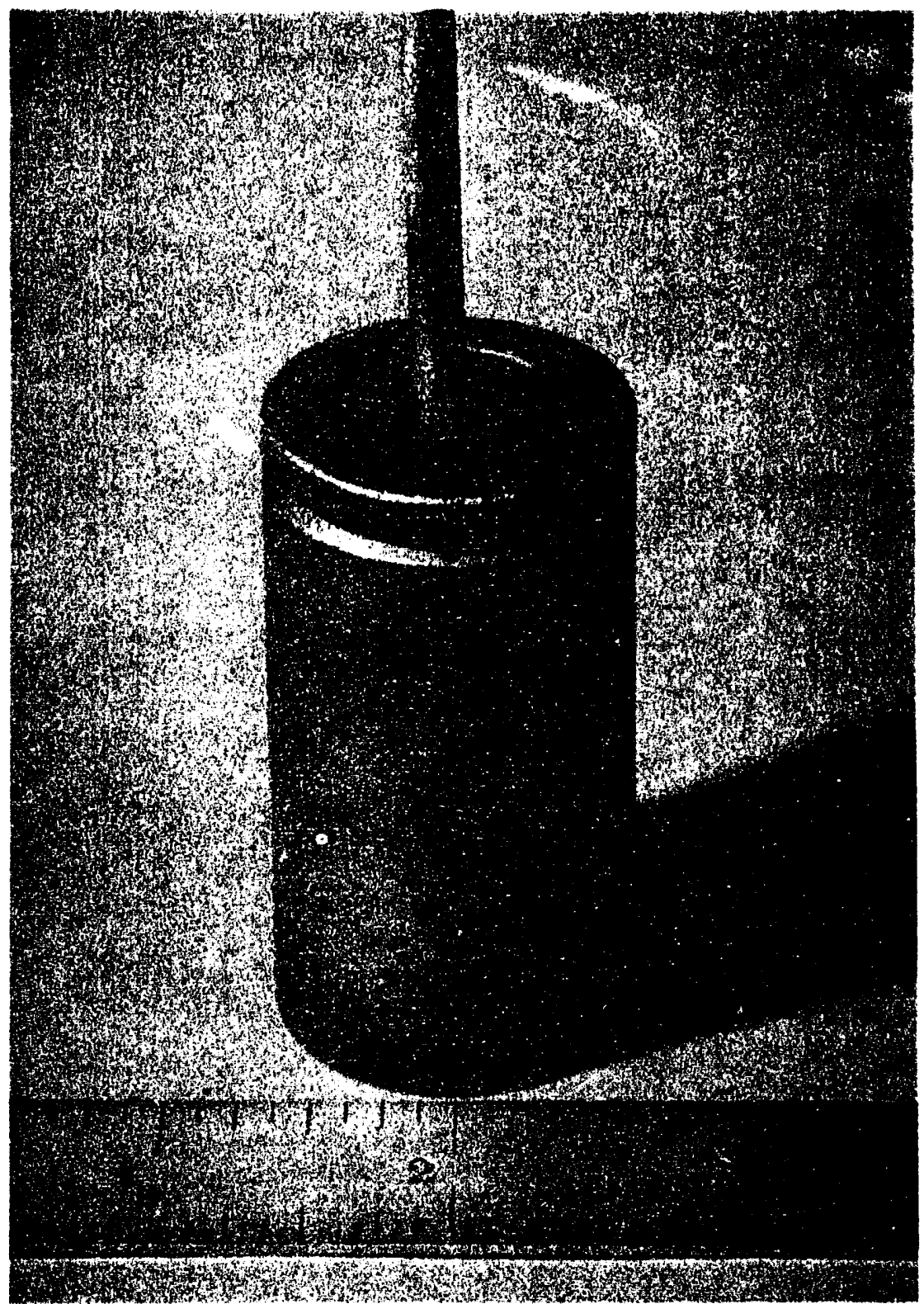

FIGURE 7. Modified Type $\mathrm{Y}$ standard $\mathrm{NiO}-\mathrm{NiFe}_{2} \mathrm{O}_{4} / 17$ wt $\% \mathrm{Cu}$ composition cermet anode. Shape obtained by machining green body. Sintered dimensions of about $1.3 \mathrm{in}$. dia $\times 2.4 \mathrm{in}$. long with a 1 in. recess having $\sim 0.25$ in. walls. A $3 / 16$ in. $N$ i rod is shown after furnace brazing to obtain the electrica! connection. 


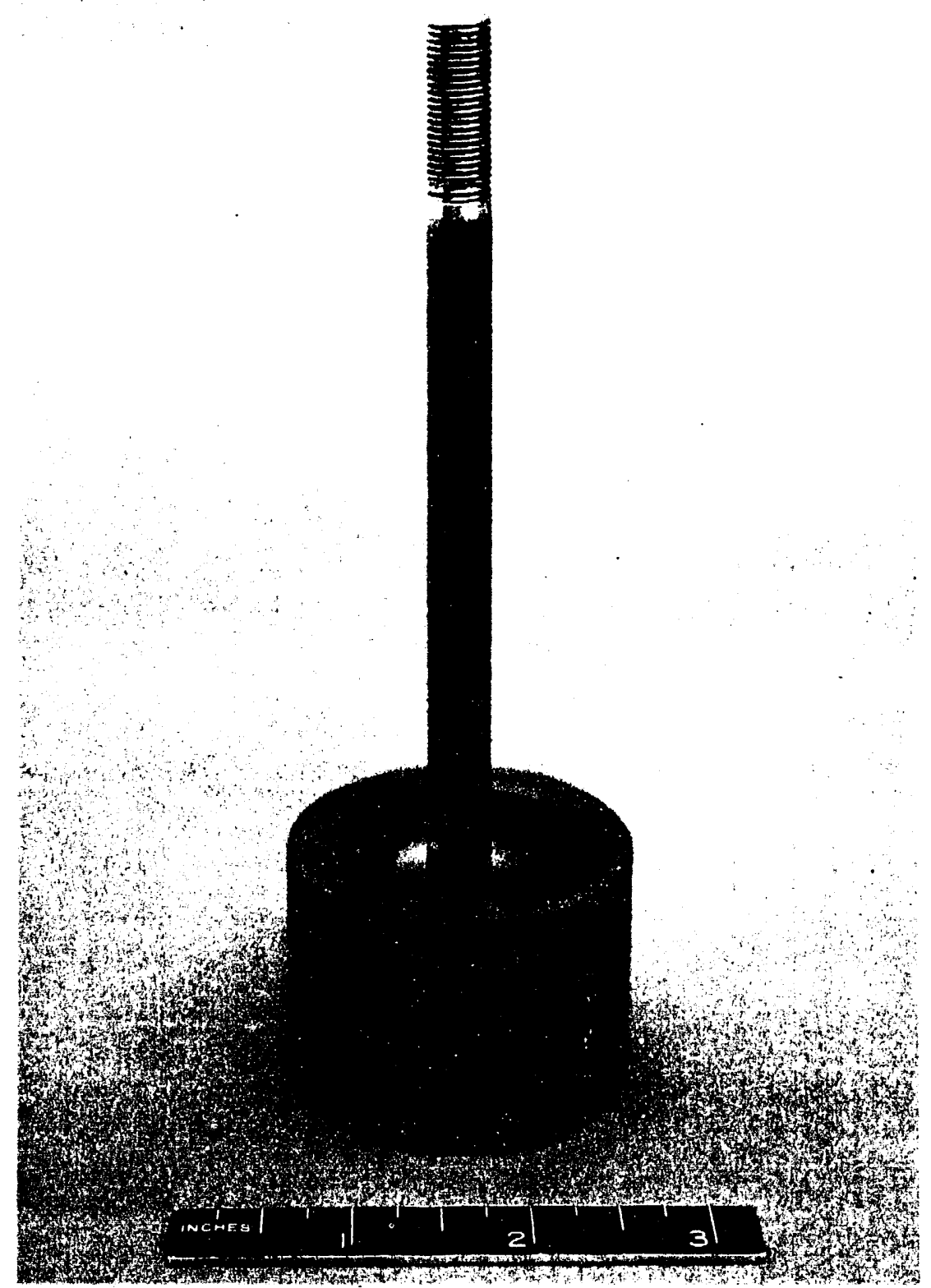

FIGURE 8. Modified Type $\mathrm{Y}$ standard $\mathrm{NiO}-\mathrm{NiFe}_{2} \mathrm{O}_{4} / 17 \mathrm{wt} \% \mathrm{Cu}$ composition cermet anode. Anode shown is from Run 30 (see Table 2). 
cold pressed to consolidate the powder, then sealed in a light-weight rubber bag and cold pressed at 20 kpsi.

\section{Type C Figures 9 and 10}

These figures illustrate a typical Type $C$ anode. Type $C$ anodes were used in later PNL laboratory cell tests and are a small scale version, $\sim 1.5$ in. dia $\times 3$ in. long, of the larger prototype anode used in the prototype anode test. The thin wall, heavy bottom cup design is formed when the packed cermet powder is isopressed around a coated mandrel in a flexible urethane mold. This design has the advantage of using less cermet material and providing the cup recess to protect the electrical/mechanical connection.

\section{Composition}

The composition of each anode sample is listed as a weight percentage on

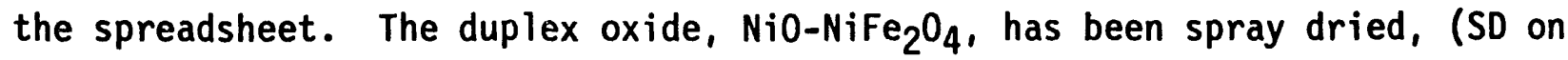
the spreadsheet). Spray-drying yields a spherical, free-flowing granuls of powder $~ 50$ microns in diameter. These granules pack to a tap density of $\sim 2.0 \mathrm{~g} / \mathrm{cm}^{3}$. A green (i.e. unsintered) density of $\sim 3.35 \mathrm{~g} / \mathrm{cm}^{3}$ can be expected when pressed at $20 \mathrm{kpsi}$. The relationship between applied pressure in forming the anode green body and its final density is shown in Figure 11 for Run 147 . This shows both the green and sintered density versus the pressing pressure for both $\mathrm{NiO}-\mathrm{NiFe}_{2} \mathrm{O}_{4}$ and the standard $83 \% \mathrm{NiO}-\mathrm{NiFe}_{2} \mathrm{O}_{4} / 17 \% \mathrm{Cu}$ cermet powder. In Run 147, the oxide sample, pressed at $20 \mathrm{kpsi}$, was held $8 \mathrm{~h}$ at $1200^{\circ} \mathrm{C}$ to yield a nearly theoretical density (TD) of $5.7 \mathrm{~g} / \mathrm{cm}^{3}$. The final sintered density may vary from the theoretical density because of reduction of the $\mathrm{NiO}$ to $\mathrm{Ni}$ by the organic binder used in the manufacture of the spray dried powder. This reduction always results in a $\mathrm{Cu} / \mathrm{Ni}$ metal alloy phase in the final sintered anode body. This $100 \%$ oxide sample is used as the density standard to compare densities obtained from the various sintering runs and processes.

Five different lots of the spray dried powder were used during tests described in this report. A comparison of the characteristics of the five lots of powder is shown in the results of the sinterability tests conducted in Run $99\left(1200^{\circ} \mathrm{C}\right)$ and Run $100\left(1300^{\circ} \mathrm{C}\right)$; both tests were 8 hnurs in duration (see Table 1). Minor differences in density are seen by comparing the results of the $1200^{\circ} \mathrm{C}$ and $1300^{\circ} \mathrm{C}$ sintering temperatures. The differences may also be 


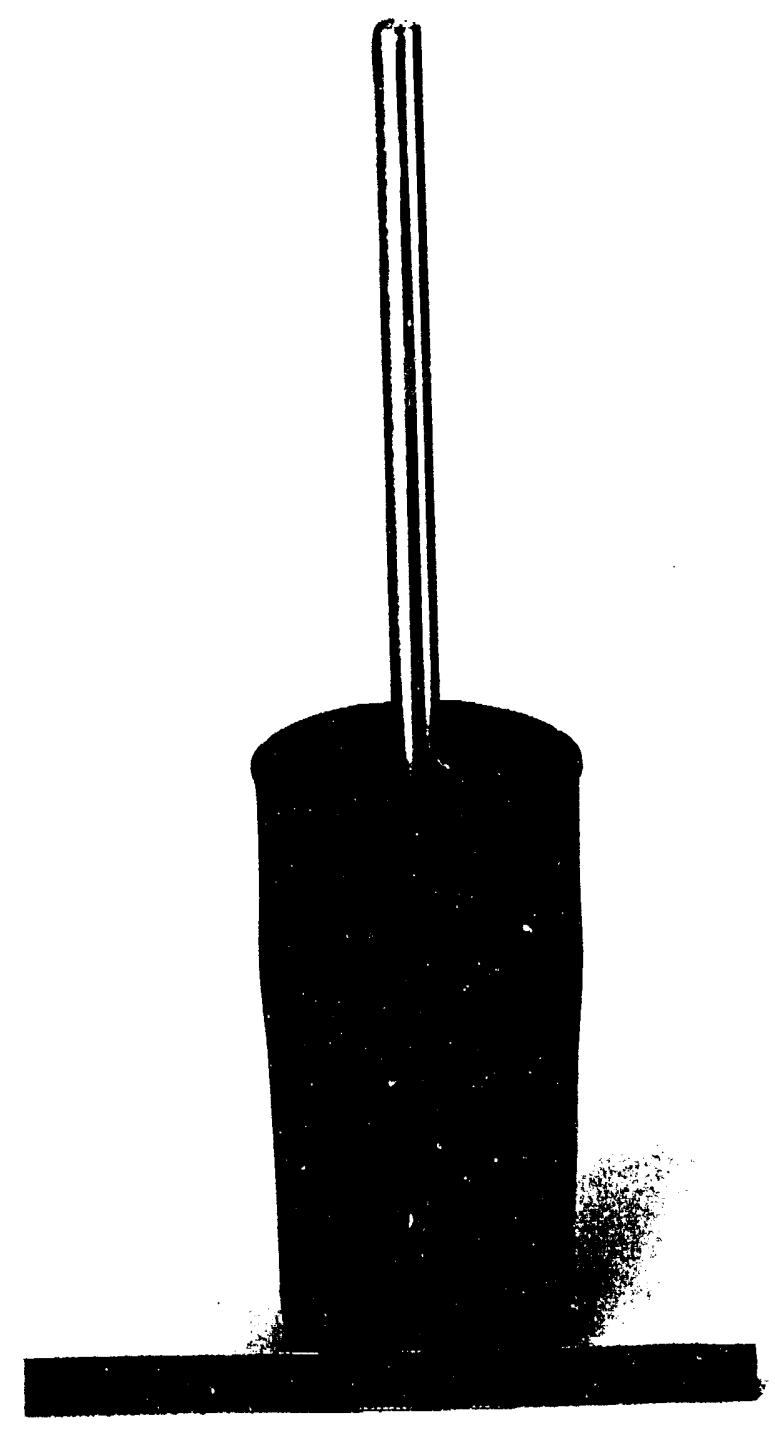

FIGURE 9. Type $\mathrm{C}$ standard $\mathrm{NiO}-\mathrm{NiFe}_{2} \mathrm{O}_{4} / 17 \mathrm{wt} \% \mathrm{Cu}$ composition cermet anode. Sintered anode dimensions of about $1.5 \mathrm{in}$. dia $\times 3$ in. long having a recess of $\sim 1.5 \mathrm{in}$. deep with thin ( $0.125 \mathrm{in.}$ ) walls. Ni rod is threaded into anode for the electrical connection. 



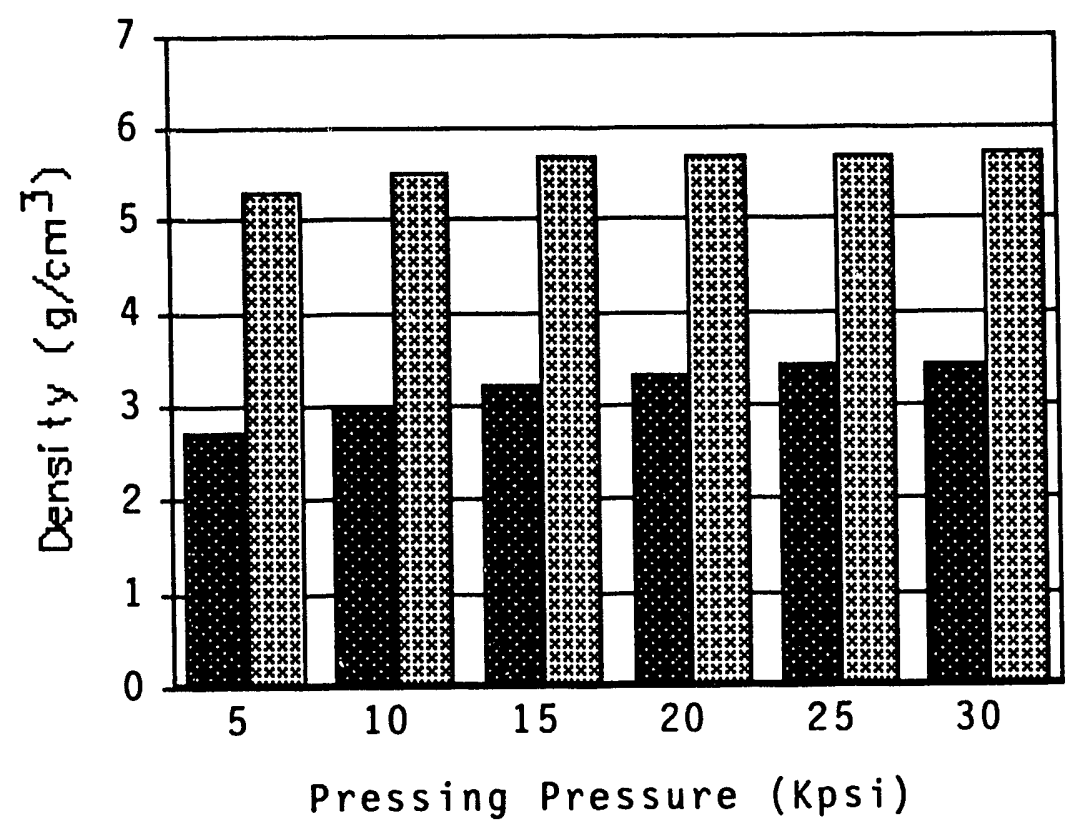

Green Density

Sintered Density

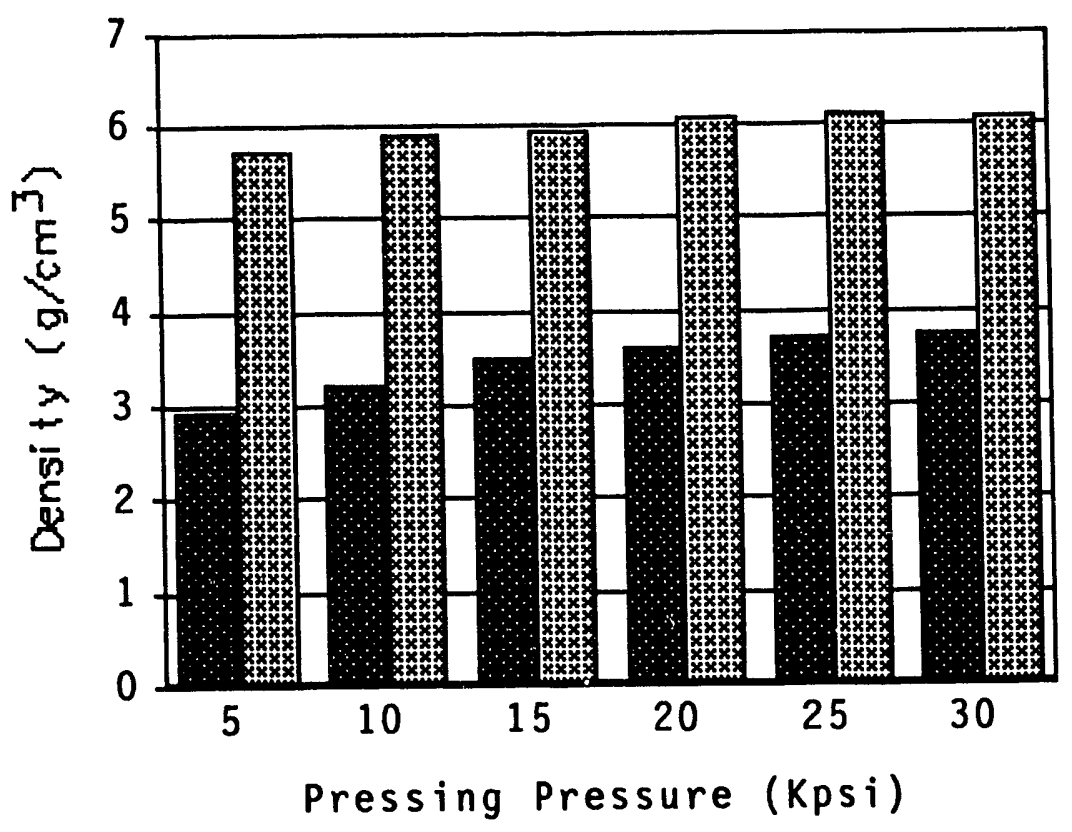

Green Density

Sintered Density

FIGURE 11. Relationship of fabrication pressing pressure to anode green and

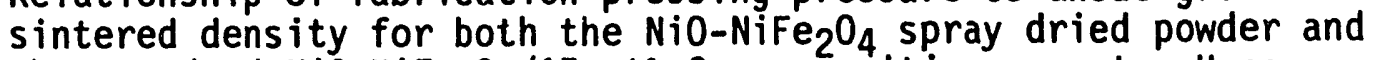
the standard $\mathrm{NiO}-\mathrm{NiFe}_{2} \mathrm{O}_{4} / 17$ wt\% $\mathrm{Cu}$ composition cermet. Upper

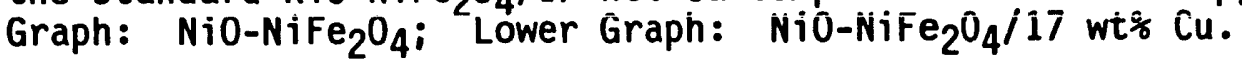




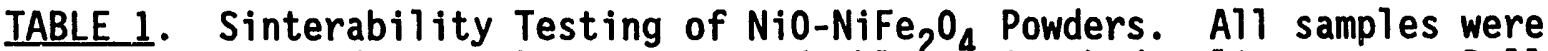
pressed to $20 \mathrm{kpsi}$ using a double-action hydraulic press. Pellets in Run 99 were sintered at $1200^{\circ} \mathrm{C}$ for $8 \mathrm{~h}$, and those in Run 100 were sintered at $1300^{\circ} \mathrm{C}$ for $8 \mathrm{~h}$.

\begin{tabular}{|c|c|c|c|c|c|}
\hline \multirow[t]{2}{*}{$\begin{array}{l}\text { First Lot }(\sim 1 \text { 1b.) } \# 5324 \\
1-501 \mathrm{~b} \text {. Container }\end{array}$} & $\begin{array}{l}\text { Run } \\
99 \\
99 \\
99\end{array}$ & $\begin{array}{l}\text { ID } \\
1 \\
2 \\
3\end{array}$ & $\begin{array}{c}\begin{array}{c}\text { Green } \\
\text { Dens ity } \\
\left(\mathrm{gm} / \mathrm{cm}^{3}\right)\end{array} \\
3.37 \\
3.40 \\
3.23\end{array}$ & 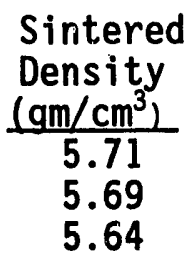 & $\begin{array}{c}W t \\
\text { Loss }(\%) \\
4.4 \\
4.4 \\
4.2\end{array}$ \\
\hline & $\begin{array}{l}100 \\
100 \\
100\end{array}$ & $\begin{array}{l}1 \\
2 \\
3\end{array}$ & $\begin{array}{l}3.44 \\
3.46 \\
3.30\end{array}$ & $\begin{array}{l}5.65 \\
5.74 \\
5.72\end{array}$ & $\begin{array}{l}4.5 \\
4.9 \\
4.8\end{array}$ \\
\hline \multirow[t]{2}{*}{$\begin{array}{l}\text { P67 AT } \\
2-50 \text { ib. containers }\end{array}$} & $\begin{array}{l}99 \\
99\end{array}$ & $\begin{array}{l}4 \\
5\end{array}$ & $\begin{array}{l}3.37 \\
3.22\end{array}$ & $\begin{array}{l}5.68 \\
5.65\end{array}$ & $\begin{array}{l}4.5 \\
4.7\end{array}$ \\
\hline & $\begin{array}{l}100 \\
100\end{array}$ & $\begin{array}{l}4 \\
5\end{array}$ & $\begin{array}{l}3.23 \\
3.17\end{array}$ & $\begin{array}{l}5.69 \\
5.62\end{array}$ & $\begin{array}{l}4.4 \\
4.8\end{array}$ \\
\hline \multirow[t]{2}{*}{$\begin{array}{l}\text { P67 Al } \\
\text { Vibratory milled } 2 \text { hours }\end{array}$} & $\begin{array}{l}99 \\
99\end{array}$ & $\begin{array}{l}6^{(a)} \\
7^{(a)}\end{array}$ & $\begin{array}{l}3.55 \\
3.50\end{array}$ & $\begin{array}{l}5.74 \\
5.84\end{array}$ & $\begin{array}{l}4.7 \\
4.5\end{array}$ \\
\hline & $\begin{array}{l}100 \\
100\end{array}$ & $\begin{array}{l}6^{(a)} \\
7^{(a)}\end{array}$ & $\begin{array}{l}3.48 \\
3.51\end{array}$ & $\begin{array}{l}5.74 \\
5.72\end{array}$ & $\begin{array}{l}4.5 \\
4.6\end{array}$ \\
\hline \multirow[t]{2}{*}{$\begin{array}{l}\text { P73 Al } \\
6-50 \text { Ib. Containers }(a, b, c)\end{array}$} & $\begin{array}{l}99 \\
99 \\
99 \\
99 \\
99 \\
99\end{array}$ & $\begin{array}{r}8 \\
9 \\
10 \\
11 \\
12 \\
13\end{array}$ & $\begin{array}{l}3.27 \\
3.29 \\
3.17 \\
3.26 \\
3.24 \\
3.27\end{array}$ & $\begin{array}{l}5.65 \\
5.64 \\
5.57 \\
5.62 \\
5.62 \\
5.65\end{array}$ & $\begin{array}{l}5.8 \\
5.7 \\
5.5 \\
5.5 \\
5.5 \\
5.7\end{array}$ \\
\hline & $\begin{array}{l}100 \\
100 \\
100 \\
100 \\
100 \\
100\end{array}$ & $\begin{array}{r}8 \\
9 \\
10 \\
11 \\
12 \\
13\end{array}$ & $\begin{array}{l}3.40 \\
3.32 \\
3.30 \\
3.26 \\
3.29 \\
3.25\end{array}$ & $\begin{array}{l}5.69 \\
5.62 \\
5.67 \\
5.68 \\
5.66 \\
5.67\end{array}$ & $\begin{array}{l}5.6 \\
5.3 \\
5.9 \\
6.2 \\
5.9 \\
5.9\end{array}$ \\
\hline \multirow[t]{2}{*}{$\begin{array}{l}\text { P68 Al } \\
2-50 \text { Ib. Containers }(d)\end{array}$} & $\begin{array}{l}99 \\
99\end{array}$ & $\begin{array}{l}14 \\
15\end{array}$ & $\begin{array}{l}3.28 \\
3.22\end{array}$ & $\begin{array}{l}5.67 \\
5.66\end{array}$ & $\begin{array}{l}4.7 \\
4.8\end{array}$ \\
\hline & $\begin{array}{l}100 \\
100\end{array}$ & $\begin{array}{l}14 \\
15\end{array}$ & $\begin{array}{l}3.40 \\
3.37\end{array}$ & $\begin{array}{l}5.69 \\
5.69\end{array}$ & $\begin{array}{l}4.6 \\
4.5\end{array}$ \\
\hline
\end{tabular}

(a) Pellets labeled 6 and 7 were prepared using oxide powder which was vibratory milled prior to pressing, and sintered densities are higher.

(b) 5-50 1b containers are in storage (as of June 21, 1989) in Building 303.).

(c) 1-50 1b container is currently being used in laboratory tests.

(d) 2-50 1b containers are in storage (as of June 21, 1989) in Building $303 \mathrm{~J}$. 
related to the powder lot, powder density and weight loss during sintering. Apparently, variables in powder preparation are reflected in differences in these parameters.

The metal powders, certified to be $99.9 \%$ pure, were purchased from the following sources:

\section{Supplier}

Aremco Products, Inc.

Cerac, Inc.

Alamo Supply Co., Inc.

Greenback Industries, Inc.
Listed Particle Size $\sim 5-15 \mu \mathrm{m} \mathrm{Cu}$ and $3 \mu \mathrm{m} \mathrm{Ni}$ $<2 \mu \mathrm{m} \mathrm{Cu}$ and $10 \mu \mathrm{m} \mathrm{Al}$ $\sim 5-15 \mu \mathrm{m} \mathrm{Cu}$ $95 \%<44 \mu \mathrm{m} \mathrm{Cu}$

Initially, the fabrication of the anodes used copper powder obtained from Aremco Products, Inc. and Cerac Inc. Differences in copper particle size did not appear to affect the performance of the powder. Later work, including the preparation of the material used to fabricate the prototype anode, used copper obtained from the Alamo Supply Co., Inc. which resulted in a final cermet very similar to that obtained using copper obtained from Aremco Products, Inc. A sample of copper powder obtained from Greenback Industries, Inc. also produced a final cermet microstructure very similar to that obtained using copper from the other sources indicated. The nickel and aluminum powders used in the preparation of anodes having high metal alloy content were obtained from the commercial vendors indicated.

A few anode samples were fabricated using powders that were prepared at PNL by a freeze drying. technique. This approach is discussed below under fabrication descriptions; other variations in composition are noted under comments.

\section{Fabrication Description}

Spray Dry - (SD)

A slurry of the nickel ferrite powder, water and an organic binder is forced through a spray orifice and allowed to free-fall through hot air which provides rapid drying. The size and density of these discrete spherical granules is controlled by the viscosity of the slurry, the size of spray 
nozzle, and/or selection of the binder. This brief description of an open spray dry process illustrates the preparation of the $\mathrm{NiO}_{-} \mathrm{NiFe}_{2} \mathrm{O}_{4}$ powder used. This work was done by the Aluminum Company of America (Alcoa) and the Stackpole Corporation. Details of the preparation of the spray dried NiO$\mathrm{NiFe}_{2} \mathrm{O}_{4}$ powder are considered proprietary information; however, much of this information is contained in reports published by Alcoa.

Freeze Dry - (FD)

Some limited development work conducted at PNL is shown on the spreadsheet. Freeze dried powders are prepared by spraying a salt solution of the powder through an orifice into a bath of hexane, which flash-freezes the solution into spherical beads. For example, a solution of $\mathrm{CuSO}_{4}$ was used to produce the copper metal powder, and $\mathrm{FeSO}_{4}$ and $\mathrm{NiSO}_{4}$ were used to produce the duplex oxide powder. These sulfate agglomerates are dried in a freezer, then heated to decomposition to produce a highly reactive oxide powder. The powder may be processed at this point, or it may be reduced to a highly sinterable metal powder, as was done with the copper. The freeze dried powders have an extremely high surface area and a low die fill density, yet, sinter at low temperature to a high final density.

\section{Process/Milling}

Conventional powder preparation processes were used to improve the homogeneity of the cermet powder and to determine whether or not comminution would improve sinterability. Tubular bending (TB) is a process amenable to the as received (AR) spray dried oxide granules. This shaker-mixer provides a three dimensional motion that uniformly mixes the powders while maintaining the integrity and flowability of the granules.

In some tests, vibratory milling (vm) was used to increase reactivity and disperse the copper in the oxide particles before consolidation. Normally this would be done before the final spray-dry granulation. In this case, the procedure was reversed, since, the spray dried powder was available, but a spray dryer was not. The high energy vibration milling was done with close $\operatorname{pack}(\sim 80 \%), \frac{1}{2} "$ steel balls either dry, (D), or wet, $(W)$, as indicated on the spreadsheet. The data indiate that the vibratory milling may result in increased density, or a reduction of sintering time or temperature. Vibratory 
milling was also effective in obtaining mechanical alloying of the metals used for preparation of anodes having a high metal alloy content.

\section{Sintering}

Sintering information shown on the spreadsheet includes temperature in degrees Celsius, partial pressure of oxygen (ppm) and time in hours ( $h$ ) indicting soak time at the sintering temperature. These parameters were selected based on experience and the results of processing of powders on previous runs. In some cases, sintering information was recorded "as run" due to some malfunctions in the furnace temperature cycle program. In early test runs the $\mathrm{O}_{2}$ level during sintering was difficult to control, and the sample anodes often had excessive reduction or oxidation. These runs are marked "scrap" under comments.

The heating and cooling rates are not shown on the spreadsheet. However, a general pattern was established for the small anode samples as a result of Thermal Gravimetric Analysis (TGA) studies conducted early in the fabrication development program. Figure 12 is a sample TGA plot. The following comments relate to the TGA plot:

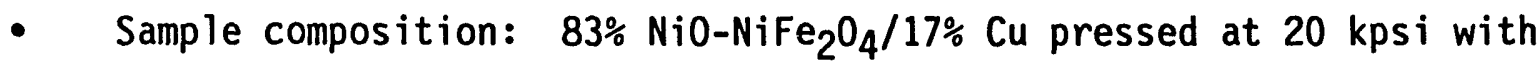
dimensions 0.2515 in. dia $\times 0.468 \mathrm{in}$. long. Sample weight was 1.3672 grams and the density was $3.59 \mathrm{~g} / \mathrm{cm}^{3}$.

- Total weight loss was $3.8 \%$, similar to other results obtained using the first oxide powder lot. However, in using later lots, the weight loss increased as much as an additional $2 \%$ (see Table 2, Runs $99 \& 100)$.

- The TGA curve shows a continuous weight loss at the $1^{\circ} \mathrm{C} / \mathrm{min}$. heating rate. Three somewhat linear slopes are identifiable: 1) Ambient to $300^{\circ} \mathrm{C}$ with $10 \%$ 10ss; 2) $300^{\circ} \mathrm{C}$ to $400^{\circ} \mathrm{C}$ with $\sim 50 \%$ additional weightloss; and 3 ) weight loss complete at $630^{\circ} \mathrm{C}$.

- In another TGA run, the sample was held overnight, 16 hours, at $375^{\circ} \mathrm{C}$ and a $73 \%$ weight loss resulted. However, a final temperature of $630^{\circ} \mathrm{C}$ was necessary to obtain further weight loss. 


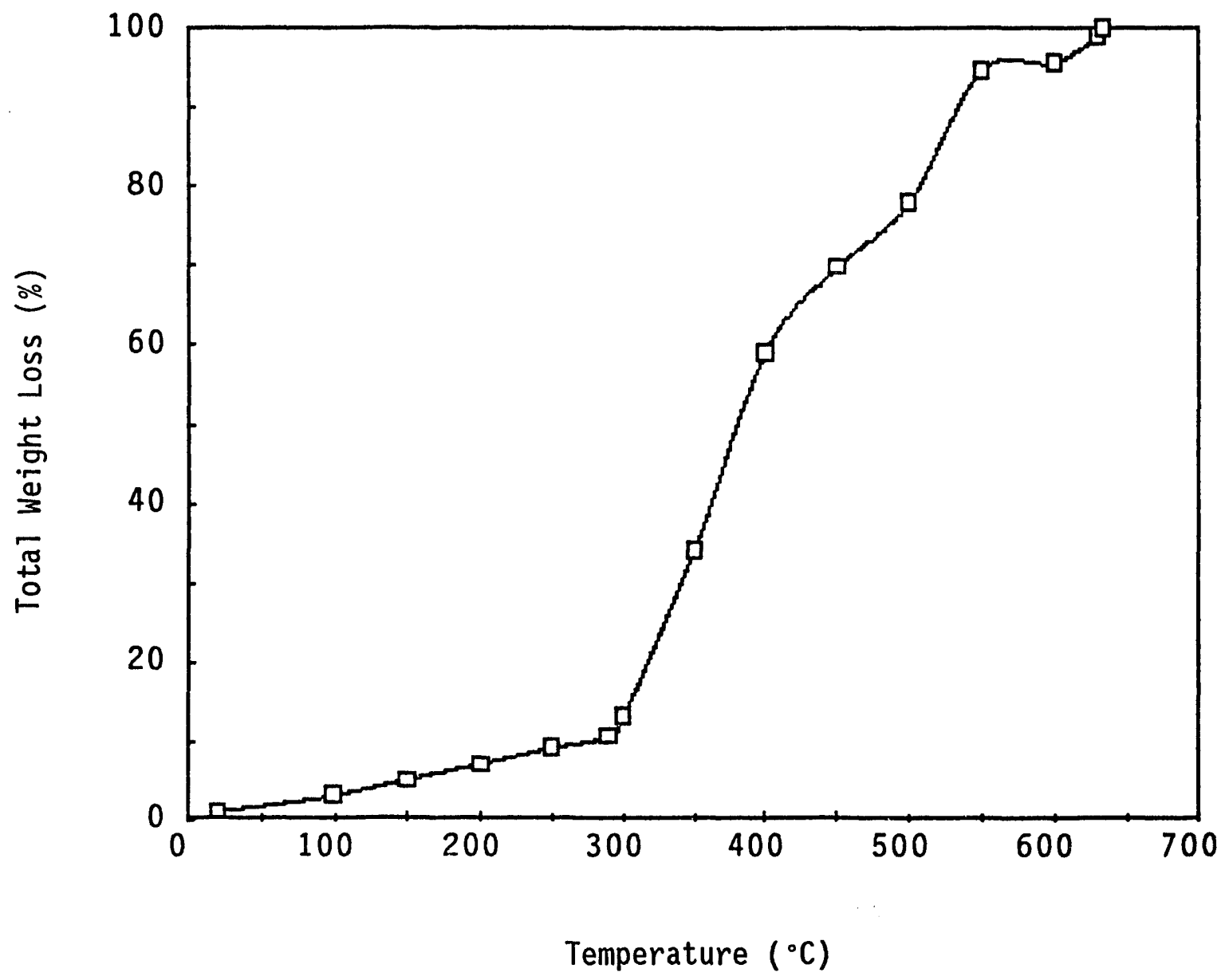

FIGURE 12. Weight loss during sintering of an $83 \mathrm{wt} \%$ $\mathrm{NiO}-\mathrm{NiFe}_{2} \mathrm{O}_{4} / 17 \mathrm{wt} \% \mathrm{Cu}$ Cermet sample. The sample was sintered in an argon atmosphere which contained $200 \mathrm{ppm} \mathrm{O}_{2}$. The sample was heated to $1000^{\circ} \mathrm{C}$ at $1^{\circ} \mathrm{C} / \mathrm{min}$, held at $1000^{\circ} \mathrm{C}$ for $2 \mathrm{~h}$, and allowed to furnace cool. The final density was $6.1 \mathrm{~g} / \mathrm{cm}$, and the total weight loss observed was $3.8 \%$. 
- These results suggest that a slower heating rate is desirable during the first $600^{\circ} \mathrm{C}$ of the cycle. Heating rates as $10 \mathrm{w}$ as $15^{\circ} / \mathrm{h}$ have been used at PNL on larger anodes.

- The TGA results show a final temperature of $1300^{\circ} \mathrm{C}$ to complete the sintering (not shown on the TGA curve). The heating rate was $1^{\circ} \mathrm{C} / \mathrm{min}$. to a temperature of $1000^{\circ} \mathrm{C}$ where it was held in argon containing $200 \mathrm{ppm}$ level of $\mathrm{O}_{2}$. The $\mathrm{O}_{2}$ was then increased to $500 \mathrm{ppm}$ and the sample started gaining weight. $\mathrm{O}_{2}$ was reduced back to 200 $\mathrm{ppm}$ and the weight stayed the same during the $1300^{\circ} \mathrm{C}$ sintering soak period. The sample's $1 \mathrm{mg}$ weight gain was lost on cooling from $1300^{\circ} \mathrm{C}$ to room temperature. The cooling atmosphere was argon with $\sim 20 \mathrm{ppm} 0_{2}$.

- The sample's sintered density, as determined by water immersion, was $6.1 \mathrm{~g} / \mathrm{cm}^{3}$ with very minimum $\mathrm{Cu}$ "bleeding".

- Minimum Cu bleeding can be obtained by maintaining a slow heating rate early in the cycle. The exact rate will be dependent on anode size; heating rates as slow as $15^{\circ} \mathrm{C} / \mathrm{h}$ have been used at $\mathrm{PNL}$. Hold the temperature at $\sim 1075^{\circ} \mathrm{C}$ just below the melting point of copper for a period of time about half that used at the maximum sintering temperature. Then proceed slowly to the sintering temperatute.

\section{Density}

The density of the anode samples is shown both as pressed green density (GD) and final sintered density (SD). The GD is based on precise measurements and calculations. The increase of green density with increasing fabrication pressure is very slight above $20 \mathrm{kpsi}$, see Figure 11. The increase in green density relative to sintered density is a more important correlation. The increase in sintered density (SD) above a fabrication pressure of 20 kpsi, (again see Figure 11) is insignificant. Although it is essential to have adequate fabrication pressure, excessive pressure will either damage the green body, cause damage that shows up during sintering or, at best, result in minor increases in sintered density. The sintered density (SD) determinations shown on this spreadsheet were made by water immersion. 


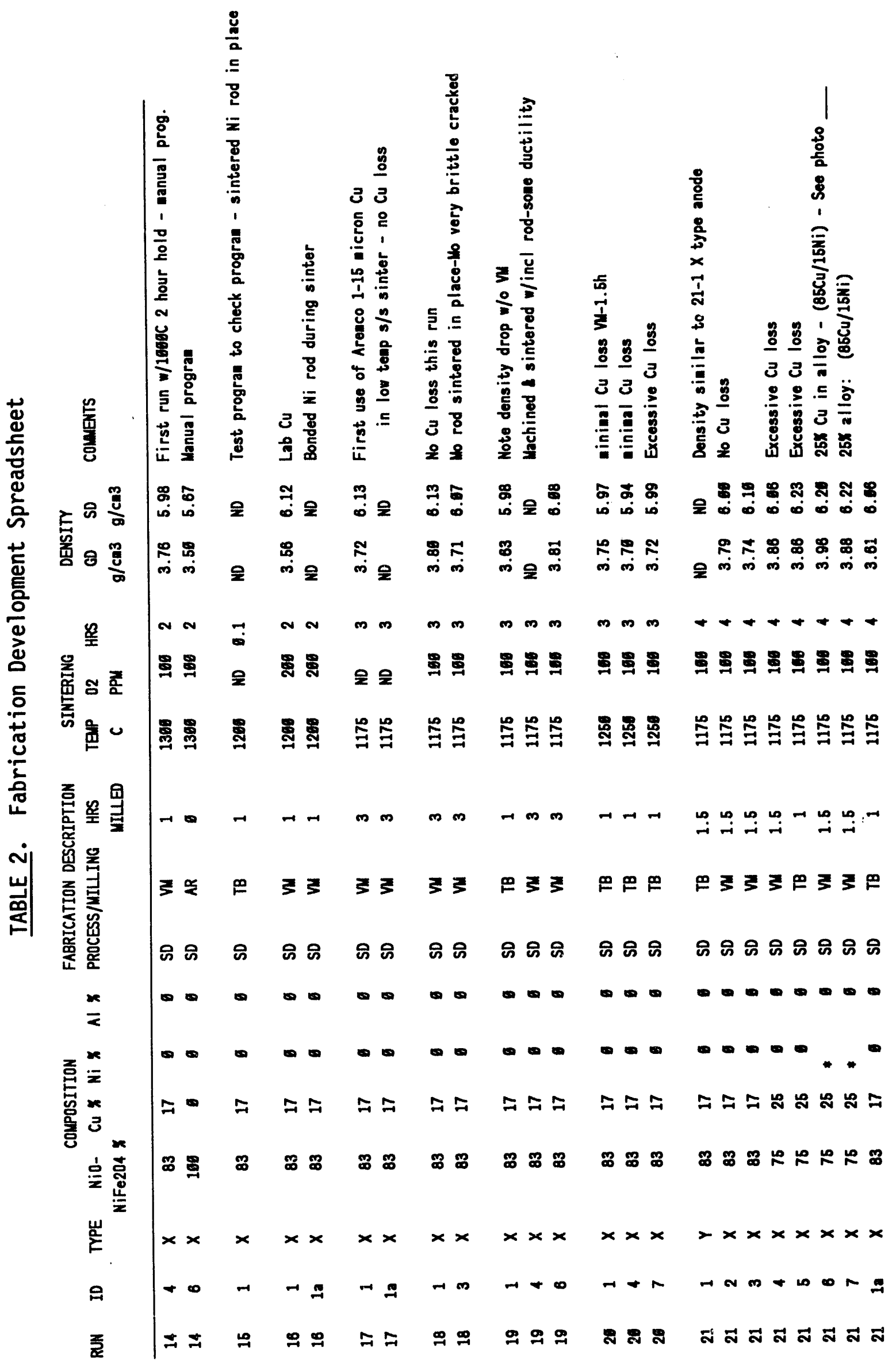




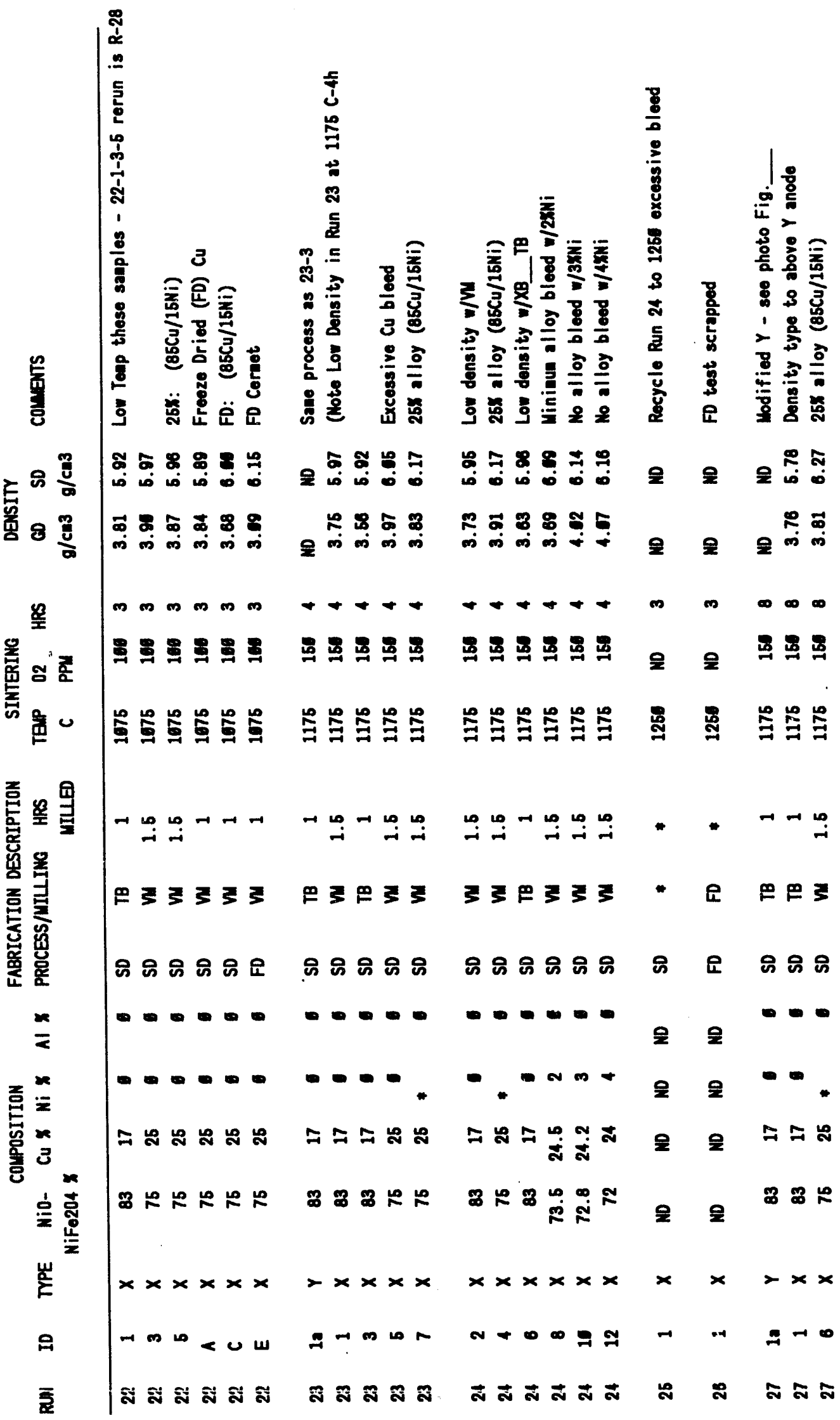




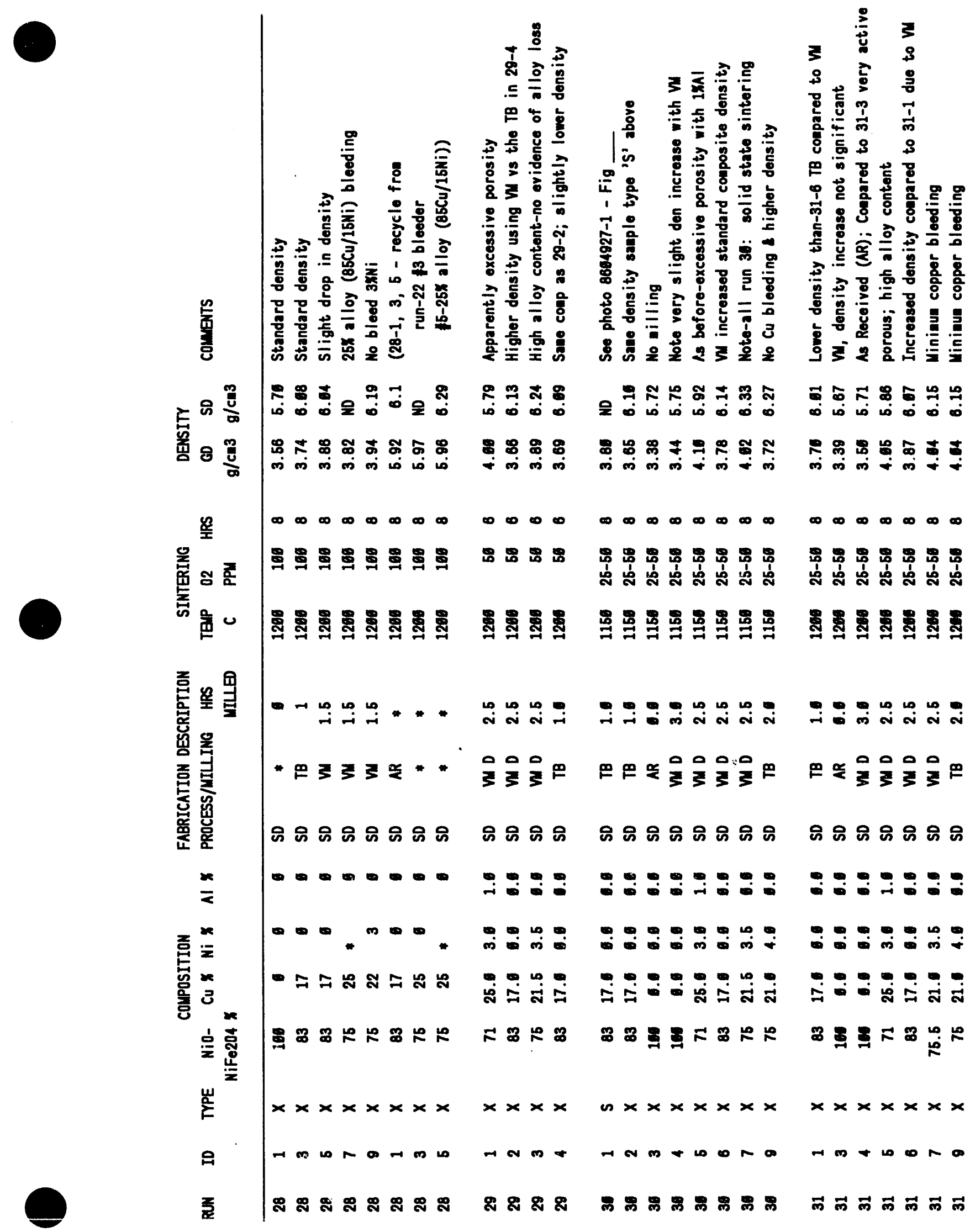




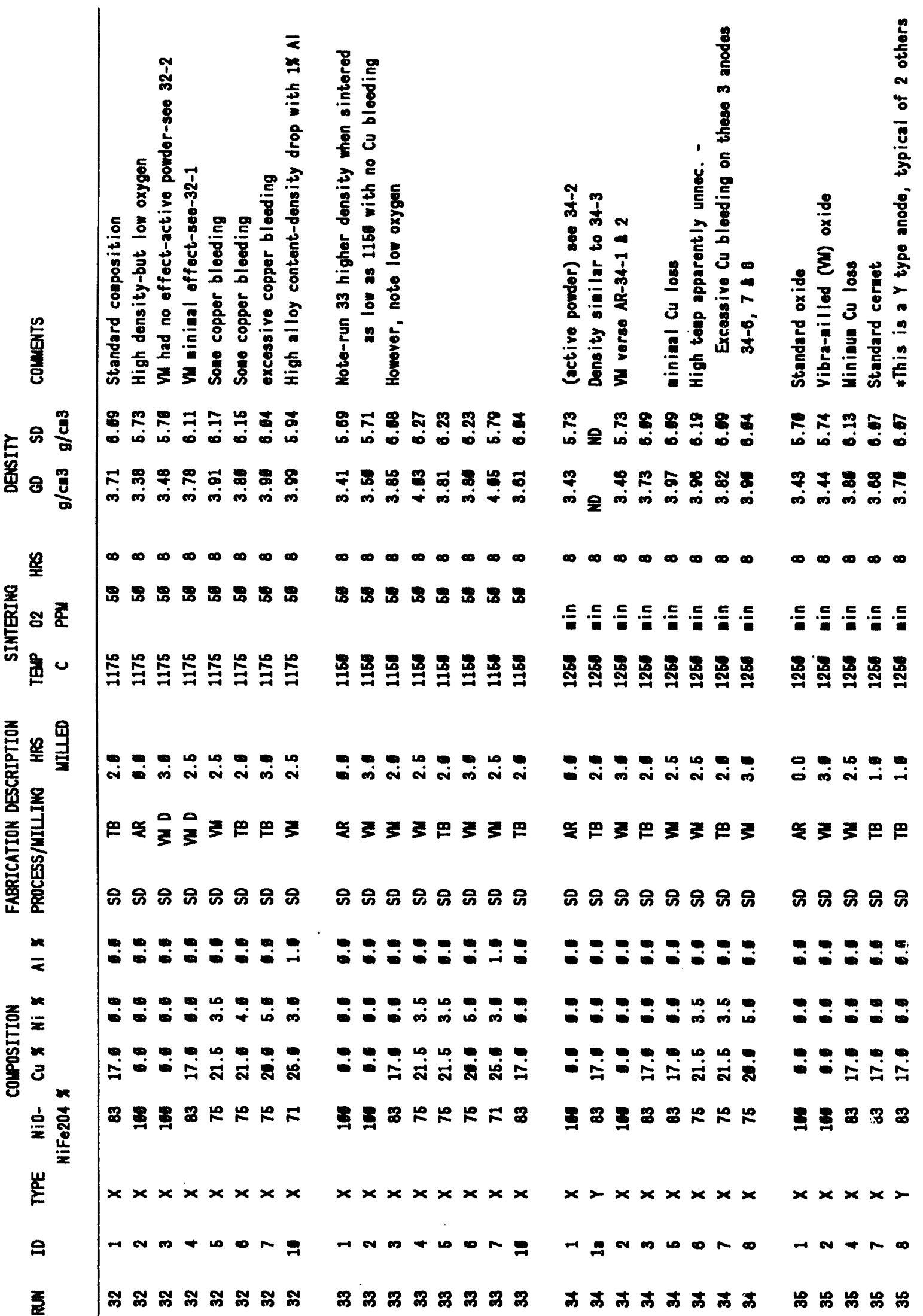


$\frac{8}{8}$

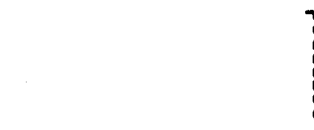

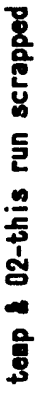

苝

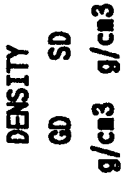

兽

졸

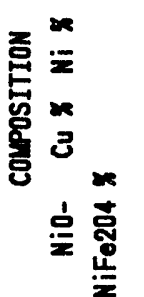

崖

ㅇ

졸

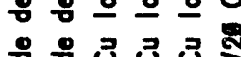

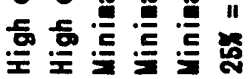

ำ 운 ำำ ำ

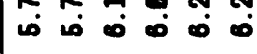

우ㅇㅠㅜ웅

is on in on $\rightarrow$ in

$\infty \infty \infty \infty \infty \infty$

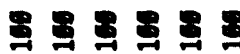

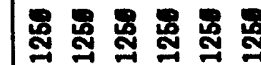

- 0.

ํํำำ

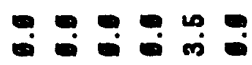

ํ.

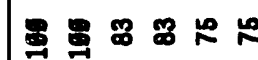

$x \times x \times x \times$

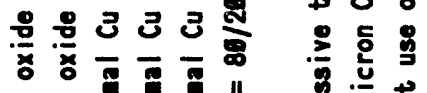

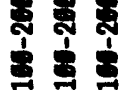

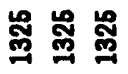

if

$++$

오ำ

$\dot{0}: \frac{1}{i}$

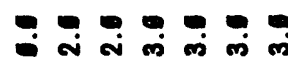

9

ลุ

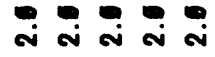

₹ラロ

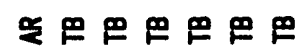

両

ऊิ ติ ถิ

웅ำ

ถิ ถิ ถิ

ำำ:ำ

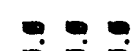

$\div \div \div \div \div$

ํํㄴ

3 $8 \%$

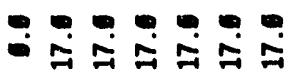

5

ํำ की

$\div \div$

뭉ํำ

$\div \div$

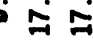

3.

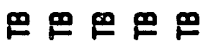

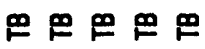

$x \times x$

$x \times x>2>2$

$x \times x$

ติ ติ ติ ติ के

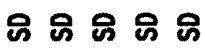

$\div \div \div$

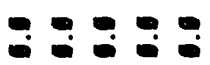

$\div \div \div$

-

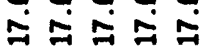

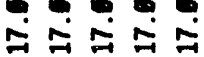

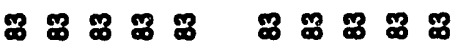

$\ln (x)$

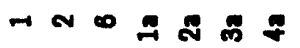

$\rightarrow \infty \infty$

Anmaghnt

㝵品

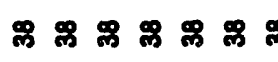

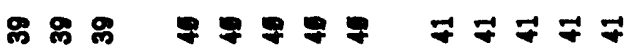




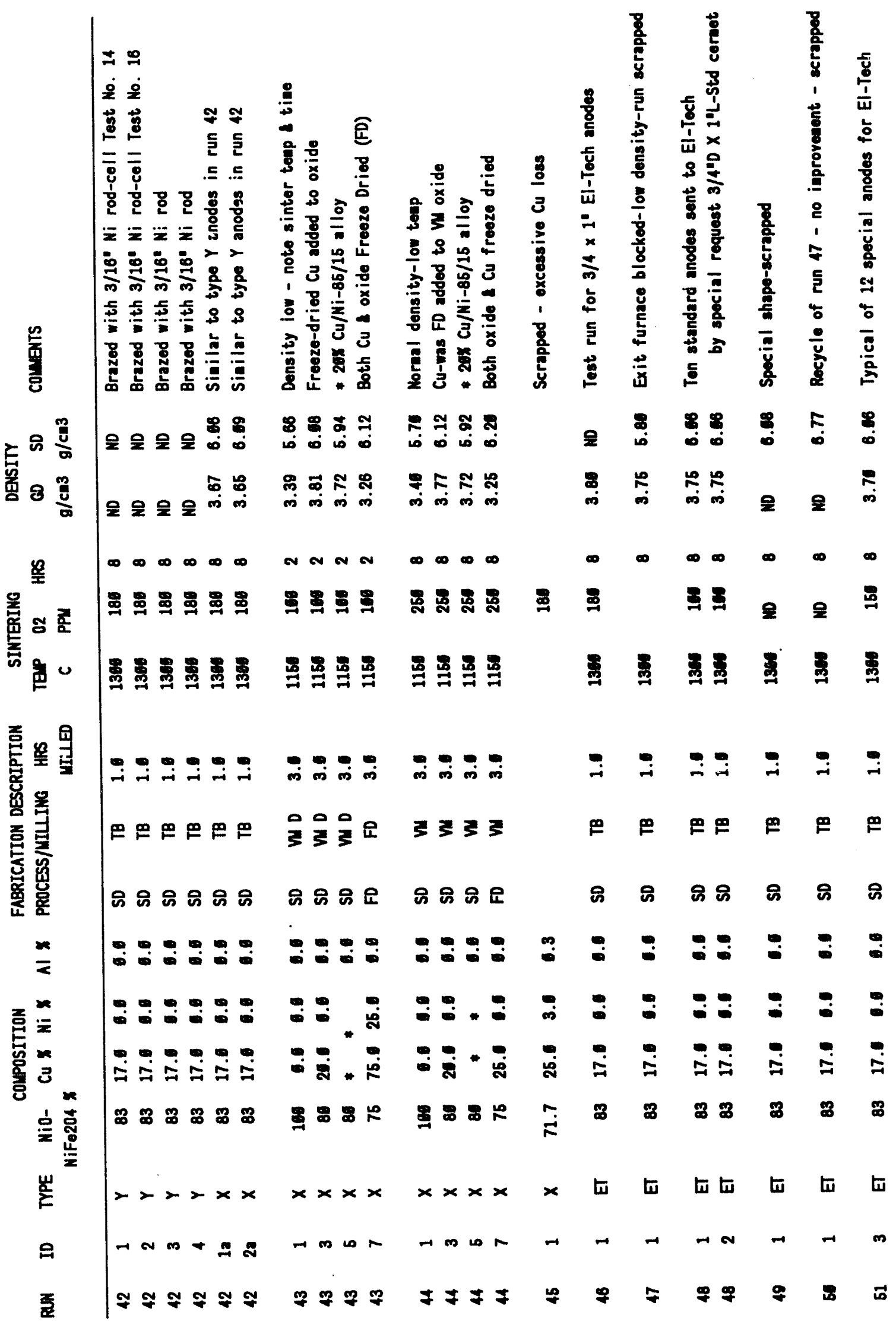




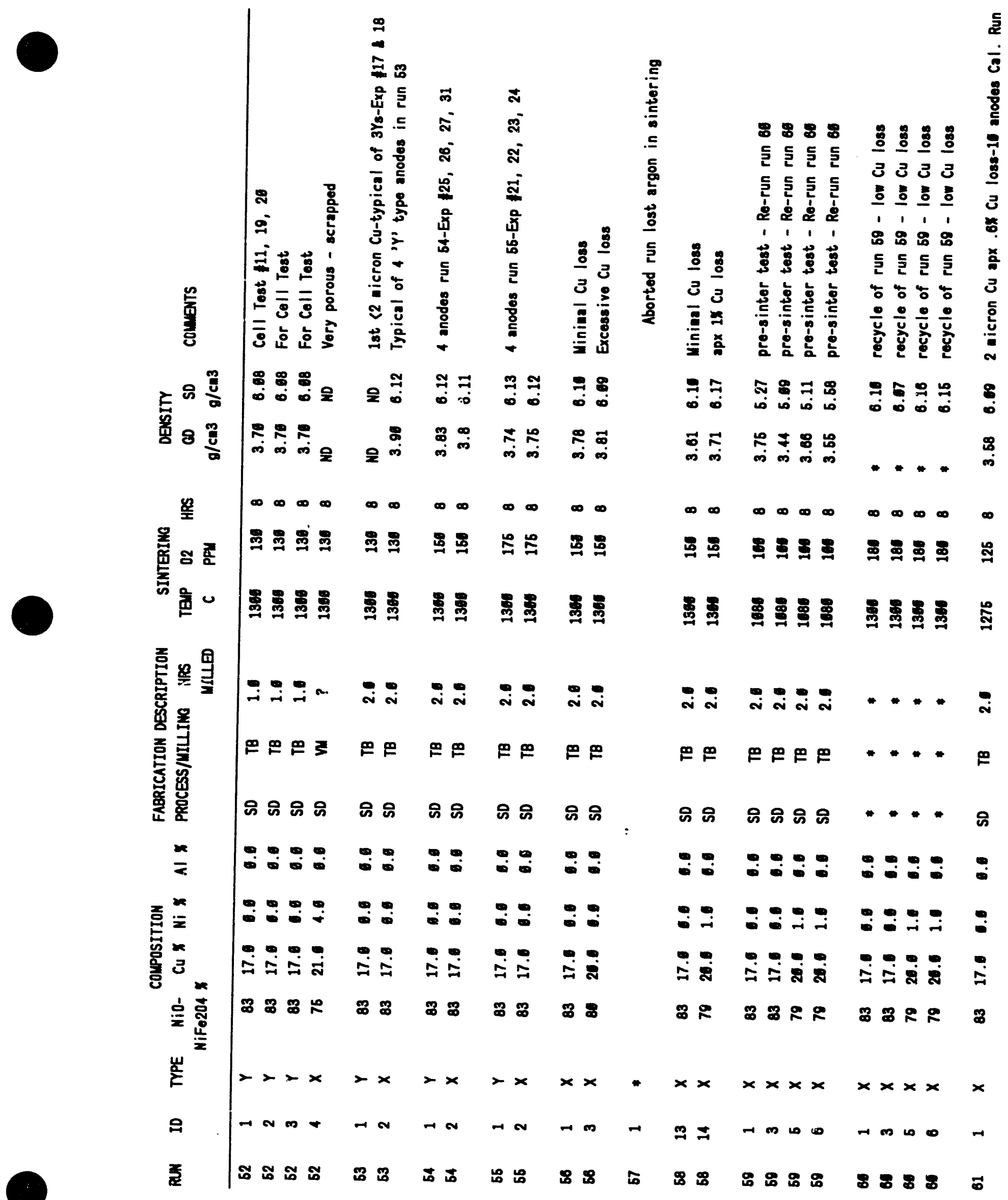




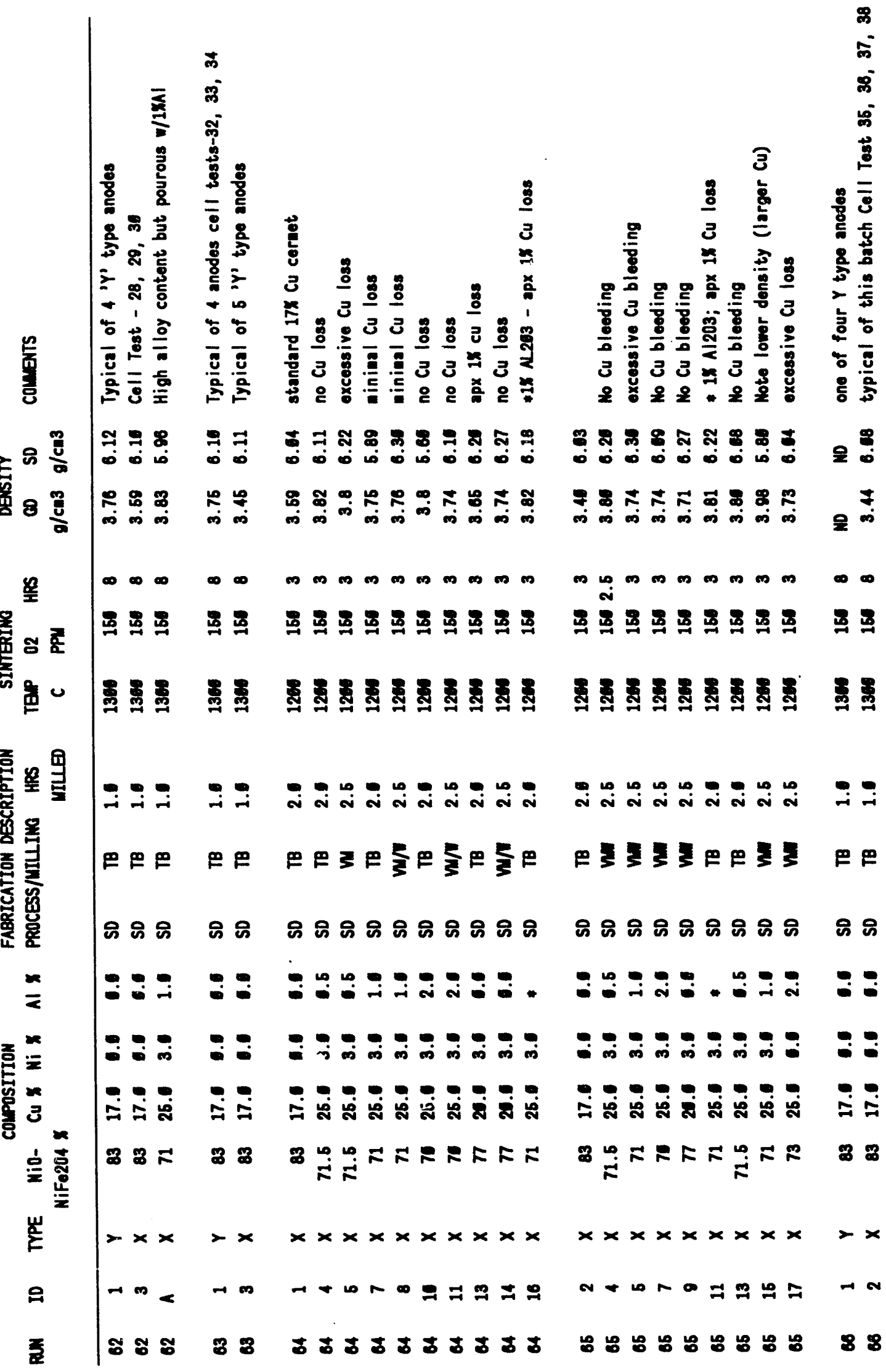




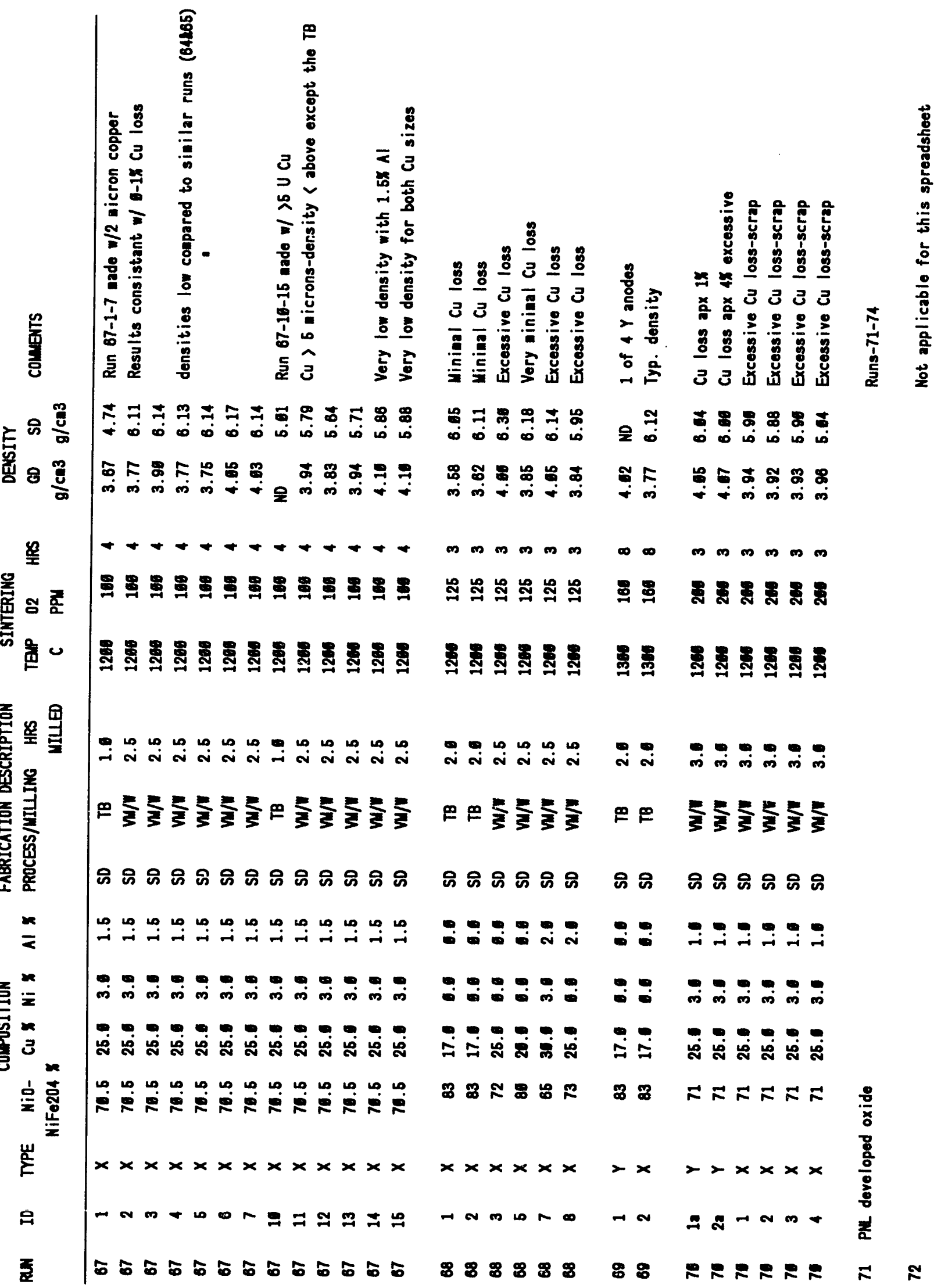




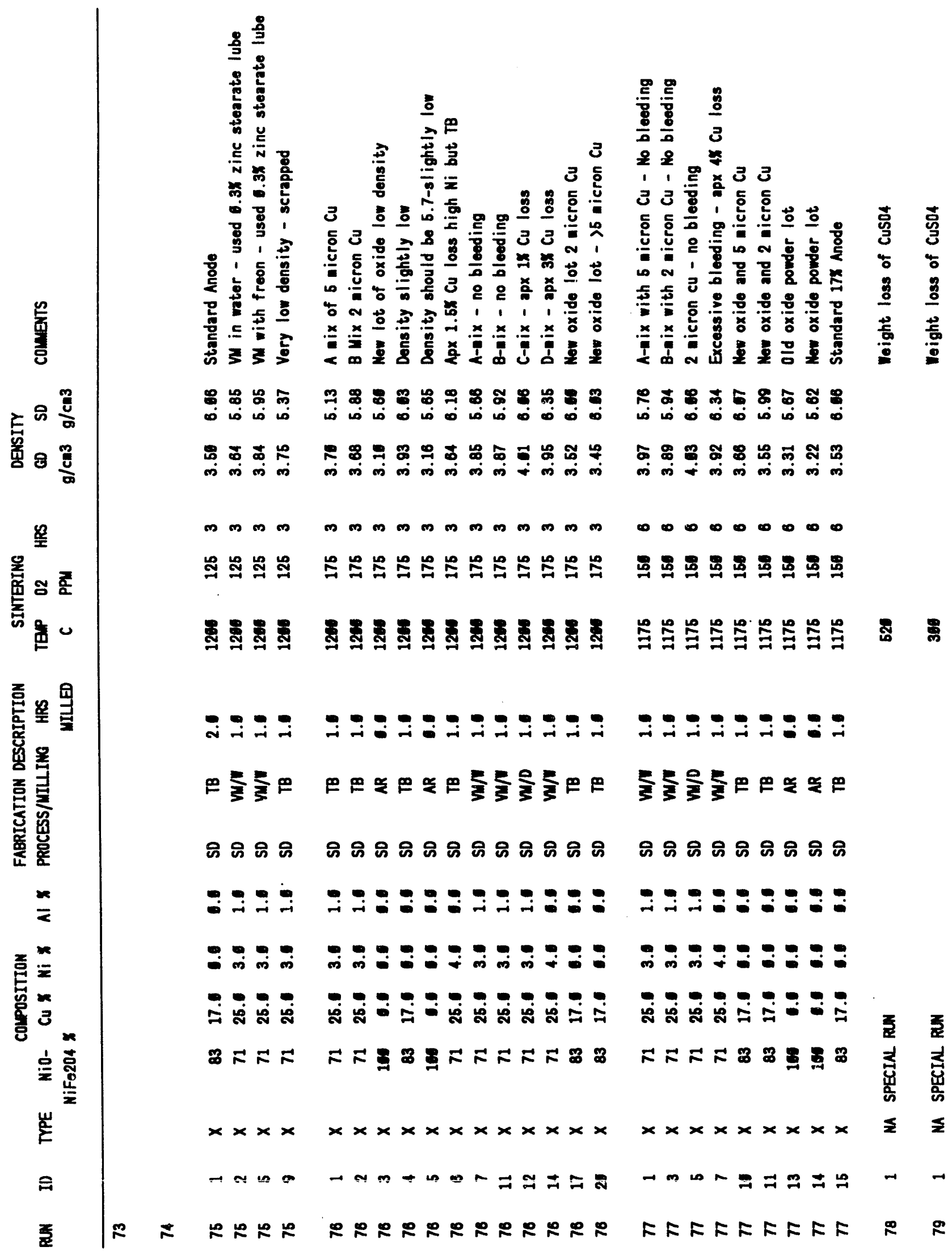




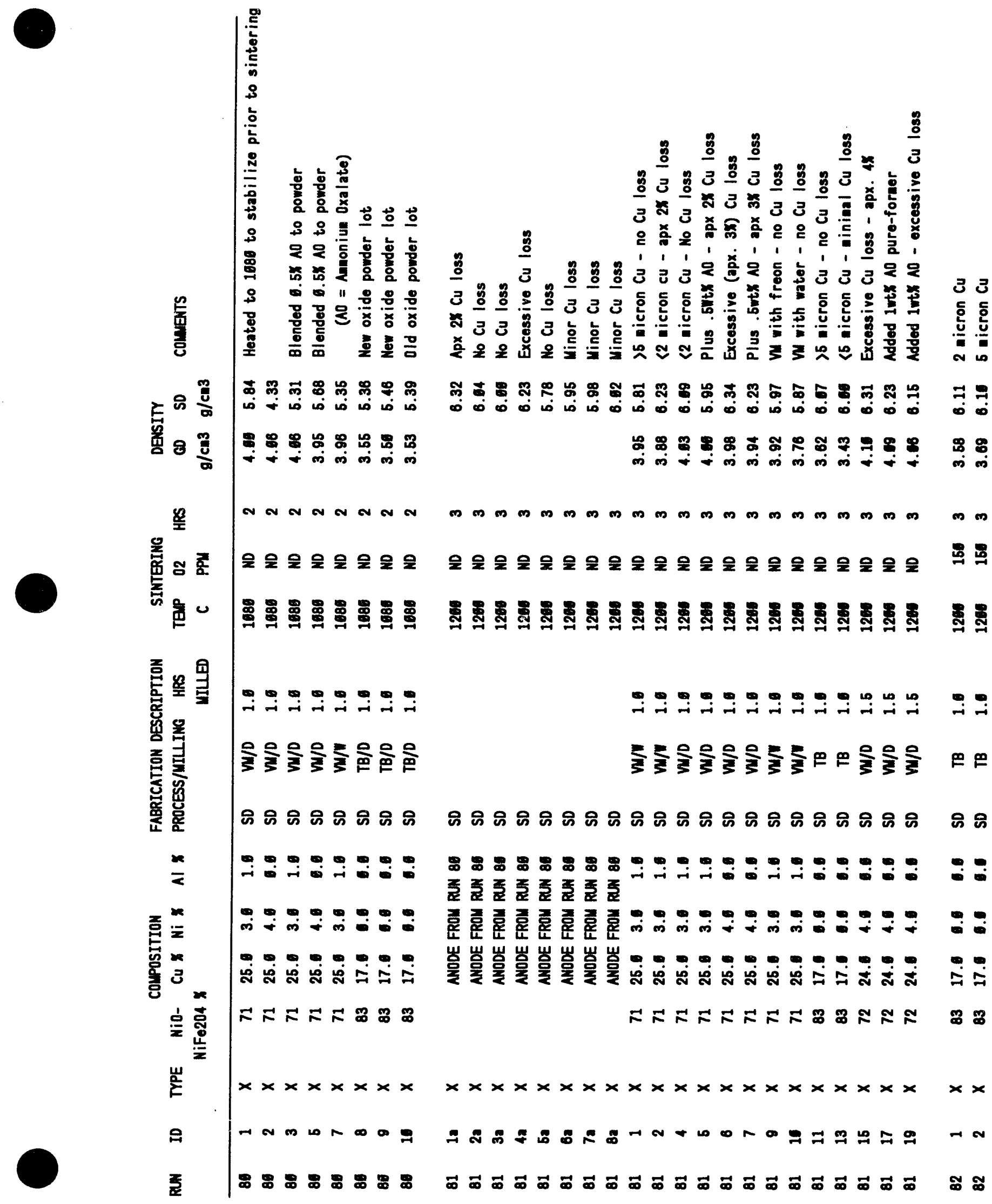




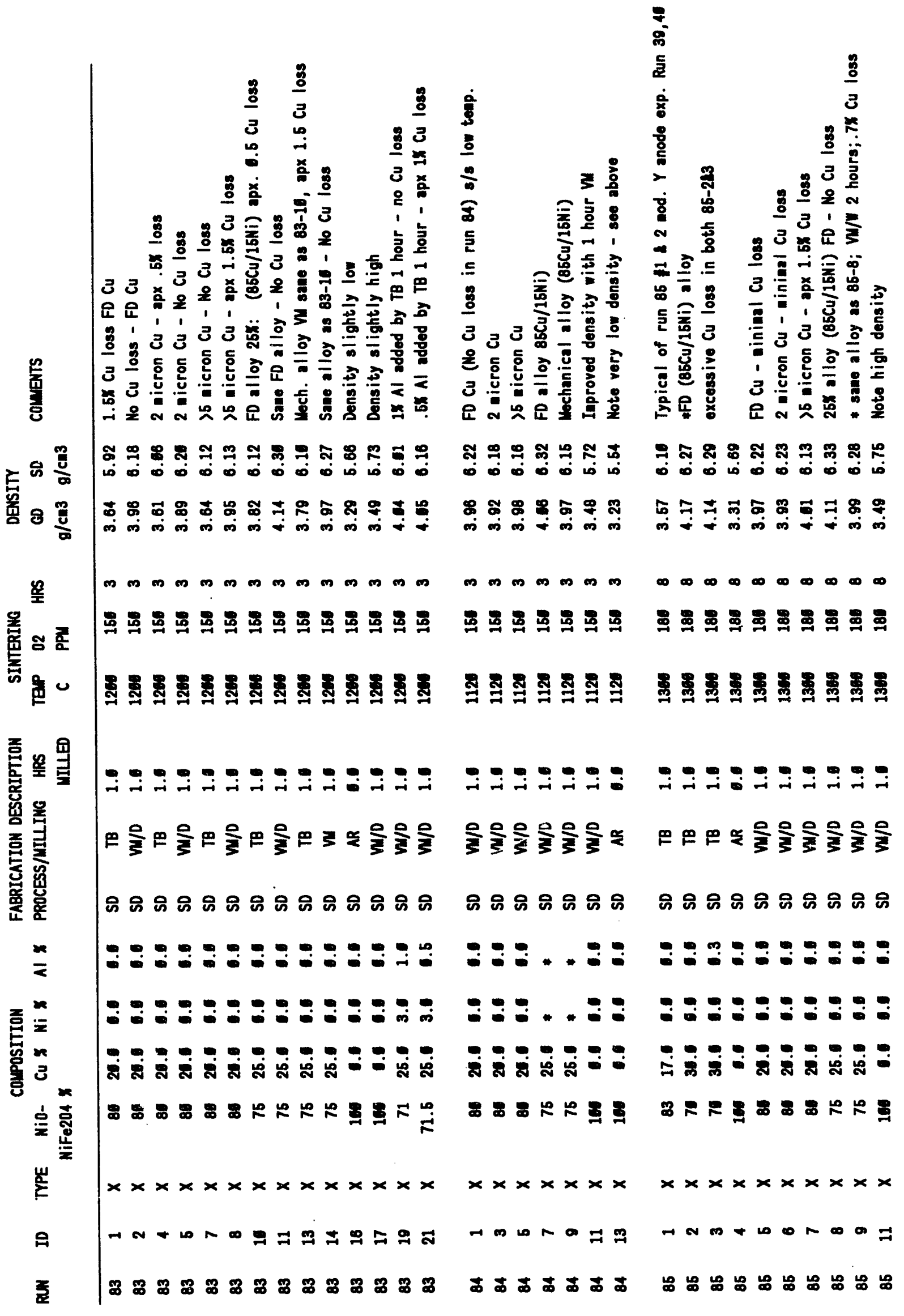




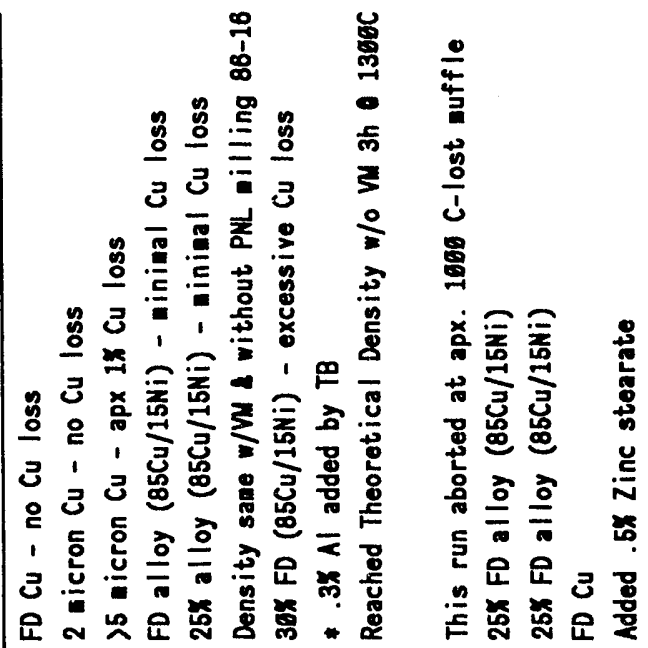

在

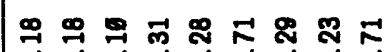
i

ஃ ஃ

कं

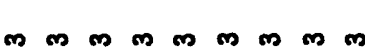

兽

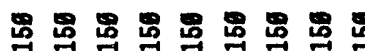

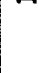

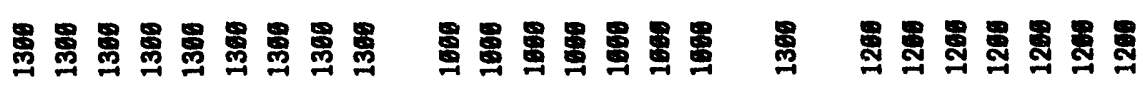

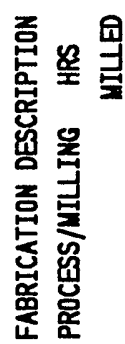

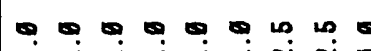

으으으으으으으은

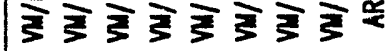

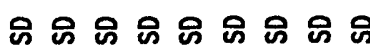

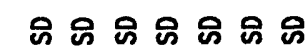

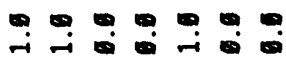

๓

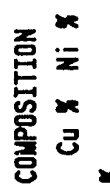

官 竞

䟖

오

굴

0. 000000

๒

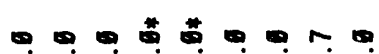

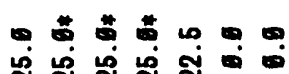

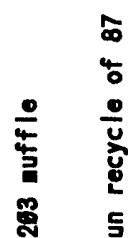

은을우은울울윤

ำ

ช

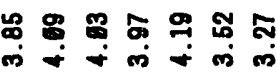

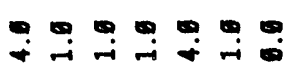

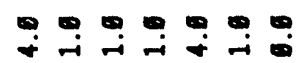

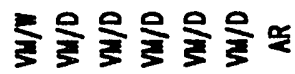

ิ ติ

ન

in

๑) *ี

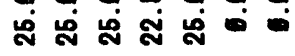

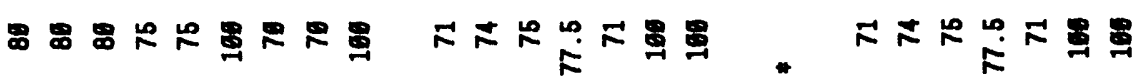

崖

$\times \times \times \times \times \times \times x$

$x \times x \times x \times$

* $\times \times \times \times \times \times \times$

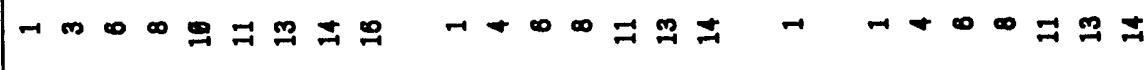

ஜ 


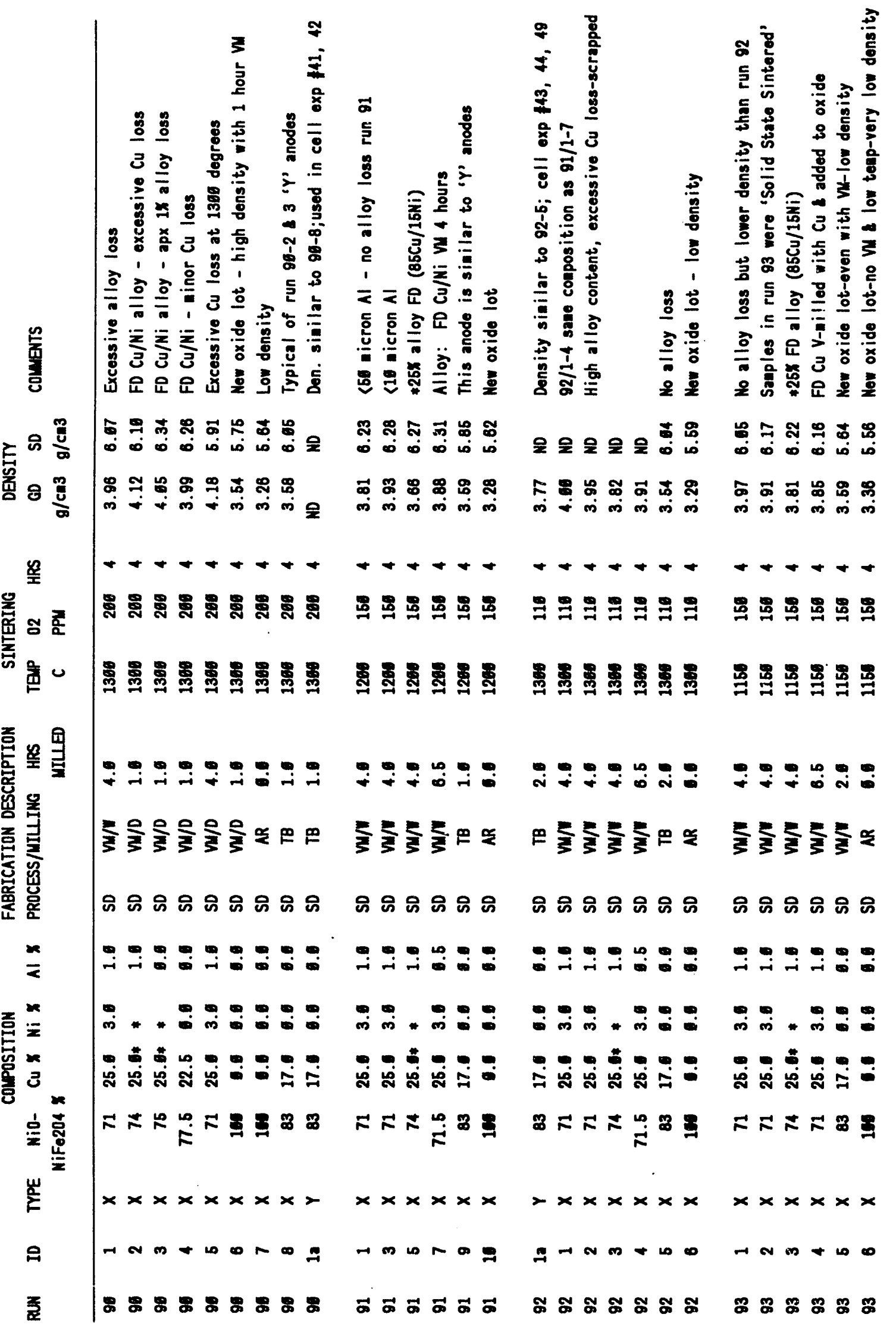




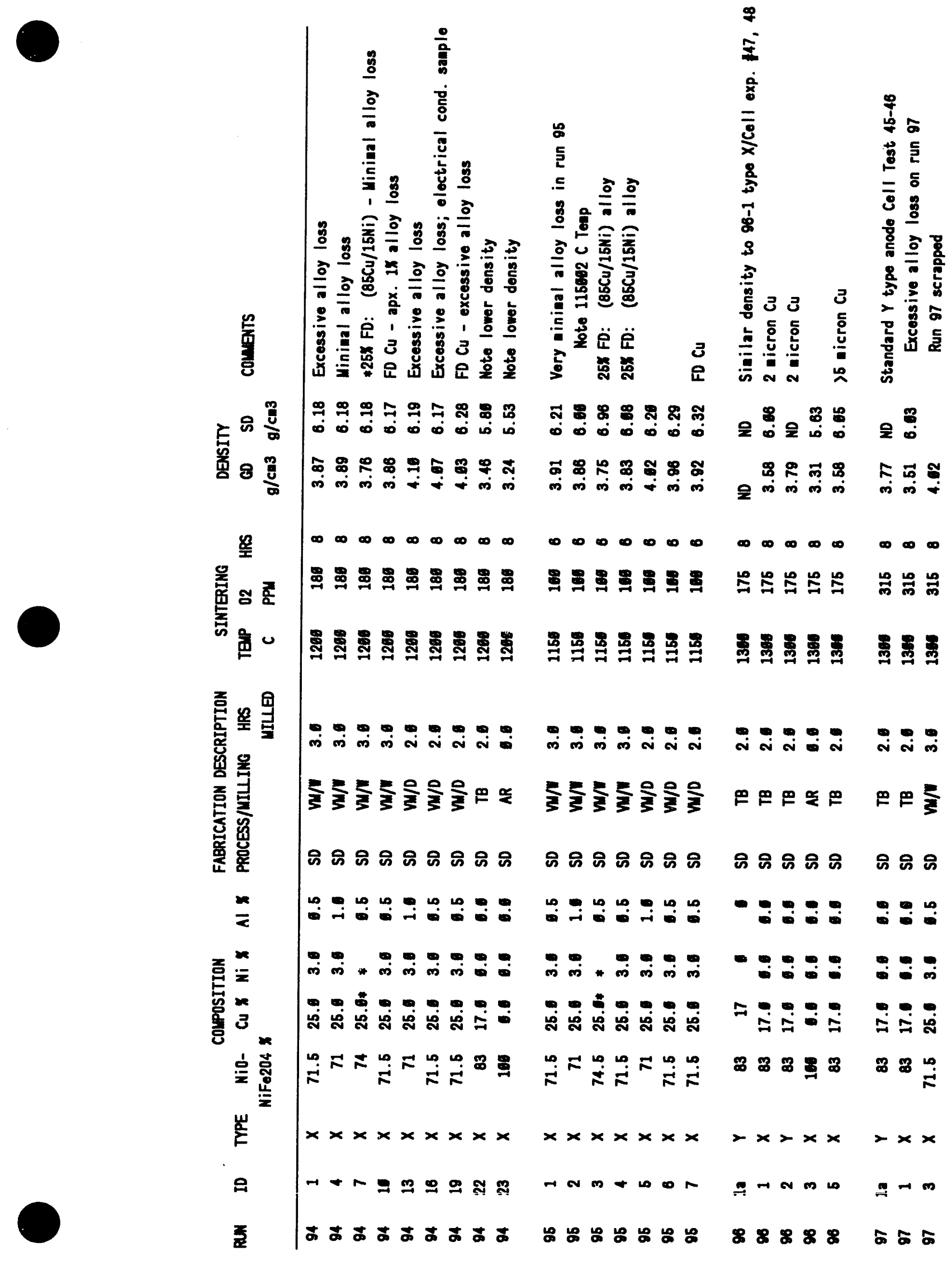




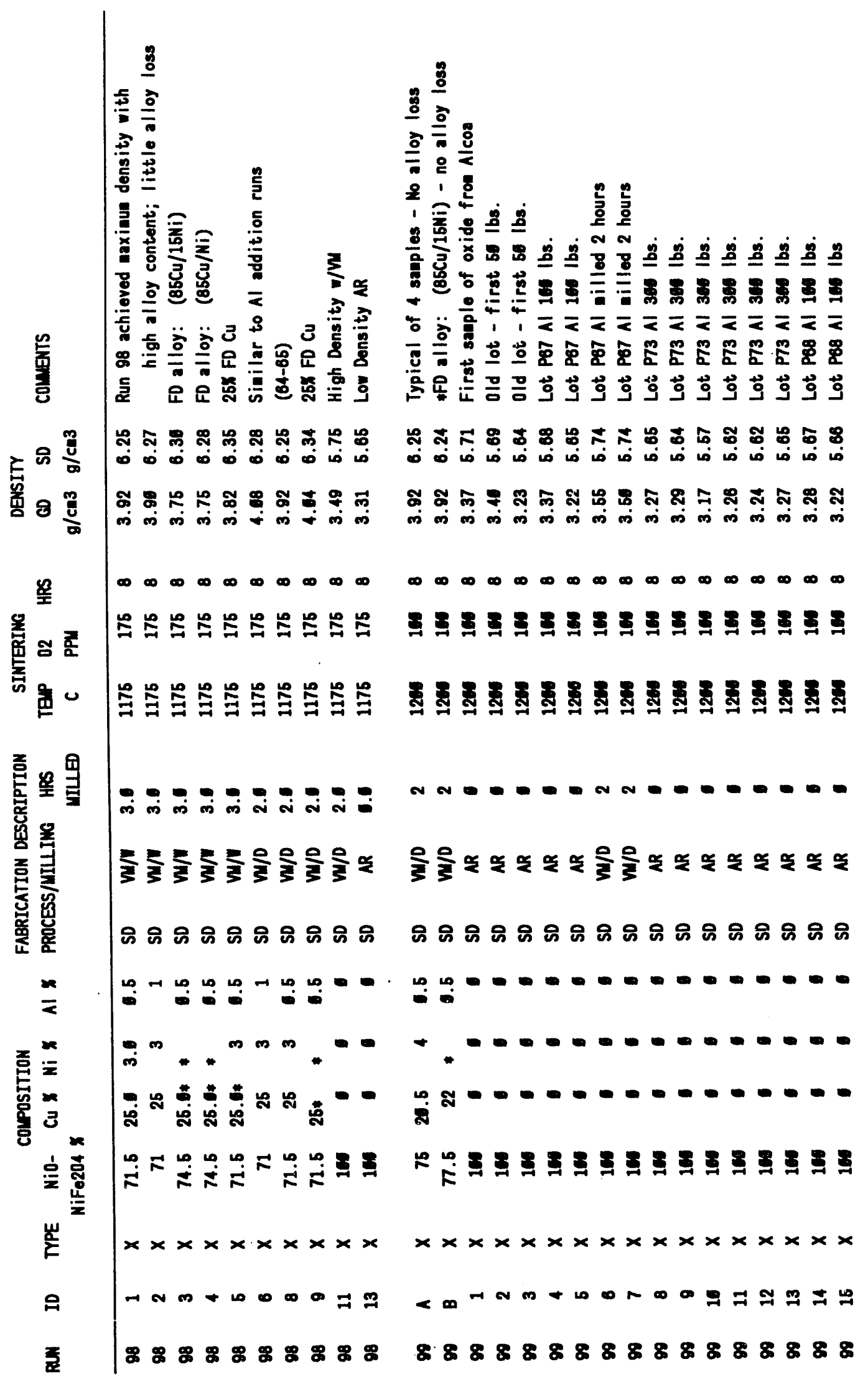




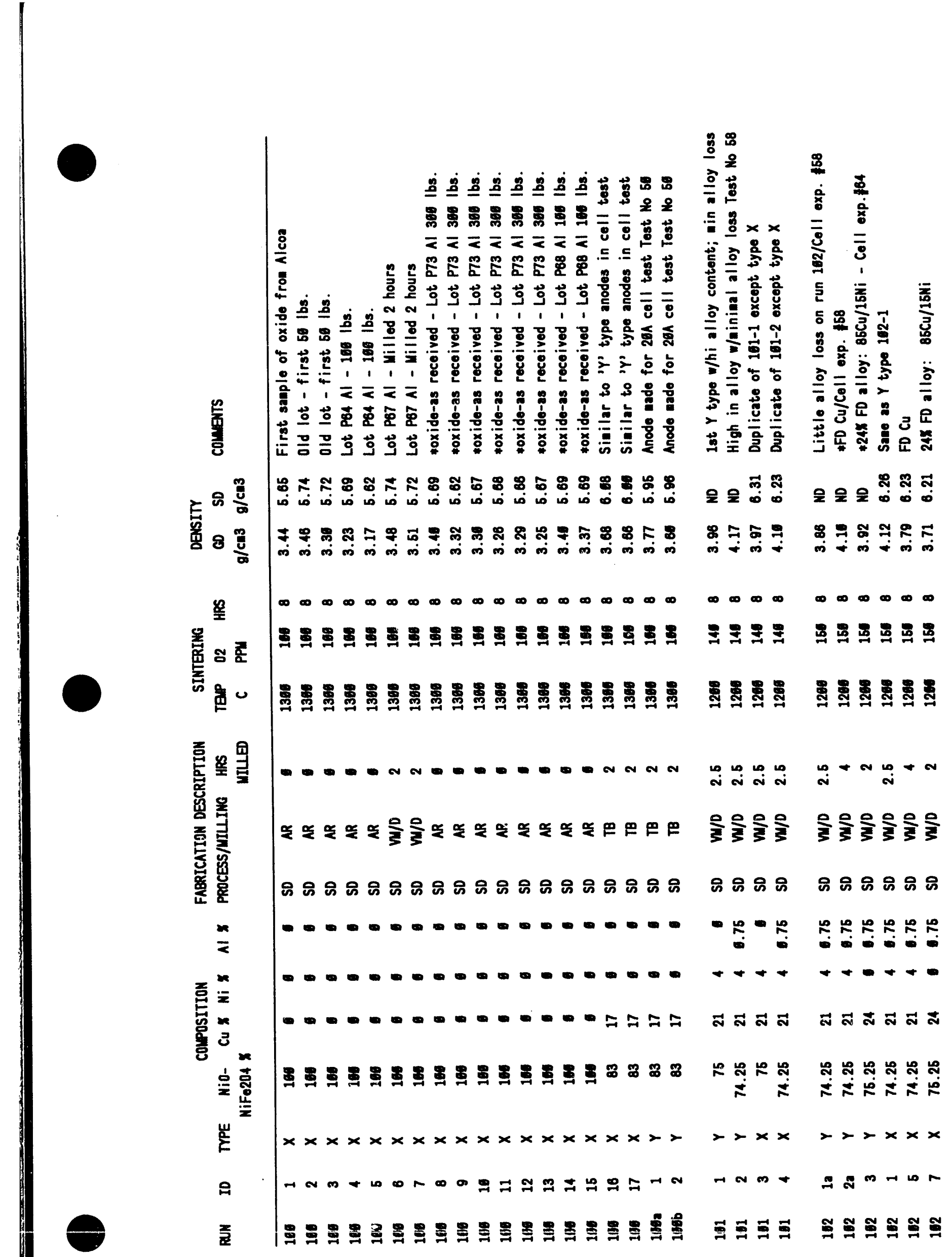




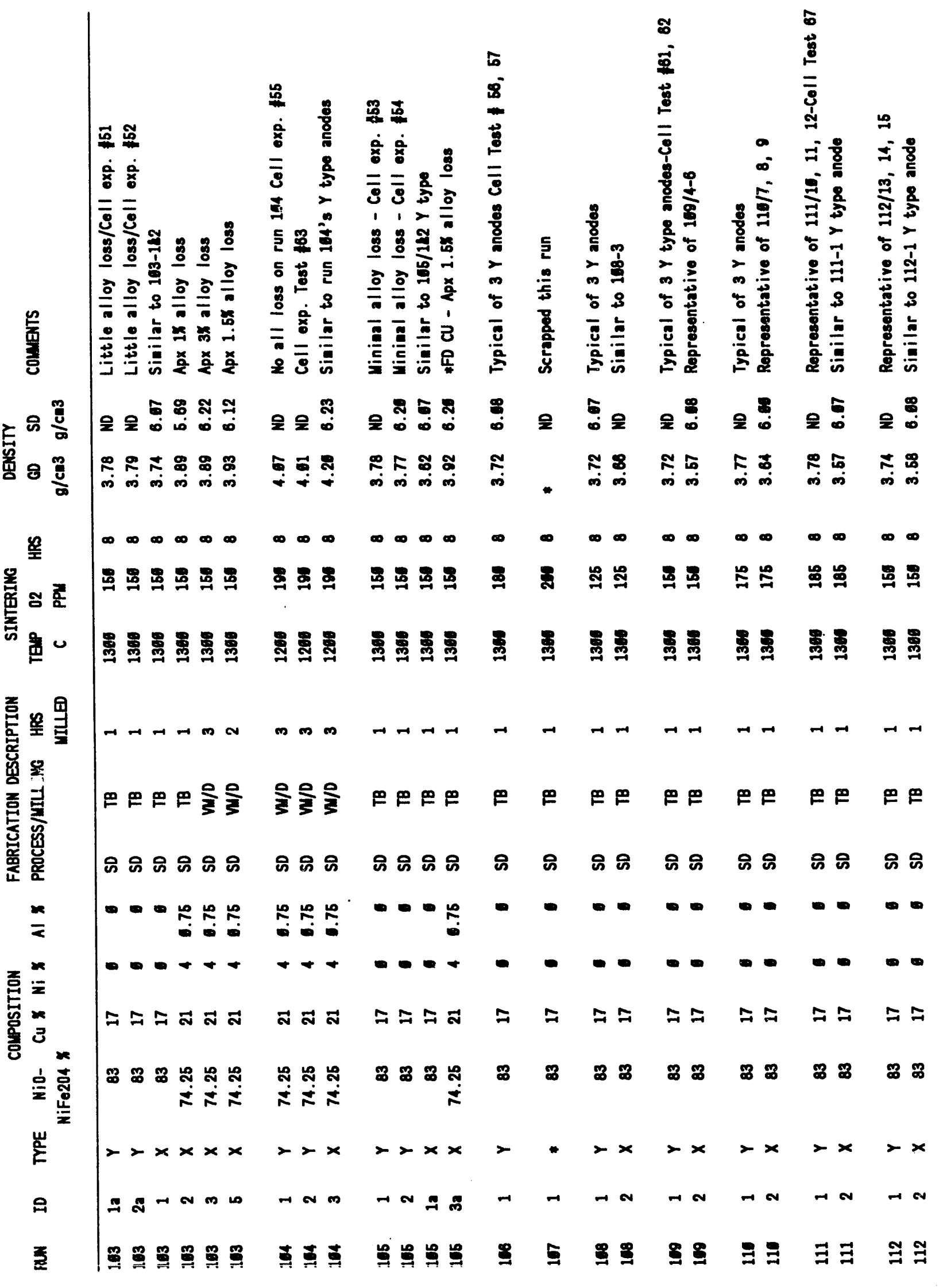




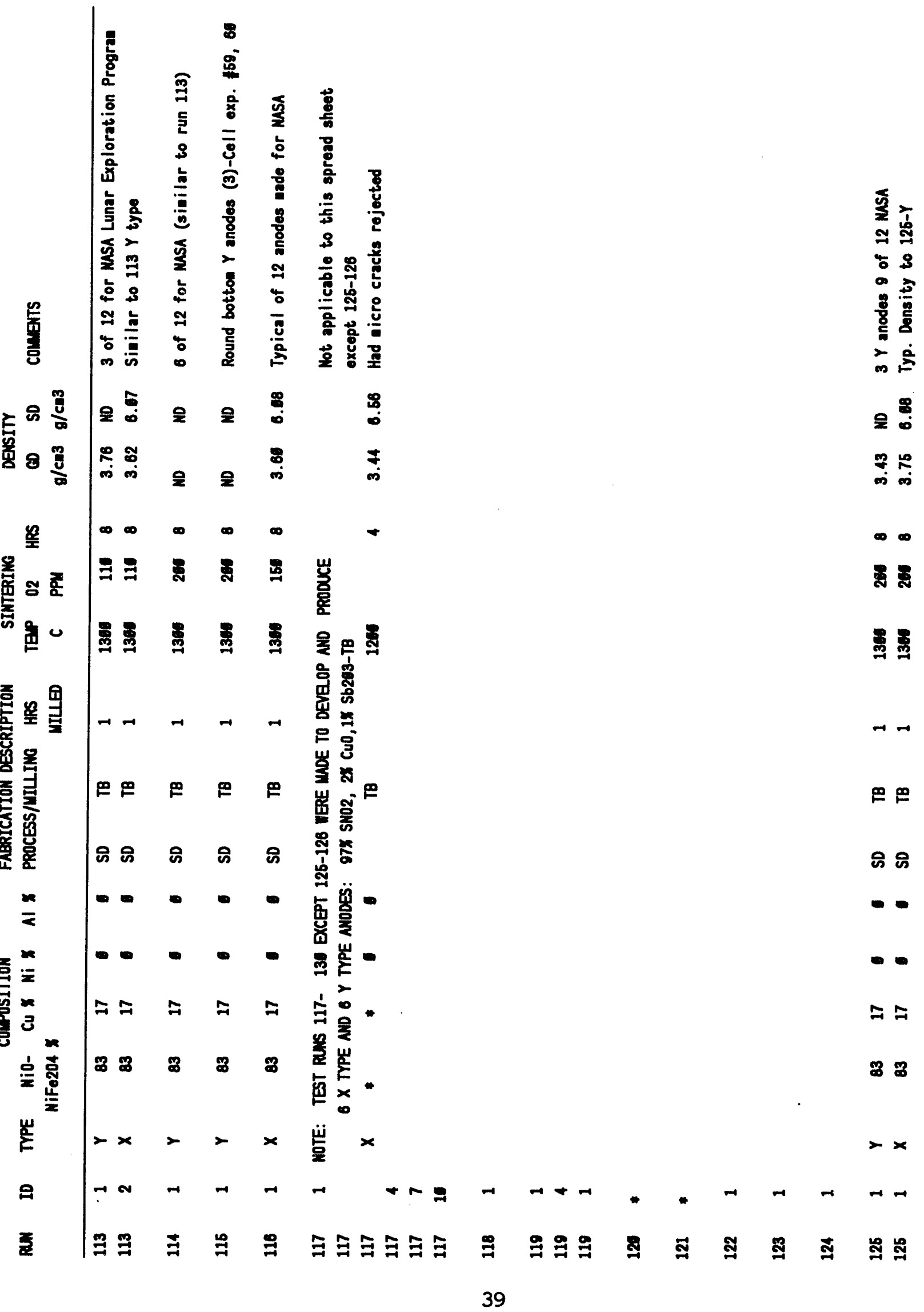




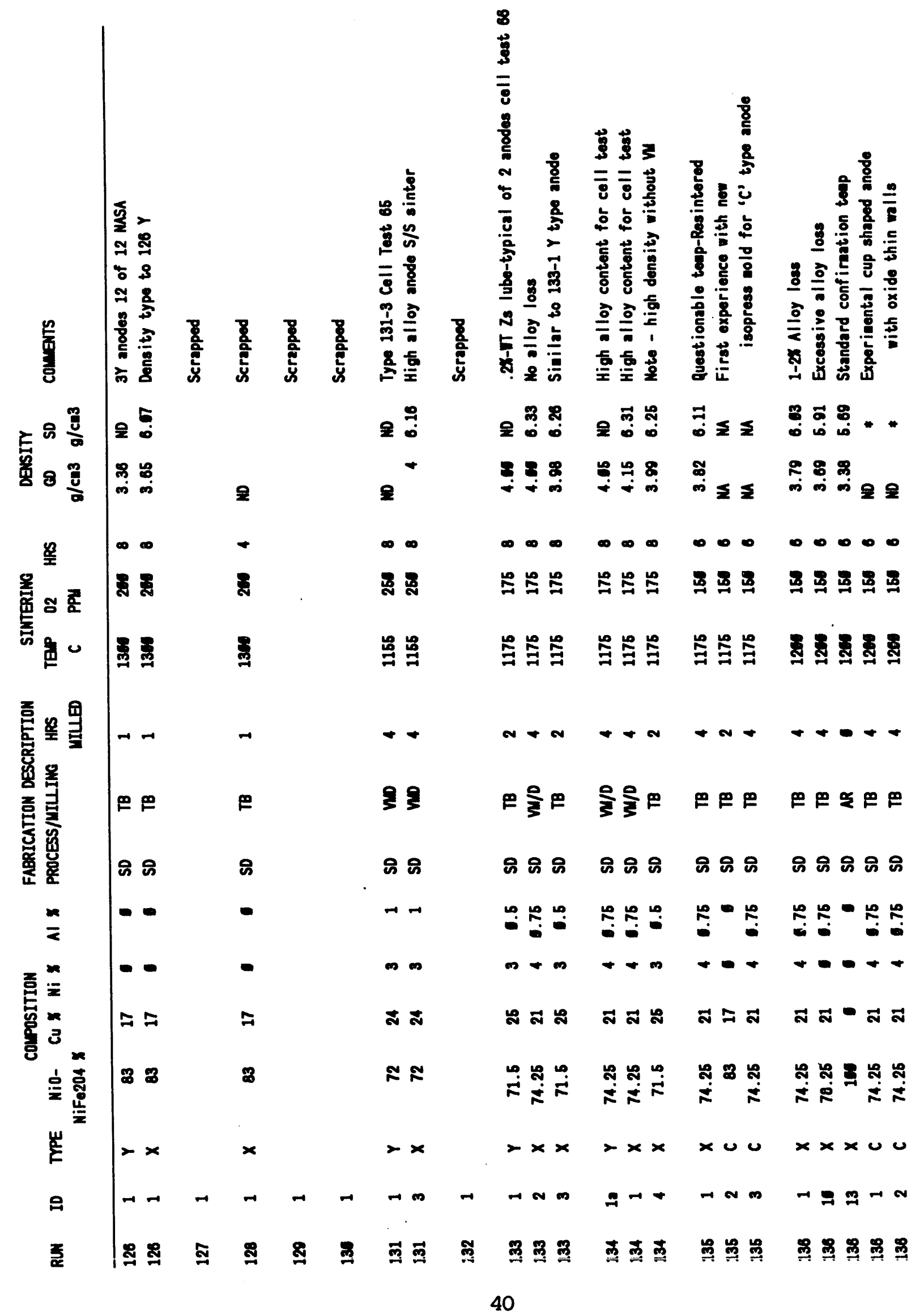



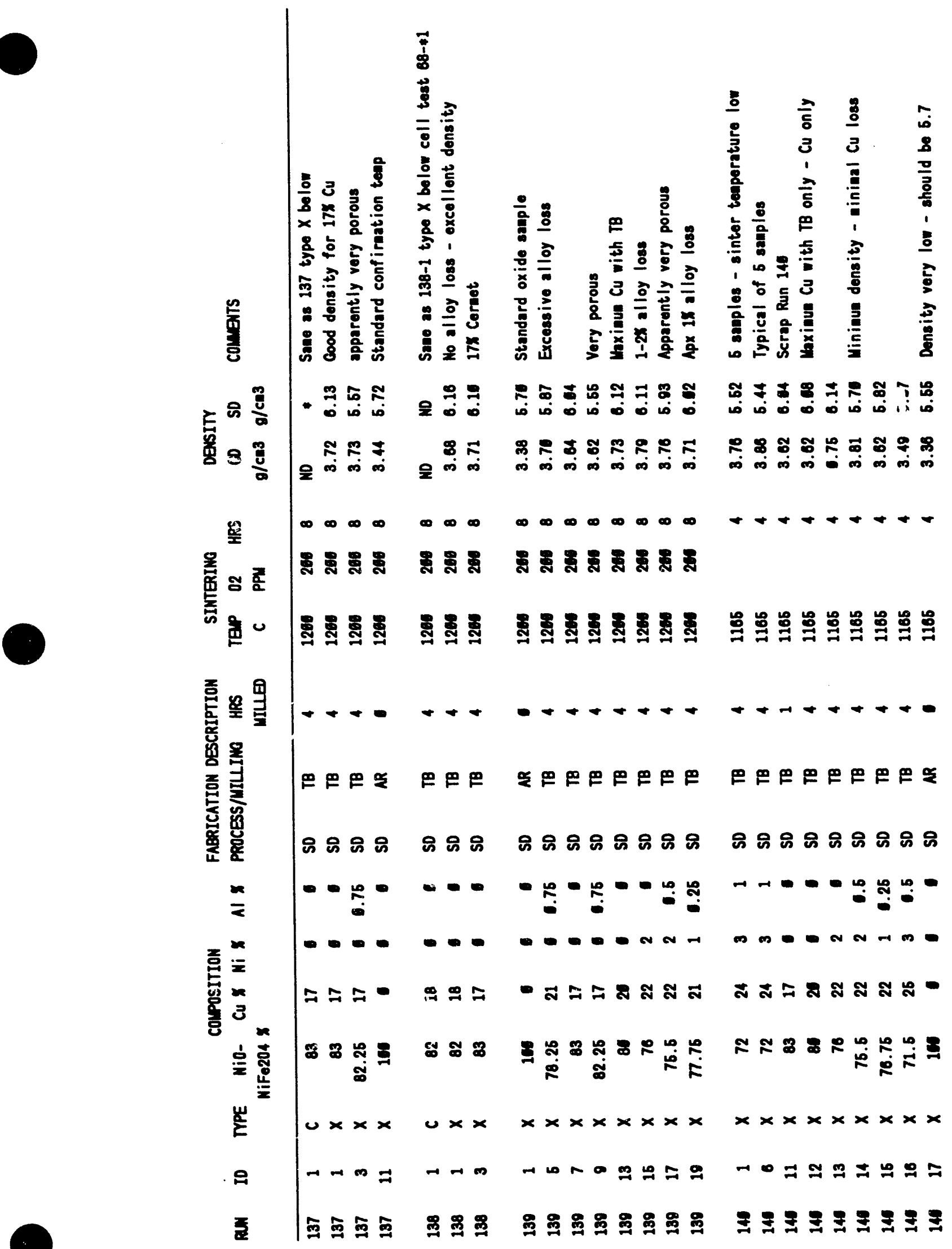


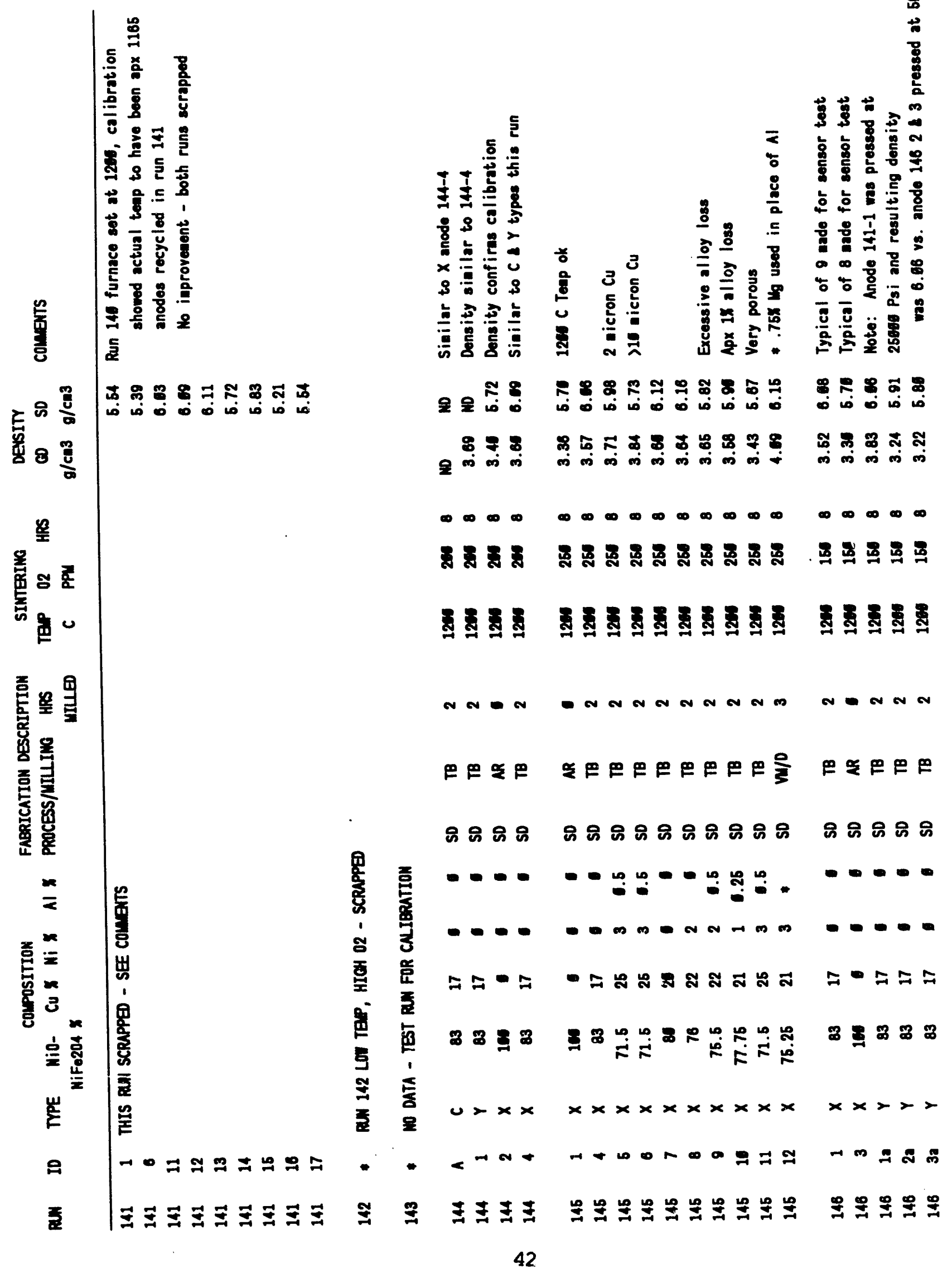




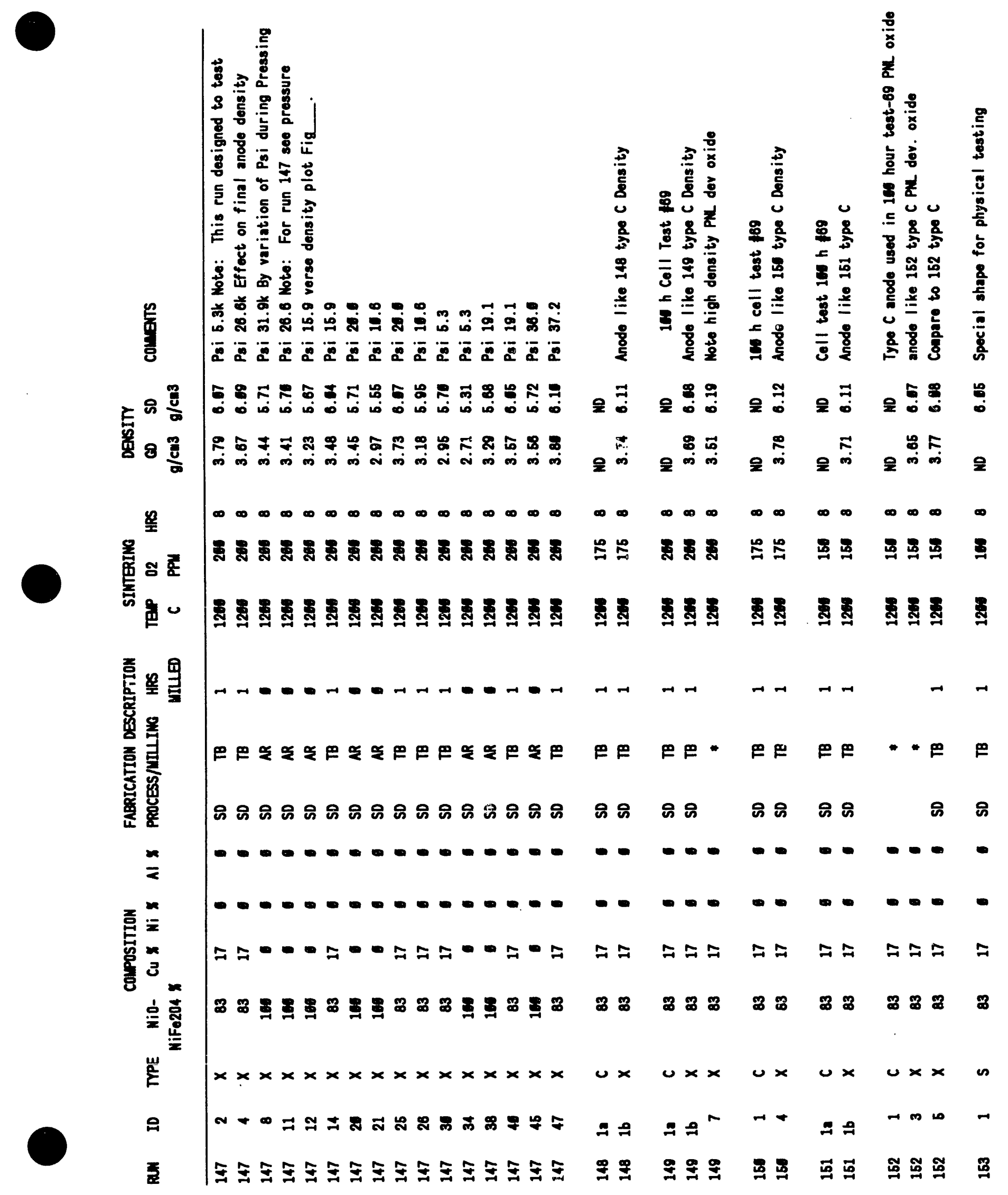




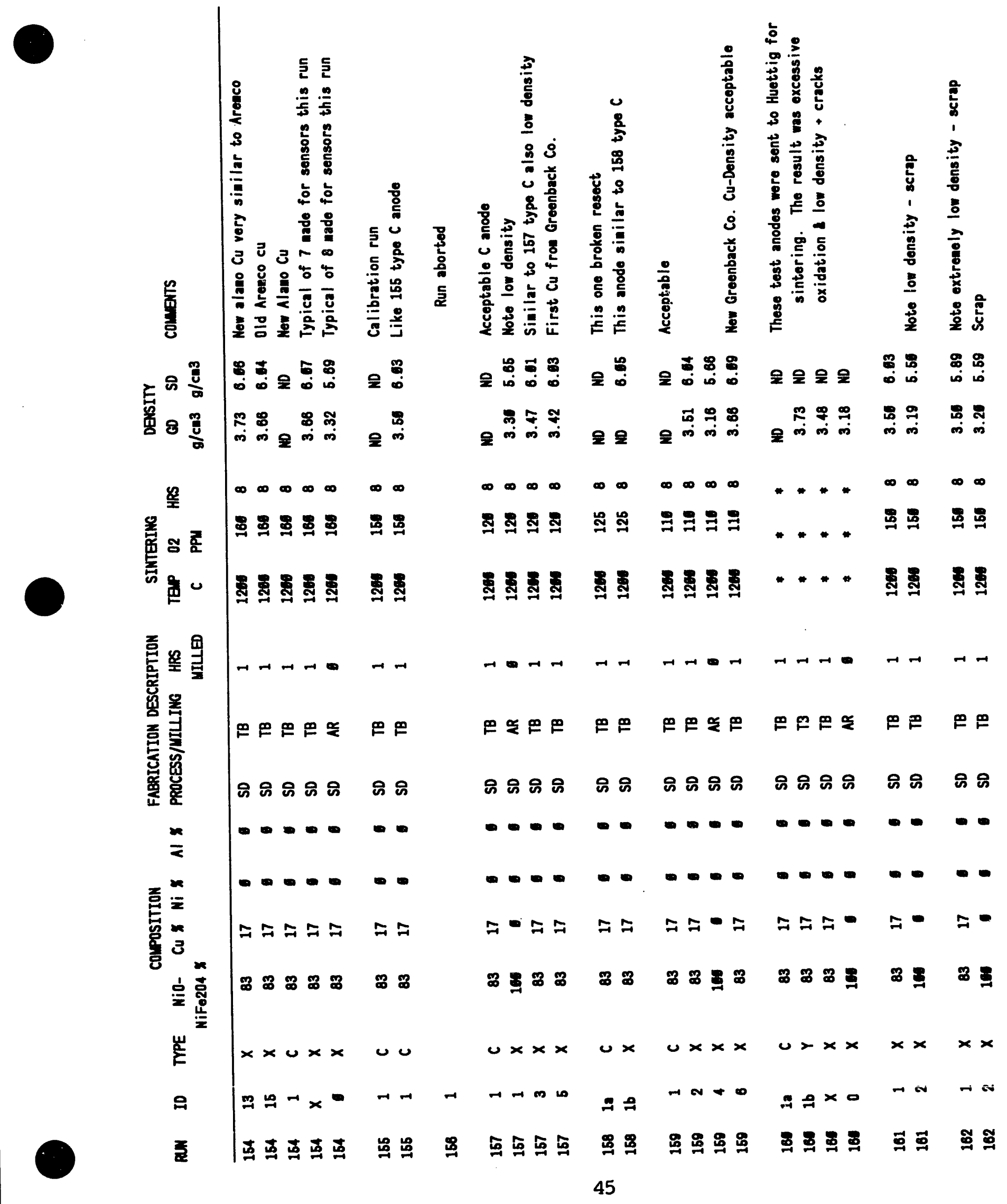




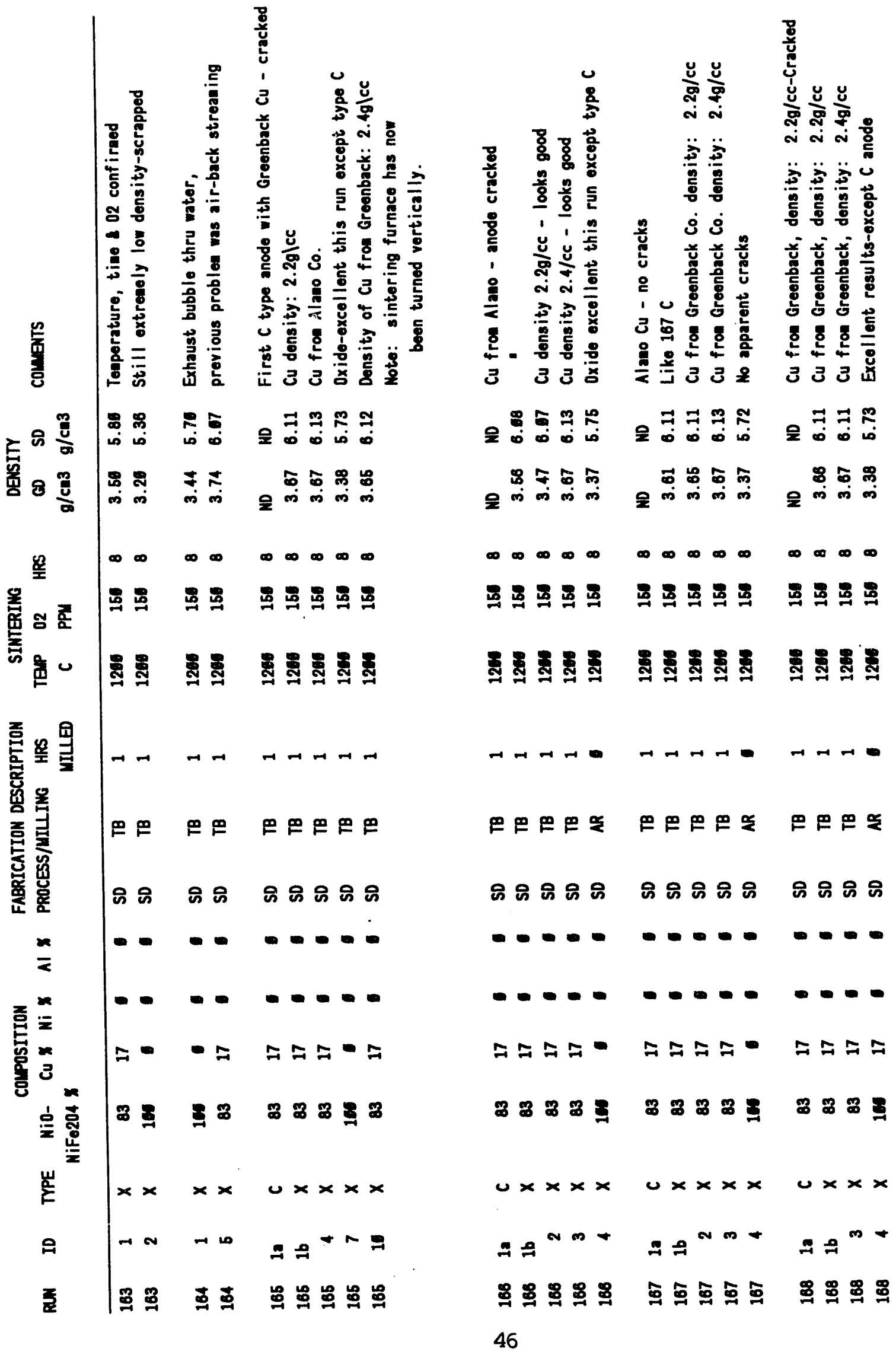




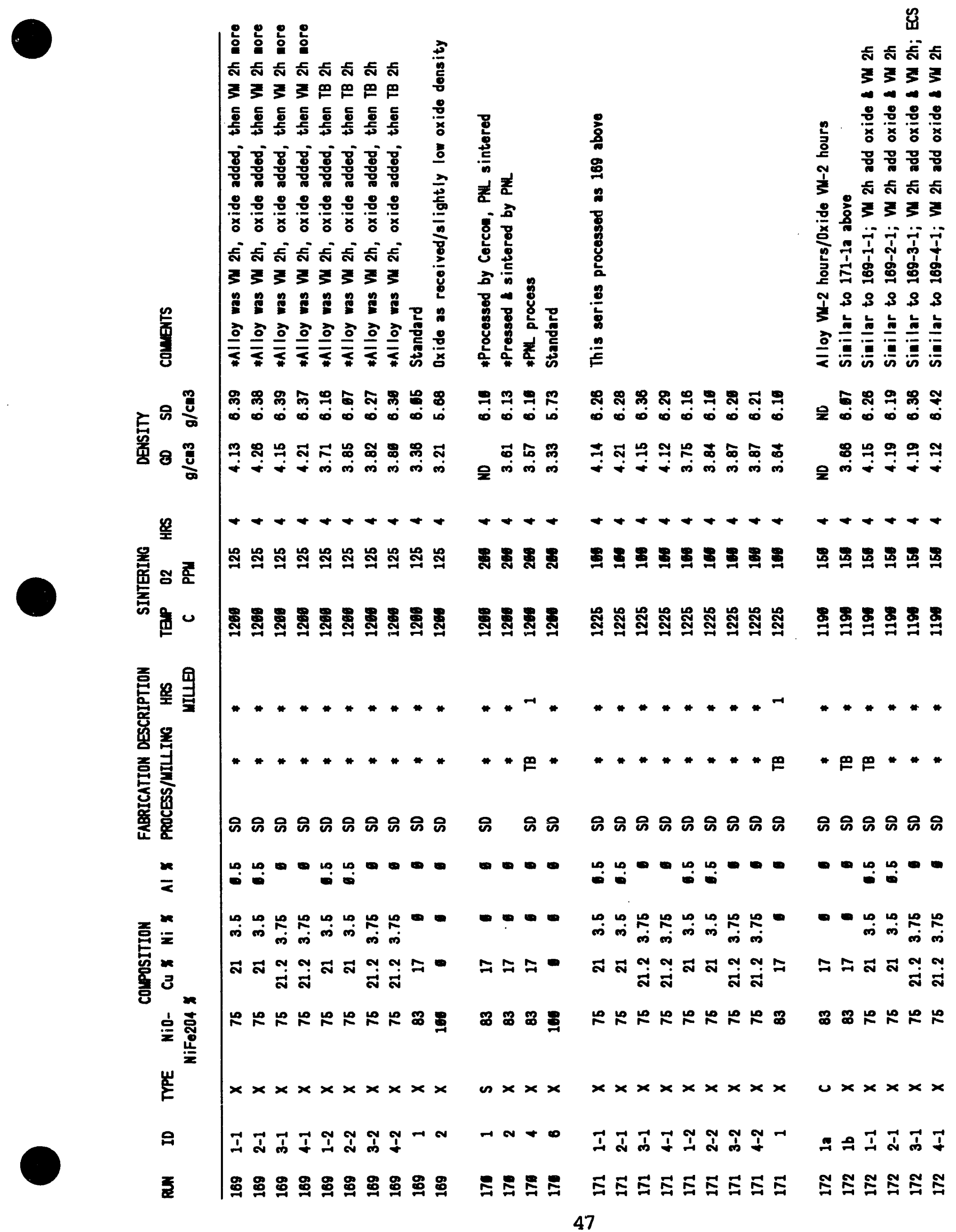




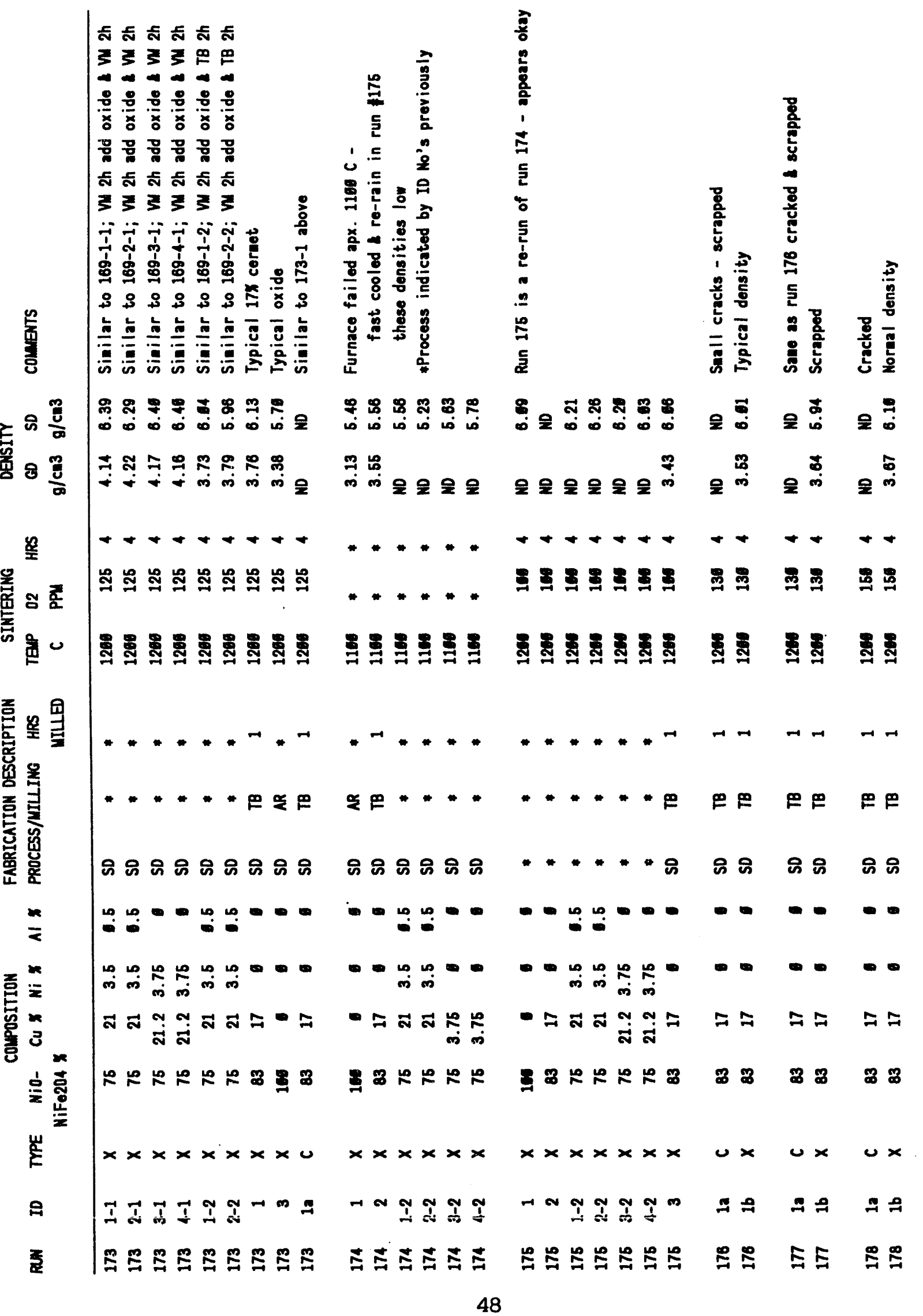





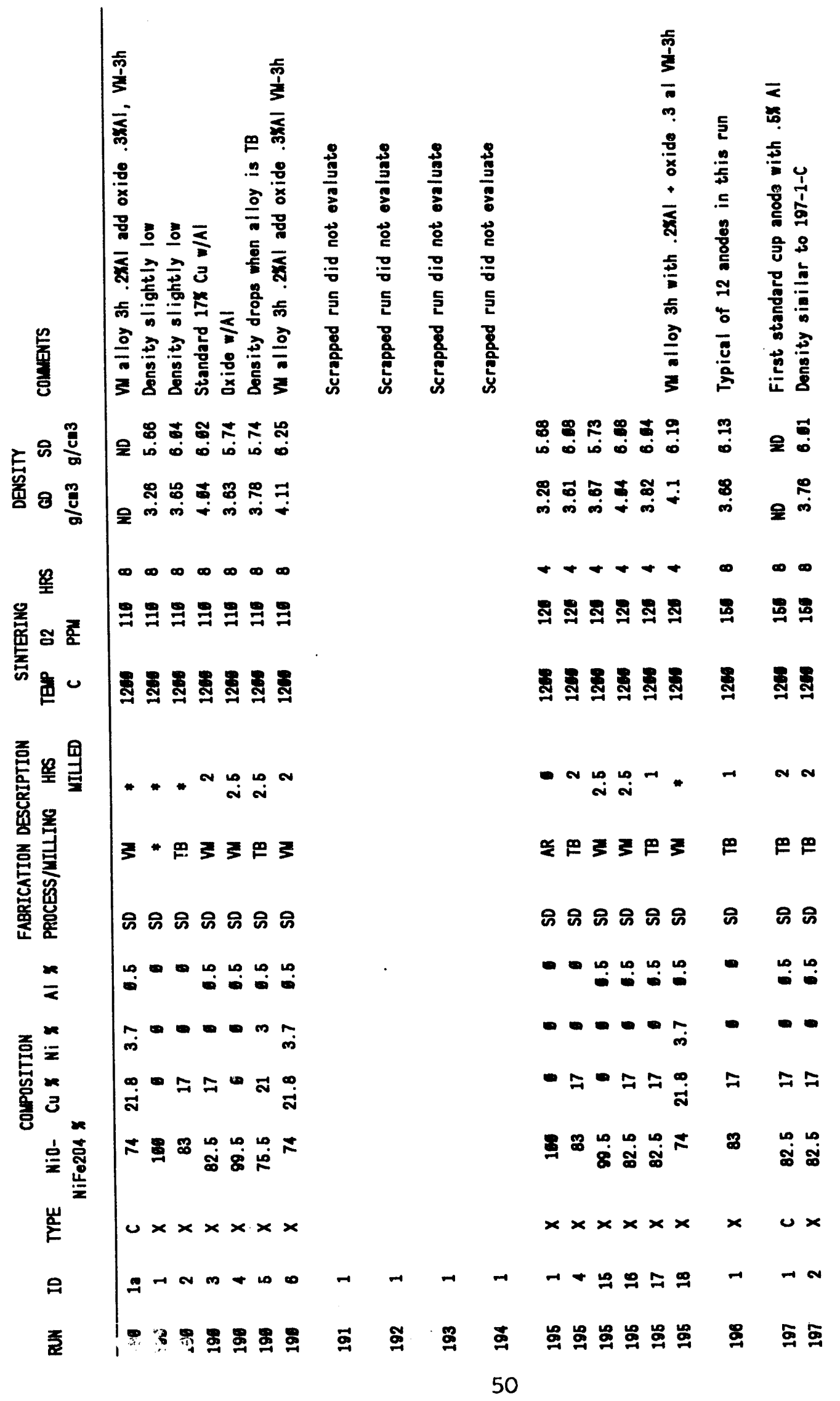




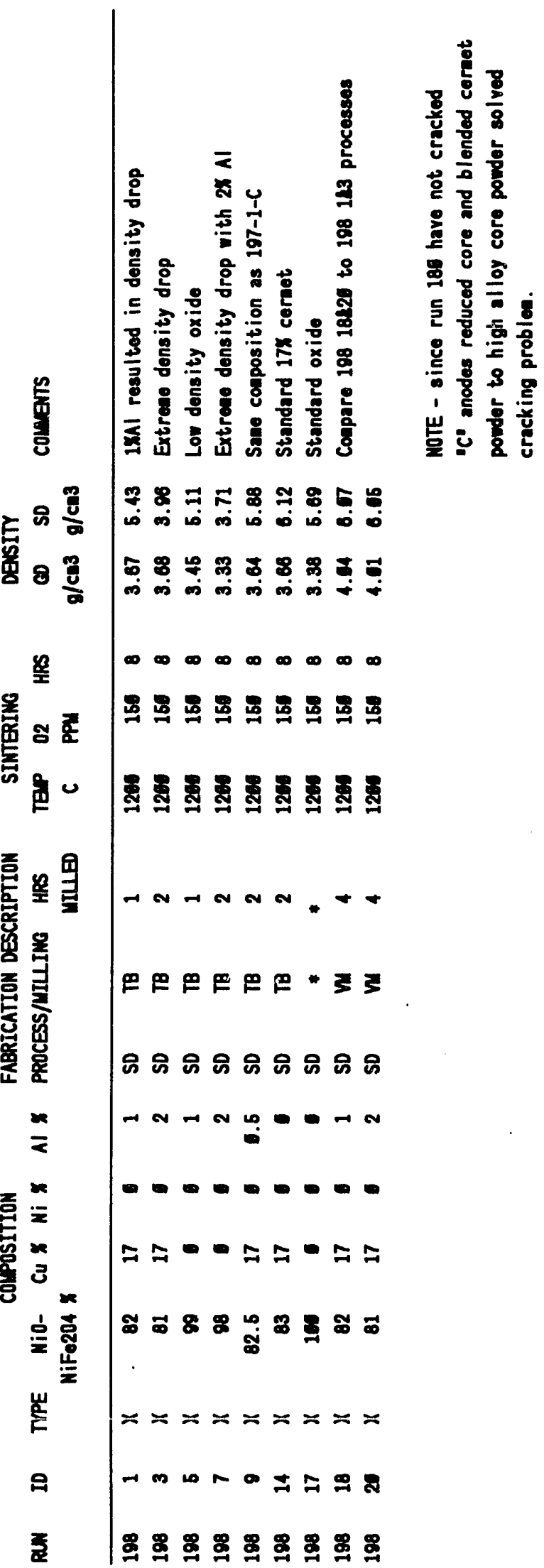




$$
\text { APPENDIX } F
$$

IESTING OF ADVANCED ANODE COMPOSITIONS 
Inert Electrodes Program

TESTING OF ADVANCED ANODE COMPOSITIONS

D. M. Strachan

March 1990

Prepared for

The U.S. Department of Energy

under Contract DE-ACO6-76RLO 1830

Pacific Northwest Laboratory

Richl and, Washington 99352 


\section{CONTENTS}

1.0 INTRODUCTION . . . . . . . . . . . . . . . . 1.1

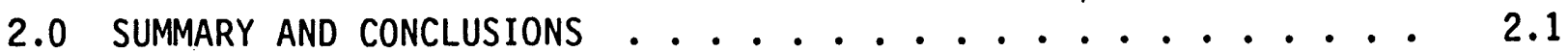

3.0 EXPERIMENTAL METHODS AND MATERIA!.S . . . . . . . . . . 3.1

3.1 ELECTRICAL MEASUREMENTS . . . . . . . . . . . 3.1

3.2 CHEMICAL ANALYSIS ............... 3.2

3.2.1 Metal Analyses ............. 3.2

3.2.2 Bath Ratio Analyses . . . . . . . . . . 3.2

3.2.3 Dissolved $\mathrm{Al}_{2} \mathrm{O}_{3}$ Analyses . . . . . . . . . 3.2

3.3 SOLID STATE ANALYSES . . . . . . . . . . . 3.3

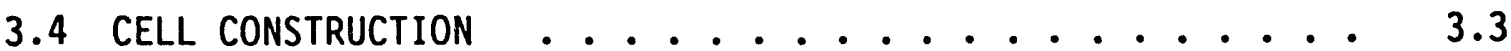

4.0 RESULTS . . . . . . . . . . . . . . . . . 4.1

4.1 ElECTRICAL MEASUREMENTS . . . . . . . . . . . 4.1

4.2 METAL PURITY ......................... 4.1

4.3 MICROSTRUCTURAL EXAMINATIONS . . . . . . . . . 4.5 


\section{FIGURES}

3.1 A Schematic of The Electrolysis Cell Used For Cell \#72 . . . 3.4

4.1 A Trai.e of The Amperage For Test \# 72 During The. Time Two Anodes Were In Use .................. 4.2

4.2 A Summary of The Current Scans Taken During Test \# 72 . . . . 4.3

4.3 A Summary of The Al Metal Analyses For Test \# 72 . . . . . . 4.4

4.4 The Fe Data From Figure 4.4 Normalized To The Anode Surface Area and Current Density ............... 4.6

4.5 A Photomicrograph of The Bottom Portion Of The Anode That Was Run For $66 \mathrm{~h}$ at $0.5 \mathrm{~A} / \mathrm{cm}^{2}$.............. 4.7

4.6 A Photomicrograph of The Electrolys is Face of The Anode Portion Shown in Figure 4.5 .............. 4.7

4.7 A Photomicrograph Of The Bottom Pgrtion of The Anode That Was Run For $66 \mathrm{~h}$ at $0.5 \mathrm{~A} / \mathrm{cm}^{2}$ Plus $24 \mathrm{~h}$ at $1.2 \mathrm{~A} / \mathrm{cm}^{2}$. . 4.8

4.8 A Photomicrograph of The Electrolys is Face of The Anode Shown In Figure 4.7 ..................... 4.8

4.9 A Photomicrograph of The Corner of The Anode Shown in Figure 4.7 . . . . . . . . . . . . . . . . 4.9

4.10 A Photomicrograph of The Bottom Portion of The Composite Anode...................

4.11 A Photomicrograph of The Upper Portion of The Composite Anode Showing Attack of The Pure Oxide Material . .

4.12 A Photomicrograph of The Bond Between The Pure Portion of The Composite Anode And the 17\% Cu Cermet Portion ..... 


\subsection{INTRODUCTION}

Numerous development anodes have been fabricated by staff members of the Pacific Northwest Laboratory (PNL) in support of the Inert Electrodes and Sensors Development Programs. During the early part of the anode fabrication development effort, anodes having a fine microstructure were sought. When these techniques were reasonably well-developed, anodes having an increased metal content were also fabricated. However, only microstructural examinations of anodes having an increased metal content were performed. The highest metal content that could be incorporated into an anode was about 25 mass\% without "bleeding" of the metal phase. Anode materials having an increased electrical conductivity were also developed by adding about 1 mass\% Al in the metal phase of the cermet when the metal was milled prior to being

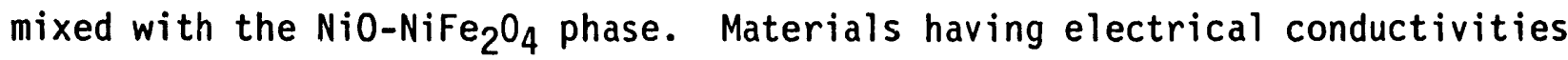
approaching 4 times that of carbon were developed, but not tested in an electrolysis test. The purpose of this test was to test anodes of advanced anode composition to determine their materials behavior during an electrolysis test.

Two advanced anode compositions have been tested. In the first portion of the test, two identical anodes were tested at a current density of 0.5 $\mathrm{A} / \mathrm{cm}^{2}$ for approximately $70 \mathrm{~h}$. One anode was then removed from the cell and the remaining anode operated at a current density of $1.3 \mathrm{~A} / \mathrm{crin}^{2}$ for about $20 \mathrm{~h}$ and was then removed from the cell. A new anode was transferred while hot to the electrolysis cell. This third anode was a composite anode. The bottom third was a high alloy material (about $25 \mathrm{wt} \% \mathrm{Cu} / \mathrm{Ni}$ ), the middle third consisted of the $17 \mathrm{wt} \% \mathrm{Cu}$ phase, and the top third contained no metal phase. This last anode was tested at a current density of $0.5 \mathrm{~A} / \mathrm{cm}^{2}$ for about $24 \mathrm{~h}$. 


\subsection{SUMMARY AND CONCLUSIONS}

During this test three anodes were tested - one at a current density of $0.5 \mathrm{~A} / \mathrm{cm}^{2}$ for approximately $66 \mathrm{~h}$, one at a current density of $0.5 \mathrm{~A} / \mathrm{cm}^{2}$ for $66 \mathrm{~h}$ and an additional $24 \mathrm{~h}$ at $1.3 \mathrm{~A} / \mathrm{cm}^{2}$, and a third anode at $0.5 \mathrm{~A} / \mathrm{cm}^{2}$ for approximately $24 \mathrm{~h}$. The first two anodes were operated together in the cell until one anode was removed from the cell after $66 \mathrm{~h}$. Results from this test were somewhat inconclusive in that the rate at which impurities dissolved in the molten Al appear to be independent of the anode current density and anode surface area. The extrapolated back emf was observed to decrease during the first $20 \mathrm{~h}$, but appeared to be caused not by the anode but by changes elsewhere in the cell.

The anode that was operated for $66 \mathrm{~h}$ at a current density of $0.5 \mathrm{~A} / \mathrm{cm}^{2}$ appeared to have only a small amount of corrosion; the anode that operated an additional $24 \mathrm{~h}$ at a current density of $1.3 \mathrm{~A} / \mathrm{cm}^{2}$ appeared to have suffered more corrosion. The composite anode that operated for about $24 \mathrm{~h}$ at a current density of $0.5 \mathrm{~A} / \mathrm{cm}^{2}$ showed little indication of corrosion. However the upper portion of the anode that was made of only oxide material did show signs of degradation. In the composite anode, the different materials bonded together well and no cracks between regions of differing materials was noted in posttest analyses. 


\subsection{EXPERIMENTAL METHODS AND MATERIALS}

In this test, electrolysis was started using two anodes operating at a current density of $0.5 \mathrm{~A} / \mathrm{cm}^{2}$ to establish a baseline of operation. After $66 \mathrm{~h}$ of operation, one anode was removed and the current density on the second anode was increased to $1.3 \mathrm{~A} / \mathrm{cm}^{2}$ and the anode operated for an additional $24 \mathrm{~h}$. These anodes were constructed from a cermet containing 25 mass\% of a $\mathrm{Cu} / \mathrm{Ni} / \mathrm{Al}$ alloy.

A third anode composition was tested to determine if an anode fabricated to have variable composition would survive in an electrolysis cell. This anode was constructed of a cermet material containing 25 mass\% $\mathrm{Cu} / \mathrm{Ni} / \mathrm{Al}$ alloy in the bottom third of the anode. The middle third of the anode was constructed of the standard 17 mass\% Cu cermet and the top third of the anode contained no metallic phase.

The surface area of the anodes to be immersed in the electrolyte was calculated assuming a right circular cylinder; this surface area was used to calculate the current needed for the test. The side wall of the anode was assumed to be $90 \%$ efficient in carrying the current.

\subsection{ELECTRICAL MEASUREMENTS}

A Fluke Helios I (Redmond, Washington) data logger was used to collect voltage, temperature, and current data at a normal rate of once every 5 minutes. Separate leads were connected to each of the two anodes; independent voltage measurements were made for each anode. Current measurements were made using a Hall effect transducer at each anode. The power supply was used in the constant current mode and the voltage varied as required to maintain constant current. Current scans were obtained by manually lowering the current and noting the current and voltage at steady state.

One channel of a two pen strip chart recorder was connected to the power supply voltage output and the other channel across a 0.1 ohm standard resistor in series with the electrolysis cell. It has been observed in previous tests at PNL that when an anode begins to corrode, the voltage, under constant current cell operation, becomes erratic and begins to fluctuate. This observed phenomenon was used in this test to determine the operating stability of the cermet anodes. 
A standard electrode (Burgman, Leistra, and Sides 1986) was also used to monitor the voltage drop between itself and the anode and cathode. The continuously monitored signals were recorded using a strip chart recorder.

\subsection{CHEMICAL ANALYSES}

Samples of the electrolyte were taken throughout the test. The samples consisted of sinall quantities (10 g to $15 \mathrm{~g})$ of electrolyte and liquid aluminum metal.

\subsubsection{Metal Analyses}

Metal samples were weighed after removing the glass tubing. Approximately $1 \mathrm{~g}$ of each metal sample was weighed accurately and dissolved in concentrated hydrochloric acid. If needed, a small volume of concentrated nitric acid was added to the hydrochloric acid in order to completely dissolve the metal. The dissolved metal solution was then diluted to a volume of $100 \mathrm{~mL}$ and the impurities quantitatively determined by Inductively Coupled Plasma (ICP) Spectroscopy. Elements with known interferences with the Al spectrum were not reported.

\subsubsection{Bath Ratio Analyses}

Electrolyte or bath ratio analyses were made using a $\mathrm{pH}$ method. A sample of finely crushed electrolyte $(=1 \mathrm{~g})$ was added to $25.0 \mathrm{~mL}$ of 1.001 = $0.010 \mathrm{~N} \mathrm{KOH}$ solution containing $\mathrm{Al}(\mathrm{OH})_{3}$ and sodium tartrate. Approximately 50 $\mathrm{mL}$ of hot deionized water was added to the beaker and the resulting solution was boiled for 6 minutes. After cooling to room temperature in a cooling bath, $25.0 \mathrm{~mL}$ of $1.005 \neq 0.010 \mathrm{~N} \mathrm{HCl}$ was added to the mixture. After 10 minutes, the $\mathrm{pH}$ was measured and recorded when the value was constant. A calibration curve was constructed by performing this analysis on a set of standard electrolyte samples.

\subsubsection{Dissolved $\mathrm{Al}_{2} \underline{0}_{3}$ Analyses}

The dissolved $\mathrm{Al}_{2} \mathrm{O}_{3}$ content of the electrolyte was routinely determined by accurately weighing an approximately $1 \mathrm{~g}$ sample of finely crushed electrolyte to the nearest $0.1 \mathrm{mg}$. About $50 \mathrm{~mL}$ of 30 mass $\% \mathrm{AlCl}_{3}$ solution was added to the sample in a beaker, and brought to a boil for 10 minutes. While the mixture was still very hot, it was rapidly transferred to a medium speed ashless filter containing a small amount of filter aid (finely divided ashless 
filter paper used to speed and enhance filtration). The material was quantitatively transferred from the beaker by washing repeatedly with boiling water. Finally, the filter was washed repeatedly with boiling water until the filtered solution tested neutral to litmus paper and gave no precipitate when added to a small portion of $0.1 \mathrm{M} \mathrm{AgCl}$. Using metal forceps, the filter paper containing the residual $\mathrm{Al}_{2} \mathrm{O}_{3}$ was transferred to a $\mathrm{Pt}$ crucible, which had been heated to constant mass in a $1000^{\circ} \mathrm{C}$ furnace. A loose-fitting cover was placed on the crucible and the crucible placed in the cooler part of the $1000^{\circ} \mathrm{C}$ furnace for 10 minutes. After the preliminary ashing was complete, the crucible was moved to the hottest portion of the furnace for an additional 15 minutes. This treatment provided sufficient time and temperature for the sample to come to constant mass.

After the high temperature treatment, the crucible was quickly transferred to a desiccator and allowed to cool for 15 minutes, and was then weighed. The mass of the residual solid was the $\mathrm{Al}_{2} \mathrm{O}_{3}$ content of the electrolyte. This method was also checked using standard electrolyte samples.

\subsection{SOLID STATE ANALYSES}

The anodes were examined microscopically using an optical microscope and a scanning electron microscope (SEM). The samples were cut in half, polished, and examined under the optical microscope. Before examining the samples in the SEM, the cermet samples were given an electrically conductive coating of carbon by vapor deposition. For the most part, the SEM was operated in the quantitative mode using pure $\mathrm{Cu}$ as an intensity standard.

\subsection{CELL CONSTRUCTION}

The cell was constructed as shown in Figure 3.1 . An $18 \mathrm{~cm} \mathrm{ID,} 19 \mathrm{~cm}$ OD pure alumina tube, closed at the bottom end, was used as the cell liner. The alumina tube was $46 \mathrm{~cm}$ in height. The connection between the $\mathrm{Al}$ and $\mathrm{TiB}_{2}$ cathode and the outer graphite crucible was made with a graphite stud through a hole drilled in the alumina tube. The $\mathrm{TiB}_{2}$ cathode plate and the graphite stud were cemented in place with graphite cement. The walls of the graphite crucible were about $2.5 \mathrm{~cm}$ thick. A $3 \mathrm{~mm}$ thick Inconel shell provided the

- Inconel is a registered trademark of INCO Alloys International (Huntington Alloys), Huntington, West Virginia. 


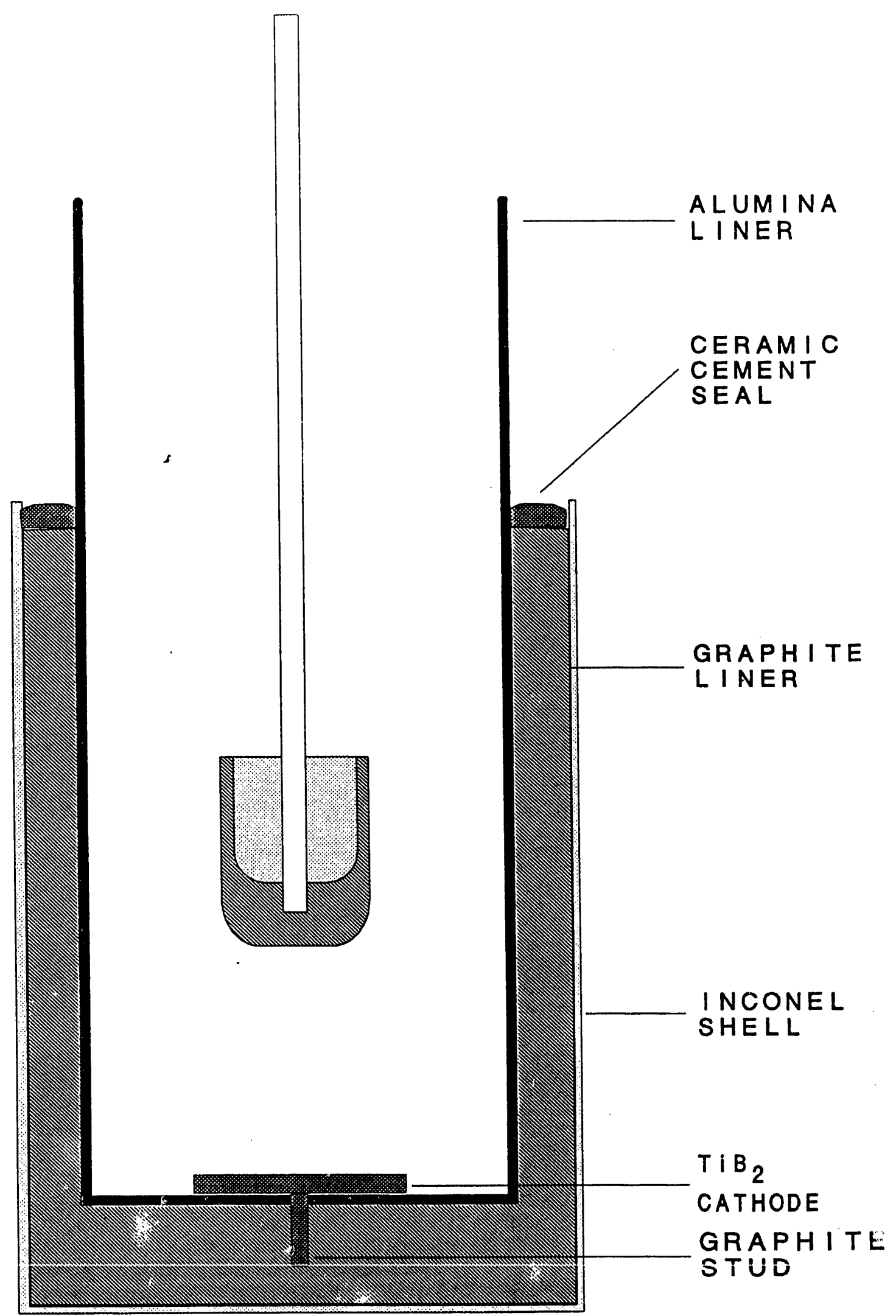

FIGURE 3.1. A Schematic of The Electrolysis Cell Used For Cell \#72 
external container. Approximately $1.5 \mathrm{~kg}$ of $\mathrm{Al}$ in the form of $7.5 \mathrm{~cm}$ diameter $4 \mathrm{~cm}$ thick disks was placed in the bottom of the cell. Approximately $6 \mathrm{~kg}$ of premixed powdered electrolyte was then placed on top of the Al metal. The exact quantities of each were determined by weight. The anodes used in this test were suspended above the powdered electrolyte during the heatup of the cell. A $6 \mathrm{~mm} \mathrm{Ni}$ rod was used as the electrical connection/mechanical support for the anode. This rod was shrouded with an alumina tube sealed at the anode with a refractory cement. The cup of the anode was filled with refractory alumina powder. 


\subsection{RESULTS}

Results from this electrolysis test are tiscussed in the following sections.

\subsection{ELECTRICAL MEASUREMENTS}

Figure 4.1 shows the current history for the period of time that two anodes were in the cell. The sharp decreases in current indicate current scans and corrective action when the cell voltage became unstable. The early instability, however, was caused by a decrease in electrolyte temperature rather than a problem with the anode. The decrease in current at about $46 \mathrm{~h}$ was due to what appeared to be an anode stability problem, but later it was determined that the reference electrode had failed, thereby giving erroneous voltage stability values. Current data for the third anode tested were lost when the switch was not set to store the data on file.

The results from the current scans are summarized in Figure 4.2. This is the first time that the extrapolated voltage varied with time. However, the extrapolated voltage became constant at $2.2 \mathrm{~V}$ after about $20 \mathrm{~h}$. The change in the extrapolated voltage at the early time period is believed to be a result of changes in the cell other than the anode, but the exact cause is unknown. One current scan was obtained during testing of the last anode and, its extrapolated voltage was the same as normally obtained, i.e., $2.2 \mathrm{~V}$.

\subsection{METAL PURITY}

Approximately 40 metal samples were collected. Figure 4.3 summarizes the results from analyses of 27 of these samples. It is interesting to note that the $\mathrm{Cu}$ and $\mathrm{Ni}$ concentrations in the metal pool become constant, but the $\mathrm{Fe}$ concentration continues to increase with time. These results suggest that $\mathrm{Cu}$ and $\mathrm{Ni}$ reach a steady state concentration in the metal pool and the balance is either dissolved in the electrolyte or lost by volatilization. Other tests indicate that the various metal components of the cermet anode volatilize, but the rate and extent are not known.

The slopes of the lines shown in Figure 4.3 are similar to those found for $\mathrm{Cu}$, Fe, and $\mathrm{Ni}$ in Test \#70, In fact; if the data shown in the report for Test \#70 are shifted by the amount of down time, the data would nearly coincide with that shown in Figure 4.3, including the time at which the concentrations 


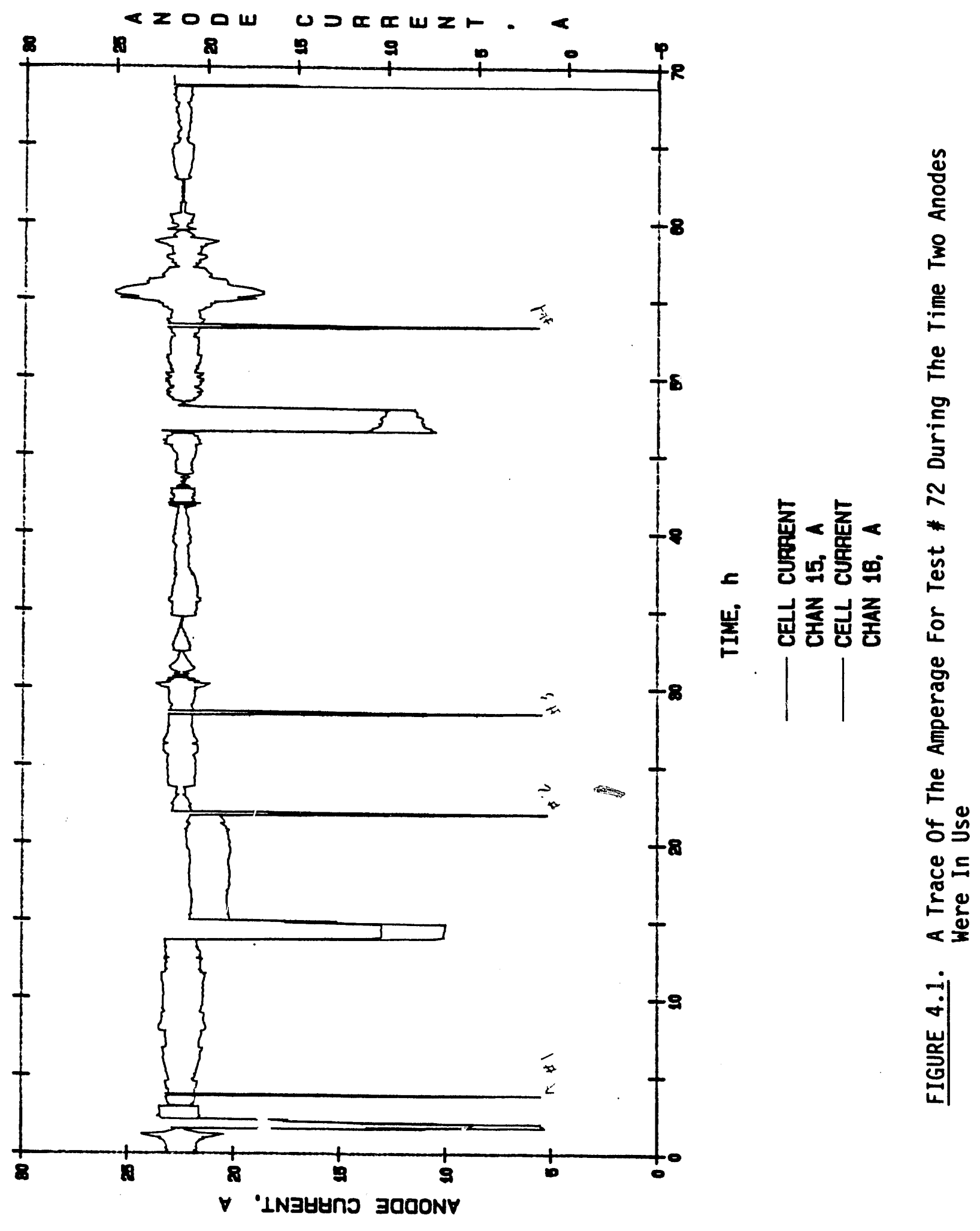




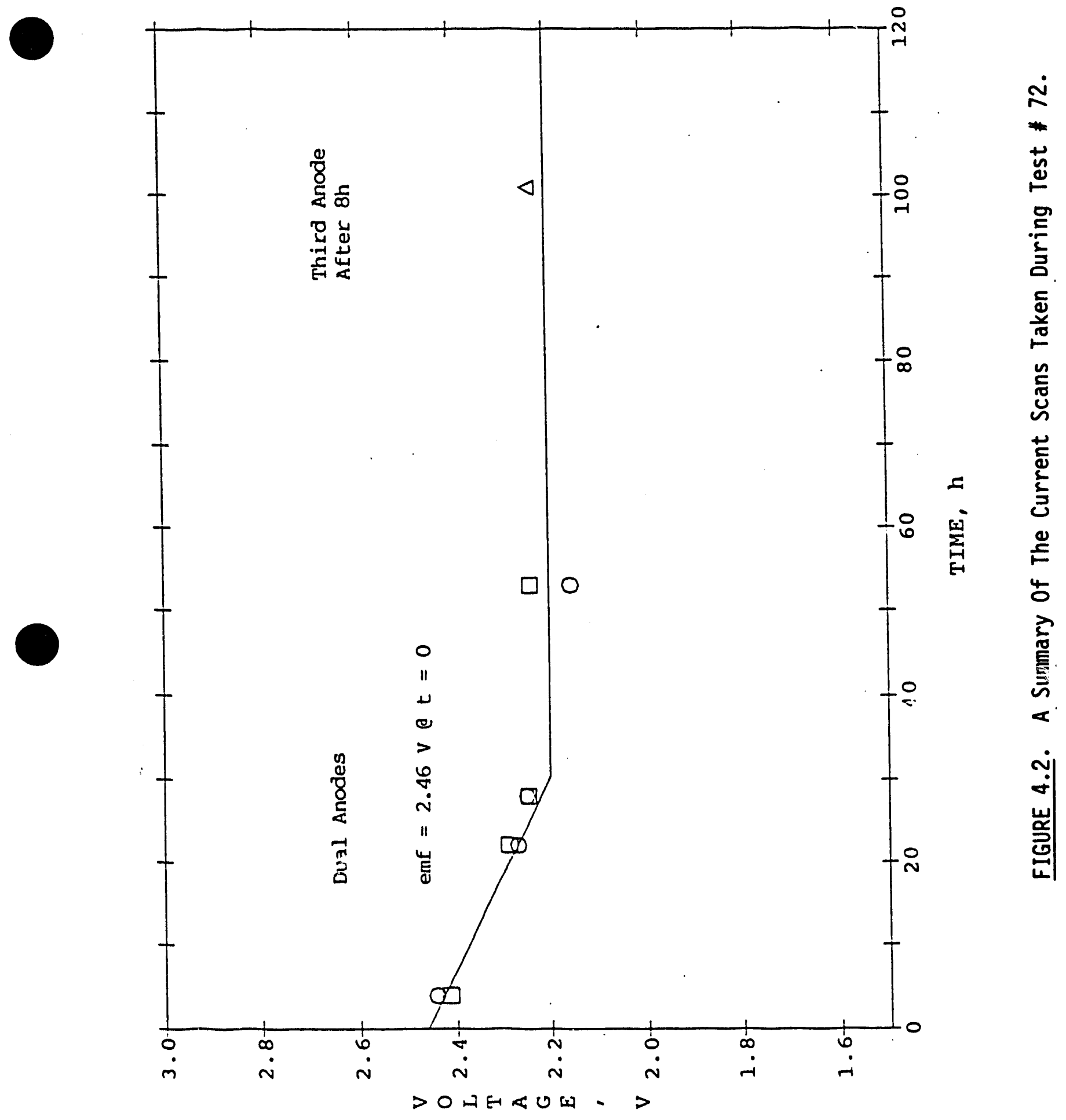




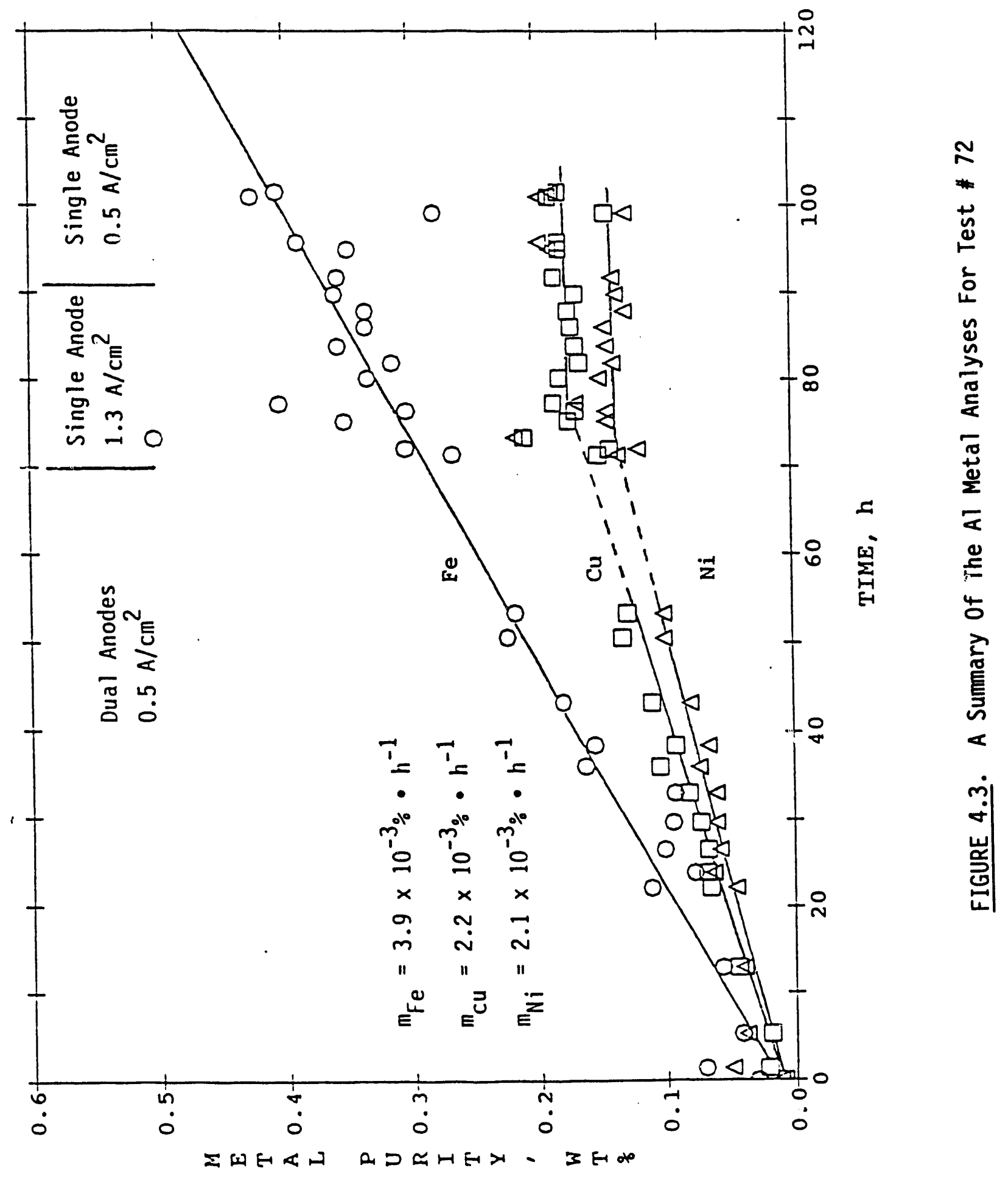


of $\mathrm{Cu}$ and $\mathrm{Ni}$ in the molten aluminum reach an apparent constant value. In the discussion of the results from Test \#70, it was reported that the $\mathrm{Cu}$ and $\mathrm{Ni}$ concentrations in the aluminum became constant because of mineral formation from the addition of $\mathrm{Si}$ to the electrolyte. Present results, however, indicate that $\mathrm{Cu}$ and $\mathrm{Ni}$ concentrations reach a steady-state value that is independent of the presence of $\mathrm{Si}$ in the bath.

An attempt was made to correlate the metal impurities with current density and/or the anode surface area exposed to the electrolyte. Therefore, the metal concentrations were normalized to the current density and the surface area. The results for Fe are shown in Figure 4.4. There does not appear to be any strong correlation in the data.

\subsection{MICROSTRUCTURAL EXAMINATIONS}

Figure 4.5 shows the bottom portion of the anode that was removed from the cell after $66 \mathrm{~h}$. There was a halo of Cu-colored material near the surface that is not visible in this photograph. The bottom face of the anode had an affected (oxidized) zone approximately $220 \mu \mathrm{m}$ thick (Figure 4.6). The sicle walls, however, only had an affected area approximately $120 \mu \mathrm{m}$ thick.

The bottom portion of the second anode that was present with the first anode and then operated at a current density of $1.2 \mathrm{~A} / \mathrm{cm}^{2}$ for an additional $24 \mathrm{~h}$ is shown in Figure 4.7. A thicker oxidized layer can readily be seen in this photograph, especially at the corners (Figure 4.8). The bottom face was not as oxidized as the corners (Figure 4.9), a feature that is usually noted in this size test anode.

Figure 4.10 shows the bottom portion of the composite anode. After only $24 \mathrm{~h}$ in the cell, only a very thin oxidized layer, about 20 to $30 \mu \mathrm{m}$, was found. However, the side walls seemed to be more oxidized, about $50 \mu \mathrm{m}$.

One of the purposes of constructing a composite anode was to determine if having only the pure oxide material in cortact with the cell atmosphere would improve the oxidation resistance of the upper portion of the anode. This does not seem to be the case. As seen in Figure 4.11, discoloration (oxidation?) of the upper portion did occur but the cause of the attack has not yet been identified. The pure oxide material, however, bound to the $17 \% \mathrm{Cu}$ cermet material without any evidence of separation or cracking in the transition zone between the two materials. (Figure 4.12). 


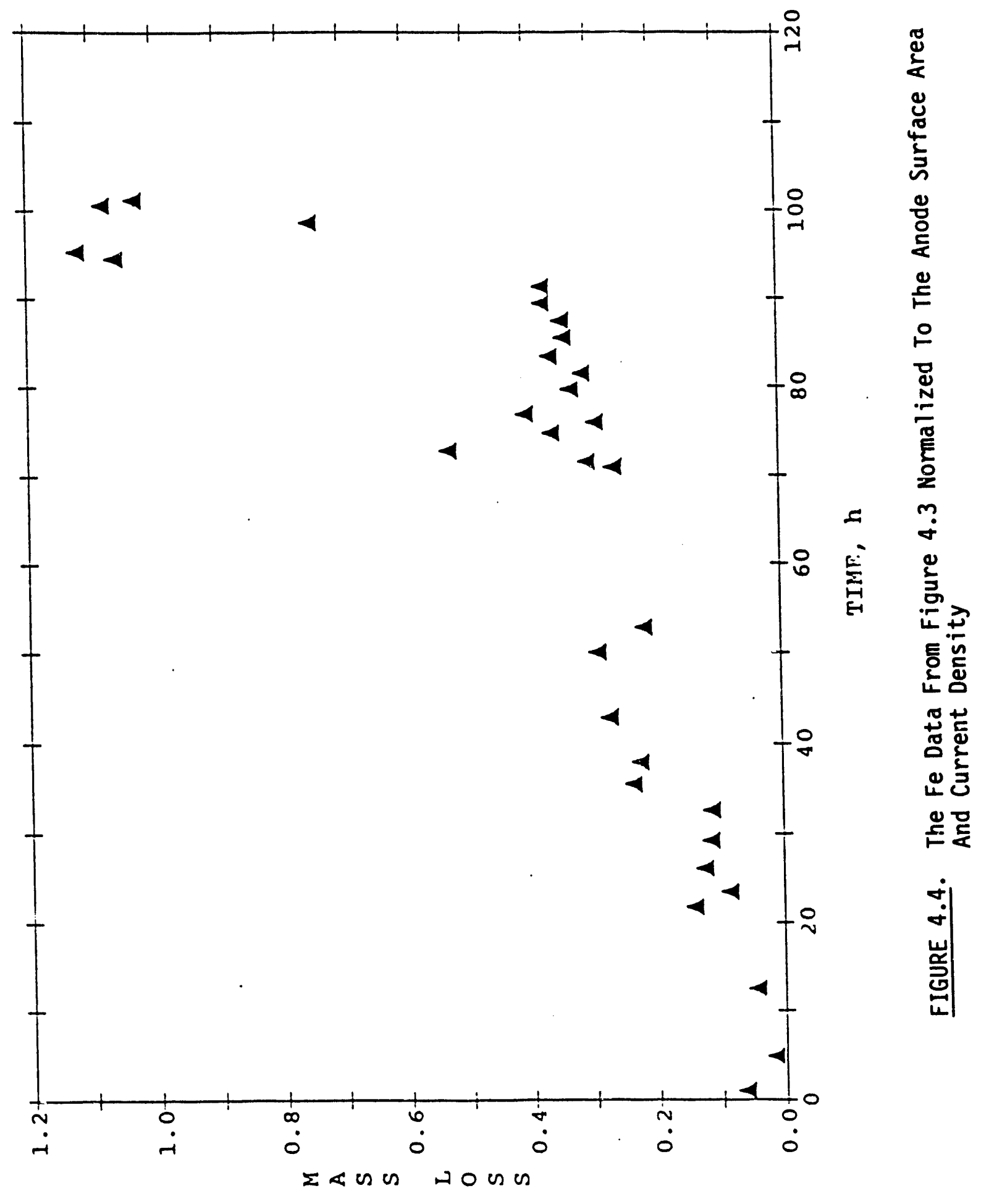

4.6 


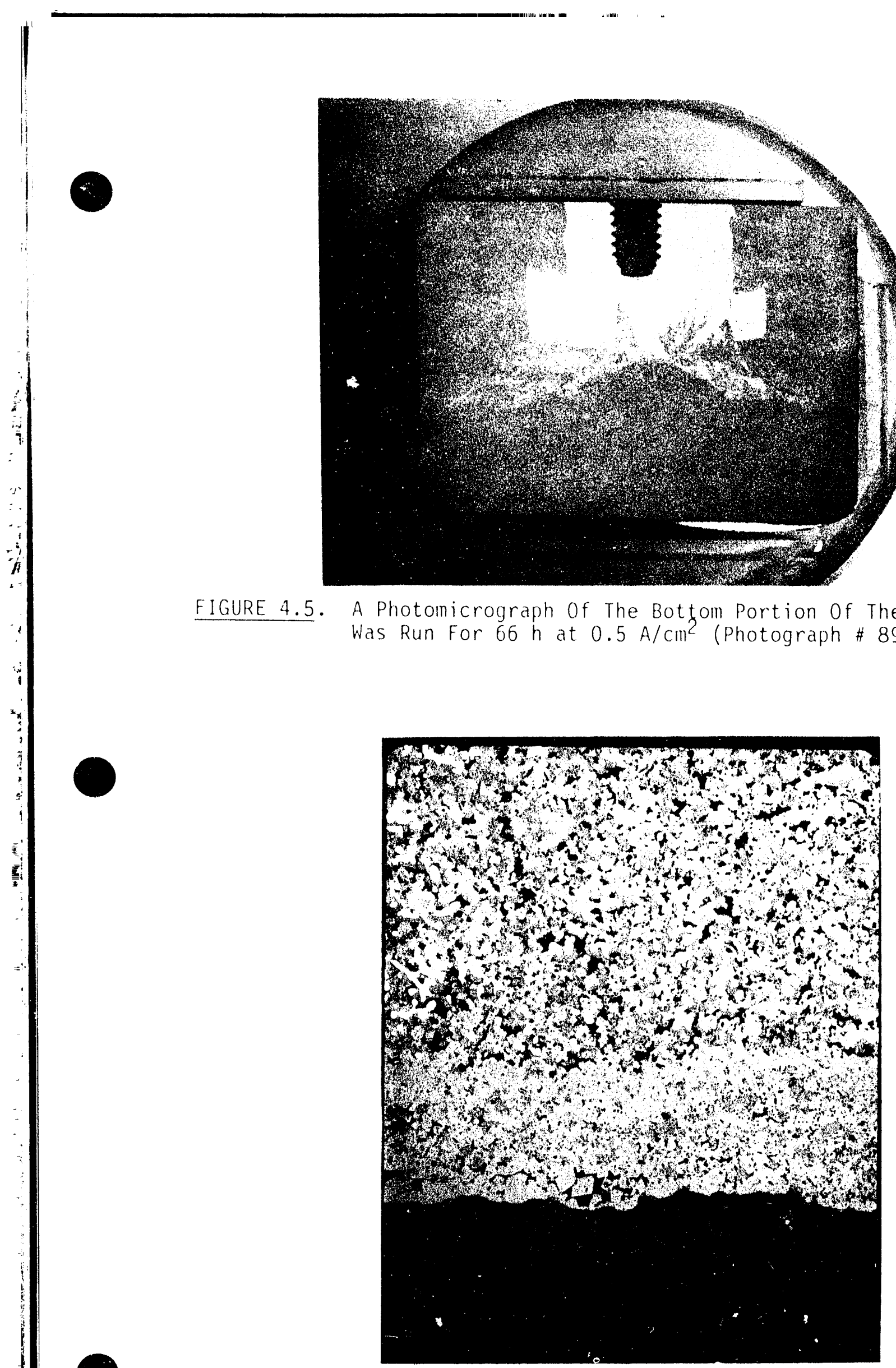

FIGURE 4.6. A Photomicrograph of The Electrolysis Face of The Anode Portion Shown In Figure 4.5 (Photograph \# 87M279B) 


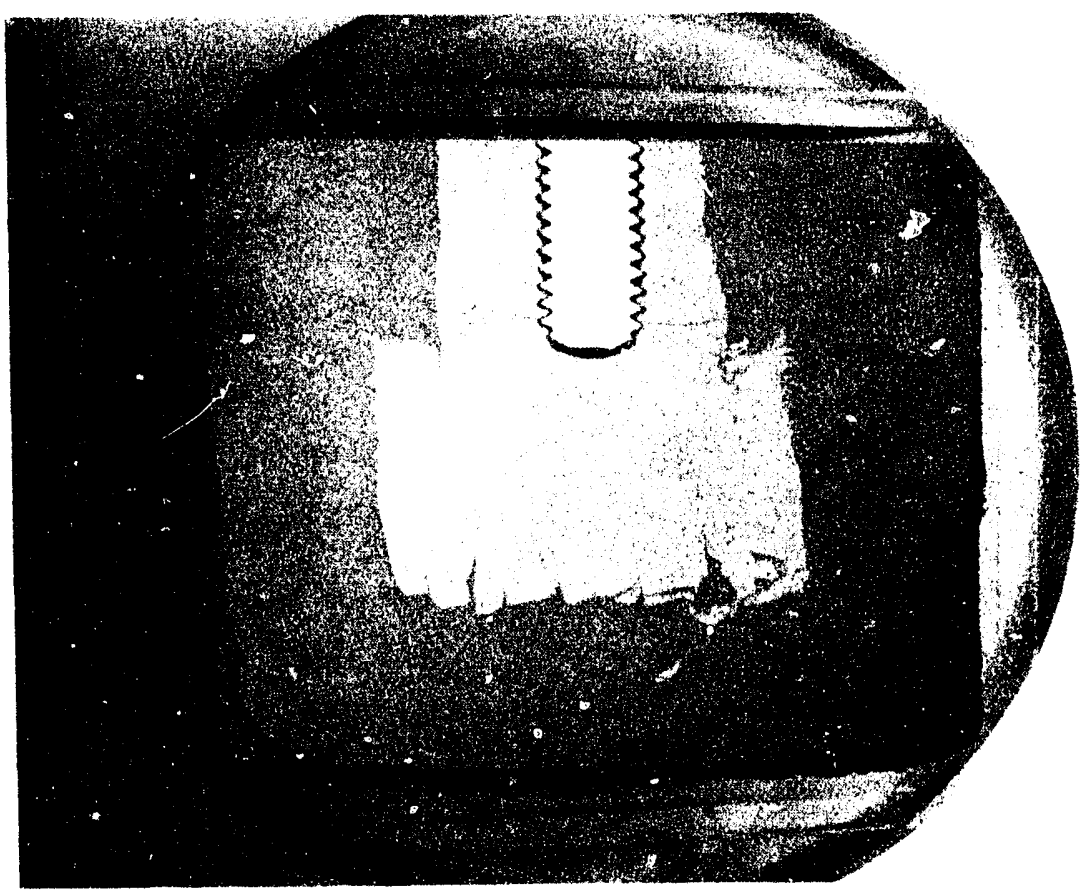

Floure 4.7. A Photomicrograph of the Bottom Portion of the Anode that Was Run for 65 h at $0.5 \mathrm{~A} / \mathrm{cm}^{2} \mathrm{P}$ lus $24 \mathrm{~h}$ at $1.2 \mathrm{~A} / \mathrm{cm}^{2}$ (Photograpm $\neq 8(9+9) 80$ A)

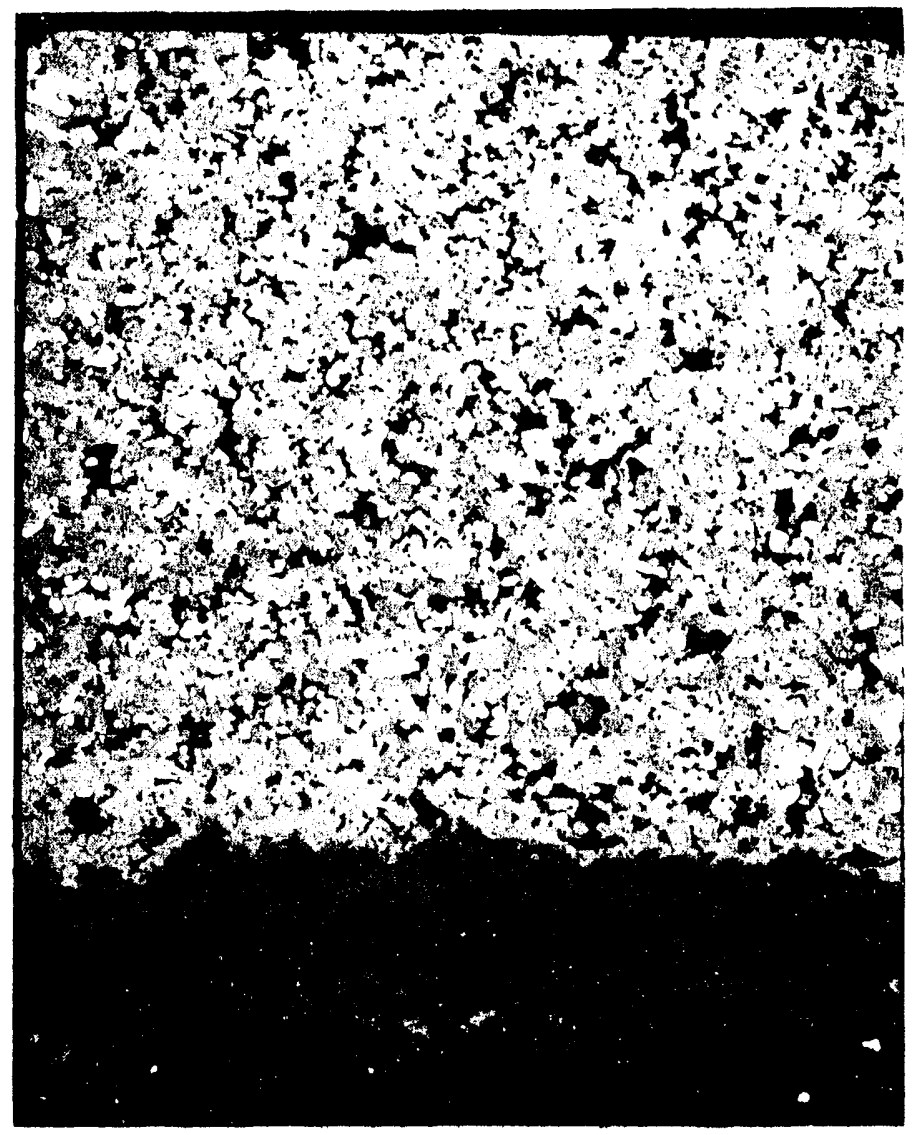

ElguRE 4.8. A Photomicrograph of the Electrolysis tace of the Anode Shown In Figure 4.7 (Photograph \# 89M2808) 


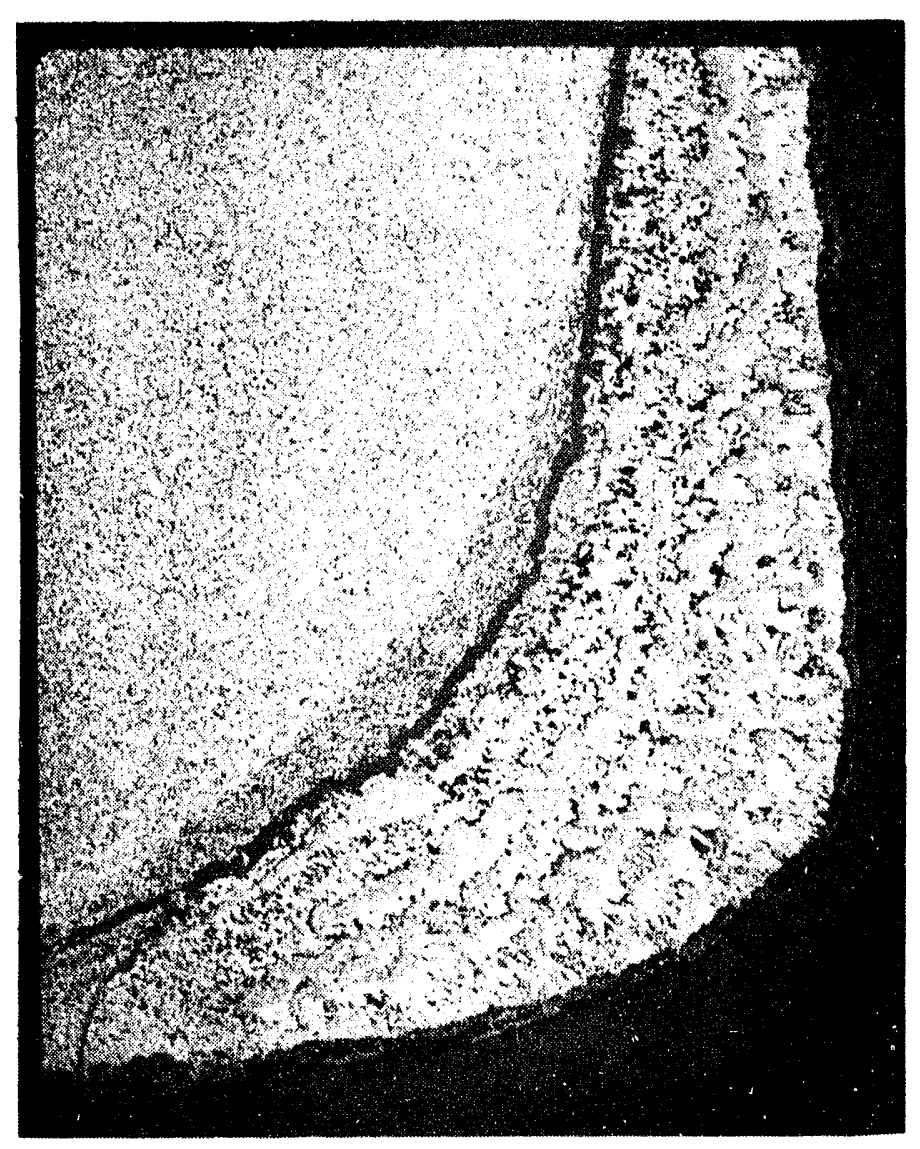

FIGURE 4.9. A Photomicrograph of The Corner of The Anode Shown In Figure 4.7 (Photograph \# 89M280H)

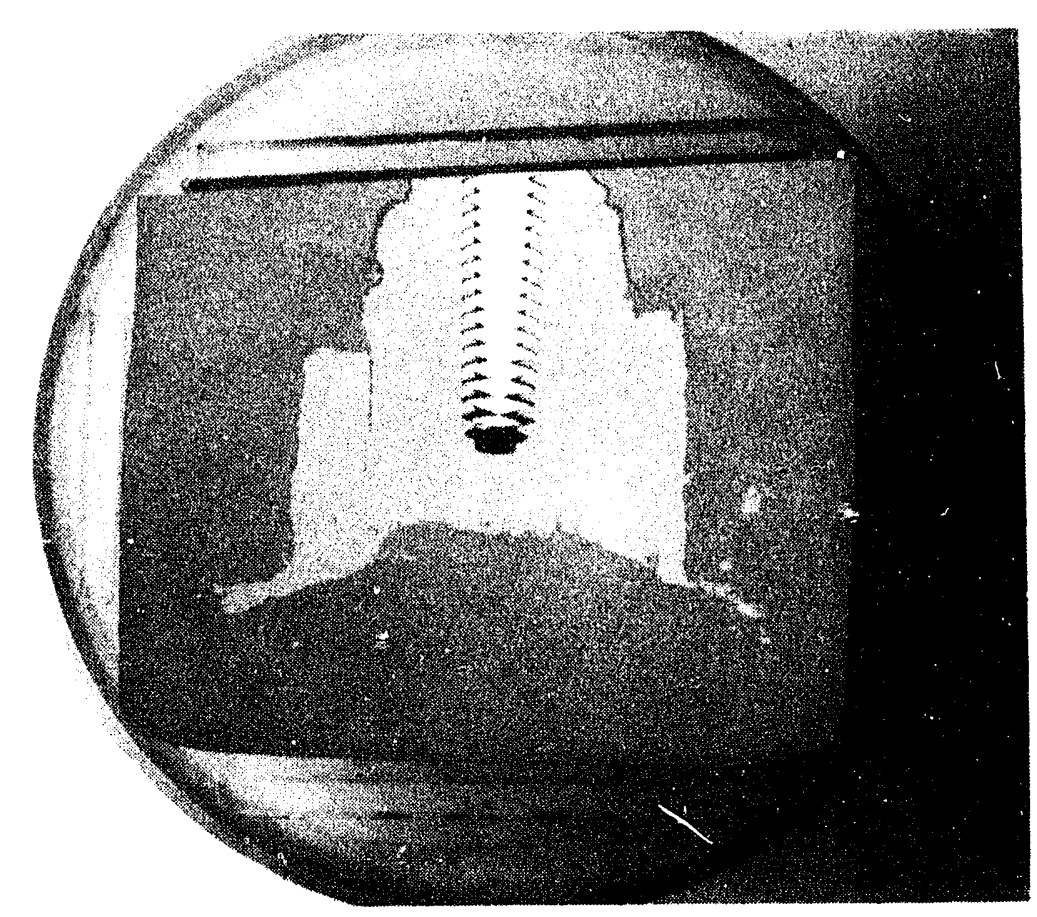

FIGURE 4.10. A Photomicrograph of The Bottom Portion Of The Composite Anode (Photograph \# 89M281A) 


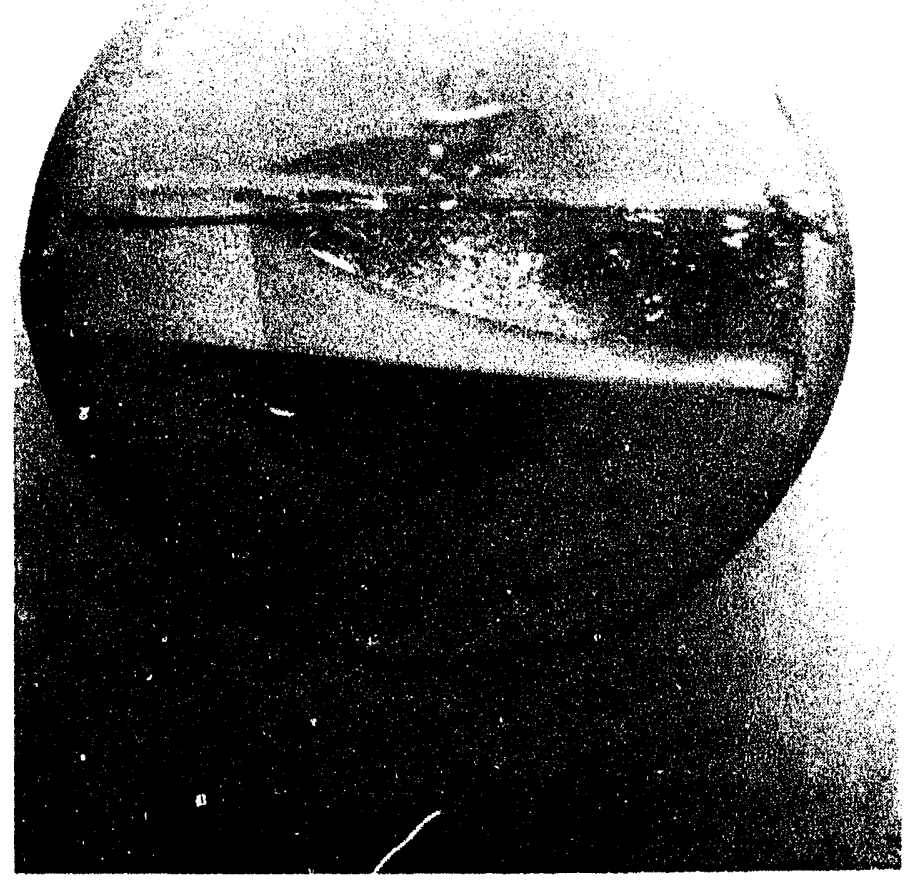

FIGURE 4.11. A Photomicrograph of The Upper Portion of The Composite Anode Showing Attack of The Pure Oxide Material (Photograph \# 89M282A)

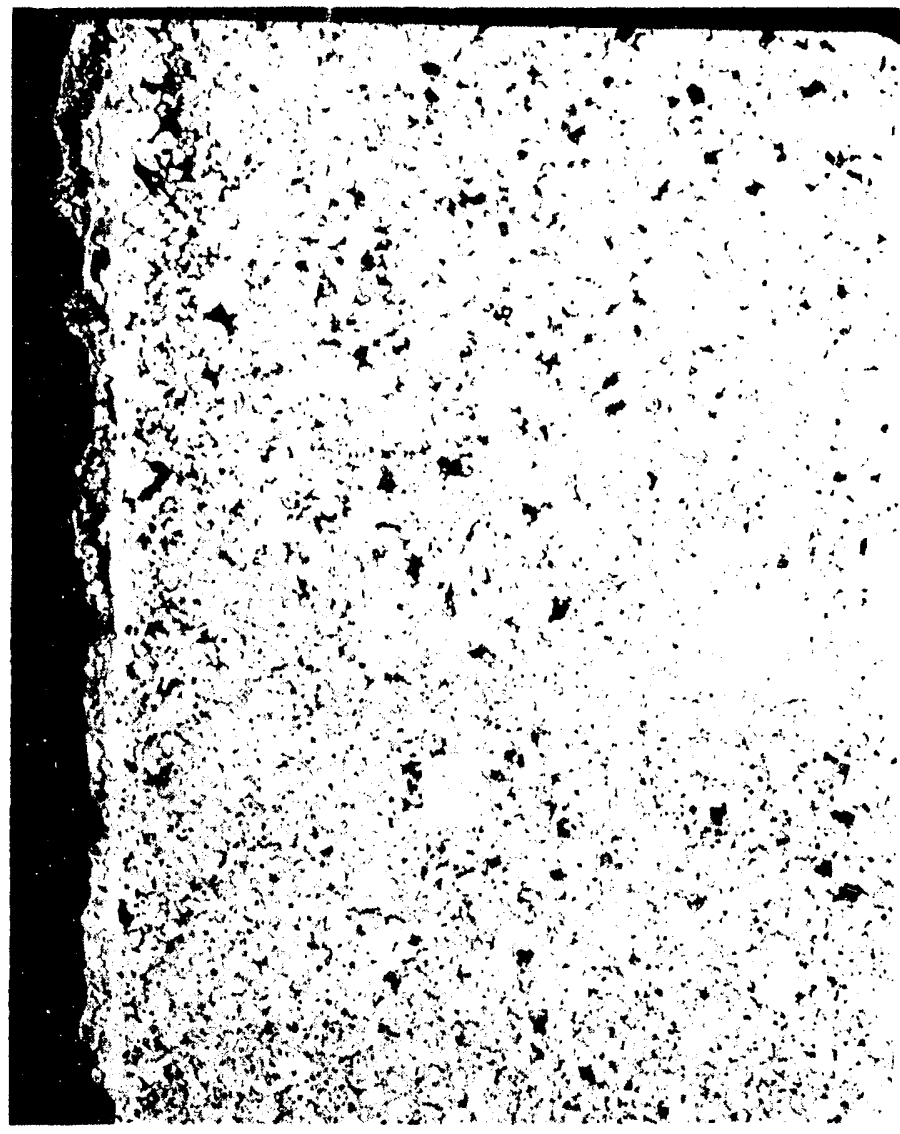

FIGURE 4.12. A Photomicrograph of The Bond Between The Pure Oxide Portion Of The Composite Anode And the $17 \% \mathrm{Cu}$ Cermet Portion (Photograph \# 89M282D) 
APPENDIX 6

MATER MODEL OF A LARGE-SCALE INERT MODE TEST 
WATER MODEL. OF A LARGE-SCALE INERT ANODE TEST

P保说

D. M. Strachan

May 1989

Prepared for

the U.S. Department of Energy

under Contract DE-AC06-76RLO 1830

Pacific Northwest Laboratory

Richland, Washington 99352 


\section{SUMMARY}

A water model of the pilot cell at the Reynolds Metals Co. was constructed for the purpose of determining the distribution of dissolved $\mathrm{Al}_{2} \mathrm{O}_{3}$ around the inert anodes in a rectangular array of six anodes. The surrogate anodes were constructed from graphite with aluminum caps. Air was forced through the graphite portion of the surrogate anodes to simulate the electrolytic production of $\mathrm{O}_{2}$. The solution in the glass aquarium was water $/ 10$ vol\% ethanol. This solution better modelled the electrolyte than did pure water. Results from this water model indicated that there should be sufficient stirring from the bubble action coupled with the thermal and concentration gradients in an actual cell to provide adequate distribution of the dissolved $\mathrm{Al}_{2} \mathrm{O}_{3}$ to each anode in the cluster. 


\section{ACKNOWLEDGMENTS}

The author wishes to acknowledge the technical assistance of P. I. Pohl for his involvement in the initial set up of the apparatus; discussions with Dr. J. W. Evans and Dr. R. Shekhar, University of California Berkeley, were very helpful in designing the apparatus; the assistance of R. E. Westerman and $D$. K. Hilliard in performing the technical and editorial reviews of the report; the programmatic assistance provided by M. J. McMonigle, Office of Industrial Programs, U.S. Department of Energy, Washington, D.C., and P. M. Pak and D. R. Segna, Richland Operations Office of the Department of Energy; and the programmatic support provided by the office of Industrial Programs. 


\section{CONTENTS}

SUMMARY . . . . . . . . . . . . . . . . . . . . . i ii ACKNOWLEDGMENTS ....................... . v v INTRODUCTION . . . . . . . . . . . . . . . . . . 1

EXPERIMENTAL EQUIPMENT AND MATERIALS ................. 3

EXPERIMENTAL METHODS ....................... 7

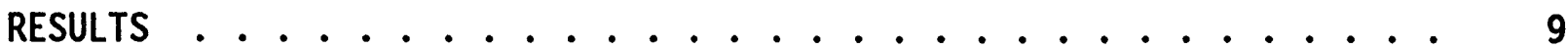

ANNOTATED VIDEO FOOTAGE . . . . . . . . . . . . . . . . 11

CONCLUSIONS . . . . . . . . . . . . . . . . . . 17 


\section{INTRODUCTION}

Materials for inert anodes are being developed at the Pacific Northwest Laborators for use in the electrochemical production of aluminum metal. Anodes produced from this material are projected to have useful lifetimes on the order of 5 years or more. Currently, carbon is used as the anode material and about $2 \mathrm{~kg}$ of carbon is consumed for every kilogram of aluminum produced. Carbon anodes weighing about $150 \mathrm{~kg}$ have a useful life of approximately 20 days. The inert anode material presently under investigation is a composite ferrite material with the general formula $\mathrm{Ni}_{x} \mathrm{Fe}_{1-x} \mathrm{O}-\mathrm{Ni}_{y} \mathrm{Fe}_{3-y} \mathrm{O}_{4}-$ $17 \% \mathrm{Cu}$. In laboratory electrolys is tests this material has exhibited a low corrosion rate and has yielded aluminum metal with low impurity levels.

During the electrolysis of aluminum, oxygen gas is released from ferrite electrodes; whereas $\mathrm{CO}_{2}(\mathrm{~g})$ is released from the carbon anodes currently used. Carbon dioxide results from the interaction of carbon and the oxygen released at the anode from the decomposition of alumina. Because the two gases are different and the surfaces from which they are released are different, the bubbles of $\mathrm{CO}_{2}$ and $\mathrm{O}_{2}$ are of different size and character. The $\mathrm{CO}_{2}(\mathrm{~g})$ bubbles released from carbon are usually large (several $\mathrm{mL}$ ), whereas the $\mathrm{O}_{2}(\mathrm{~g})$ bubbles released from the inert anode are smaller (about $50 \mu \mathrm{L}$ ). This difference in bubble character and size can be expected to cause differences in the stirring of the molten electrolyte during electrolysis.

A large-scale test of the ferrite inert anode concept is scheduled to be performed in a pilot cell at the Reynolds Metals Company, Sheffield, Alabama. In this test, six ferrite anodes will be tested under nearly industrial conditions to determine the survivability of the material. The $15-\mathrm{cm}(6-\mathrm{in}$. diameter anodes will be arranged in a rectangle. There is a concern that the rising $\mathrm{O}_{2}$ bubbles from each of the anodes in the cluster will cause insufficient stirring of the molten electrolyte to uniformly distribute dissolved $\mathrm{Al}_{2} \mathrm{O}_{3}$ to each anode. Adequate distribution of dissolved $\mathrm{Al}_{2} \mathrm{O}_{3}$ is necessary to prevent excessive corrosion of the anodes. To address this potential problem, a water model was constructed of the anode cluster and the half of the cell in which the inert anodes will be tested. Using this model, flow patterns in the cell could be observed. 
To model the oxygen evolution at the anodes, air was passed through graphite surrogate anodes. Room temperature water with 10 vol\% ethanol was used as a surrogate for the electrolyte. This solution was found to have about the same viscosity as a typical electrolyte would at $960^{\circ} \mathrm{C}$. In addition, when air was passed through graphite in this electrolyte smaller bubbles were formed than when $\mathrm{H}_{2} \mathrm{O}$ was used. A schematic of the surrogate anode is shown in Figure 1 and the experimental apparatus is schematically illustrated in Figure 2.

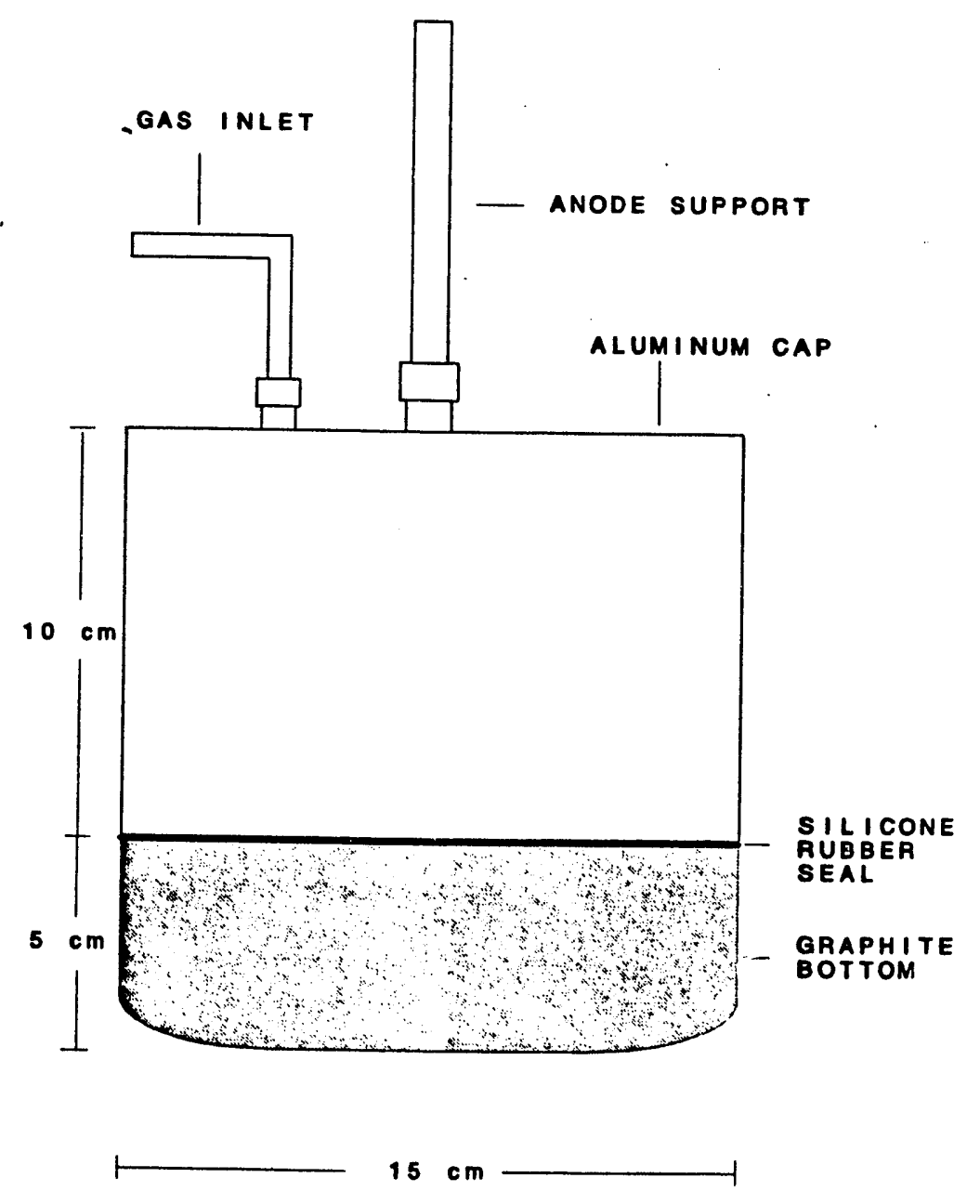

FIGURE 1. Schematic of the Surrogate Anode Used in the Water Model 


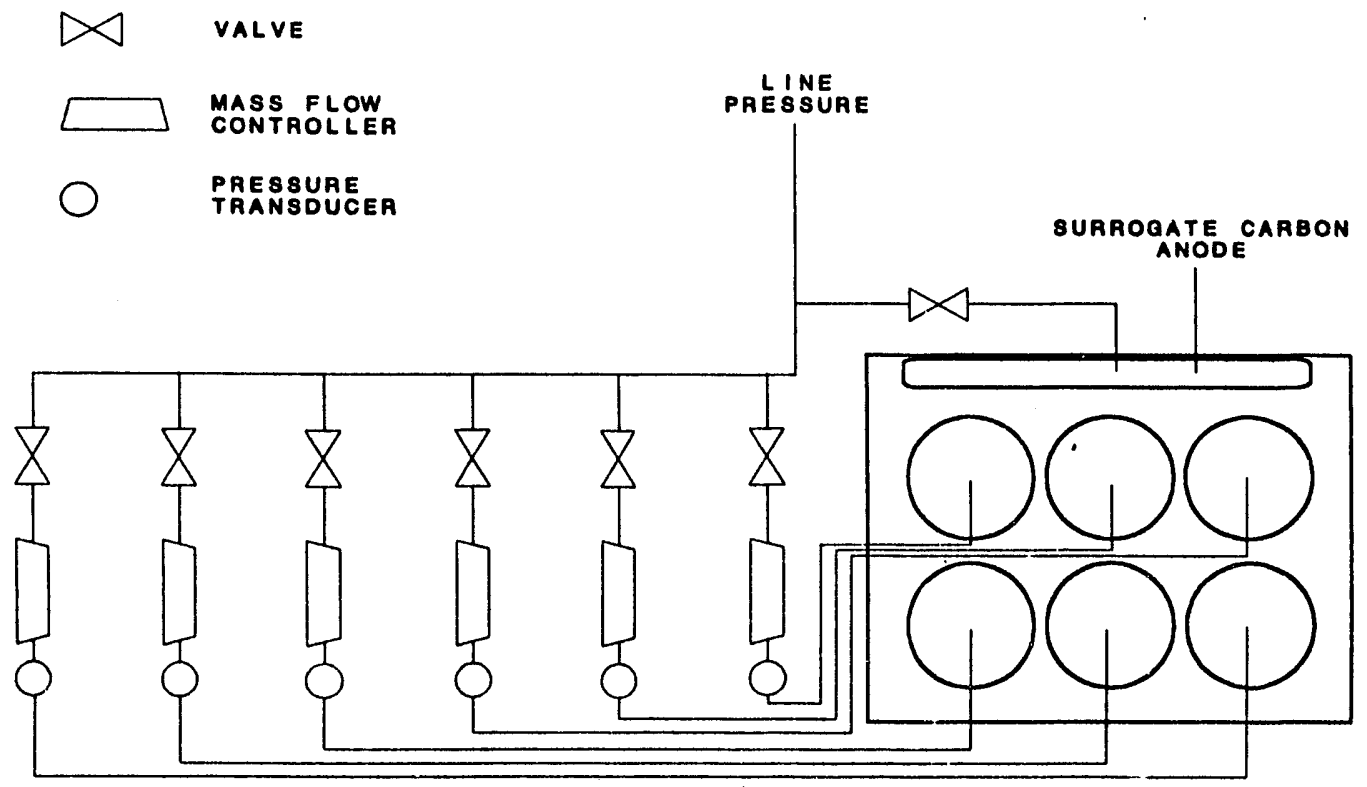

EIGURE 2. Schematic of the Water Model Experiment. The "cathode" is a piece of clear plastic $(1.5 \mathrm{~cm}$ thick) lying parallel to the bottom of the aquarium and beneath the anodes.

The surrogate anode is constructed from a commercial grade high-density graphite. Before the anode was made it was determined that the particular grade and manufacturer of the graphite had little impact on the behavior of the emitted gas. The bottom portion of the anode, made of graphite in the form of a right circular cylinder closed on one end, represents the inmersed portion of an actual inert anode. The exposed walls and the bottom of the graphite were $2.5 \mathrm{~cm}$ thick. The top $5 \mathrm{~cm}$ of the graphite were threaded to match the threads on the inside of the aluminum cap. The threaded aluminum cap was used to complete the pressure containment. Silicone caulking was used to make the seal between the aluminum cap and the graphite. This was accomplished by threading the cap on to the graphite cup to the last two or three threads, applying the caulking, and threading the cap to the last thread. If this was not done, air passed preferentially through the thin exposed portion of the graphite at the last thread.

A glass aquarium was used to simulate the walls of the pilot cell. A bubbler made from clear plastic was placed on the back wall of the "cell" to simulate the bubbling action of the carbon anode, which will also be in the Reynolds test. This bubbler was in the form of a rectangular parallelepiped 
with one wall missing. The open side was immersed in the water solution to form the bubbler. The gas flow through the bubbler was used to simulate the $\mathrm{CO}_{2}(\mathrm{~g})$ evolution from the carbon anode. The actual gas flow through this bubbler was not measured but estimated to be in the range of 1.5 to $2.5 \mathrm{x}$ $10^{-5} \mathrm{~m}^{3} / \mathrm{s}$ (100 to $200 \mathrm{cfh}$ ). The actual flow rate of gas from one face of the carbon anode in the pilot cell was calculated by R. D. Peterson (Reynolds Metals (o.) to be about $2 \times 10^{-5} \mathrm{~m}^{3} / \mathrm{s}(150 \mathrm{cfh})$ at the operating temperature of the cell.

It was difficult to control the gas flow through the anodes by means of the needle valves and rotameters originally used. Electronic flow controllers proved to be much more reliable than rotameters. The flow rate through the rotameters was very sensitive to changes in the back pressure; electronic flow controllers automatically compensated for changes in the back pressure as well as changes in the line pressure. Only five of the Datametrics(a) electronic flow controllers were located, so one rotameter was needed. The flow rate through the rotameter was calibrated using one of the electronic flow meters.

The pressure on each anode was monitored using electronic pressure transducers (Validyne Corp.). (b) These pressure transducers were calibrated using an absolute pressure gauge (Heise Inc.).(c) Because there were slight differences in the thickness of the graphite anodes and some differences in the porosity of the graphite, even within the same batch oi material, each anode required a different pressure to obtain the correct gas flow rate.

Plotter pen ink was used to determine the flow patterns in the cell. The movement of the ink through the "cell" was monitored with a video camera and recorded on tape. The results discussed later in this document summarize the information shown in the video.

(a) Datametrics, Willmington, Massachusetts.

(b) Validyne Corporation, Northridge, California.

(c) Heise Inc., is no longer in business. 
In order to determine the gas flow rate needed for each anode, the effective permeability of each anode was measured. The gas flow through porous media is related to the pressure drop and the permeability by Darcy's equation (Amyx, Bass, and Whiting 1960):

$$
Q_{b}=\frac{k A}{2 \mu L} \frac{P_{1}^{2}-P_{2}^{2}}{P_{b}}
$$

where: $Q_{b}=$ the gas flow rate at the low pressure side of the medium $\left(\mathrm{m}^{3} / \mathrm{s}\right)$

$A=$ the area of the medium $\left(m^{2}\right)$

$L=$ the thickness of the medium (m)

$k=$ the permeability $\left(\mathrm{m}^{2}\right)$

$\mu=$ the viscosity of the gas $(\mathrm{Pa} \cdot \mathrm{s})$

$P_{1}=$ the pressure at the high-pressure side of the medium $(\mathrm{Pa})$

$P_{2}=$ the pressure at the low-pressure side of the medium and, for this application, equal to $\mathrm{P}_{\mathrm{b}}(\mathrm{Pa})$.

Rather than measure the permeability of the graphite in each of the anodes and determining the anode surface area and thickness, the effective permeability of each anode was measured. Here, the effective permeability of the graphite portion of each anode includes all of the non-pressure terms on the right side of Equation 1. These effective permeabilities were determined by measuring the pressure at each anode at three flow rates. The gas flow rate on the high-pressure side of an anode can be measured and the flow rate at the low-pressure side can be calculated using the ideal gas equation. These effective permeabilities were used to calculate the flow rate at the high-pressure (control) side of the anode that was needed to simulate the oxygen evolution at the surface of an operating anode.

It was assumed that each anode in the large-scale test would be operating at 200 amperes. The oxygen evolution corresponding to this operating current and an operating temperature of $1243 \mathrm{~K}(970 \cdot \mathrm{C})$ is $3.19 \mathrm{~L} / \mathrm{min}$. This 
flow rate was used as the flow rate from each surrogate anode at room temperature and was converted to standard conditions that are the units of measure used for the flow controllers. Equation 1 was used with the effective permeabilities of the anodes and the flow rate at standard conditions to calculate the steady-state pressures in each anode. From the value of the pressure, the set point for the flow controller at each anode was calculated.

Gas flow through the anodes was started before the anodes were submerged in water. It has been observed (and corroborated by $\mathrm{Dr}$. James Evans at the University of California Berkeley) that uneven gas flow and high pressures resulted when the anodes were placed in water before initiating the gas flow. Pressure increases of $15 \mathrm{kPa}$ to $20 \mathrm{kPa}$ ( 2 to $3 \mathrm{psi}$ ) were observed upon immersion of the anodes even when the gas flow was started before immersion. This is undoubtedly due to the capillarity of water in the graphite; it takes extra pressure to keep water from entering the pores. The increase in pressure was not used to correct the flow rate because of its variability and low impact on the results.

A "cathode" was also present in the tank to determine the effect of changes in the anode-to-cathode distance. The "cathode" consisted of a piece of clear plastic approximately the size of the aquarium bottom with adjustable-length legs. The anode-to-cathode distance could be changed by adjusting the length of the legs. Two anode-to-cathode settings were used: $7.5 \mathrm{~cm}$ (3 in.) and $3.8 \mathrm{~cm}(1.5$ in.).

In an actual experiment, gas flow was initiated in the anodes, which were in position at a set anode-to-cathode distance. Gas flow to the surrogate carbon anode was also started at this time. Water was then added to the tank until the anodes were partially submerged. Sufficient ethanol was added to the tank to make the final solution 90 vol\% water and 10 vol\% ethano1. After stirring the solution to mix the two liquids, additional water was added to bring the level to the top of the graphite portion of the anodes. [It should be noted that one anode was inadvertently cut about $2.5 \mathrm{~cm}$ (1 in.) too short during final machining. This did not seem to have a significant effect on the results of the experiment.] 


\section{RESULTS}

The results of this test are documented in the video DMS-V-89-1 and DHS-V-4, an edited version of DMS-V-89-1. However, some of the results obtained are stated here.

In general, the bubhie size was quite small once the air was released to the solution. The air bubbles from some of the anodes appeared to be somewhat larger than the oxygen bubbles evolved from the inert anode in molten cryolite. Two of the anodes (\#5 and \#6) (see Figure 3) seemed to evolve bubbles with a distribution weighted toward smaller sizes, while anodes \#1 through \#3 seemed to evolve slightly larger bubbles. On anodes \#1 through \#3 the bubbles seemed to collect into larger bubbles more readily than the other three anodes. This may have given the appearance of evolving larger bubbles.

Stirring of the water by the bubble evolution is most easily seen by the motion of the fine bubbles. These bubbles seem to be carried to a depth

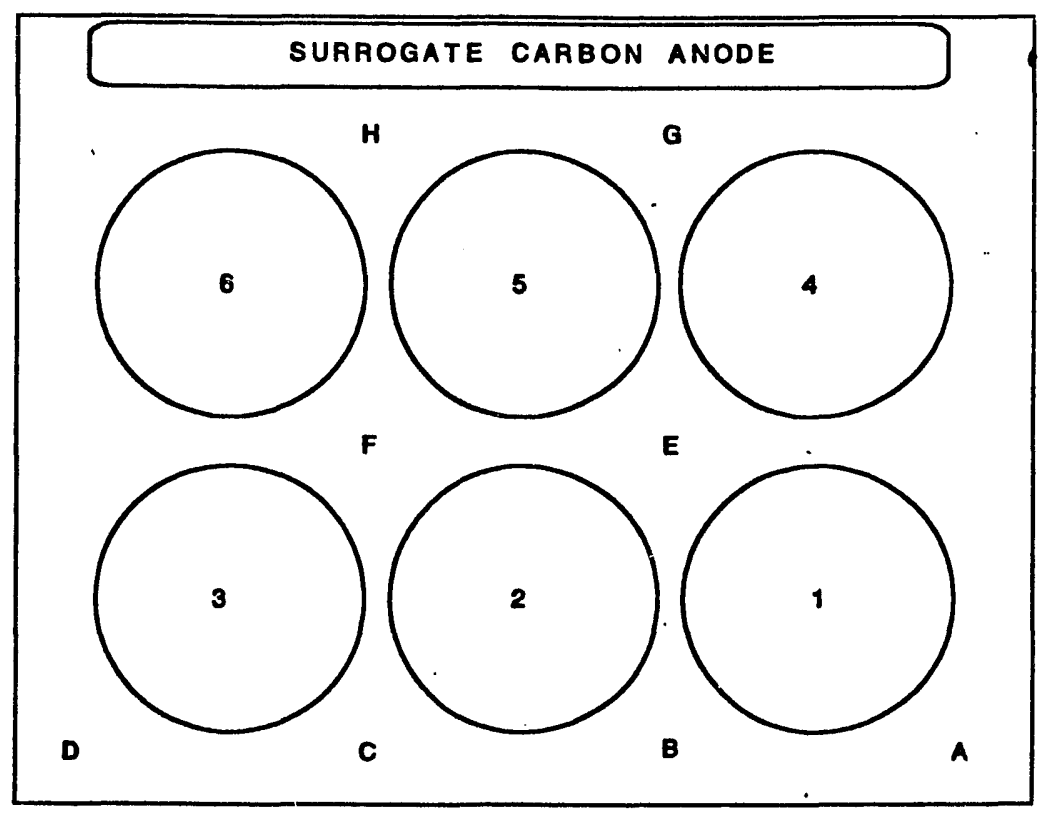

FIGURE 3. Layout of the Surrogate Anodes and Position Reference Points for the Water Model (not to scale) 
of about 3 to $7 \mathrm{~cm}$ below the bottom of the anodes. The effect of the bubbles evolved from the surrogate carbon anode was to cause a gentle rocking of the entire contents of the tank.

In the original test matrix, plans called for adding ink and/or nylon beads at several places in the tank. After several additions of ink, it became apjarent that only the addition of ink near the surface of the water was effective. When the ink was added at the cathode, the ink formed a layer on the cathode that remained for long periods of time and essentially gave no useful information. Ink additions at the surface or near the surface were effective in dotermining the broad flow patterns in the water model. While some of the nylon beads remained suspended in the water solution, most sank immediately to the cathode. Some information can be obtained from observing the motion of the nylon beads, but in general, useful information was obtained from the injections of ink. These experiments indicate that the alumina feed may be added at almost any point in the cell to achieve adequate distribution of the alumina. However, to err on the conservative side, alumina should be added at two points--E and $F$ (Figure 3 ). 
The following information is supplied for understanding the video tapes DMS-V-89-1 and DMS-V-89-4 (copy). The first tape is unedited and approximately $90 \mathrm{~min}$ in length. The latter tape [DMS-V-89-4 (copy)] is an edited version and approximately $35 \mathrm{~min}$ in length. Ink or nylon beads were added at the places specified by letters; refer to Figure 3 for the positions to which these letters refer.

\section{NOTES ON THE EVENTS SHOWN ON \\ VIDEO TAPE DMS-V-89-1 (UNEDITED)}

\begin{tabular}{|c|c|}
\hline Feet & Comment \\
\hline $0-33$ & $\begin{array}{l}\text { No additions; lighting from the right side with a } 1000 \mathrm{~W} \\
\text { spot light. The anode-to-cathode distance is about } 7.5 \mathrm{~cm} \\
\text { (3 in). The solution is water-10 vol\% ethanol at room } \\
\text { temperature. }\end{array}$ \\
\hline $33-154$ & $\begin{array}{l}\text { Ink added at position } F \text { and then at position } E \text {. Lighting } \\
\text { from the right side }\end{array}$ \\
\hline $154-262$ & $\begin{array}{l}\text { Ink added under \#2 anode. The ink goes directly to the bot- } \\
\text { tom indicating poor solution flow at this point or insuffi- } \\
\text { cient flow to overcome the density difference between the } \\
\text { water and the ink. }\end{array}$ \\
\hline $262-586$ & Ink added at $E$ and $F$. \\
\hline $586-612$ & $\begin{array}{l}\text { No additions. New solution in the tank; new run with better } \\
\text { lighting. The lighting consists of } 1000 \mathrm{~W} \text { quartz lamps at } \\
\text { each side and above the tank. }\end{array}$ \\
\hline $612-634$ & Ink added by drops at positions $E$ and $F$. \\
\hline $634-652$ & Ink added by drops at positions $B$ and $C$. \\
\hline $652-690$ & Ink added by drops at positions $A$ and $D$. \\
\hline $690-722$ & Ink added by drops at positions $G$ and $H$. \\
\hline $722-795$ & Nylon beads added first at position $E$ then at $F$. \\
\hline $795-841$ & Ink added under anode \#2. \\
\hline $841-865$ & $\begin{array}{l}\text { Equipment: pressure readout and transducers and flow } \\
\text { controller readout and transducers. }\end{array}$ \\
\hline
\end{tabular}


Feet

$865-916$

$916-965$

$965-1038$

$1038-1040$

$1040-1048$

$1048-1075$

$1075-1111$

$1111-1137$

$1137-1187$

$187-1265$

$1265-1359$

$1359-1392$

$1392-1484$
Nylon beads added first at positions $E$ and $F$, then from $G$ to $\mathrm{H}$.

Ink added first at position $E$ and then at $F$.

Ink added at position $E$. The hand seen at the rear of the tank was adjusting the height of the surrogate carbon anode.

Water-only footage. In this picture, which lasts only a short time, the anodes are not quite fully submerged but will be when the ethanol is added. The ACD is $3.8 \mathrm{~cm}$ (1.5 in).

Ethanol has been added. Note the fine bubbles that were not present in the water-only case.

Nylon beads added.

Ink added at position $E$. Note that the flow appears to be from the right toward the left.

More ink added at position $E$. The ink cannot be seen well.

More ink added in front of anodes \#1 and \#3.

Attempted to add ink under anode \#3 through a hole in the cathode. Finally, ink was added on the cathode at position $F$. The movement still appears to be from the right toward the left. The ink appears to be more intense in the middle because of the side illumination. Close up of anode \#2.

Ink added at position $G$.

New run with fresh solution. Bottom view of the cell. The photographic lights are off. Forgot to turn on the surrogate carbon anode. Lights come on at 1377 feet, but the overhead light is left off to prevent camera saturation with light.

Ink added at positions $E$ and $F$. Upper quartz lamp is switched on at 1446 feet. At 1449 feet more ink is added. 


\section{Feet}

$1484-1573$

$1573-1646$

$1646-1810$

$1810-1844$

$1844-1911$

More ink is added at positions $E$ and $F$. Note that anode \#1 is at the lower left of the screen and \#6 is at the upper right. This is because of the camera orientation under the tank. Ink is added through the wand at 1515 feet at position F. Note that the ink is on the "cathode" and there is a spiral of rising ink between anodes \#5 and \#6. If the light were better a similar spiral could be seen between anodes \#2 and \#3.

A close up of anodes \#2 and \#3. The ink on the "cathode" is the same as in the previous footage (1515 feet). The ink is actually rising at position $C$ - between the front of the tank and anodes \#2 and \#3.

Ink is added at position F. Anode \#2 is shown at the right of the screen (note the shallower graphite section).

Nylon beads are added at position $E$. The side view is now of anodes \#1 and \#2. Anode \#2 is now shown on the left side of the screen. More beads are added at 1829 feet.

Ink is added with the wand at position $E$ on the cathode. More ink is added at 1873 feet, but between anodes \#1 and \#2. More ink is added at 1894 feet. 
NOTES ON THE EVENTS SHOWN ON

VIDEO TAPE DMS-V-89-4 (COPY) (EDITED)

Feet

000

056

120

173

268

346

445

545

565

658

773

853

952

1148

1248

1365

Comment

Color bars

Equipment: pressure readout and flow controller readout -an extra flow transducer is on top of the flow controller; pressure transducers and flow controller transducers. Note the rotameter at the left of the screen.

Aquarium (the water is dark from added ink)

The $A C D=7.5 \mathrm{~cm}(3$ in.). A strong light is located on the right side. Ink is added at position $F$.

Ink added at position E.

Ink added under anode \#2.

Ink added under anode \#1.

Ink added at position $E$.

New lighting $1 \mathrm{~kW}$ quartz 1 ight above and $1 \mathrm{~kW}$ quartz 1 ight on each side. The $A C D=3.8 \mathrm{~cm}$.

Add nylon beads at positions $F$ and $E$.

Ink added at positions $F$ and $E$.

Ink added at position $G$.

Ink added in front of anodes \#1 and \#3.

Ink added on the cathode at positions $E$ and $F$.

Bottom view. In this view the front anodes in the previous pictures are at the bottom of the screen and the right anode from previous footage is now at the left of the screen. Ink is added just below the surface at positions $F$ and $E$.

Still bottom view. Ink is added on the cathode at positions $F$ and $E$. Note swirling ink rising between upper right anodes (position $\mathrm{H}$ ).

Close up side view of rising ink shown in the previous footage of the bottom view. Rising ink is coming from a pool of ink lying on the cathode. Swirls indicate turbulent flow rising between the anodes. View is of position $C$. 
Feet

1585

1683

1782

1860

1910

1970

20,'s

2142

2308

2367

2419
Comment

Switch to the anodes on the right hand side of the aquarium. Note that the anode with the short graphite section is now on the left whereas in the previous footage it was on the right of the screen. View is of position $B$.

Nylon added at position $E$.

Ink added on the cathode at position $E$.

Ink is added on the cathode at a position between anodes \#1 and \#2.

Ink added on the cathode at position $E$.

Ink added at positions $F$ and $E$.

Ink added at positions $C$ and $B$.

Ink added at position $G$.

Ink added at position $E$.

Ink added under anode \#2.

End 
It is important to note that, because of the lighting in this tank, it often appears that the ink is not well distributed in the tank. In general, the ink did distribute throughout the tank, but did so somewhat slowly. 


\section{CONCLUSIONS}

In general, the system appears to be well stirred, but slowly stirred. The ink tracer did not function as well as had been anticipated in part because of the probable density difference and in part because of the gentleness of the stirring. The ink tracer tended to be rapidly dispersed when injected into the areas of fine hubbles. Results also indicated that ore additions to the pilot cell at Reynolds from the existing feeder (located at approximately position $G$ in Figure 3 ) would probably be distributed to all of the inert anodes in the cell. However, to err on the conservative side, it would appear prudent to add ore at the equivalent of positions $E$ and $F$ (Figure 3 ) to ensure good distribution of the dissolved alumina.

Results from the water model were inconclusive with respect to changes in the anode-to-cathode distance. The action of the fine bubbles suggest that the flow of solution on the cathode should have been more turbulent when the distance was $3.8 \mathrm{~cm}$ than at $7.5 \mathrm{~cm}$, but when ink was placed on the cathode no observable changes in distribution were noted.

The water model appears to be a rather quiescent model of the actual situation in a large electrolysis cell. The bubbles that are formed on the ferrite surfaces in molten cryolite appear to be smaller and more readily released from the surface than those observed in the water model. The presence of thermal gradients and concentration gradients due to the actual electrolysis processes is likely to result in more turbulent conditions in the actual electrolysis cell. This fact, coupled with the observations made in assessing the behavior of the water model, lead to the conclusion that there should be adequate ore distribution to all inert anodes in the pilot cell. 


\section{REFERENCE}

Amyx, J. W., D. M. Bass, Jr., and R. L. Whiting. 1960. Petroleum Reservoir Engineering - Physical Properties. McGraw-Hil1 Book. Company, New York. 


\section{DISTRIBUTION}

No. of

Copies

\section{OFFSITE}

M. J. McMonigle

U.S. Department of Energy

Office of Industrial Programs

Forrestal Building

Washington, DC 20585

P. H. Salmon-Cox

U.S. Department of Energy

Office of Industrial Programs

Forrestal Building

Washington, DC 20585

12 DOE Office of Scientific and

Technical Infornation

C. Anderson

Columbia Aluminum Co.

85 John Day Dam Road

Goldendale, WA 98620

J. V. Anderson

WCVE3

EG\&G Idaho, Inc.

Idaho Falls, ID 83415

D. Auburg

Bonneville Power Administration

P.0. BoX 3621, PDX 97208

Portl and, OR 97208

F. W. Baker

Ceramics Division

Alcoa Laboratories

Alcoa Center, PA 15069

M. Baltzell

Eastalco Aluminum Company

Alumax, Inc.

5601 Manor Woods

Frederick, MD 21701
No. of

Copies

J. A. Barclay

U.S. Bureau of Mines 2401 "E" Street N.W. Washington, DC 20241

H. Robert Baumgartner Ceramics Division

Alcoa Laboratories

Alcoa Center, PA 15069

T. R. Beck

Electrochemical Technology Corp.

1601 Dexter Avenue

Seattle, WA 98109

S. Berwagan

Bonneville Power

Adrninistration

P.0. Box $3621 \mathrm{~K}$

Portland, OR 97208

T. M. Besmann

Metals and Ceramics Division

Oak Ridge National Laboratory

P.0. Box X, B 7 dg. 4515

Oak Ridge, TN 37831-6063

K. A. Blakely

President

Advanced Refractory

Technologies, Inc.

699 Hertel Ave.

Buffalo, NY 14207

M. H. Blenk

Du Pont

P.0. Box 787

Niagara Falls, NY 14302

L. G. Boxall

Martin Marietta Laboratories

1450 South Rolling

Baltimore, MD 21227 
No. of

Copies

J. Bracher

Kaiser Aluminum and Chemical Corp.

825 N.E. Multnomah St., Suite 960

Portland, OR 97232-2150

R. Brandt

Department of Materials Science and Engineering University of Washington FB-10 Seattle, WA 98195

J. J. Brown, Jr.

Materials Engineering

Virginia Polytechnic Institute Blacksburg, VA 24061

A. Budner

Bonneville Power

Administration

P.0. Box 3621--EPA

Portland, OR 97208

A. J. Caputo

Developmeni Division

Oak Ridge $Y-12$ Plant

Building 9202 MS-8095

Oak Ridge, TN 37831-8095

N. Clark

Bonneville Power

Administration

Industrial Conservation

P.0. Box 3621

Porti and, OR, 97208

A. Cooke

Martin Marietta Laboratories

1450 South Rolling

Baltimore, MD 21227

J. A. Coppola

Standard 0il Engineered Materials Company

P.0. Box 156

Niagara Falls, NY 14302
No. of

Copjes

Business Expansion

Division Library

Washington State ient of Trade

Business Expansion Library

2001 6th Avenue \# 2700

Seattle, WA 98121-2522

R. Curtis

Materials Development Corporation

81 Hicks Avenue

Medford, MA 02155

J. V. Day

Kaiser Aluminum and Chemical Corp

E2111 Hawthorne Road

Mead, WA 99021

D. H. DeYoung

Alcoa Technical Center

Alcoa Center, PA 15069

S. Diamond

Battelle Columbus Laboratories

505 King Avenue

Columbus, $\mathrm{OH}$ 43201-2693

C. W. Doerr

The Stackpole Corporation

Cermag Division

201 Stackpole Street

St. Marys, PA 15847

T. Dwonch

Snake River District

BPA

101 W. Poplar

Walla Walla, WA 99362

G. L. Eitel

Stone \& Webster Engineering

Corp.

Greenwood Plaza Box 5406

Denver, CO 80217 
No. of

Copies

R. Engdah1

Deposits and Composites, Inc.

318 Victory Drive

Herndon, VA 22070

J. F. Elliott

MIT

Room 4-138

77 Massachusetts Avenue

Cambridge, MA 02139

B. G. Epstein

A. D. Little, Inc.

955 l.enfant Plaza SW 4200

Washington, DC 20024-2119

J. W. Evans

University of California

Dept of Mat1. Sci. and Mineral Eng.

Berkeley, CA 94720

R. A. Fenimore

ICI Advanced Materials

Rollins Building, Eighth Floor

Wilmington, DE 19897

D. A. Figgins

ARCO Petroleum Products Co.

P.0. Box 61004

Anaheim, CA 92803-6104

P. Foster

Alcoa Laboratories

P.0. Box 772

New Kensington, PA 15068

J. Gee

Great Lakes Research Corp

P.0. Box 1031

Elizabethton, TN 37643

T. Gilligan

Eitech Systems Corp.

625 East Street

Fairport Harbor, $\mathrm{OH} 44077$
No. of

Copies

W. M. Goldberger

Superior Graphite Co.

120 S. Riverside Plaza

Chicago, IL 60506

J. Goodwel1

Center for Metals Production

Mellon Institute

$4400 \mathrm{Fifth}$ Avenue

Pittsburgh, PA 15213

J.A.S. Green

Mart in Marietta Laboratories

1450 South Rolling

Baltimore, MD 21227

C. Griffin

Ceramatec Inc.

2425 S. 900 West

Salt Lake City, UT 84119

L. I. Grindstaff

Great Lakes Research Corp.

P.0. Box 1031

Elizabethon, TN 37643

J. Haggerty

MIT

Building 12, Room 009

77 Massachusetts Avenue

Cambridge, MA 02139

I. L. Harry

Electric Power Research Institute

P.0. Box 10412

Palo Alto, CA 94303

W. E. Haupin

2820 7th Street Road

Lower Burre11, PA 15068

R. $\mathrm{Hill}$

Union Carbide Corp.

P.0. Box 94637

Cleveland, $\mathrm{OH} \quad 44101$ 
No. of

Copies

H. F. Hillegass

Alcoa Wenatchee Works

P.0. Box 221

Wenatchee, WA 98807

D. G. Howitt

College of Engineering

University of California, Davis

Davis, CA 95616

F. R. Huettig

Advanced Magnetics, Inc.

45 Corey Lane

Mendham, NJ 07945

G. R. Hyde

U.S. Bureau of Mines

2401 "E" Street N.W.

Washington, DC 20241

S. C. Jacobs

Primary Processing

Aluminum Company of America

Alcoa Technical Center

Alcoa Center, PA 15069

S. H. Jan

Tennessee Valley Authority

R\&D Division - MR 3A

Chattanooga, TN 37401

N. Jarrett

149 Jefferson Avenue

New Kinsington, PA 15068

J. Johnson

Intalco Aluminum Company

P.0. Box 937

Ferndale, WA 98248

M. H. Johnson

Alcoa Wenatchee Works

P.0. Box 1031

Elizabethon, TN 37643
No. of

Copies

L. Joo

Great Lakes Research Corp

P.0. Box 1031

Elizabethon, TN 37643

M. Karmous

Oregon State Department of Energy

625 Marion Street, N.E.

Salem, OR 97310

R. Keller

RD 3 Roundtop Road

Export, PA 15632

K. Krupinski

Mail Stop 57

U.S. Steel Technical Center

1 Technical Center Drive

Monroeville, PA 15146

G. Y. Lai

Cabot Corporation

P.0. Box 9013

Kokomo, IN 46902-9013

R. A. Landy

Director of Research

North American Refractories

Co.

3127 Research Dr.

State College, PA 16801

J. E. Lane

Ceramic Research and

Development Center

Westinghouse Electric

Corporation

1310 Beulah Road

Pittsburgh, PA 15235

Sai-Kwing Lau

Standard $0 i 1$ Engineered

Materials Company

Niagara Falls R\&D Center

P.0. Box 832

Niagara Falls, NY 14302 
No. of Copies

J. J. Leddy

Dow Chemical U.S.A.

1776 Building

Midl and, MI 48640

W. W. Liang

Gas Research Institute

8600 West Bryne Mawr Avenue

Chicago, IL 60631

W. H. Link

Columbia Aluminum Corp.

85 John Day Dam Road

Goldendale, WA 98620

Steve Loftness

Washington State Energy Office 400 E. Union

Olympia, WA 98504

\section{W. Long}

Building B815

Dow Chemical

Freeport, Texas 77541

\section{A. G. Longmuir}

Kaiser Aluminum and Chemical Corp.

P.0. Box 877

Pieasonton, CA 94566

R. A. Lowden

Metals and Ceramics Division

Oak Ridge National Laboratory

P.O. Box X, Bldg, 4515

Oak Ridge, TN 37831-6063

\section{W. N. Maclay}

Koppers Company, Inc.

1005 William Pitt Way

Pittsburgh, PA 15238-1336

J. C. McCloskey

Ten Mile River Associates

$296 \mathrm{Mt}$. Hope Street

North Attleboro, MA 02760
No. of

Copies

S. C. Manaktala

Manager. of Technology

Reduction Division

Kaiser Aluminum and Chemical Corp

300 Lakeside Drive

Oakland, CA 94643

V. H. Markant

Du Pont

P.0. Box 787

Niagara Falls, NY 14302

C. J. McMinn

Extractive Metallurgical Department

Reynolds Metals Company

P.0. Box 1200

Sheffield, AL 35660

C. H. McMurtry

Standard 0 il Engineered Materials Company

Niagara Falls R\&D Center

P.0. Box 832

Niagara Falls, NY 14302

M. A. Mitnick

Avco Specialty Materials

Subsidiary of Textron Inc.

2 Industrial Avenue

Lowel1, MA 01851

H. Mortensen

R. Palika

Cercom, Inc.

P.0. Box 70

Vista, CA 92083

B. C. Mutsuddy

Battelle Columbus Division 505 King Avenue

Columbus, $\mathrm{OH}$ 43201-2693 
No. of

Copies

P. Ness

Washington State Dept of Trade and Economic Development

2001 6th Avenue \#2600

Seattle, WA 98121-2522

J. R. Payne

Kaiser Aluminum and Chemical Corp.

P.0. Box 877

Pleasanton, CA 94566

T. Payne

Columbia Falls Aluminum Co.

Columbia Falls, MT

W. Pebley

Oregon Freeze Dry Corp.

525 25th Avenue SW

P.0. Box 1048

Albany, OR 97321

K. Peterson

Columbia Aluminum Corp.

85 John Day Dam Road

Goldendale, WA 98620

R. D. Peterson

Reynolds Metals Company

P.0. Box 1200

Sheffield, AL 35660

T. R. Pritchett

Kaiser Aluminum and Chemical Corp.

P.0. Box 877

Pleasanton, CA

W. W. Pritsky

Aluminum Association

900 19th St. N.W.

Washington, DC 20006

S. P. Ray

Alcoa Technical Center

Alcoa Center, PA 15069
No. of

Copies

J. F. Rhodes

Advanced Composite Materials Corp.

$1525 \mathrm{~S}$. Buncomb Rd.

Greer, SC 29651

N. E. Richards

Reduction Laboratory

Reynolds Aluminum Corporation P.0. Box 1200

Sheffield, AL 35660

J. J. Ritter

Ceramics Division

National Bureau of Standards

Gaithersburg, MD 20899

R. C. Rohwedder

3028 Ohio Street

Longview, WAD. R. Sadoway

MIT

Room 8-109

77 Massachusetts Avenue

Cambridge, MA 02139

W. Scott

Department of Materials

Science \& Engineering

Wilcox Hall FB-10

University of Washington

Seattle, WA 98195

D. R. Secrist

Great Lakes Research Corp.

P.0. Box 1031

Elizabethon, TN 37643

A. B. Shah

Noranda Aluminum, Inc.

P.0. Box 70

New Madras, MO 63869

N. Shelton

Intalco

1300 S. W. 5th, Suite 3508

Portland, OR 97201 
No. of

Copies

Brian Spector

Pace Consultants

4848 Loop Central Drive

Houston, TX 77081

F. W. Spillers

Dow Chemical U.S.A.

B-1210 Building

Freeport, TX 77541

Dr. Richard M. Spriggs

Office of the Director

Center for Advanced Ceramic Technology

Alfred University

Alfred, NY 14802

D. V. Stewart

Reynolds Metals Co.

P.0. Box 1200

Sheffield, AL 35660

D. Strahan

Reynolds Metals Company

P.0. Box 27003

Richmond, VA 23261

A. T. Tabereaux

Reynolds Metals Company

P.0. Box 1200

Sheffield, AL 35660

G. P. Tarcy

Aluminum Company of America

Alcoa Technical Center

Alcoa Center, PA 15069

P. Thaure

Primary Planning and

Production Al umax

400 S. El Camino Rd.

San Mateo, CA 94402

W. H. Thielbahr

Conservative Technology Div.

DOE-Idaho Operations Office

785 DOE Place

Idaho Falls, ID 83402
No. of

Copies

S. Thomson

General Manager

K1 ickitat PUD

$1313 \mathrm{~S}$. Columbus

Goldendale, WA 98620

R. Unger

Merner Research

P.0. Box 248

Ridgewood, NJ 07451A. Vinnard

Bonneville Power Administration (KWI)

P.0. Box 3621

Portland, OR 97208

T. Von Muller-KWI

Bonneville Power

Administration

P.0. Box 3621

Portland, OR 97208

D. H. Weinblatt

AIMCOR

One Parkway North

Deerfield, IL 60015

J. D. Weyand

EG\&G Idaho, Inc.

Idaho Falls, ID 83415

B. Wilcox

Northwest Aluminum Co.

3313 W. Second St.

The Dalles, OR 97058

C. B. Wilson

Dow Chemical U.S. A.

Texas Operations

B-101 Building

Freeport, TX 77541

\section{FOREIGN}

D. Brodie

Comalco Ltd.

55 Collins St.

Melbourne, AUSTRALIA 
No. of

Copies

H. Connor

Group Licensing Controller

Johnson Matthey, plc

New Garden House

78 Hatton Garden

London ECIN 8JP ENGLAND

L. Dion

Alcan International Limited

C.P. 6090

Montreal, Quebec

CANADA, H3C $3 \mathrm{H} 2$

T. Kjar

Comalco Ltd.

55 Collins St.

Melbourne, AUSTRALIA

E. W. Dewing

Alcan International

P.0. Box 8400

Kingston, Ontario

CANADA K7L $4 Z 4$

D. N. MacMillan

Alcan International

C.P. 1250

Jonquieve, Quebec

CANADA G7S $4 K 8$

J. H. Reimers

Jan H. Reimers and Associates

Inc.

221 Lakeshore Road East

Oakville, Ontario

CANADA, L6J $1 \mathrm{H7}$

A. Oye

Institute of Inorganic

Chemistry

Norwegian Institute of

Technology

University of Trondheim

N-7034 Trondhe im-NTH, NORWAY
No. of

Copies

J. Thonstad

Laboratories of Industrial

Electrochemistry

Norwegian Institute of

Technology

University of Trondheim

N-7034 Trondheim-NTH, NORWAY

K. 0 . Vee

ASV Ardal Verk

N-5875 Ardalstargen, NORWAY

Dr. Eric Frazer

CSIRO Australia

Division of Mineral Products

339 Williamstown Road

P.0. Box 124

Port Melbourne, Vic 3207

\section{ONSITE}

DOE Field Office, Richland

R. B. Goranson

25 Pacific Northwest Laboratory

M. Clement

N. C. Davis

D. K. Hilliard

G. L. McVay

N. L. Moore

L. G. Morgan

C. H. Schilling

D. M. Strachan

R. E. Westerman

C. F. Windisch (10)

Publishing Coordination

Technical Report Files 

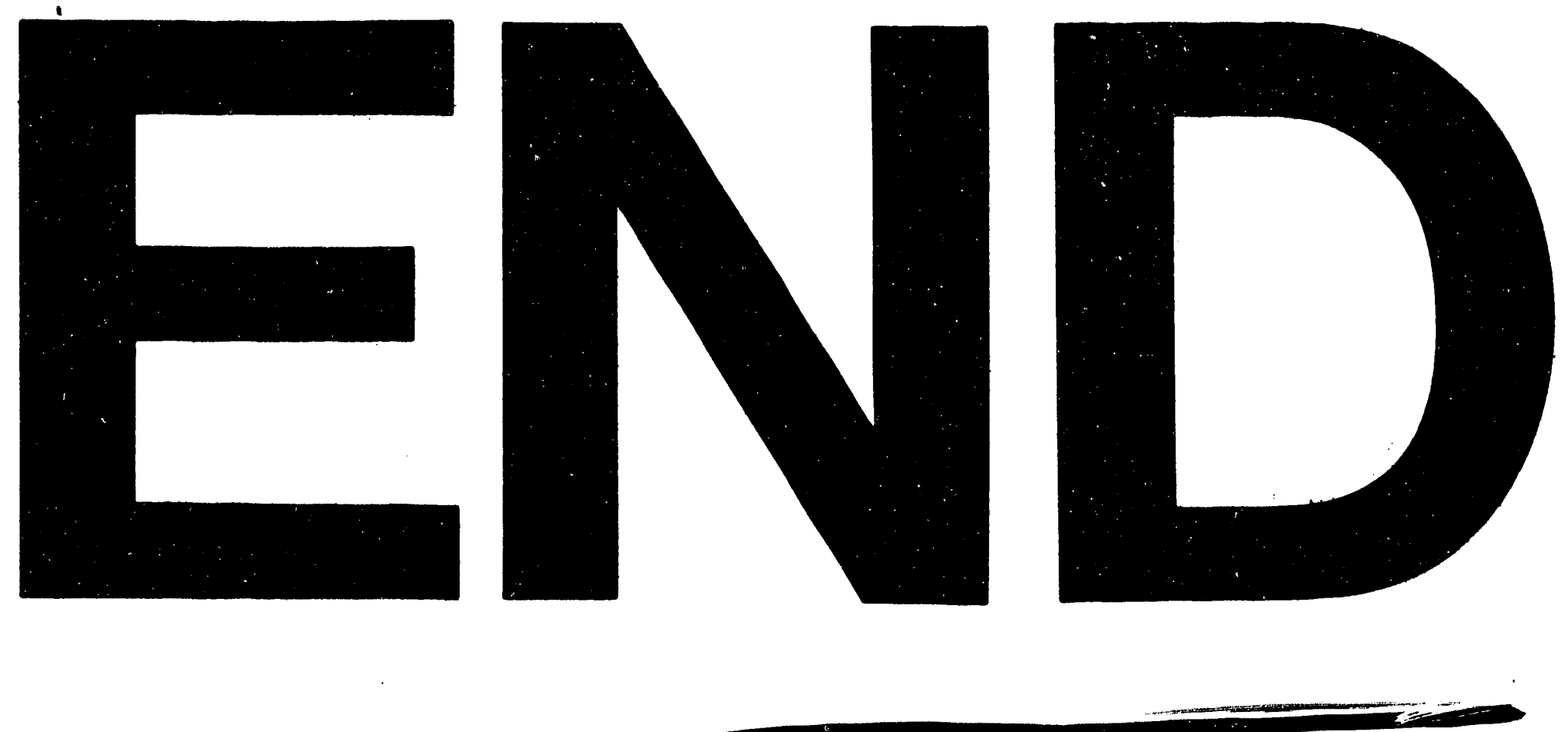

4

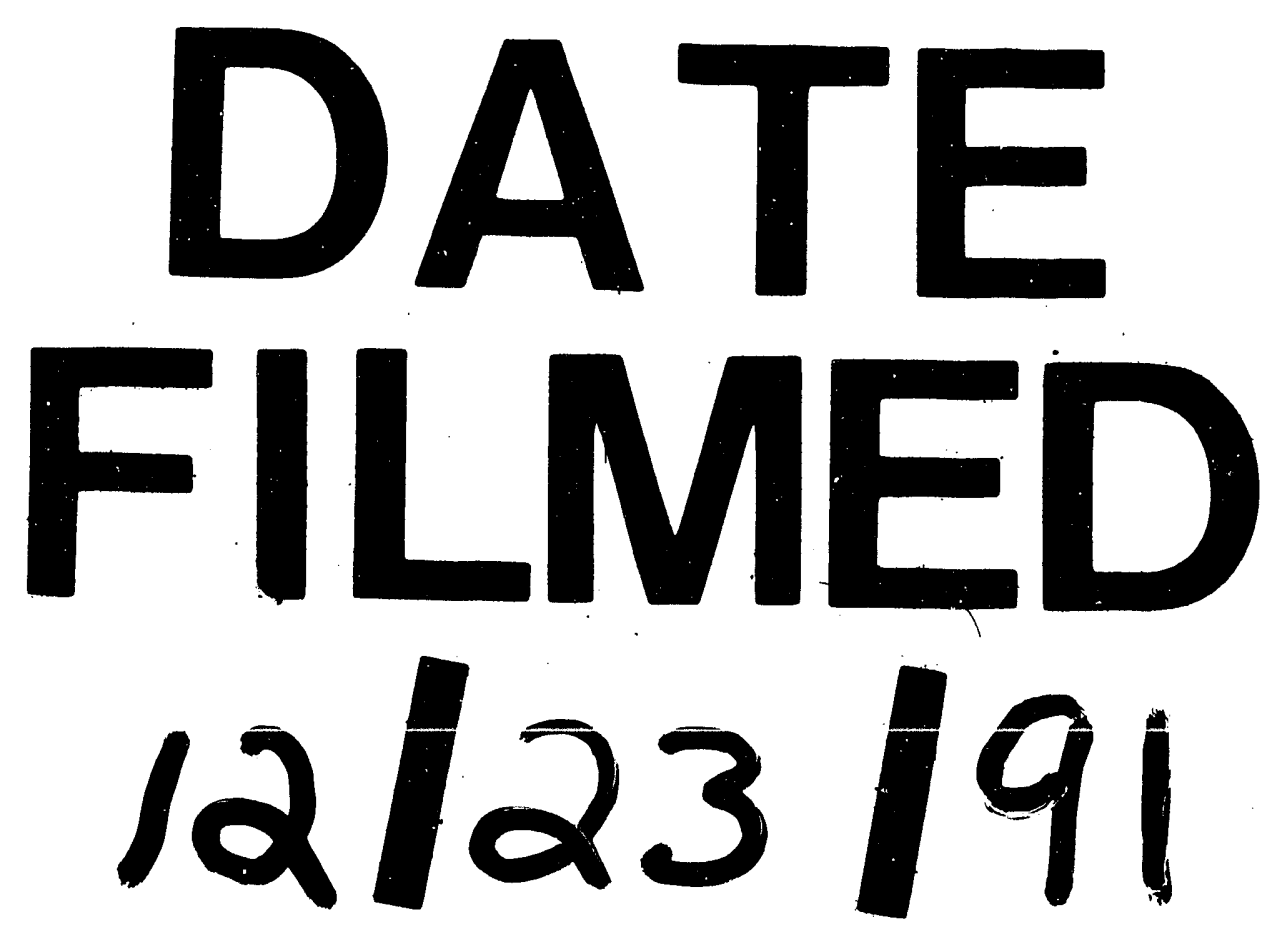

$I$ 


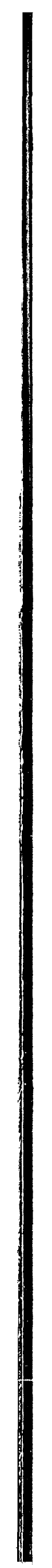

